AUTARQUIA ASSOCIADA À UNIVERSIDADE DE SÃO PAULO

CONTROLE DE PROPRIEDADES MULTIFERROICAS EM FILMES

FINOS ÓXIDOS DOPADOS COM ÍONS TERRAS RARAS PARA APLICAÇÃO COMO DISPOSITIVOS LÓGICOS E DE MEMÓRIA

EVERTON BONTURIM

Tese apresentada como parte dos requisitos para a obtenção do Grau de Doutor em Ciências na Área de Tecnologia Nuclear - Materiais.

Orientadora:

Profa. Dra. Maria Claudia França da Cunha Felinto 
INSTITUTO DE PESQUISAS ENERGÉTICAS E NUCLEARES

Autarquia Associada à Universidade de São Paulo

CONTROLE DE PROPRIEDADES MULTIFERROICAS EM FILMES

FINOS ÓXIDOS DOPADOS COM ÍONS TERRAS RARAS PARA APLICAÇÃO COMO DISPOSITIVOS LÓGICOS E DE MEMÓRIA

EVERTON BONTURIM

Tese apresentada como parte dos requisitos para a obtenção do Grau de Doutor em Ciências na Área de Tecnologia Nuclear - Materiais.

Orientadora:

Profa. Dra. Maria Claudia França da Cunha Felinto

Versão Corrigida

Versão original disponível no IPEN 
Fonte de Financiamento: CNPq, CAPES

Autorizo a reprodução e divulgação total ou parcial deste trabalho, para fins de estudo e pesquisa, desde que citada a fonte

Como citar:

BONTURIM, E. CONTROLE DE PROPRIEDADES MULTIFERROICAS EM FILMES

FINOS ÓXIDOS DOPADOS COM ÍONS TERRAS RARAS PARA APLICAÇÃO C

MO DISPOSITIVOS LÓGICOS E DE MEMÓRIA. 2017. 158 p. Tese (Doutorado em

Tecnologia Nuclear), Instituto de Pesquisas Energéticas e Nucleares, IPEN-CNEN/SP, São Paulo. Disponível em: <www.teses.usp.br> (data de consulta no formato:

$\mathrm{dd} / \mathrm{mm} / \mathrm{aaaa})$

Ficha catalográfica elaborada pelo Sistema de geração automática da Biblioteca IPEN/USP, com os dados fornecidos pelo(a) autor(a)

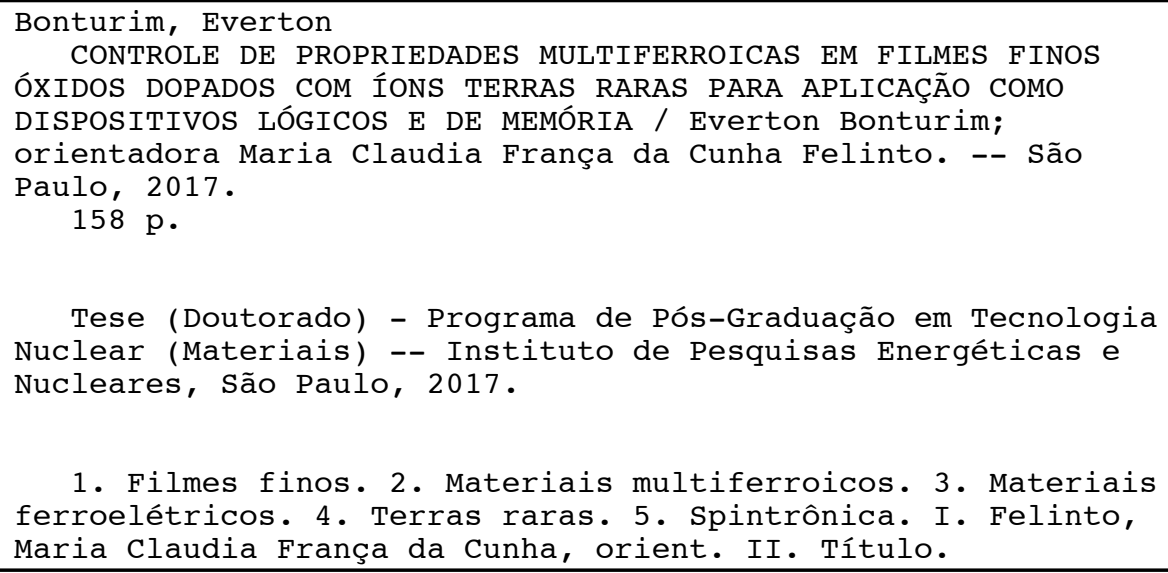




\section{FOLHA DE APROVAÇÃO}

Autor: Everton Bonturim

\section{Título: CONTROLE DE PROPRIEDADES MULTIFERROICAS EM FILMES FINOS ÓXIDOS DOPADOS COM ÍONS TERRAS RARAS PARA APLICAÇÃO COMO DISPOSITIVOS LÓGICOS E DE MEMÓRIA}

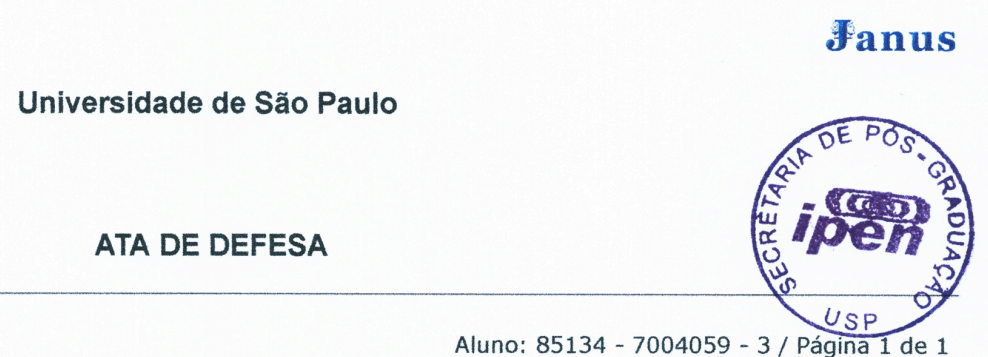

Ata de defesa pública de Tese do(a) Senhor(a) Everton Bonturim no Programa: Tecnologia Nuclear, do(a) Instituto de Pesquisas Energéticas e Nucleares da Universidade de São Paulo.

Aos 22 dias do mês de agosto de 2017, no(a) Auditório Dr. Rui Ribeiro Fran realizou-se a Defesa da Tese do(a) Senhor(a) Everton Bonturim, apresentada para a obtenção do título de Doutor intitulada:

"Controle de propriedades multiferroicas em filmes finos óxidos dopados com íons terras raras para aplicação como dispositivos lógicos e de memória"

Após declarada aberta a sessão, o(a) Sr(a) Presidente passa a palavra ao candidato para exposição e a seguir aos examinadores para as devidas arguições que se desenvolvem nos termos regimentais. Em seguida, a Comissão Julgadora proclama o resultado:

$\begin{array}{llll}\text { Nome dos Participantes da Banca } & \text { Função } & \text { Sigla da CPG } & \text { Resultado } \\ \text { Maria Claudia França da Cunha Felinto } & \text { Presidente } & \text { IPEN(IPEN) } & \text { Não Votante } \\ \text { Henrique Eisi Toma } & \text { Titular } & \text { IQ - USP } & \text { Aprovad } \\ \text { Marcia Tsuyama Escote } & \text { Titular } & \text { UFABC - Externo } & \text { Aprovado } \\ \text { Jriginski Cezar } & \text { Titular } & \text { Externo } & \text { Aprovado }\end{array}$

Resultado Final:

Parecer da Comissão Julgadora *

Eu, Paulo Albino Balan Junior

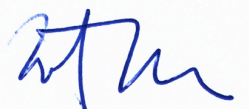

os(as) Senhores(as). São Paulo, aos 22 dias do mês de agosto de 2017.

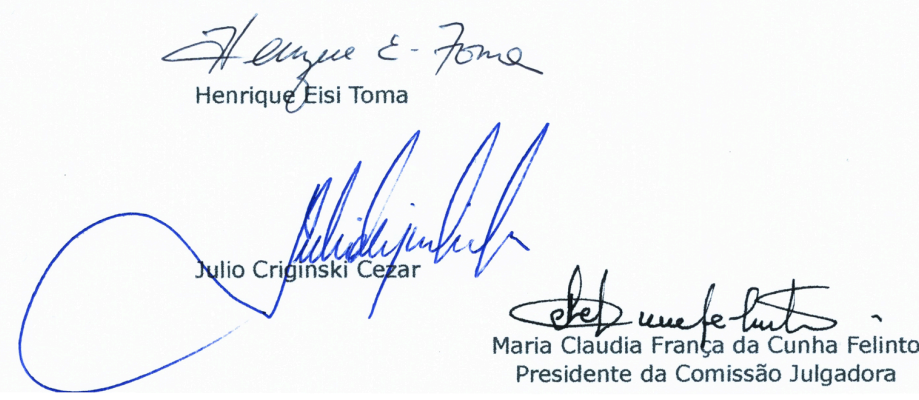


"Aos que buscam o caminho da Ciência, usando-a para construir o conhecimento e o saber; aos que fazem jus ao sábio pensamento crítico, contribuindo para o desenvolvimento social, científico e tecnológico."

E. Bonturim 


\section{AGRADECIMENTOS}

De forma geral, deixo meus agradecimentos aos profissionais que contribuíram direta ou indiretamente para a realização deste trabalho. Muitas vezes a ajuda não vem das respostas, mas sim dos questionamentos feitos frente a um problema.

À Dra. Maria Claudia França da Cunha Felinto pela orientação neste trabalho, aos seus ensinamentos pessoais, acadêmicos e profissionais durante todo o percurso deste trabalho de Doutorado.

Ao professor PhD. Ramamoorthy Ramesh, quem me coorientou durante o processo de execução do projeto para o estudo e desenvolvimento de materiais multiferroicos e sua aplicação como dispositivos lógicos e de memória, os meus mais sinceros agradecimentos por todo o apoio profissional durante minha participação como membro de sua equipe na University of California - Berkeley (UCB).

Aos pesquisadores do grupo internacional de pesquisas em materiais filmes finos multifuncionais e heteroestruturas multiferroicas do Department of Materials Science and Engineering of University of California - Berkeley onde desenvolvi todo o projeto e parte experimental da pesquisa apresentada neste Doutorado. Com a imensa colaboração de Charles Henri-Lambert PhD., Ms. Liv Dedon, James D. Clarkson PhD., Ryan Olsen PhD., Suraj Cheema PhD., Ruijuan Xu PhD., Julia Mundy PhD., Sahar Saremi PhD., Shishir Pandya PhD., do professor Lane Martin e demais amigos.

Aos professores do Departamento de Química Fundamental do Instituto de Química da USP Dr. Lucas Carvalho Veloso Rodrigues e Dr. Hermi Felinto de Brito, grandes amigos que contribuíram com suas discussões acadêmicas, grande apoio e colaboração em momentos importantes deste processo. 
Aos profissionais e amigos do Instituto de Química da Universidade de São Paulo: Leonnam, Israel, Ian, César, Helliomar, Andreza, Dr. Cássio, Dr. Ivan, Dr. José Carvalho entre outros pela amizade, momentos de distração e também pelos momentos de discussão acadêmica.

Aos funcionários da biblioteca "Terezine Arantes Ferraz" e da Divisão de Ensino do IPEN-CNEN/SP pela dedicação e colaboração nas funções administrativas.

Ao Instituto de Pesquisas Energéticas e Nucleares IPEN-CNEN/SP em conjunto com a Comissão Nacional de Energia Nuclear CNEN, pelo acolhimento e infraestrutura acadêmica e profissional para minha formação e treinamento.

À Universidade de São Paulo - USP, pela oportunidade da obtenção do título de Doutor em Ciências, naquela considerada a maior e melhor universidade do país.

À Coordenação de Aperfeiçoamento de Pessoal de Nível Superior (CAPES) pelo apoio financeiro concedido por meio de Bolsa PDSE de estágio sanduíche na University of California - Berkeley, sob processo N.99999.009511/2014-08.

Ao Conselho Nacional de Desenvolvimento Científico e Tecnológico (CNPq) pelo apoio financeiro da bolsa de Doutorado de cota institucional pelo processo $\mathrm{N}$. 146622/2013-2. 
/1

What could we do with layered structures with just the right layers? What would the properties of materials be if we could really arrange the atoms the way we want them? They would be very interesting to investigate theoretically. I can't see exactly what would happen, but I can hardly doubt that when we have some control of the arrangement of things on a small scale we will get an enormously greater range of possible properties that substances can have, and of different things that we can do.

When we get to the very, very small world - say circuits of seven atoms - we have a lot of new things that would happen that represent completely new opportunities for design. Atoms on a small scale behave like nothing on a large scale, for they satisfy the laws of quantum mechanics. So, as we go down and fiddle around with the atoms down there, we are working with different laws, and we can expect to do different things. We can manufacture in different ways. We can use, not just circuits, but some system involving the quantized energy levels, or

the interactions of quantized spins.

Richard Phillips Feynman

"There's Plenty of Room at the Room" December 29th 1959 


\title{
CONTROLE DE PROPRIEDADES MULTIFERROICAS EM FILMES FINOS ÓXIDOS DOPADOS COM ÍONS TERRAS RARAS PARA APLICAÇÃO COMO DISPOSITIVOS LÓGICOS E DE MEMÓRIA
}

\author{
Everton Bonturim
}

\section{RESUMO}

Nas últimas décadas, o consumo de dispositivos eletrônicos e a alta demanda por armazenamento de dados tem mostrado grandes oportunidades para a criação de novas tecnologias que garantam as necessidades mundiais na área de computação e desenvolvimento. Alguns materiais multiferroicos têm sido amplamente estudados e o $\mathrm{BiFeO}_{3}$, considerado o único material multiferroico em temperatura ambiente, ganhou destaque como candidato para produção de dispositivos lógicos e de memória. O uso de técnicas de crescimento como a deposição por laser pulsado permitiu a produção de filmes finos de $\mathrm{BiFeO}_{3}$ com elevado controle de qualidade. Heteroestruturas de filmes multiferroicos de $\mathrm{BiFeO}_{3}$ e $\mathrm{LaBiFeO}_{3}$ foram crescidas com diferentes espessuras sobre substratos de $\mathrm{SrTiO}_{3}(100), \mathrm{DyScO}_{3}(110)$ e $\mathrm{SrTiO}_{3} / \mathrm{Si}(100)$ para avaliação e teste de suas propriedades elétricas e magnéticas. Filmes ferromagnéticos de $\mathrm{Co}_{0,9} \mathrm{Fe}_{0,1}$ foram depositados por sputtering sobre os filmes multiferroicos para avaliação da interação interfacial entre ordenamentos magnéticos. Técnicas como fotolitografia foram utilizadas para padronização de microdispositivos gravados sobre as amostras. Tanto os filmes finos de $\mathrm{BiFeO}_{3}$ como os de $\mathrm{LaBiFeO}_{3}$ foram crescidos epitaxialmente sobre os substratos já cobertos com uma camada buffer de $\mathrm{SrRuO}_{3}$ usado como contato elétrico inferior. A estrutura cristalina romboédrica das ferritas de bismuto foi confirmada pelos dados de difração de raios $X$, bem como a manutenção de tensão estrutural causada pela rede cristalina do substrato para amostras de $20 \mathrm{~nm}$. Os valores de coeficiente do tensor piezelétrico $\mathrm{d}_{33}$ foram da ordem de $0,15 \mathrm{~V}\left(\sim 60 \mathrm{kV} . \mathrm{cm}^{-2}\right)$ para amostras com $20 \mathrm{~nm}$ de espessura enquanto que os valores de voltagem coerciva para as análises de histerese elétrica foram da ordem de $0,5 \mathrm{~V}$ para as mesmas amostras. A relação de coercividade elétrica com a espessura corresponde ao perfil encontrado na literatura pela relação $E \approx \mathrm{d}^{-2 / 3}$. As amostras de CoFe/BFO e CoFe/LBFO depositadas em diferentes substratos apresentam acoplamento interfacial entre ordenamento ferromagnético $\mathrm{e}$ antiferromagnético com momento ferromagnético de rede. 


\title{
CONTROL OF MULTIFERROIC PROPERTIES IN RARE EARTH DOPED OXIDE THIN FILMS FOR MEMORY AND LOGIC DEVICE APPLICATIONS
}

\author{
Everton Bonturim
}

\begin{abstract}
For the last few decades, the consumption of electronic devices and the high demand for data storage have shown great opportunities to create modern technologies that assure the worldwide needs in computing and development. Some multiferroic materials have been extensively studied and $\mathrm{BiFeO}_{3}$, considered the only multiferroic material at room temperature, has received attention as a candidate to produce logic and memory devices. The use of growth techniques such as pulsed laser deposition allowed the production of thin films of $\mathrm{BiFeO}_{3}$ with high quality control. Multiferroic film heterostructures of $\mathrm{BiFeO} 3$ and $\mathrm{LaBiFeO}_{3}$ were grown with different thicknesses on $\mathrm{SrTiO}_{3}(100), \mathrm{DyScO}_{3}(110)$ and $\mathrm{SrTiO}_{3} / \mathrm{Si}(100)$ substrates to evaluate and test their electrical and magnetic properties. The allow $\mathrm{Co}_{0.9} \mathrm{Fe}_{0.1}$ ferromagnetic films were deposited by sputtering on the multiferroic films to evaluate the interfacial interaction between magnetic ordering. Techniques such as photolithography were used to pattern microdevices on the samples. Both the $\mathrm{BiFeO}_{3}$ and $\mathrm{LaBiFeO}_{3}$ thin films were grown epitaxially on the substrates already covered with a $\mathrm{SrRuO}_{3}$ buffer layer used as the lower electrical contact. The rhombohedral crystalline structure of the bismuth ferrites was confirmed by the X-ray diffraction data as well as the strain maintenance caused by the crystal lattice of the substrate for $20 \mathrm{~nm}$ samples. The coefficient values of the piezoelectric tensor $d_{33}$ were around $0.15 \mathrm{~V}\left(\sim 60 \mathrm{kV} . \mathrm{cm}^{-2}\right)$ for $20 \mathrm{~nm}$ thick samples whereas the coercive voltage values for the electrical hysteresis analyzes were about $0.5 \mathrm{~V}$ for the same samples. The relation between electric coercivity and the thickness corresponds to the profile found in the literature by the relation $E \approx d^{-2 / 3}$. The samples of CoFe/BFO and CoFe/LBFO deposited in different substrates present interfacial coupling between ferromagnetic and antiferromagnetic arrangement with net ferromagnetic moment.
\end{abstract}




\section{SUMÁRIO}

1. INTRODUÇÃO

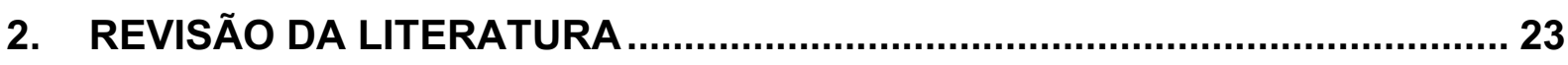

2.1. Uma breve abordagem sobre a evolução tecnológica e a indústria de semicondutores ............................................................................................... 23

2.2. A contribuição dos materiais funcionais na indústria eletrônica ........ 28

2.3. Os desafios tecnológicos na aplicação de materiais funcionais ......... 32

2.4. A engenharia nanotecnológica dos Filmes finos ................................ 37

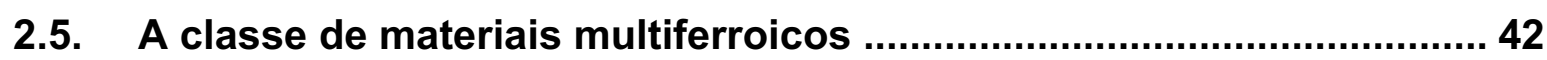

2.5.1. Propriedade ferroelétrica em materiais multiferroicos ....................... 46

2.6. O composto $\mathrm{BiFeO}_{3}$ como material multiferroico de temperatura

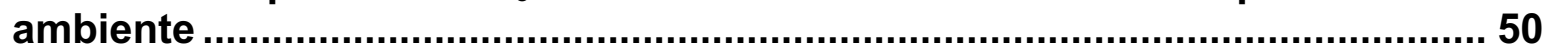

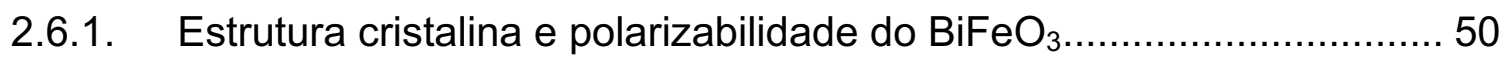

2.6.2. Sistema substitucional por dopagem isovalente com íons terras raras 55

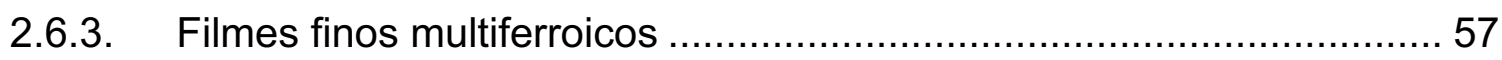

2.7. Panorama geral de publicações relacionadas à área............................59

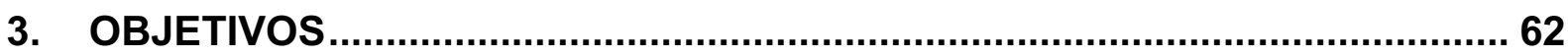

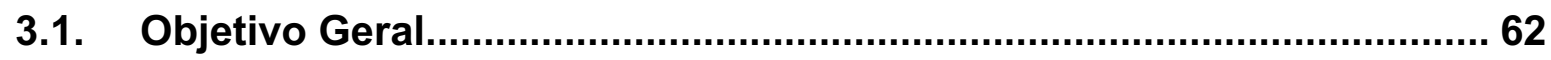

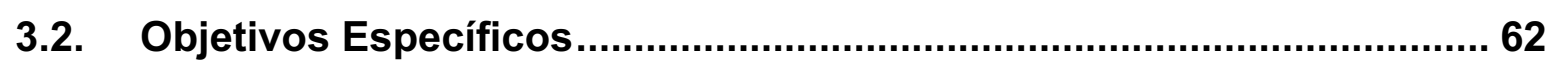

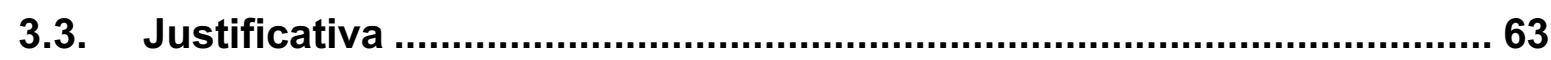

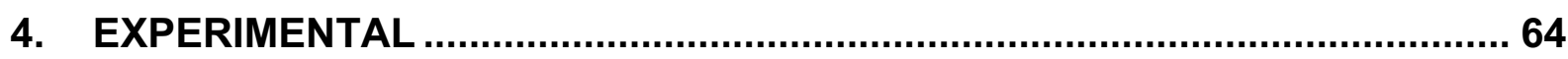

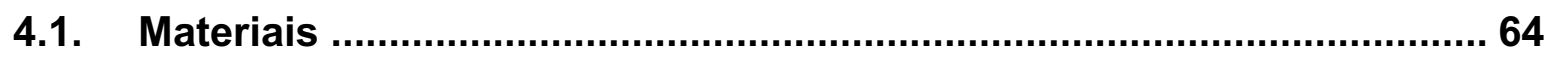

4.1.1. Principais materiais utilizados no processo de crescimento de filmes

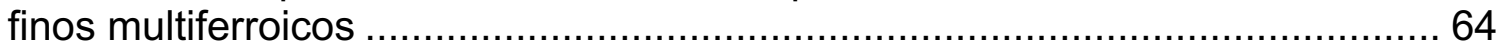

4.1.2. Materiais utilizados na preparação de amostras para ensaios elétricos

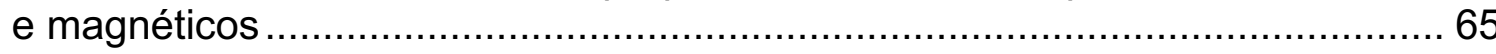

4.1.3. Sistemas utilizados no crescimento de filmes finos............................ 65

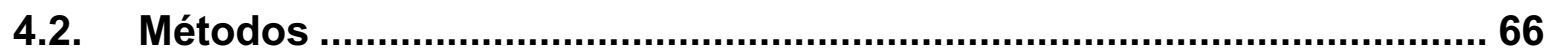

4.2.1. Deposição de filmes finos heteroestruturados..................................... 66

4.2.2. O processo de fotolitografia de microdispositivos .............................. 71

4.2.3. Caracterização de filmes finos multiferroicos e microdispositivos ........ 73

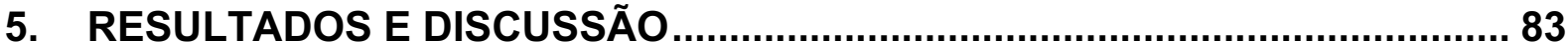

5.1. Crescimento e caracterização de filmes finos de $\mathrm{BiFeO}_{3} \ldots \ldots \ldots \ldots \ldots \ldots \ldots . . . . . . . . .84$ 
5.1.1. Topografia e imagem de domínios ferroelétricos por microscopia de

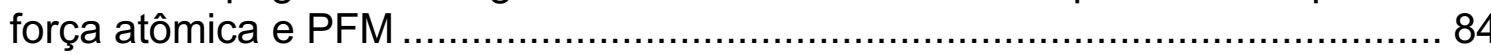

5.1.2. Perfil cristalográfico dos filmes finos de $\mathrm{BiFeO}_{3} \ldots \ldots \ldots \ldots \ldots \ldots \ldots \ldots \ldots \ldots . . . . . . . . . . . . . . .90$

5.2. Crescimento e caracterização de filmes finos de $\mathrm{LaBiFeO}_{3} \ldots \ldots \ldots \ldots . . . . . . .93$

5.2.1. Topografia e imagem de domínios ferroelétricos por microscopia de

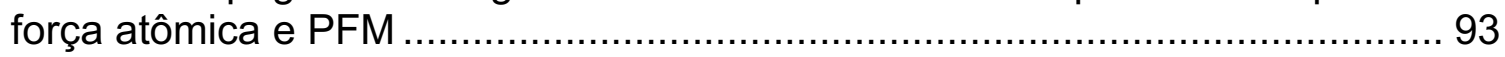

5.2.2. Perfil cristalográfico das amostras de $\mathrm{LaBiFeO}_{3} \ldots \ldots \ldots \ldots \ldots \ldots \ldots \ldots \ldots . . . . . . . . . . . . . . . . .94$

5.2.3. Microscopia eletrônica de transmissão dos filmes de $\mathrm{LaBiFeO}_{3} \ldots \ldots . . .98$

5.2.4. Piezo deslocamento medido por coeficiente de piezoresposta do tensor $\mathrm{d}_{33} \quad 101$

5.2.5. Dicroísmo circular magnético de raios $X$ e dicroísmo linear magnético

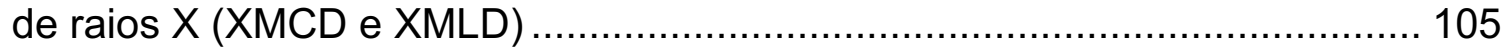

5.2.6. Polarização elétrica de filmes finos de $\mathrm{Bi}_{0,90} \mathrm{La}_{0,10} \mathrm{FeO}_{3} \ldots \ldots \ldots \ldots \ldots \ldots . . . . . .107$

5.2.6.1. Ensaios de histerese elétrica por curvas P-E ............................... 107

5.2.6.2. Ensaios de polarização elétrica dinâmica por (PUND) ...................... 109

5.2.6.3. Medidas de fadiga das amostras de LBFO com $20 \mathrm{~nm}$................... 111

5.2.6.4. Polarização elétrica ultra rápida medida por curvas de corrente e campo elétrico em função da duração de pulso .......................................... 112

5.3. Crescimento e caracterização de filmes de $\mathrm{LaBiFeO}_{3}$ ultrafinos $(10 \mathrm{~nm})$ 115

5.3.1. Estrutura cristalográfica e ensaios de polarização elétrica................. 115

5.4. Propriedades ferrolétricas das amostras $\mathrm{LaBiFeO}_{3}$ em função da espessura.

5.5. Ensaios de gravação e leitura (Write-Read) ….................................... 125

5.6. Acoplamento spin-órbita de interface entre filmes finos antiferromagnéticos de $\mathrm{BiFeO}_{3}$ e ferromagnéticos de $\mathrm{Co}_{0,9} \mathrm{Fe}_{0,1} \ldots \ldots \ldots \ldots \ldots . . . . . .128$

5.7. Acoplamento spin-órbita de interface entre filmes finos antiferromagnéticos de $\mathrm{Bi}_{0,90} \mathrm{La}_{0,10} \mathrm{FeO}_{3}$ e ferromagnéticos de $\mathrm{Co}_{0,90} \mathrm{Fe}_{0,10 . .} 133$

6. CONCLUSÃO

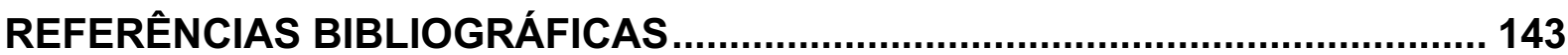

ANEXO A: Arquivo CIF 2102913 da estrutura cristalina do $\mathrm{BiFeO}_{3} \ldots \ldots \ldots \ldots . . . . . . .152$

ANEXO B: Princípios da técnica de Difração de raios X .................................. 154 


\section{LISTA DE TABELAS}

Tabela 1 - Alguns dos materiais ferroicos mais conhecidos da literatura e seus respectivos valores de transição de fase pela temperatura de Curie, pela temperatura de Néel e polarização elétrica

Tabela 2 - Possíveis rotações de vetores de polarização elétrica do $\mathrm{BiFeO}_{3}$ de estrutura romboédrica.

Tabela 3- Parâmetros de deposição de filmes finos multiferroicos epitaxiais pela técnica de PLD.

Tabela 4 - Parâmetros de deposição de filmes metálicos ferromagnéticos por Sputtering. 70

Tabela 5 - Descrição dos valores de coercividade e shift magnético no plano e fora do plano para diferentes amostras de BFO e LBFO crescidas em diferentes condições e diferentes substratos. 


\section{LISTA DE FIGURAS}

Figura 1 - Quadro da história dos dispositivos eletrônicos na era dos semicondutores mostrado pela a) primeira predição de Gordon E. Moore sobre a evolução dos componentes eletrônicos publicado em 1965, b) esboço de Russel Ohl sobre seu experimento de medição de resistência em uma amostra de silício puro como origem da criação da primeira junção p-n em 1940, c) primeiro transistor de germânio produzido nos laboratórios da companhia Bell Labs em 1950 e d) primeiro transistor semicondutor comercial produzido pela Texas Instruments em 1954. 27

Figura 2 - Imagens de microscopia eletrônica de transmissão (a) de transistores do tipo FinFET (b), o consequente aumento de densidade (c) e performance (d) de transistores em função dos diferentes tamanhos de dispositivos produzidos por fotolitografia. 28

Figura 3 - Esquema de uma célula unitária (a) da estrutura cristalina tetragonal $(P 4 m m)$ do tipo Perovskita do $\mathrm{BaTiO}_{3}$ e suas possíveis direções de polarização elétrica "UP" e "DOWN" (b). As setas mostradas no átomo central da célula unitária representam o deslocamento do sítio $B$ em função dos átomos da posição $A$. 31

Figura 4 - Classificação das tecnologias e dispositivos voláteis e não-voláteis para armazenamento e processamento de informações na industria eletrônica atual. .... 34

Figura 5 - Principais tecnologias de dispositivos lógicos processadores baseados em transistores na industria eletrônica atual, incluindo as tecnologicas convensionais (quadrante azul) suportadas em silício com canal semicondutor e tecnologias emergentes baseadas em spintrônica (quadrante amarelo).

Figura 6 - Principais tipos de nanomateriais filmes finos (a) e diferentes arranjos heteroestruturados formados por esses nanomateriais (b).

Figura 7 - Principais materiais ferroelétricos, eletrodos e substratos ordenados em função do seu parâmetro de rede.

Figura 8 - Diagrama de interações entre ordenamentos ferroicos de materiais funcionais e suas propriedades multiferroicas.

Figura 9 - Ordenamento macroscópico sob efeito de um campo conjugado externo (acoplamento magnetoelétrico M,P - E, H).

Figura 10 - Diagrama esquemático do comportamento ferroelétrico de um material ferroelétrico em função de um campo elétrico externo aplicado (a) e a representação de domínios e paredes de domínios ferrolétricos num sistema em equilibrio nativo antes da interação com qualquer campo elétrico (b).

Figura 11 - Diagrama esquemático da formação de domínios fora do plano (out-ofplane) com vetor de polarização UP (a) quando uma tensão negativa é aplicada ao 
contato elétrico superior e de domínios com vetor de polarização DOWN (b) quando uma tensão positiva é aplicada ao sistema.

Figura 12 - Representação estrutural do arranjo atômico do composto $\mathrm{BiFeO}_{3}$ ao longo da direção de polarização ferroelétrica [111] (a) extraído de uma célula unitária de estrutura cristalina trigonal $(R 3 c)$ (b) e sua representação romboédrica formada por duas células pseudo-cúbicas (c) e ao longo da direção [111] pc de polarização espontânea.

Figura 13 - Representação estrutural do arranjo atômico do composto $\mathrm{BiFeO}_{3}$ ao longo das possíveis direções de polarização ferroelétrica (a) e as três configurações de domínios ferroelétricos criados pela região de transição entre diferentes vetores $\mathrm{P}$, chamadas de paredes de domínios. 53

Figura 14 - Estrutura cristalina do tipo Perovskita com célula unitária pseudo-cúbica e simetria romboédrica ferroelétrica do $\mathrm{BiFeO}_{3}$ indicando as direções pependiculares dos vetores de polarizabilidade e momento magnético $M$ (a), ordenamento antiferromagnético do tipo $\mathrm{G}$ com planos ferromagnéticos (111) (b) e ilustração da interação Dzyaloshinskii-Moriya entre planos (111) na intensificação do momento ferromagnético fraco da estrutura (c).

Figura 15 - Esquema de diagrama de fases universal para dopagem por terras-raras na estrutura do $\mathrm{BiFeO}_{3}(\mathrm{a})$, esquema de diagrama de fases calculado na substituição por $\mathrm{La}^{3+}(\mathrm{b})$, e a evolução das curvas de histerese na transição de fase ferroelétrica e paraelétrica com diferentes concentrações de dopagem por Sm e La(c). 56

Figura 16 - Esquema de um dispositivo magnetoelétrico formado pela interação de uma camada multiferroica de $\mathrm{BiFeO}_{3}$ e uma camada de material ferromagnético CoFe (a), magnetoresistência anisotrópica alterada em função da aplicação de campo elétrico externo ao dispositivo com efeito magnetoelétrico. 58

Figura 17 - Perfil de publicações contabilizadas nos bancos de dados da Web of Knowledge entre os anos 1945 e 2017 para as palavras-chave a) Thin film. Ferroelectric, Pulsed Laser Deposition (abreviado pela sigla PLD na figura) e Multiferroic, b) Barium titanate, Lead zirconate titanate e $\mathrm{BiFeO}_{3}$ e para os principais gargalos tecnológicos da área da computação c) Data storage, spintronic, FeRAM e Moore's Law. 60

Figura 18 - Esquema ilustrativo de um sistema de deposição por laser pulsado (PLD). 67

Figura 19 - Fotografia do processo de crescimento durante a ablasão do alvo em uma câmara de PLD (a) e o perfil de densidade de energia do feixe pulsado de laser do sistema de ablasão em função da posição do conjunto óptico sobre o ponto focal do sistema antes (energia total) e depois da janela de quartzo da câmara (energia atenuada) (b).

Figura 20 - Representação do perfil e da área de interação do feixe de laser pulsado sobre a superfície do alvo cerâmico em função da posição relativa da lente focalizadora do conjunto óptico entre as marcações 0 e 2 (a-e). 68 
Figura 21 - Esquema ilustrativo de um sistema de deposição por pulverização catódica (Sputtering) (a), fotografia do porta-amostras na pré-câmara (b) e o processo de deposição pela formação do plasma acima da amostra (c).................................69

Figura 22 - Esquema ilustrativo do processo de litografia por luz ultravioleta e ablação iônica para criação de microdispositivos em filmes finos heteroestruturados.

Figura 23 - Esquema de funcionamento de um microscópio de força atômica (AFM).

Figura 24 -Esquema ilustrativo de um PFM com os principais componentes e arranjos (a) e a distribuição do campo elétrico aplicado em modo local (esquerda) quando um eletrodo abaixo da camada ferroelétrica permite o circuito entre ponteira e superfície da amostra e em campo elétrico global quando um eletrodo superior entre a superfície ferroelétrica e a ponteira distribui uniformemente o campo aplicado (b). ................ 75

Figura 25 - Difratômetro X'Pert3 MRD Panalytical para filmes finos........................ 76

Figura 26 - Representação tridimensional da estrutura de um contato elétrico superior (esquerda) e sua imagem obtida por microscopia de força atômica (AFM)............... 78

Figura 27 - Esquema de configuração dos padrões de pulso elétrico para as análises de polarização dinâmica pelo método PUND (a) e ensaios de gravação e leitura de estados ferroelétricos (write and read) (b). 79

Figura 28 - Sequência (a-i) de alteração de estados ferroelétricos nos ensaios PUND para determinação da polarização dinâmica PUND. 80

Figura 29 - Representação gráfica (a) e imagem de microscopia otica (b) dos dispositivos e conexões para medidas de magnetoresistência anisotrópica. 82

Figura 30 - Esquema de crescimento das amostras heteroestruturadas em multimadas de filmes finos de $\mathrm{BiFeO}_{3}$ e $\mathrm{SrRuO}_{3}$ sobre um substrato monocristalino. 84

Figura 31 - Imagens de microscopia de força atômica dos filmes finos de $\mathrm{SrRuO}_{3}(\sim 10$ nm de espessura) sobre substratos de $\mathrm{SrTiO}_{3}(100)$ e $\mathrm{DyScO}_{3}$ (110) em função da energia de ablação do laser pulsado (a) e da temperatura do substrato durante o crescimento (b).

Figura 32 - Esquema de funcionamento da varredura no plano (in-plane, IP) por microscopia de força de piezoresposta no sistema $\mathrm{BiFeO}_{3}$ de domínio ferrolétricos.

Figura 33 - Imagens de microscopia de força atômica (AFM - imagens superiores e IPPFM - imagens inferiores) de filmes finos de $\mathrm{BiFeO}_{3}$ crescidos com diferentes espessuras sobre $10 \mathrm{~nm}$ de $\mathrm{SrRuO}_{3}$ em substratos de $\mathrm{DyScO}_{3}(110)$.

Figura 34 - Distribuição das coordenadas de domínios ferroelétricos stripe-like com 2 variantes (a) e 4 variantes (b) obtidos pela análise dos vetores das imagens de microscopia de força atômica (IPPFM) de filmes finos de $\mathrm{BiFeO}_{3}(100 \mathrm{~nm}$ e $50 \mathrm{~nm}$, 
respectivamente) crescidos sobre $10 \mathrm{~nm}$ de $\mathrm{SrRuO}_{3}$ em substratos de $\mathrm{DyScO}_{3}(110)$.

Figura 35 - Difratograma de raios $X$ (a) das amostras de $\mathrm{BiFeO}_{3}(10-100$ $\mathrm{nm}) / \mathrm{SrRuO}{ }_{3} / \mathrm{DyScO}_{3}$ com ênfase na reflexão 110 do substrato de $\mathrm{DyScO}_{3}$ (b) e com ênfase na reflexão 220 do substrato de $\mathrm{DyScO}_{3}$ (c).

Figura 36 - Mapeamento de espaço recíproco de raios $\mathrm{X}$ da amostra $\mathrm{BiFeO}_{3}(100$ $\mathrm{nm}) / \mathrm{SrRuO}_{3} / \mathrm{DyScO}_{3}$ (a) com ênfase nas reflexões (334) do substrato e (203)pc do filme de $\mathrm{BiFeO}_{3}(100 \mathrm{~nm})$.

Figura 37 - Imagens de microscopia de força atômica da topografia, piezoresposta vertical e piezoresposta horizontal de filmes finos de $\mathrm{Bi}_{0,9} \mathrm{La}_{0,1} \mathrm{FeO}_{3}$ com espessura de $20 \mathrm{~nm}$ crescido sobre $10 \mathrm{~nm}$ de $\mathrm{SrRuO}_{3}$ em substratos de $\mathrm{DyScO}_{3}(110)$. 94

Figura 38 - Difratogramas de raios $X$ das amostras de $\mathrm{Bi}_{0,90} \mathrm{La}_{0,10} \mathrm{FeO}_{3} / \mathrm{SrRuO}_{3} / \mathrm{DyScO}_{3}$ crescidos com diferentes frequências de pulso do laser $\left(03,05\right.$ e $10 \mathrm{~Hz}$ ) entre 20 e $80^{\circ} 2 \theta$ (a) e uma ampliação dos picos em torno da reflexão (220) do substrato (b). 95

Figura 39 - Mapeamento de espaço recíproco (RSM) de raios $\mathrm{X}$ das amostra de $\mathrm{Bi}_{0,90} \mathrm{La}_{0,10} \mathrm{FeO}_{3} / \mathrm{SrRuO}_{3} / \mathrm{DyScO}_{3}$ crescidos e posteriormente tratados em diferentes temperaturas após o crescimento sob atmosfera dinâmica de $\mathrm{O}_{2} \ldots \ldots \ldots \ldots \ldots \ldots \ldots \ldots \ldots . . . . . . . . . . . .66$

Figura 40 - Imagens de microscopia de força atômica das amostras de $\mathrm{Bi}_{0,90} \mathrm{La}_{0,10} \mathrm{FeO}_{3}$ após diferentes condições de tratamento térmico.......................... 97

Figura 41 - Micrografia de microscopia eletrônica de transmissão de alta resolução da seção transversal da amostra de $\mathrm{Bi}_{0,90} \mathrm{La}_{0,10} \mathrm{FeO}_{3} / \mathrm{SrRuO}_{3} / \mathrm{DyScO}_{3}$ (a) e imagem de STEM em modo HAADF da estrutura cristalina do filme $\mathrm{Bi}_{0,90} \mathrm{La}_{0,10} \mathrm{FeO}_{3}$ (b). 99

Figura 42 - Micrografia de microscopia eletrônica de transmissão de alta resolução da seção transversal da amostra de $\mathrm{Bi}_{0,90} L_{0} a_{0,10} \mathrm{FeO}_{3} / \mathrm{SrRuO}_{3} / \mathrm{DyScO}_{3}$ em diferentes magnificações. 100

Figura 43 - Micrografia de microscopia eletrônica de transmissão de alta resolução da seção transversal da amostra de $\mathrm{Bi}_{0,90} \mathrm{La}_{0,10} \mathrm{FeO}_{3} / \mathrm{SrRuO}_{3} / \mathrm{DyScO}_{3}$ (a), imagem de STEM em modo HAADF da estrutura cristalina do filme $\mathrm{Bi}_{0,90} \mathrm{La}_{0,10} \mathrm{FeO}_{3}$ (b) e sua respectiva representação de célula unitária (c). 100

Figura 44 - Curvas de resposta piezoelétrica por coeficiente $d_{33}$ registrados em fase (a,c,e,g) e amplitude de deslocamento (b,d,f,h) do sistema $\mathrm{Bi}_{0,90} \mathrm{La}_{0,10} \mathrm{FeO}_{3}(20$ $\mathrm{nm}) / \mathrm{SrRuO}_{3}(10 \mathrm{~nm}) / \mathrm{DyScO}_{3}$ variando passo de aquisição entre $0,2 \mathrm{~V}$ e 0,01 V... 102

Figura 45 - Curvas de resposta piezoelétrica por coeficiente $d_{33}$ registrados em fase $(a, c)$ e amplitude de deslocamento (b,d) do sistema $\mathrm{Bi}_{0,90} \mathrm{La}_{0,10} \mathrm{FeO}_{3}(20$ $\mathrm{nm}) / \mathrm{SrRuO}_{3}(10 \mathrm{~nm}) / \mathrm{DyScO}_{3}$ variando tensão $\mathrm{AC}$ senoidal de $0,4 \mathrm{~V}$ e 0,3 V aplicadas ao cantilever. 103

Figura 46 - Curvas de resposta piezoelétrica por coeficiente $d_{33}$ registrados em fase (a,c,e) e amplitude de deslocamento (b,d,f) do sistema $\mathrm{Bi}_{0,90} \mathrm{La}_{0,10} \mathrm{FeO}_{3}(20$ $\mathrm{nm}) / \mathrm{SrRuO}_{3}(10 \mathrm{~nm}) / \mathrm{DyScO}_{3}$ variando a voltagem AC bias aplicada ao cantilever. 104 
Figura 47 Espectros de absorção de raios $X$ na borda $L_{2}$ e $L_{3}$ do $F e$ sob dicroismo linear (a) e circular (c) magnético de raios $\mathrm{X}$ para a amostra de $\mathrm{LaBiFeO}_{3}$, o perfil de assimetria de XMLD (b) e a curva de comportamento antiferromagnético em função da temperatura (d) obtida pelo ajuste e integração do pico A indicado na imagem.

Figura 48 - Curvas de histerese ferroelétrica das amostras de LBFO (20 nm) em diferentes frequências. 108

Figura 49 - Gráfico do ensaio de PUND da polarização 2P para diferentes durações de pulsos com diferentes valores de tensão da amostra LBFO de $20 \mathrm{~nm}$......

Figura 50 - Curvas de histerese ferroelétrica tomadas nas frequências de 10, 20 e 100 $\mathrm{kHz}$ das amostras de LBFO (20 nm) em diferentes temperaturas.

Figura 51 - Esquema da configuração do sistema de ciclagem ferroelétrica aplicada nas amostras de $\mathrm{LaBiFeO}_{3}$

Figura 52 - Medidas de fadiga elétrica das amostras de LBFO com $20 \mathrm{~nm}$ de espessura.

Figura 53- Curvas de histerese elétrica das amostras de LBFO com $20 \mathrm{~nm}$ de espessura antese após as medidas de fadiga.

Figura 54 - Curvas de polarização das amostras de LBFO com $20 \mathrm{~nm}$ de espessura em regime ultra rápido com duração de pulso de 100 ns.

Figura 55 - Curvas de polarização das amostras de LBFO com $20 \mathrm{~nm}$ de espessura em regime ultra rápido com duração de pulso de 100 ns para perfil de Ps diferentes (a) e cálculo de parâmetros de dinâmica de polarização pelo modelo KAl (b, c)... 115

Figura 56 - Difratograma da amostra de LBFO $(10 \mathrm{~nm})$ crescido sobre SRO e DSO (110) como substrato.

Figura 57 - Curvas de histerese ferroelétrica das amostras de LBFO (10 nm) em diferentes frequências. 117

Figura 58 - Curvas de histerese ferroelétrica remanescente das amostras de LBFO $(10 \mathrm{~nm})$ sob campo elétrico de $0,8 \mathrm{~V}$ e duração de pulso de $0,1 \mathrm{~ms}$.

Figura 59 - Gráfico da polarização 2P do ensaio PUND para diferentes durações de pulsos com diferentes valores de tensão da amostra LBFO de10 $\mathrm{nm}$ seus respectivos valores de $T_{0}$ em função do campo elétrico aplicado calculado com base no modelo $\mathrm{KAI}(\mathrm{b}, \mathrm{c})$... 118

Figura 60 - Curvas de histerese ferroelétrica das amostras de LBFO em diferentes espessuras para a frequência de $100 \mathrm{kHz}$ (a), curvas de histerese remanescente (b), e curva de relação entre os valores de coercividade $E_{C}$ e polarização remanescente $\operatorname{Pr}(d)$ em função da espessura da camada ferroelétrica. 120 
Figura 61 - Gráfico da coercividade elétrica das amostras de LBFO para espessuras de 10 (a), 20 (b), 40 (c) e $80 \mathrm{~nm}$ (d) da camada ferroelétrica em função da frequência de eventos de polarização obtida por histerese convencional e remanescente..... 121

Figura 62 - Gráfico da coercividade elétrica das amostras de LBFO para diferentes espessuras da camada ferroelétrica em função da frequência de eventos de polarização

Figura 63 - Resposta de polarização elétrica em função do campo elétrico aplicado em uma dada frequência de variação de campo no intervalo entre os regimes quaseestático e dinâmico para diferentes espessuras 10, 20, 40 e $80 \mathrm{~nm}$. 123

Figura 64 - Gráfico de superfície da resposta de polarização elétrica em função do campo elétrico aplicado em uma dada frequência de variação de campo no intervalo entre os regimes quase-estático e dinâmico. 124

Figura 65 - Gráfico do ensaio de PUND da polarização 2P normalizada para diferentes valores de tensão com diferentes valores de duração de pulso da amostra LBFO de $40 \mathrm{~nm}$ (a) e $80 \mathrm{~nm}$ (d) e seus respectivos valores de $T_{0}$ em função do campo elétrico aplicado (b,c-40 nm) (e,f-80 nm) 126

Figura 66 - Gráfico dos valores de dimensionalidade $n$ (a) e $T_{\infty}$ (b) calculados por ajuste usando os modelos KAl e Lei de Merz dos dados medidos pelos ensaios PUND das amostras com espessuras de 40 e $80 \mathrm{~nm}$.

Figura 67 - Esquema representativo da interface e interação spin-órbita entre os domínios ferromagnéticos da camada $\mathrm{FM}$ e os planos antiferromagnéticos com momento ferromagnético de rede da camada AFM do $\mathrm{BiFeO}_{3}$.

Figura 68 - Imagens de microscopia AFM e PFM (no plano) das amostras de BFO crescidas sobre SRO em substratos de STO/Si.

Figura 69 - Difratograma da amostra de BFO crescidas sobre SRO em substratos de $\mathrm{STO} / \mathrm{Si}$.

Figura 70 - Difratometria em modo de reflectância XRR (a) e histerese magnética (b) de uma amostra de CoFe crescido sobre STO(100)

Figura 71 - Histerese magnética de uma amostra de CoFe de 2,3 nm (a) e 3,2 nm (b) crescido sobre BFO/SRO/STO/Si(100).

Figura 72 - Histerese magnética de uma amostra de CoFe de 2,3 nm crescido sobre $\mathrm{BFO} / \mathrm{SRO} / \mathrm{STO} / \mathrm{Si}(100)$ obtido por VSM em diferentes ângulos da amostra como indicado na figura central. 131

Figura 73 - Histerese magnética de uma amostra de CoFe de 2,3 crescido sobre $\mathrm{BFO} / \mathrm{SRO} / \mathrm{STO} / \mathrm{Si}(100)$ obtido por VSM por diferentes ciclos de campo magnético.

Figura 74 - Difratometria em modo de reflectância (a) e histerese magnética (b) de uma amostra de $\mathrm{Co}_{0,9} \mathrm{Fe}_{0,1}$ crescido sobre STO(100). 
Figura 75 - Micrografia de microscopia eletrônica de transmissão de alta resolução da seção transversal da amostra de $\mathrm{Pt} / \mathrm{Co}_{0,90} \mathrm{Fe}_{0,10} / \mathrm{Bi}_{0,90} \mathrm{La}_{0,10} \mathrm{FeO}_{3} / \mathrm{SrRuO}_{3} / \mathrm{SrTiO}_{3}$ (a), imagem de STEM em modo HAADF da interfaec entre as estruturas cristalinas do filme $\mathrm{Bi}_{0,90} \mathrm{La}_{0,10} \mathrm{FeO}_{3}$ e do filme $\mathrm{Co}_{0,90} \mathrm{Fe}_{0,10}$ (b).

Figura 76 - Curvas de histerese magnética $\mathrm{MH}$ da amostra $\mathrm{Pt} / \mathrm{Co}_{0,90} \mathrm{Fe}_{0,10} / \mathrm{Bi}_{0,90} \mathrm{La}_{0,10} \mathrm{FeO}_{3} / \mathrm{SrRuO}_{3}$ crescida em dois diferentes substratos $\mathrm{SrTiO}_{3}$ e $\mathrm{SrTiO}_{3} / \mathrm{Si}$

Figura 78 - Dispositivo Hall formado por filme ultrafino de $\mathrm{LaBiFeO}_{3}(20 \mathrm{~nm})$ e filme ferromagnético de CoFe $(2 \mathrm{~nm})$ crescidos sobre DSO(110).

Figura 79 - Magnetoresistência anisotrópica do sistema $\mathrm{Co}_{0,9} \mathrm{Fe}_{0,1} / \mathrm{LBFO}$ crescido sobre DSO.

Figura 80 - Esquema de geração de raios $X$ : (a) foto de um tubo de raios $X$; (b) representação esquemática de um tubo de raios $X$ e seus principais componentes; (c) emissão de fótons pela interação de elétrons incidentes sobre um átomo de um elemento metálico.

Figura 81 - Representação esquemática da interação de feixes de raios $X$ com planos A e B de um material cristalino, promovendo sua difração 155

Figura 82 - Modelo de difratograma do metal molibdênio. 


\section{INTRODUÇÃO 01}

\section{INTRODUÇÃO}

O uso de componentes eletrônicos cresce exponencialmente na sociedade moderna e como resultado do aumento dessa demanda a indústria de semicondutores expande suas atribuições na busca por tecnologias e inovação que possam acompanhar a evolução da Lei de Moore. De fato, os setores de pesquisa e desenvolvimento na área de semicondutores trabalham exaustivamente para não apenas suprir uma demanda em que o número de transistores por unidade de espaço dobra a cada ano, mas também para alcançar o domínio de tecnologias que superem os desafios e limites físicos impostos pela física tradicional aplicada em uma plataforma baseada em silício. (MARKOV, 2014; ITRS, 2015; DREISMANN et al., 2016)

Desde a concepção da arquitetura para computadores que conhecemos hoje, criada por Von Neumann em 1945, os avanços alcançados pela ciência estavam focados em performance de sistemas cada vez mais poderosos em capacidade de processamento. A abordagem usada pela indústria para o crescimento do poder de processamento levou em conta dois fatores principais: 1) o aumento da densidade de dispositivos, aumentando o número de transistores por unidade de espaço e 2) transistores com capacidade de transição de estados "on/off" operando em frequências cada vez maiores (ITRS, 2015). 
Com o aumento na densidade de transistores, na escala de bilhões de unidades por processador, e sua frequência de operação variando entre algumas dezenas de mega-hertz a alguns giga-hertz, as abordagens usadas na engenharia de sistemas e circuitos integrados se aproxima dos limites de construção de mecanismos viáveis para dissipação de energia térmica gerada durante condições de operação desses sistemas. A partir deste ponto a indústria passa a perceber a necessidade de investir em desenvolvimento e pesquisa para criar soluções tecnológicas de alto impacto principalmente em novos materiais que possam mitigar o problema do consumo e perda de energia em sistemas cada vez menores e mais rápidos (ITRS, 2015; DREISMANN et al., 2016; FIEBIG et al., 2016; MARTIN; RAPPE, 2016; MILLER, 2016).

A dissipação de energia em microchips tem se tornado um parâmetro cada vez mais importante para o controle do consumo de energia em escala global e tem sido um fator limitante nos processos de fabricação de dispositivos em nano escala. A redução das dimensões físicas na arquitetura de processadores e memórias de estado sólido tem um impacto fundamental na indústria de microeletrônica e telecomunicações. (KEYES, 2005; ITRS, 2015)

Sustentado pelo advento de um novo ambiente interligado mundialmente entre sistemas, vivemos na era conhecida como "Internet das Coisas" (do termo em inglês, The Internet of Things - IoT). O momento de elaboração de diretrizes para o avanço na produção de sistemas integráveis impõe a eficiência e baixo consumo como itens essenciais para garantir a sustentabilidade de um cenário complexo que envolve competências para lidar com Big Data, mobilidade, conectividade entre plataformas e pessoas no mundo inteiro e armazenamento e processamento de informações. Uma dessas diretrizes, essencial para a base de um sistema eficiente é a busca por novos materiais (ITRS, 2015).

No contexto do desenvolvimento de materiais para soluções fundamentais da indústria eletrônica, o investimento em pesquisas sobre materiais com propriedades adequadas para manipulação e controle de mecanismos de deslocamento de cargas (ferroelétricos) e estados de ordenação de spin (ferromagnéticos), trazem enorme potencial para criação de novas tecnologias mais eficientes, robustas e de baixo consumo energético (TRASSIN, 2016).

Materiais ferroelétricos começaram a ser estudados a partir de 1960 como possibilidade para criação de dispositivos de memória não volátil, mas com a limitação 
tecnológica para o crescimento controlado de filmes finos de alta qualidade, somente a partir de 1990 os primeiros estudos aplicados começaram a mostrar o enorme potencial de aplicação desses materiais em memórias, sensores piezoelétricos, atuadores, dispositivos de radiofrequência e micro-ondas (MARTIN; RAPPE, 2016).

Compostos como $\mathrm{BaTiO}_{3}$ (BTO) e $\mathrm{PbZrTiO}_{3}$ (PZT) amplamente estudados na literatura são exemplos clássicos do desenvolvimento tecnológico para aplicação em dispositivos de memória e sensores, ao passo que compostos como o $\mathrm{BiFeO}_{3} \mathrm{e}$ $\mathrm{LuFeO}_{3}$ são vistos como materiais multifuncionais de interesse uma vez que sua característica como composto multiferroico proporciona novas possibilidades na engenharia de filmes finos heteroestruturados com acoplamento entre ordens ferroicas, o que abre caminhos para o avanço na criação de dispositivos lógicos e de memória mais eficientes (DAMODARAN et al., 2016; MARTIN; RAPPE, 2016; MUNDY et al., 2016).

Inúmeros sistemas baseados em spintrônica também são estudados atualmente, mas estes ainda apresentam limitações quanto da sua aplicação, especialmente pela perspectiva de consumo energético uma vez que tais dispositivos são intrinsicamente baseados no uso de correntes de carga para criar e manipular diferentes fenômenos de spin. Ainda assim, o controle de transporte de spin por campo elétrico externo (via mecanismos de acoplamento magnetoelétrico) é um campo fundamental para o desenvolvimento de novas tecnologias mais eficientes na produção de dispositivos lógicos e memórias. (MATSUKURA; TOKURA; OHNO, 2015)

A demanda por tecnologia necessária para garantir a evolução deste cenário global em dispositivos eletrônicos traz à tona pesquisas de ponta para o estudo de fenômenos, mecanismos e engenharia de novos materiais, suportando assim a essência de um trabalho dedicado ao entendimento e desenvolvimento de novos materiais, como é o caso dos materiais multifuncionais multiferroicos, que possam se tornar protagonistas deste cenário moderno e futurista.

Como foco desta Tese de Doutorado, é apresentado a seguir uma série de estudos sobre o composto $\mathrm{BiFeO}_{3}$, um dos compostos multiferroicos mais estudados até o momento pelas características únicas que serão apresentadas nos capítulos a seguir, para aplicação como memória e dispositivos lógicos. 


\section{REVISÃO 02}

DA LITERATURA

\section{REVISÃO DA LITERATURA}

2.1. Uma breve abordagem sobre a evolução tecnológica e a indústria de semicondutores

$\mathrm{Na}$ história da civilização, desde os diversos períodos pré-históricos, entre a idade da pedra e a idade dos metais, até a idade moderna e contemporânea, estes dois mais recentes descritos pelas descobertas e avanços tecnológicos nas diversas áreas da ciência, o domínio do homem sobre os fenômenos naturais e a matéria serve como base para o entendimento da importância da ciência básica e aplicada no desenvolvimento da sociedade (ASKELAND; FULAY; WRIGHT, 2010; JR.; RETHWISCH, 2013).

São inúmeros os exemplos importantes dentro das diferentes classes de materiais responsáveis pelos avanços tecnológicos alcançados pela humanidade. Neste contexto, de forma resumida, a classe dos materiais metálicos (e suas ligas), poliméricos, compósitos, cerâmicos e semicondutores foram preenchendo as lacunas dos questionamentos feitos pelos cientistas na busca pela compreensão de sua origem e dos mecanismos que regem o mundo onde vivemos. A despeito da história na sociedade moderna, evidentemente que a classe dos materiais metálicos teve 
fundamental importância nos avanços conquistados a partir da Revolução Industrial (1760 - 1840), ao passo que a classe de matérias cerâmicos tem fundamental importância no desenvolvimento de diversas eras e sociedades desde a antiguidade à idade contemporânea (HUMMEL, 2004; ROCKETT, 2008; JR.; RETHWISCH, 2013).

Diferente das classes de materiais que serviram para definir a idade do ferro, idade do cobre, idade do bronze etc, a classe de materiais cerâmicos não é citada como fruto de algum período histórico específico, e um dos motivos desse fato devese a presença desses materiais de forma contínua e consistente durante toda a história evolutiva da sociedade, desde pinturas corporais e decorações datadas de 50 mil anos antes de Cristo até os mais modernos sistemas de turbinas e boa parte dos materiais eletrônicos do século XXI (HUMMEL, 2004).

A Era dos Materiais Eletrônicos, assim como os demais períodos citados acima, é caracterizada pelas mudanças expressivas na forma como a humanidade se relaciona, se comunica e evolui interconectada em escala global. Junto com os materiais eletrônicos (cerâmicas e semicondutores), a Era da Informática evoluiu em um ritmo nunca antes presenciado pela história da ciência (FURUKAWA, 1990; HUMMEL, 2004; ROCKETT, 2008).

Como qualquer fruto comercial da indústria, os produtos e tecnologias evoluíram das principais descobertas da ciência de base. Historicamente, o filósofo grego Tales de Mileto, durante os anos 600 a.C., descreve a essência de suas observações a respeito do comportamento eletrostático do âmbar quando friccionado com um pedaço de tecido. A partir destas observações, o comportamento elétrico dos materiais passa a atrair a atenção de outros cientistas em diversas épocas da história da ciência, como por exemplo o cientista britânico Stephen Gray (1666 or 1667 - 1736) que descreveu pela primeira vez suas observações, publicadas na respeitada revista "Philosophical Transactions of the Royal Society" (GRAY, 1731), a respeito do comportamento de condutividade elétrica de alguns materiais (BUSCH, 1989).

Em um trabalho publicado por George Busch (1989), o termo semicondutor, ou pelo menos a ideia de materiais com característica semicondutora, aparece pela primeira vez em notas e trabalhos de Alessandro Volta durante o século 18. As primeiras observações documentadas sobre este fenômeno veem de experimentos sobre a influência da temperatura sobre a condutividade do sulfeto de prata $\left(\mathrm{Ag}_{2} \mathrm{~S}\right)$ 
que foram relatadas por Michael Faraday em suas notas publicadas no capítulo "On conducting power generally" da (SOCIETY OF LONDON, 1833) como citado a seguir: "I have lately met with an extraordinary case of this kind, for electricity of low tension, or that of the voltaic pile, and which is in direct contrast with the influence of heat upon metallic bodies, as observed and described by Sir Humphry Davy."

As observações de Faraday mostraram um novo cenário que se contrapunha as observações de Volta e Davy em anos anteriores, o comportamento anômalo do sulfeto de prata que aumentava sua condutividade com o aumento da temperatura era algo intrigante e oposto ao comportamento resistivo de metais. Com o passar dos anos as pesquisas nesta área mostraram a influência da concentração de portadores de carga e de defeitos estruturais que determinavam o comportamento resistivo de alguns materiais. O ponto de transição entre metal-semicondutor no diagrama de fases tornou-se objeto de interesse para aplicações comerciais na produção de detectores, receptores etc (BUSCH, 1989; LYTOVCHENKO; STRIKHA, 2014).

A busca por respostas ao comportamento de materiais semicondutores passa pelas observações de importantes cientistas como Paul Drude (1863 - 1906) com sua teoria de condutividade de metais, Johann Koenigsberger (1874 - 1946) com sua teoria de energia dissociativa Q e posteriormente Alan Wilson (1906 - 1995) com o desenvolvimento da teoria de bandas de semicondutores que ajudou a compreender o "extraordinário" comportamento relatado por Farady anos atrás (BUSCH, 1989; LYTOVCHENKO; STRIKHA, 2014).

Os principais avanços na indústria de semicondutores passam a ter maior visibilidade com a ampliação do uso destes materiais no mercado de eletrônicos e computadores. Um dos primeiros passos para o progresso do mercado de silício foi a criação das junções p-n por Russel Ohl em 1940, mostrado na Figura 01b. Em suas pesquisas com silício, Ohl observou um significativo aumento de condutividade quando um pedaço de silício puro era exposto a luz. Outros trabalhos envolvendo a dopagem de silício com elementos como fósforo e boro produziram regiões chamadas de (região $n$ ) para o lado com excesso de cargas negativas e (região p) para o lado com deficiência de cargas negativas e excesso de buracos, portadores de carga positiva como já definido por Werner Heisenberg em 1931. Testes com irradiação de luz visível na região limite entre os lados p e n provocava a movimentação de cargas entre os lados, produzindo corrente elétrica. Essa barreira foi então denominada como 
junção p-n e o efeito fotovoltaico usado nas células solares descoberto (RIORDAN; HODDESON, 1997).

$\mathrm{Na}$ história evolutiva da eletrônica e computação, os primeiros passos de William Shockley nas instalações da Bell Laboratories com o desenvolvimento de um amplificador de campo elétrico baseado em germânio e silício foram a chave, junto com os estudos e experimentos de John Bardeen e Walter Brattain, para a criação do primeiro transistor mostrado na Figura 01c. Estes cientistas receberam o Prêmio Nobel de Física em 1956 pelos seus esforços neste campo (BARDEEN, 1956; RIORDAN; HODDESON, 1997).

Com os avanços no manuseio e produção de materiais, incluindo o desenvolvimento da técnica de purificação de silício por refino de zona em 1951, a criação do primeiro transistor de silício em 1954 por Morris Tenenbaum, a utilização da técnica de fotolitografia para produção de microdispositivos sobre silício e a produção de circuitos eletrônicos de estado sólido durante o final dos anos 1950, os primeiros chips passaram a ser produzidos com alguns transistores semicondutores (mostrado na Figura 01d) em circuitos integrados, o que trouxe grandes possibilidades para o mundo da computação, e evidentemente para a indústria de semicondutores e eletrônicos (LYTOVCHENKO; STRIKHA, 2014).

Como já mencionado por Gordon Moore, responsável pelas primeiras previsões a respeito do avanço no número de componentes por área em um chip, a complexidade na criação e desenvolvimento de novas tecnologias para circuitos integrados mais avançados esbarra nas limitações impostas por fatores como custo de produção, eficiência e dissipação de calor. Ainda assim, como publicado em 1965 e recolocado em 1975, Moore foi capaz de observar e predizer a evolução dos componentes eletrônicos quanto do aumento no número de componentes por área a um fator de 2 por ano (em sua primeira publicação, mostrado na Figura 01a e posteriormente, na publicação de 1975, um aumento a um fator de 2 componentes a cada 2 anos (MOORE, 1965, 1975). 
Figura 1 - Quadro da história dos dispositivos eletrônicos na era dos semicondutores mostrado pela a) primeira predição de Gordon E. Moore sobre a evolução dos componentes eletrônicos publicado em 1965, b) esboço de Russel Ohl sobre seu experimento de medição de resistência em uma amostra de silício puro como origem da criação da primeira junção p-n em 1940, c) primeiro transistor de germânio produzido nos laboratórios da companhia Bell Labs em 1950 e d) primeiro transistor semicondutor comercial produzido pela Texas Instruments em 1954.

a)

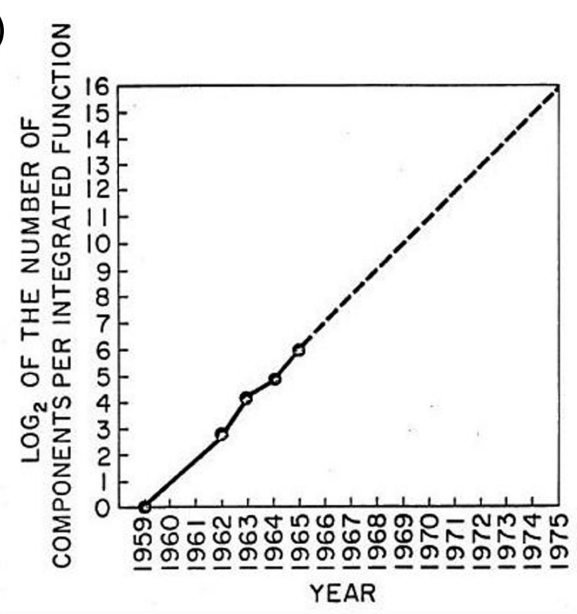

c)

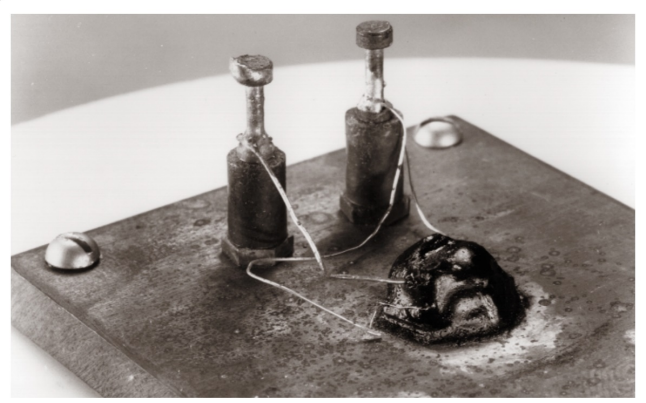

b)

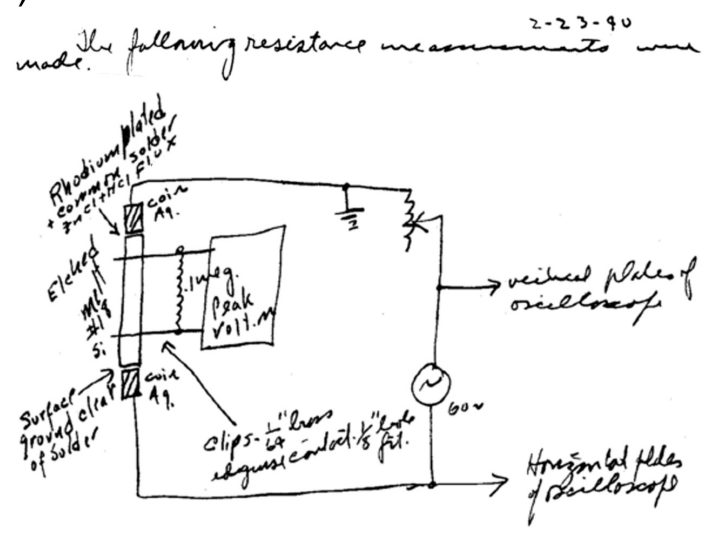

d)

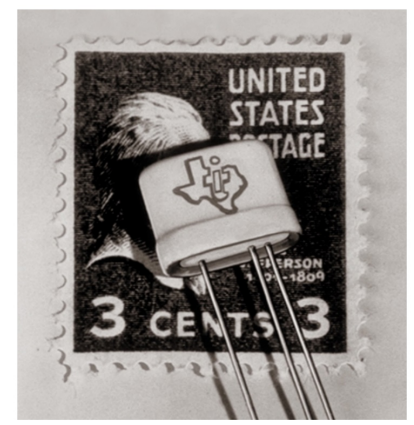

Fonte: a) (MOORE, 1965), b) adaptado de (RIORDAN; HODDESON, 1997), c) (RIORDAN, 2004)

O cenário atual conta com dispositivos cada vez menores e mais rápidos, tal como os processadores comercializados pela Intel Corporation, com o mais avançado conjunto de dispositivos transistores com dimensões entre 22 e 10 nm (Fig. 2a) de largura para cada FinFET (Fig. 2b). Essa diminuição no tamanho de cada componente colabora com a manutenção da Lei de Moore, uma vez que, além de consequentemente promover o aumento do número de transistores por unidade de área de um chip de silício, ainda há o aumento de performance e redução de consumo energético, como indicado pelos dados de densidade de transistores e performance da própria fabricante de processadores na Fig. 2c e Fig. 2d, respectivamente. 
Figura 2 - Imagens de microscopia eletrônica de transmissão (a) de transistores do tipo FinFET (b), o consequente aumento de densidade (c) e performance (d) de transistores em função dos diferentes tamanhos de dispositivos produzidos por fotolitografia.

a)

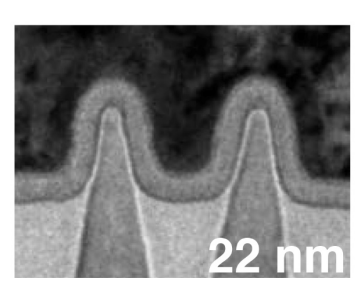

c)

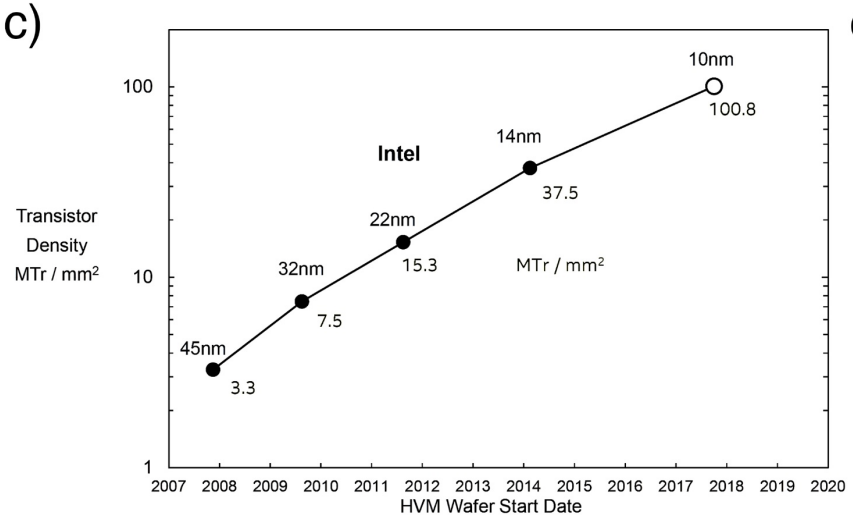

b)
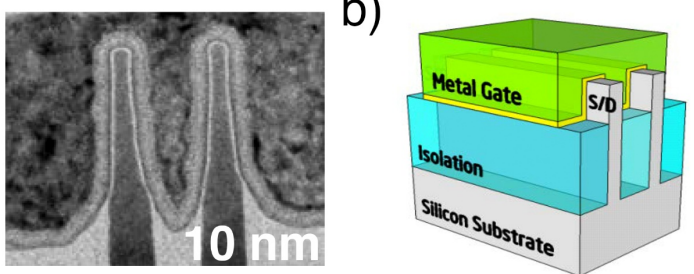

d)

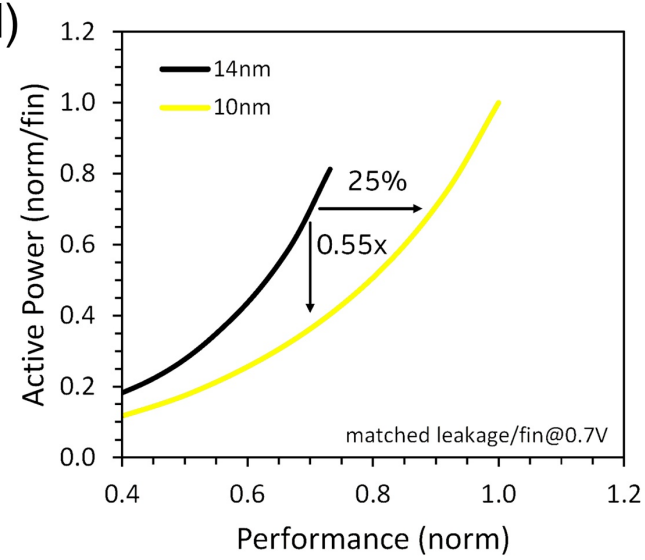

Fonte: Adaptado de (MISTRY, 2017)

O desenvolvimento de materiais funcionais eficientes e de menor consumo energético, bem como o desenvolvimento de novas tecnologias de arquitetura e operação de dispositivos baseados em spintrônica, passa a tomar a atenção das industrias e centros de pesquisas dada a demanda mundial por tecnologia e a transição para a era da Internet das Coisas.

2.2. A contribuição dos materiais funcionais na indústria eletrônica

Como parte dessa breve linha do tempo, apresentada na seção anterior, a história da ciência e indústria eletrônica foram evoluindo com as descobertas nas áreas da física e ciência dos materiais sobre as propriedades de diversos elementos como o germânio e silício. Dado o foco deste trabalho, abordaremos alguns aspectos da participação dos materiais cerâmicos ferroicos como parte essencial para a criação de novos dispositivos eletrônicos. 
Não menos importante que o silício, os materiais funcionais com propriedades de interesse em diversas aplicações trouxeram um horizonte ilimitado de possibilidades para a criação de novos dispositivos como sensores, memórias, transistores, atuadores, transdutores etc. O mundo moderno no período da Segunda Guerra Mundial passou a observar a evolução de dispositivos eletrônicos desenvolvidos pelos militares, como os sonares, e os materiais funcionais ferroelétricos são um dos exemplos mais conhecidos neste aspecto.

Algumas definições sobre materiais funcionais podem ser observadas de acordo com a classe cristalina (ou Grupo Pontual) a qual ele pertence. Encontramos um total de 32 grupos pontuais usados para classificar o sistema de simetria cristalina formado pela estrutura do composto em questão, destes, 10 grupos básicos e 22 combinações entre eles. Todas as 32 classes apresentam eletroestricção, quando uma tensão elástica é provocada na estrutura cristalina na presença de campo elétrico externo. Adicionalmente, materiais isolantes são dielétricos, o que causa deslocamento de carga durante a aplicação de campo elétrico, promovendo uma polarização elétrica transiente (XU, 1991; POWELL et al., 2010; MARTIN; RAPPE, 2016).

Dentro dos 32 grupos pontuais temos 20 classes de materiais piezoelétricos, os quais induzem potencial elétrico quando submetidos a estresse mecânico - ou o inverso, produzido deslocamento mecânico - devido a distorções na sua rede cristalina - mediante a aplicação de campo elétrico. Os materiais piroelétricos somam 10 grupos pontuais representadas por estruturas com eixo polar e com polarização espontânea que podem criar corrente elétrica quando submetidos a diferentes temperaturas. Alguns dos materiais com eixo polar ou piroeletricidade possuem diferentes eixos estáveis (estados) de polarização quando não submetidos a campos elétricos, mas que podem ser alternados entre si pela aplicação de um campo elétrico externo. Estes materiais ferroelétricos também podem ser classificados como ferroelásticos quando a alternância entre estados é ocasionada por estresse mecânico (MARTIN; RAPPE, 2016).

A classe de Materiais Ferroelétricos é objeto de estudos há muitos anos e desde suas primeiras aplicações como transdutores e sensores, inúmeras pesquisas buscam compreender os mecanismos e eventos de polarizabilidade em estruturas ferroelétricas bulks, e mais recentemente em filmes finos. 
A ferroeletricidade foi descrita primeiramente pela observação das propriedades do tartarato de sódio e potássio $\left(\mathrm{KNaC}_{4} \mathrm{H}_{4} \mathrm{O}_{6} \cdot 4 \mathrm{H}_{2} \mathrm{O}\right)$, um sal duplo descoberto em 1675 por Pierre Seignette em La Rochelle, França. As primeiras considerações sobre suas propriedades ferroelétricas foram feitas em 1921 e a partir de então outras substâncias, como iodetos, fluoretos, polímeros e frameworks orgânicos, passaram a ser estudadas sob a ótica das interações entre estrutura cristalina e campos elétricos aplicados (WHATMORE; ABRAHAMS; NASSAU, 2007; ALGUERÓ; GREGG, 2016).

Majoritariamente, a classe dos materiais com estrutura cristalina do tipo Perovskita ${ }^{1}$ fazem parte do cenário de materiais funcionais com inúmeras aplicações e possibilidades. Constituído pela fórmula unitária $\mathrm{ABO}_{3}$, seus cátions localizados nos sítios $A$ possuem radio iônico maior que os dos sítios $B$, seguido pelos átomos de oxigênio (no caso dos óxidos) localizados geometricamente pelos vértices de um octaedro $\mathrm{BO}_{6}$ no centro da estrutura. Um grande número de compostos apresenta essa estrutura, como alguns carbetos, haletos, nitretos e de forma mais expressiva os óxidos (PEÑA; FIERRO, 2001).

Certamente a classe de materiais óxidos se tornou referência no estudo dos compostos ferroelétricos, um dos materiais mais estudados e bastante conhecidos por apresentar esta propriedade é o titanato de Bário $\left(\mathrm{BaTiO}_{3}\right)$, também mencionado na literatura como BTO (Fig. 03). Identificado como material ferroelétrico em 1944, o BTO apresenta um comportamento muito característico, com um diagrama de transição de fases polimórficas em função da temperatura de Curie $^{2} T_{C}$, abaixo da qual, a presença de fases de menor simetria (romboédrica, ortorrômbica e tetragonal, esta última mostrada na Figura 03a), promovem a formação de estados ferroelétricos, até a formação de sua fase cúbica de maior simetria presente acima de $120{ }^{\circ} \mathrm{C} \mathrm{T}_{\mathrm{C}}$.

De fato, o polimorfismo está presente em boa parte dos materiais ferroelétricos e no caso do BTO, suas transições de baixa simetria determinam as condições para

\footnotetext{
${ }^{1}$ Dada a importância da classe de materiais com estrutura do tipo Perovskita, maiores informações sobre esse assunto podem ser consultadas nas referências (PEÑA; FIERRO, 2001; PETROVIĆ; CHELLAPPAN; RAMAKRISHNA, 2015)

${ }^{2}$ Descoberto por Jacques Curie e Pierre Curie em 1880, o feito piezoelétrico também deu origem a definição da temperatura de Curie $T_{C}$ onde a transição entre as fases piezo/ferroelétrica e paraelétrica determinam presença ou não das características de polarização espontânea no material (CURIE; CURIE, 1880, 1881).
} 
o deslocamento do átomo central da estrutura $\left(\mathrm{Ti}^{4+}\right.$ no sítio $\left.\mathrm{B}\right)$ dentro do octaedro de oxigênio em uma direção preferencial determinada pelo eixo polar (eixo de polarização espontânea) conforme indicada pelas setas no centro do octaedro das estruturas na Figura 03b.

O deslocamento dos átomos de $\mathrm{Ti}^{4+}$ determinam a direção de polarização espontânea da estrutura, como visto na Figura 03b, quando há um deslocamento superior do sítio B, o vetor de polarização aponta para a direção [001], também conhecido como polarização "UP". Uma vez que o deslocamento do sítio B ocorre para o sentido inferior da célula unitária, o vetor de polarização passa a ser direcionado para a direção [00-1], denominado polarização “DOWN".

Apesar de não ser evidenciado nas representações, o deslocamento dos octaedros de oxigênio ocorre concomitantemente, mas em sentido contrário, ao deslocamento do átomo central da estrutura.

Figura 3 - Esquema de uma célula unitária (a) da estrutura cristalina tetragonal $(P 4 m m)$ do tipo Perovskita do $\mathrm{BaTiO}_{3}$ e suas possíveis direções de polarização elétrica "UP" e "DOWN" (b). As setas mostradas no átomo central da célula unitária representam o deslocamento do sítio $B$ em função dos átomos da posição $A$.

a)

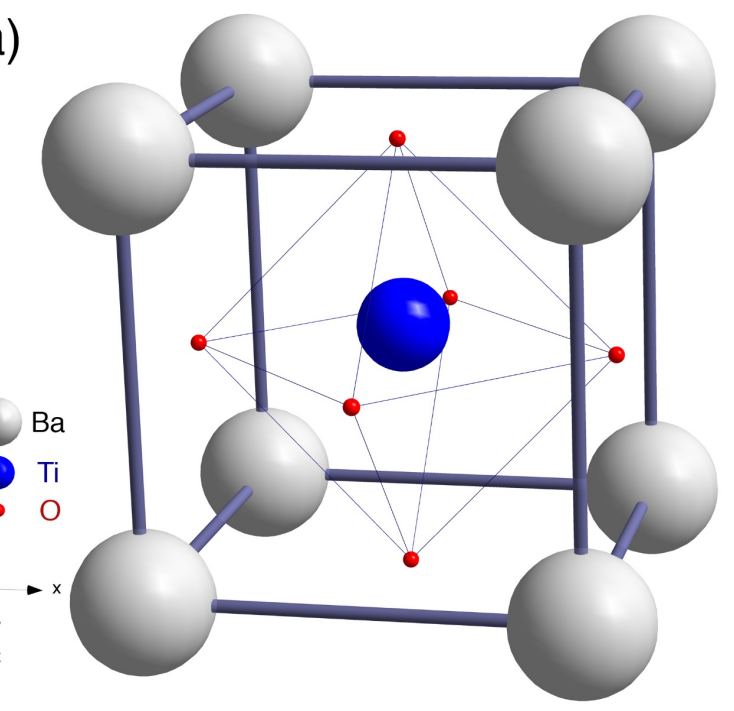

b)
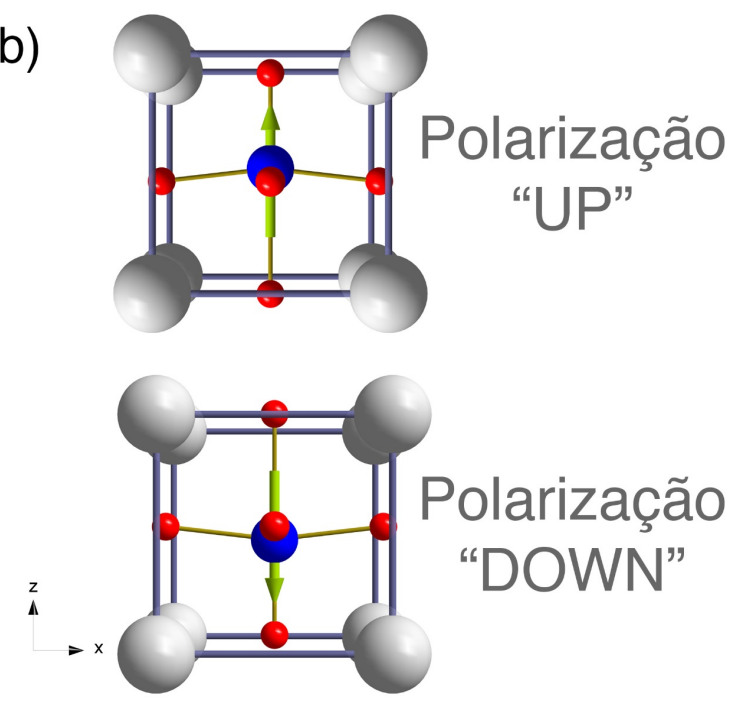

Fonte: $\mathrm{O}$ autor.

Nota: A estrutura mostrada acima foi elaborada de acordo com as informações do arquivo de coordenadas atômicas CIF disponível na referência (YASUDA et al., 2009). 
Com o avanço tecnológico na manufatura de materiais em escala bulk, capacitores cerâmicos de BTO se tornaram um dos produtos de interesse na indústria da microeletrônica, além disso, junto com o desenvolvimento de métodos de crescimento de monocristais puros veio a possibilidade no uso desse material capacitivo para armazenamento de energia (XU, 1991).

Outro exemplo da classe de materiais piezo/ferroelétricos é o $\mathrm{Pb}(\mathrm{Zr}, \mathrm{Ti}) \mathrm{O}_{3}$, também identificado como PZT na literatura. Como modelo de material funcional, o PZT é considerado um caso de sucesso na indústria dos transdutores eletromecânicos, dos sensores e atuadores como acelerômetros e motores piezoelétricos para microscópios de força atômica. Sistemas integrados de vibração, produção de ultrassom, sensores de imageamento e sonares submarinos também contam com a presença desta cerâmica piezoelétrica (DINEVA, 2014; ALGUERÓ; GREGG, 2016).

Baseado na estrutura cristalina do tipo Perovskita da cerâmica $\mathrm{PbTiO}_{3}$, o PZT também apresenta propriedades ferroelétricas e ferroelásticas. Suas características de polarização espontânea são manipuladas por estresse mecânico e campo elétrico externo, o que também pode ser controlado do ponto de vista da formação e movimentação de domínios e paredes de domínios ferroelétricos em fases específicas (ALGUERÓ; GREGG, 2016).

As possibilidades de aplicação comercial dessas cerâmicas são enormes, dispositivos sensores de radiofrequência e micro-ondas já são realidade, e com os avanços na engenharia de materiais funcionais, o PZT já pode ser visto como candidato para aplicações em energy harvesting ${ }^{3}$ e dispositivos magnetoelétricos (SUN et al., 2017).

2.3. Os desafios tecnológicos na aplicação de materiais funcionais

Como parte fundamental do desenvolvimento tecnológico, a produção de materiais com maior controle de suas propriedades e características torna-se ponto

\footnotetext{
${ }^{3}$ Energy harvesting é um termo usado para definir tecnologias capazes de aproveitar a energia disponível no ambiente (energia térmica, mecânica, solar etc) para conversão e posterior utilização como energia elétrica (CHOI et al., 2017; SUN et al., 2017).
} 
essencial para a criação de dispositivos eletrônicos mais eficientes e assim, como mencionado no início deste capítulo, desde o nascimento da era dos semicondutores, as indústrias passaram a investir em tecnologias para o crescimento de monocristais puros, implantação iônica e produção de filmes finos para miniaturização dos componentes eletrônicos.

De forma mais significativa, a partir dos anos de 1960, começaram a aparecer novas tecnologias para o crescimento de filmes finos com propriedades de interesse industrial como os materiais ferroelétricos. A tecnologia de produção de camadas de óxidos ferroelétricos nanoestruturados passa a fazer parte da implementação de dispositivos eletrônicos do tipo CMOS (sigla para a expressão em Inglês "complementary metal-oxide semiconductor") (CHANDRAKASAN; BRODERSEN, 1995; ALGUERÓ; GREGG, 2016).

Como início de uma sequência de processos complexos para criação de componentes nanoestruturados em dispositivos eletrônicos, os primeiros filmes ferroelétricos produzidos nesta década não deram origem a significativas mudanças nos dispositivos já conhecidos uma vez que a qualidade dos materiais crescidos ainda era considerada insuficiente para o controle das propriedades de interesse nas aplicações eletrônicas (MARTIN; RAPPE, 2016).

Já durante os anos seguintes a 1990, com o avanço dos estudos no crescimento de filmes finos, os óxidos ferroelétricos se tornaram a base para o desenvolvimento de dispositivos de memória não volátil, dispositivos de radiofrequência, MEMS piezoelétricos, ressonadores de ondas acústicas, sensores piroelétricos e piezoelétricos etc. Materiais como $\mathrm{Pb}(\mathrm{Zr}, \mathrm{Ti}) \mathrm{O}_{3}(\mathrm{PZT})$ e $\mathrm{SrBi}_{2} \mathrm{Ta}_{2} \mathrm{O}_{7}$ (SBT) se tornaram parte essencial de produtos comerciais como os cartões de banco e as etiquetas de segurança de radiofrequência (SETTER et al., 2006; ALGUERÓ; GREGG, 2016).

A indústria de dispositivos eletrônicos tem evoluído constantemente no desenvolvimento de sistemas mais estáveis, robustos, eficientes, rápidos e seguros para o armazenamento e processamento de informações. Alguns exemplos das atuais tecnologias empregadas nesta área, como as memórias não-voláteis, são mostrados na Figura 04. 
As memórias ferroelétricas não voláteis de estado sólido, também conhecidas como FeRAM (do inglês, Ferroelectric Random Access Memory), se tornaram produtos comerciais indispensáveis aos computadores e demais dispositivos de armazenamento de informações. Filmes finos ferroelétricos usados nestas memórias são capazes de serem polarizados em duas direções opostas de polarização espontânea, criando os estados binários usados na arquitetura binária (0 e 1) dos computadores (RAMANATHAN, 2010).

Figura 4 - Classificação das tecnologias e dispositivos voláteis e não-voláteis para armazenamento e processamento de informações na industria eletrônica atual.

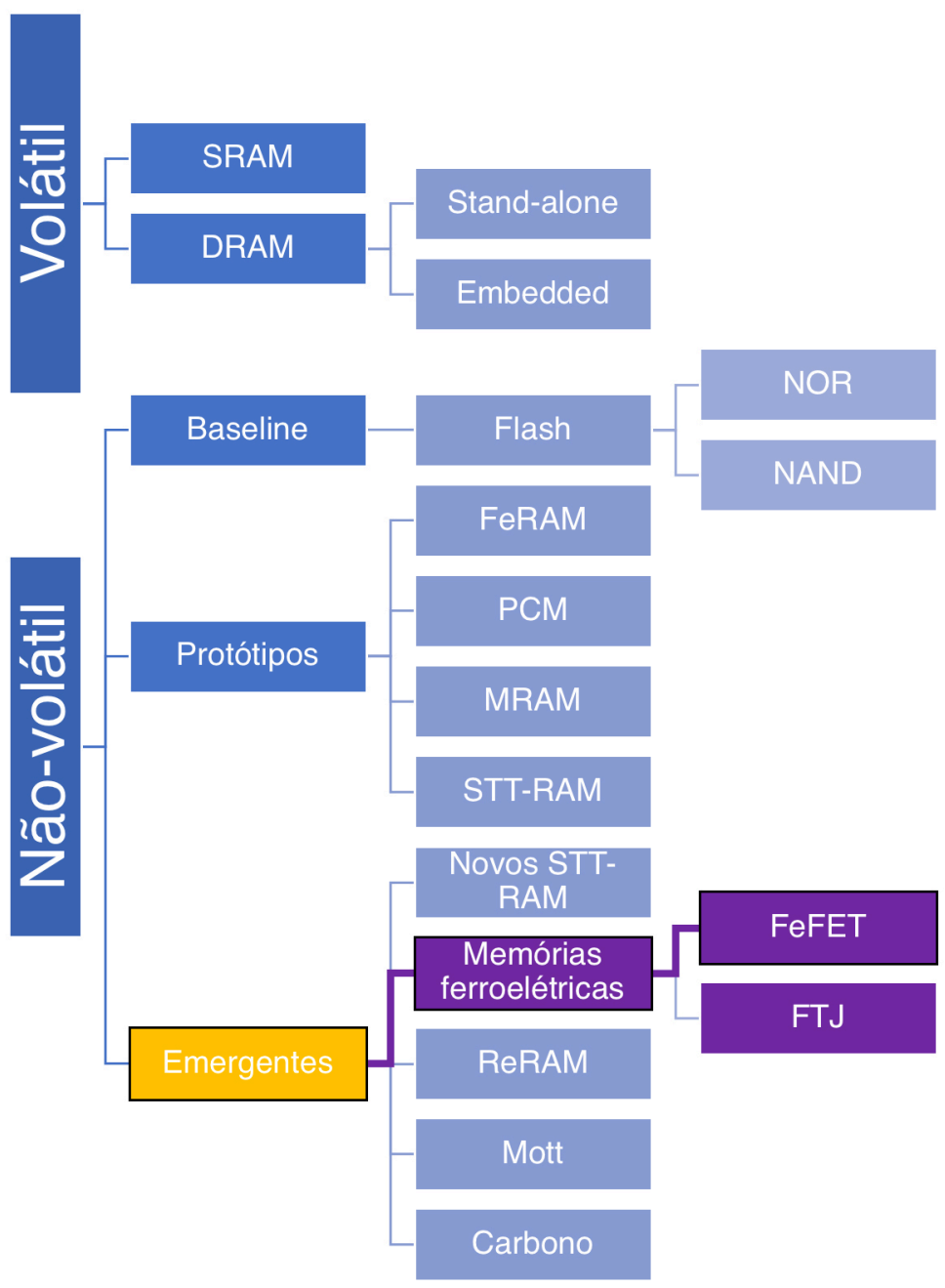

Fonte: Adaptado de (ITRS, 2015)

Nota: Em destaque, a evolução dos dispositivos emergentes em memórias ferroelétricas não voláteis como parte do apelo tecnológico deste trabalho. 
A aplicação dos materiais funcionais em dispositivos de processamento como os transistores também faz parte de um grande gargalo tecnológico fundamental para o desenvolvimento de equipamentos mais rápidos e de menor consumo energético. As principais tecnologias já existentes no mercado baseiam-se em transistores de efeito de campo - FET - (do inglês, Field-Effect Transistor) suportados sobre silício semicondutor (ITRS, 2015).

Os materiais ferroelétricos, especialmente o $\mathrm{Pb}(\mathrm{Zr}, \mathrm{Ti}) \mathrm{O}_{3}(\mathrm{PZT})$ e 0 $\mathrm{SrBi}_{2} \mathrm{Ta}_{2} \mathrm{O}_{7}$ (SBT) são comumente usados como camada dielétrica sobre o contato do tipo "gate" para movimentação de cargas no canal semicondutor de transistores suportados em silício e o comportamento de histerese ferroelétrica destes materiais determina boa parte do consumo energético destes dispositivos (CHANDRAKASAN; BRODERSEN, 1995; ULRICH et al., 2000; NAGARAJAN et al., 2002; SETTER et al., 2006).

De acordo com informações da empresa Texas Instruments (SARWAR, 1997), a classe de dispositivos CMOS operava com tensão de 3,3 e 5 VDD em 1997. Em comparação, a classe de processadores mais avançada e comercializada atualmente pela maior empresa fabricante destes dispositivos, a Intel Corporation, apresenta arquitetura de 64 bits construída com tecnologia de fotolitografia para fabricação de transistores de $14 \mathrm{~nm}$ e opera com consumo de 1,2 $\mathrm{V}_{\mathrm{DD}}$ por operação de leitura e gravação DDR4 a 100 MHz (INTEL, 2016).

Contudo, existem inúmeros fatores a serem levados em consideração para determinação de consumo de energia em transistores, uma vez que a corrente de fuga gerada em cada ciclo de operação é uma função de fenômenos de tunelamento de carga pela camada de óxido dielétrica, da temperatura, da frequência e tensão de operação. Alguns modelos de transistores do tipo TFET (do inglês, Tunnel FieldElectric Transistor) já são capazes de operar a $0,5 \mathrm{~V}$, mas as dificuldades tecnológicas citadas acima ainda não permitem a comercialização destes dispositivos (SARASWAT, 1996; RANUÁREZ; DEEN; CHEN, 2006; ITRS, 2015).

A aplicação de materiais óxidos ferroelétricos como camada dielétrica em transistores já faz parte das pesquisas para a elaboração de dispositivos mais rápidos e eficientes, como por exemplo o conceito de FeFET explicado por (SETTER et al., 
2006) e algumas novas tecnologias para a implementação de melhorias em sistemas do tipo Fe-MOSFET mostradas no trabalho de (OTA et al., 2017).

As novas tecnologias para criação de dispositivos lógicos mais eficientes estão sendo elaboradas sobre conceitos fundamentais de uma área relativamente nova conhecida como spintrônica, principalmente pela possibilidade de controle de efeitos de spin magnético por aplicação de campos elétricos, o que reduz significativamente o consumo energético de cada operação lógica (ITRS, 2015). Alguns exemplos destas tecnologias são mostrados na Figura 05.

Figura 5 - Principais tecnologias de dispositivos lógicos processadores baseados em transistores na industria eletrônica atual, incluindo as tecnologicas convensionais (quadrante azul) suportadas em silício com canal semicondutor e tecnologias emergentes baseadas em spintrônica (quadrante amarelo).

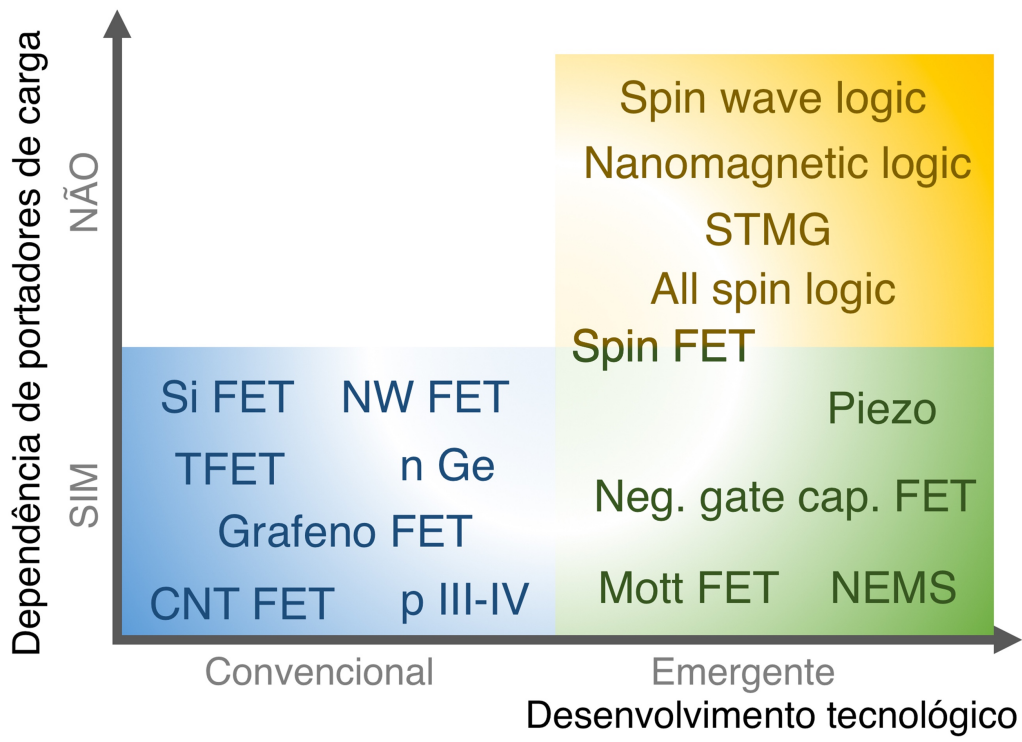

Fonte: Adaptado de (ITRS, 2015)

A implementação de materiais multiferroicos como componente de controle em dispositivos lógicos baseados em spintrônica passa a se tornar extremamente atrativa e cada vez mais próxima da realidade, uma vez que estes materiais possuem ao menos duas ordens ferroicas acopladas por interações que podem ser manipuladas e que serão explicadas adiante (TRASSIN, 2016).

Grande parte destas conquistas tecnológicas partiram de esforços mútuos entre as pesquisas teóricas que ajudam a compreender os fenômenos físicos por trás 
de cada material, bem como os avanços nas áreas experimentais e de caracterização das propriedades intrínsecas, em escala espacial atômica e temporal na faixa de femtosegundos, das diversas composições estudadas (MARTIN; RAPPE, 2016).

A criação de novos materiais funcionais, em especial os materiais ferroicos, passa por etapas fundamentais e limitantes que envolvem processos de síntese e abordagens de crescimento de filmes finos para obtenção de sistemas estáveis e mais importante que isso, controláveis do ponto de vista fundamental da matéria, sua estrutura e arranjo atômico. As abordagens de modificação composicional por meio de dopagem, criação de defeitos estruturais e controle de condições de tensão/estresse em sistemas epitaxiais são parte do cenário atual para a engenharia de novos materiais com características únicas (MARTIN; CHU; RAMESH, 2010).

\subsection{A engenharia nanotecnológica dos Filmes finos}

Nanotecnologia como uma área ampla da ciência dos materiais em nanoescala $\left(1 \mathrm{~nm}=10^{-9} \mathrm{~m}\right)$ passa a ter enorme importância no desenvolvimento e aplicação de materiais bidimensionais (2D) como filmes finos e ultrafinos. Genericamente, como definição de nanomaterial, o objeto em estudo deve apresentar ao menos uma de duas dimensões $(x, y, z)$ na escala nanométrica, comumente definida abaixo de 100 $\mathrm{nm}$, mas é possível encontrar conceitos mais elaborados que também incluem aqueles materiais com dimensões acima de $100 \mathrm{~nm}$ que apresentem propriedades diferentes daquelas encontradas na mesma composição em escala bulk (SENGUPTA; SARKAR, 2015; ZHANG, 2015).

Os filmes finos usados para aplicações eletrônicas, como alguns casos já mencionados no texto, por terem 1 de suas dimensões (espessura) dentro da escala nanométrica, apresentam propriedades especiais de caráter quântico, em alguns casos devido ao confinamento de elétrons, que alteram significativamente seus comportamentos magnético, elétrico, óptico etc (NGO; VAN DE VOORDE, 2014; SENGUPTA; SARKAR, 2015; ZHANG, 2015). 
De acordo com (ZHANG, 2015), além do grafeno como uma descoberta revolucionária na nanotecnologia, outras classes de materiais podem apresentar nanoestruturas de filmes finos, como alguns exemplos mostrados na Figura 06a.

Figura 6 - Principais tipos de nanomateriais filmes finos (a) e diferentes arranjos heteroestruturados formados por esses nanomateriais (b).

a)

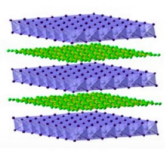

LDHs

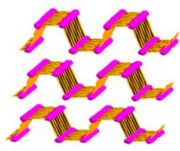

$\mathrm{BP}$

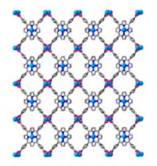

MOFs
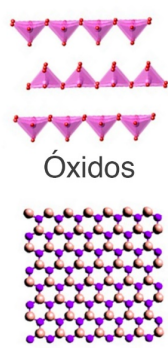

h-BN

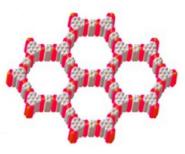

COFs

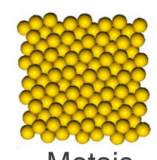

Metais

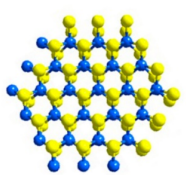

TMDs

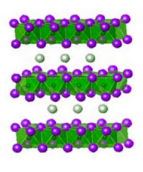

MXenes b)

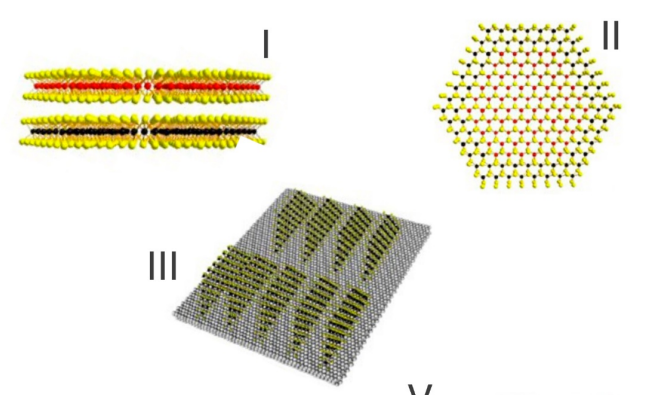

IV

$2 \mathrm{H}$

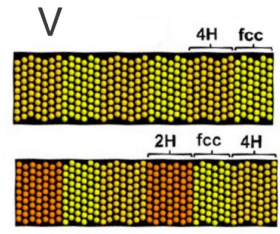

Fonte: Extraído e adaptado de (ZHANG, 2015)

Com o desenvolvimento de novas técnicas de síntese e crescimento dessas estruturas, passamos a produzir materiais monofásicos mais puros e até arquiteturas específicas desses arranjos, como o caso das heteroestruturas mostradas na Figura 06b. Alguns tipos de arranjos epitaxiais são bem conhecidos na literatura como os filmes finos monofásicos crescidos sobre um substrato cristalino também monofásico, as heteroestruturas epitaxiais horizontais formadas materiais ferroelétricos e ferromagnéticos e as heteroestruturas verticais como os nanopilares ou nanodots crescidos sobre um monocristal (RAMESH; SPALDIN, 2007; MARTIN; CHU; RAMESH, 2010).

O crescimento controlado destas estruturas 2D trouxe os avanços mais importantes no desenvolvimento de materiais funcionais, especialmente pela possibilidade do controle das suas propriedades em função da forma como realizamos a interação entre estruturas e composições químicas diferentes. 
Como destaque deste trabalho, os filmes finos óxidos crescidos epitaxialmente em heteroestruturas hoje em dia são a base tecnológica dos diversos dispositivos eletrônicos e sensores/atuadores produzidos e comercializados mundialmente (MARTIN; CHU; RAMESH, 2010).

Em geral, o crescimento epitaxial de estruturas cristalinas acontece a partir da deposição de átomos sobre a superfícies de um monocristal como substrato. Podemos separar este processo de acordo com o tipo de material depositado sobre o material de base (substrato), sendo assim, a homoepitaxia é a deposição/crescimento de uma composição igual àquela já existente no substrato e a heteroepitaxia é o processo de deposição de materiais diferentes, porém com estrutura cristalina semelhante àquela do substrato monocristalino usado como base (MARTIN; CHU; RAMESH, 2010).

No caso de estruturas heteroepitaxiais, um fator muito importante e que é usado para o controle de algumas propriedades dos filmes finos é o estresse estrutural gerado na interface de materiais que apresentam estruturas cristalinas com parâmetros de rede diferentes. Neste caso, fenômenos de tensão e compressão podem ser observados nas estruturas, o que eventualmente pode propagar defeitos ou gerar distorções na rede cristalina quando a estrutura não apresentar condições favoráveis para a relaxação através de sua espessura (MARTIN; CHU; RAMESH, 2010).

Por conta disso, o planejamento para o crescimento de heteroestruturas com propriedades específicas também passa pela etapa de escolha adequada dos materiais com parâmetros de rede que atendam às necessidades do experimento. Uma lista dos materiais ferroelétricos, dos óxidos condutores para uso como eletrodo inferior e dos substratos mais estudados atualmente e seus respectivos parâmetros de rede pode ser vista na Figura 07.

As composições $\mathrm{BiFeO}_{3}$ (multiferroico), $\mathrm{SrRuO}_{3}$ (eletrodo inferior e superior) e os substratos $\mathrm{DyScO}_{3}$ (DSO) e $\mathrm{SrTiO}_{3}$ (STO) usadas neste trabalho estão indicadas em amarelo na lista da Figura 07. É possível identificar a proximidade dos parâmetros de rede entre eles. Para o caso das estruturas com baixo fator de estresse estrutural, foram escolhidos os substratos de $\mathrm{DSO}_{(110)}$, nos casos onde a influência da tensão estrutural foi foco de investigação, foram usados substratos de $\mathrm{STO}_{(001)}$. 
Os efeitos causados devido as forças de deformação estrutural (tensão e compressão) em filmes heteroepitaxiais trouxeram grandes informações a respeito das interações estruturais e o controle das propriedades destes materiais de forma precisa. Muitos trabalhos a respeito do estudo dos efeitos de estresse na transição de fases, modificação na simetria do cristal e intensificação de polarizabilidade em filmes finos ferroelétricos passaram a ser publicados e este passou a ser um campo novo a ser explorado na engenharia nanotecnológica de novos dispositivos (AGAR et al., 2016; MARTIN; RAPPE, 2016).

Figura 7 - Principais materiais ferroelétricos, eletrodos e substratos ordenados em função do seu parâmetro de rede.

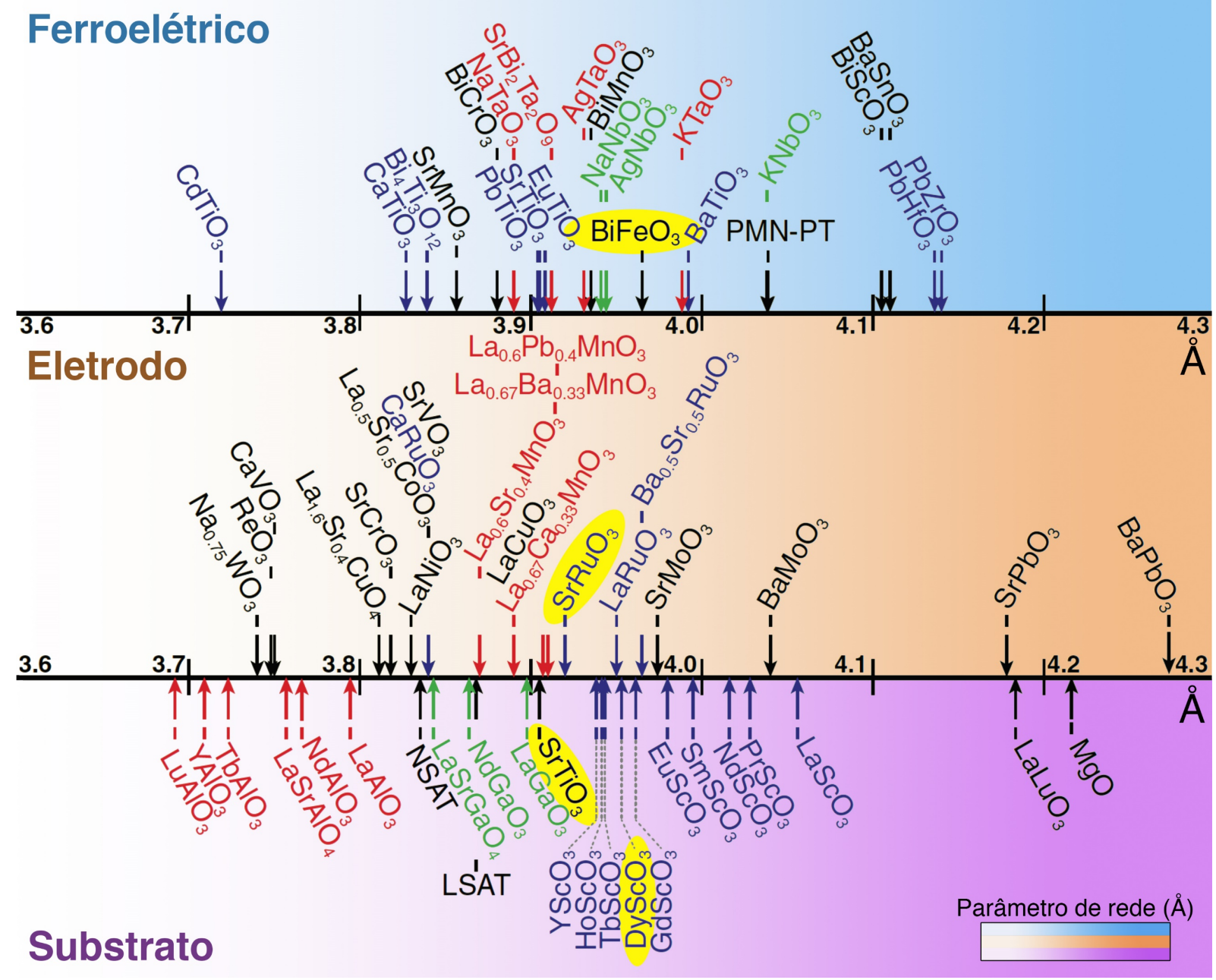

Fonte: Adaptado de (DAMODARAN et al., 2016)

Nota: Os compostos indicados em amarelo foram usados neste trabalho e por isso foram evidenciados na imagem. 
Não apenas os filmes finos óxidos, mas também os metálicos podem ser obtidos por diversos métodos de deposição/crescimento que podem ser classificados de acordo com o ambiente onde eles ocorrem. Temos como dois principais mecanismos de deposição a 1) Deposição Química na fase de vapor - CVD , do inglês "Chemical Vapor Deposition" e 2) Deposição física na fase de vapor - PVD, do inglês "Physical Vapor Deposition". De forma simplificada, na técnica de CVD a fase vapor do material alvo promove reações químicas durante o processo de deposição.

No processo de deposição física na fase vapor, o material que compõe o alvo a ser consumido é atingido por um feixe de elétrons, fótons ou íons de alta energia que transferem parte de sua energia via colisões inelásticas para a sua estrutura, promovendo assim a vaporização, sublimação ou a pulverização dos átomos e espécies/partículas do alvo em direção à superfície de um substrato sob baixa pressão de algum gás inerte ou reativo ou em vácuo. $\mathrm{O}$ transporte de massa entre o alvo e o substrato pode ser controlado pela presença de gases no trajeto das partículas em direção ao substrato, podendo inclusive reagir com gases redutores ou oxidantes para a formação da composição final desejada, por exemplo um óxido (MOORTHY, 2015).

Técnicas como a deposição térmica, deposição por feixe de elétrons, epitaxia por feixe molecular - MBE (Molecular Beam Epitaxy) e a deposição por laser pulsado - PLD (Pulsed Laser Deposition) são exemplos de processos térmicos gerados por um feixe de elétrons ou fótons de alta energia que promovem a evaporação/sublimação do material presente no alvo (EASON, 2007; CHRISTEN; ERES, 2008; MOORTHY, 2015).

No caso das técnicas de deposição por pulverização, citando os sistemas de Sputtering de corrente direta (DC), Sputtering por radiofrequência (RF) e magnetronSputtering, processos de colisão não térmicos entre gases ionizados e os átomos presente na superfície do alvo promovem a vaporização do material por ejeção das espécies em direção ao substrato (MOORTHY, 2015).

Como principais técnicas de deposição e crescimento de filmes finos usadas no desenvolvimento deste trabalho, os detalhes técnicos sobre a Deposição por Laser Pulsado - PLD e a Deposição por Sputtering são apresentados e discutidos de forma mais consistente no capítulo Materiais e Métodos. 
Muito do conhecimento de fenômenos físicos dos materiais multifuncionais como os compostos ferroelétricos, piezoelétricos e multiferroicos e consequentemente das conquistas tecnológicas provenientes da aplicação dessas propriedades em dispositivos eletrônicos vem das possibilidades que a tecnologia de crescimento de filmes finos proporcionou na ciência e indústria.

2.5. A classe de materiais multiferroicos

Por definição, materiais monofásicos multiferroicos são aqueles que possuem pelo menos duas ou todas as três propriedades chamadas ferroicas: ferroeletricidade, ferromagnetismo e ferroelasticidade. (EERENSTEIN et al., 2006)

Estudos recentes mostram a capacidade de interação entre propriedades multiferroicas como resultado de mecanismos de transformação térmica e mecânica (Fig. 8) em óxidos para aplicação tecnológica. (AGAR et al., 2016; TRASSIN, 2016)

Dentre os acoplamentos mostrados na Figura 08, uma interação torna-se ponto de atenção neste trabalho. $\mathrm{O}$ acoplamento do tipo magnetoelétrico, discutido sob o ponto de vista da estrutura do composto $\mathrm{BiFeO}_{3}$ como uma das bases do presente estudo, é mostrado na Figura 09. 
Figura 8 - Diagrama de interações entre ordenamentos ferroicos de materiais funcionais e suas propriedades multiferroicas.

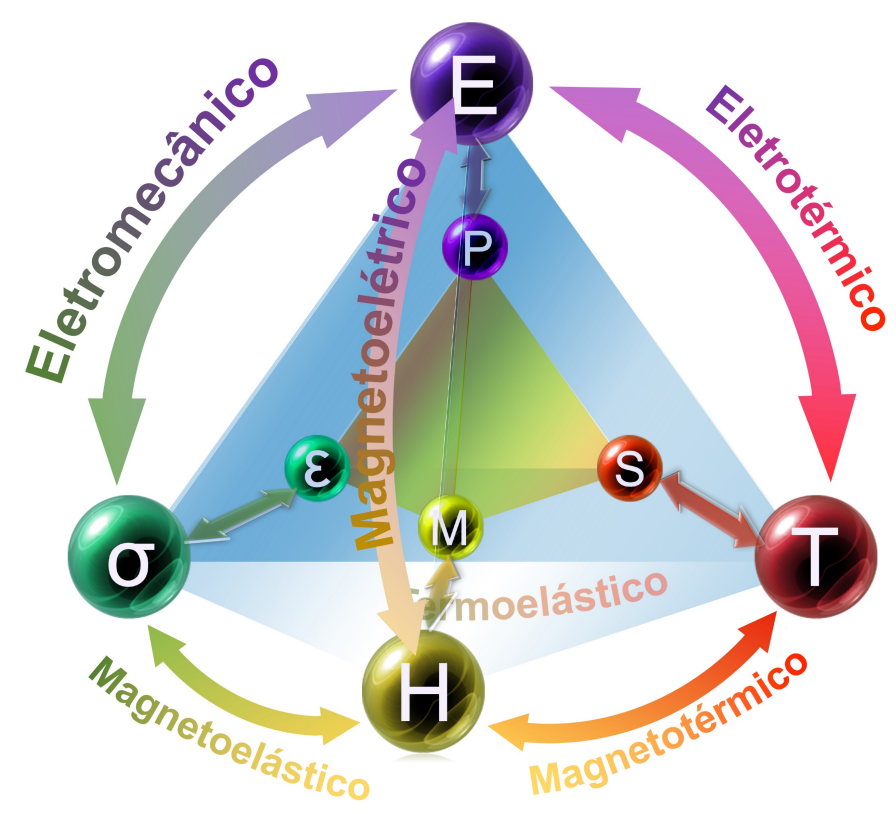

Fonte: Adaptado de (AGAR et al., 2016)

Figura 9 - Ordenamento macroscópico sob efeito de um campo conjugado externo (acoplamento magnetoelétrico $\mathrm{M}, \mathrm{P}-\mathrm{E}, \mathrm{H})$.

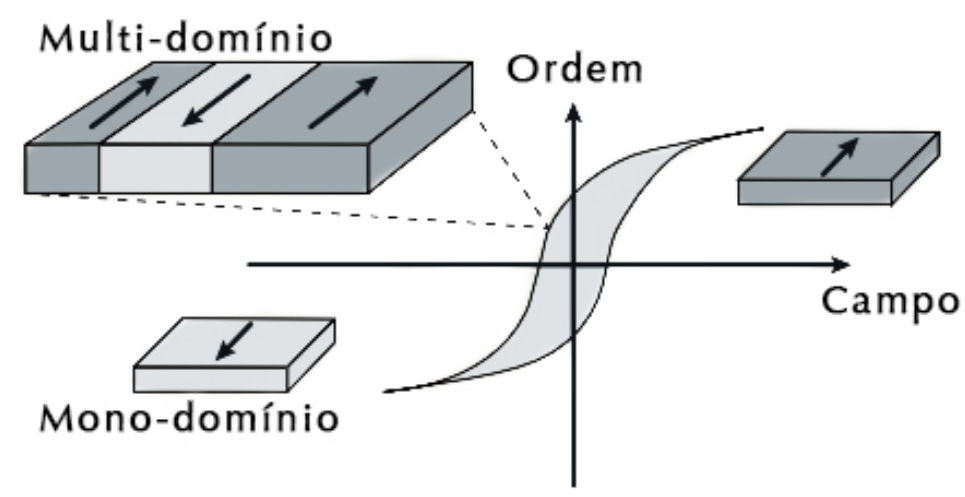

Multiferroico magnetoelétrico ideal
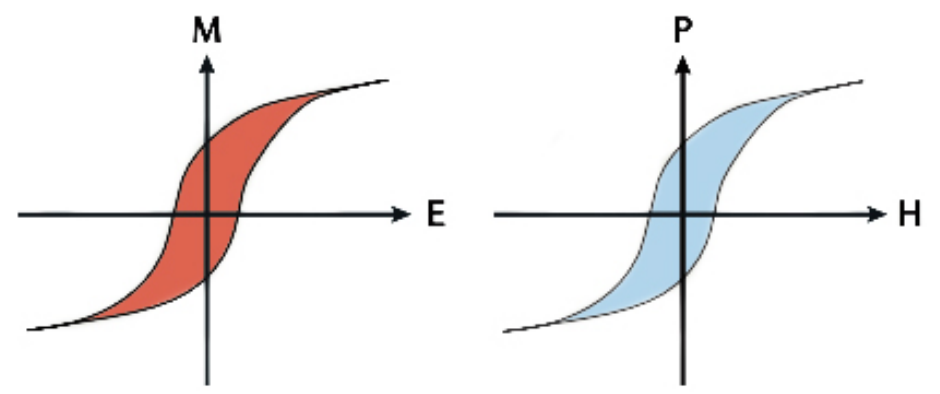

Fonte: Adaptado de (AGAR et al., 2016; FIEBIG et al., 2016) 
Para efeito de comparação, o comportamento de histerese em sistemas de ordenamento ferroelétrico, bem conhecido na literatura, bem como o comportamento de histerese para materiais ferromagnéticos são descritos em função do ordenamento de cargas e spins distribuídos na estrutura e agrupados de acordo com a sua orientação, formando os domínios ferroelétricos e ferromagnéticos, respectivamente, como pode ser facilmente observado no esquema superior geral da Figura 09. Em um cenário onde estas ordens ferroicas interagem entre si devido a um acoplamento chamado de magnetoelétrico, a modulação de uma das ordens interfere no comportamento da outra, o que gera uma interação cruzada onde um campo elétrico aplicado pode modular a orientação de spins magnéticos e vice-versa em uma estrutura cristalina. Essa interação cruzada pode ser melhor compreendida pelas curvas de histerese P-H e M-E mostradas na Figura 09.

O início dos estudos de materiais que apresentam propriedades ferroelétricas e ferromagnéticas simultaneamente deu-se por volta dos anos 1960 e 1970, surgindo então os primeiros e poucos trabalhos sobre materiais multiferroicos com interação magnetoelétrica. A necessidade de aprimoramento dos processos de produção de cristais desses compostos e a pouca viabilidade tecnológica para o entendimento e caracterização dessas novas propriedades tornaram os avanços nesta área pouco produtivos neste período (RAMESH; SPALDIN, 2007).

A retomada dos trabalhos com materiais multiferroico foi possível a partir do início da interação de diversas áreas de conhecimento atreladas à elaboração de novas tecnologias de crescimento de cristais, caracterização e desenvolvimento computacional de modelos que explicassem fenômenos até então pouco entendidos e difíceis de serem reproduzidos e avaliados em laboratório.

A presença de ferroeletricidade e ferromagnetismo na estrutura da ferrita de bismuto tem colocado este composto na posição dos materiais magnetoelétricos mais estudados nos últimos 20 anos como promissor para aplicações tecnológicas no desenvolvimento de dispositivos lógicos, memórias e processadores (CATALAN; SCOTT, 2009).

De forma breve e simplificada, a interação entre dois ordenamentos de longa distância como o ordenamento de cargas (anti)ferroeletricidade e de spins 
(anti)ferromagnetismo é conhecida como acoplamento magnetoelétrico, podendo surgir de fatores intrínsecos como simetria, composição química, tensão estrutural e estrutura eletrônica, uma vez que todas estas propriedades relacionam-se com o funcional de energia livre do sistema, como mostrado na equação 1 (MARTIN et al., 2008).

$$
\begin{aligned}
F(\vec{E}, \vec{H})=F_{0} & -P_{i}^{S} E_{i}-M_{i}^{S} H_{i}-\frac{1}{2} \epsilon_{0} \epsilon_{i j} E_{i} E_{j}-\frac{1}{2} \mu_{0} \mu_{i j} H_{i} H_{j}-\frac{1}{2} \beta_{i j k} E_{i} H_{j} H_{k} \\
& -\frac{1}{2} \gamma_{i j k} H_{i} E_{j} E_{k}-\cdots
\end{aligned}
$$

onde $\vec{E}$ e $\vec{H}$ correspondem aos campos elétrico e magnético, respectivamente. Parâmetros de polarização e magnetização derivam das equações 2 e 3, respectivamente.

$$
\begin{aligned}
& P(\vec{E}, \vec{H})=-\frac{\partial F}{\partial E_{i}}=P_{i}^{S}+\varepsilon_{0} \varepsilon_{i j} E_{j}+\alpha_{i j} H_{j}+\frac{1}{2} \beta_{i j k} H_{j} H_{k}+\gamma_{i j k} H_{i} E_{j}+\cdots \\
& M(\vec{E}, \vec{H})=-\frac{\partial F}{\partial H_{i}}=M_{i}^{S}+\mu_{0} \mu_{i j} H_{j}+\alpha_{i j} E_{i}+\beta_{i j k} E_{i} H_{j}+\frac{1}{2} \gamma_{i j k} E_{j} E_{k}+\cdots
\end{aligned}
$$

onde $\varepsilon$ e $\mu$ correspondem às susceptibilidades elétrica e magnética e $\alpha$ o coeficiente de efeito magnetoelétrico linear. Uma vez que a interação magnetoelétrica depende da susceptibilidade $X$ de cada componente (elétrico e magnético), nem sempre a resposta deste sistema será suficientemente boa para aplicações, tornando isso uma limitação a ser trabalhada. 
2.5.1. Propriedade ferroelétrica em materiais multiferroicos

Existe na literatura uma série de compostos indicados como multiferroicos ou da classe de materiais com propriedades ferroelétricas e ferromagnéticas, os mais conhecidos e amplamente estudados são o $\mathrm{BaTiO}_{3}$ (BTO), $\mathrm{PbZrTiO}_{3}$ (PZT), $\mathrm{PbTiO}_{3}$ (PTO), $\quad \mathrm{PbMgNbO}_{3} / \mathrm{PbTiO}_{3}$ (PMN-PT) dentre outros listados na Tabela 1. (DAMODARAN et al., 2016)

Um dos materiais da classe "Bi-based" mais conhecidos e que apresenta simultaneamente propriedades ferroelétricas e (anti)ferromagnéticas em temperatura ambiente é a ferrita de bismuto $\mathrm{BiFeO}_{3}$ (BFO). (RAMESH; SPALDIN, 2007; CATALAN; SCOTT, 2009)

A resposta de histerese de um material ferroelétrico em função da variação do campo elétrico externo aplicado pode ser descrita pela curva de histerese mostrada na Figura 10a. Como característica dos materiais com polarização espontânea, a classe de materiais ferroelétricos apresenta estados de orientação de dipolos elétricos (Fig. 10b) que podem ser manipulados (alternados) de acordo com um campo elétrico aplicada ao sistema capacitor, permanecendo naquele estado de saturação remanescente mesmo após a remoção do campo elétrico. Os efeitos estruturais deste fenômeno de polarização foram detalhados anteriormente para o $\mathrm{BaTiO}_{3}$. 
Figura 10 - Diagrama esquemático do comportamento ferroelétrico de um material ferroelétrico em função de um campo elétrico externo aplicado (a) e a representação de domínios e paredes de domínios ferrolétricos num sistema em equilibrio nativo antes da interação com qualquer campo elétrico (b).

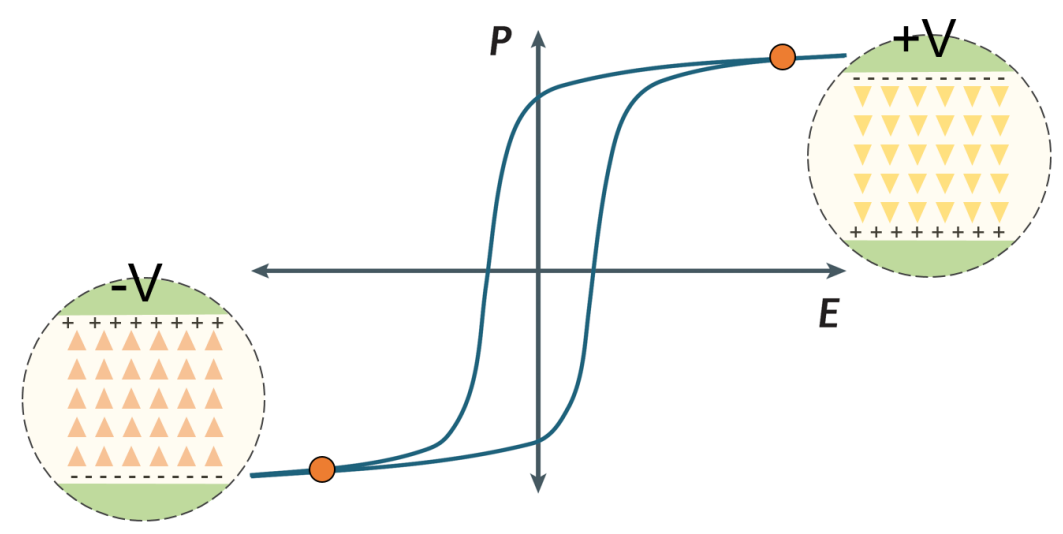

(a)

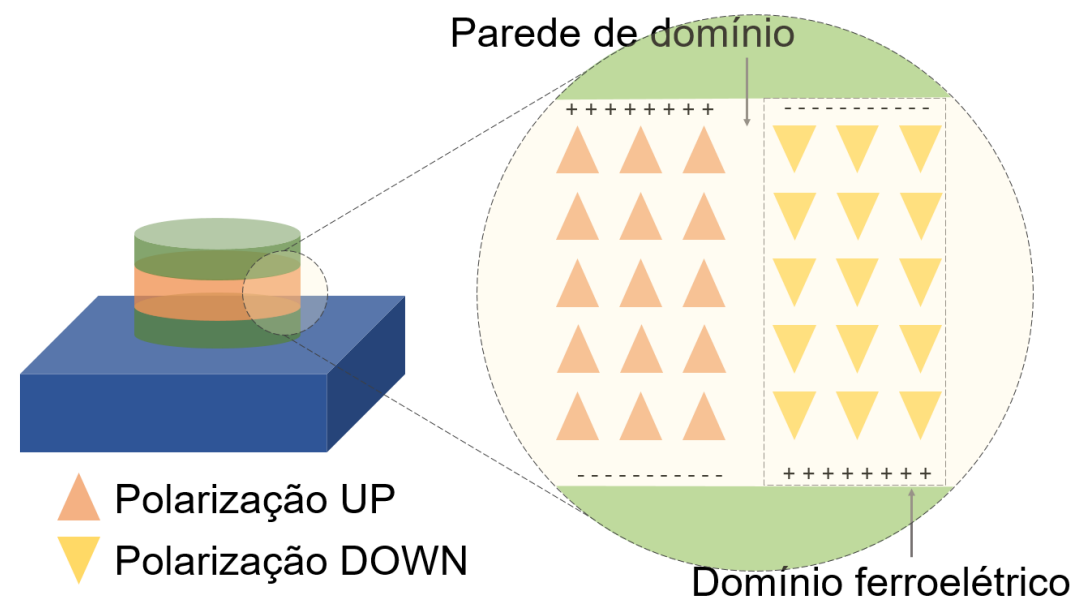

(b)

Fonte: $\mathrm{O}$ autor.

Os sistemas ferroelétricos necessitam da interação de uma força externa para orientar seus dipolos elétricos, a polarização positiva (UP) ou negativa (DOWN) de sua estrutura pode ser simplificada de acordo com os diagramas da Figura 11. 
Figura 11 - Diagrama esquemático da formação de domínios fora do plano (out-of-plane) com vetor de polarização UP (a) quando uma tensão negativa é aplicada ao contato elétrico superior e de domínios com vetor de polarização DOWN (b) quando uma tensão positiva é aplicada ao sistema.

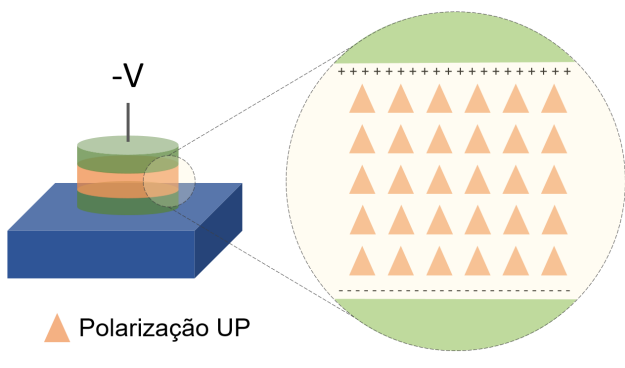

(a)

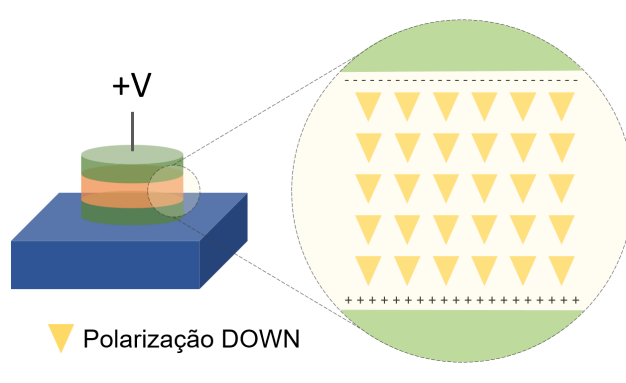

(b)

Fonte: $\mathrm{O}$ autor.

Como relatado na literatura, na área de materiais multifuncionais aplicados, dentre as composições livres de chumbo que apresentam propriedades ferroelétricas e ferromagnéticas com interação direta na estrutura cristalina, o $\mathrm{BiFeO}_{3}$ seja talvez o único material multiferroico com ambas as propriedades estáveis em temperatura ambiente (Tabela 1), o que o torna um excelente candidato ao posto de material multifuncional para aplicações em dispositivos lógicos eletrônicos baseados em spintrônica (CATALAN; SCOTT, 2009). 
Tabela 1 - Alguns dos materiais ferroicos mais conhecidos da literatura e seus respectivos valores de transição de fase pela temperatura de Curie, pela temperatura de Néel e polarização elétrica

\begin{tabular}{|c|c|c|c|c|}
\hline Composição & Ordem ferroica & $\mathrm{T}_{\mathrm{C}}\left({ }^{\circ} \mathrm{C}\right)$ & $\mathrm{T}_{\mathrm{N}}\left({ }^{\circ} \mathrm{C}\right)$ & $P_{s}\left(\mu C . \mathrm{cm}^{-2}\right)$ \\
\hline $\mathrm{PbTiO}_{3}(\mathrm{PTO})$ & Ferroelétrico & 490 & - & $75(\mathrm{RT})$ \\
\hline $\mathrm{BaTiO}_{3}(\mathrm{BTO})$ & Ferroelétrico & 120 & - & $26(\mathrm{RT})$ \\
\hline SbSI & Ferroelétrico & 20 & - & $20(270 \mathrm{~K})$ \\
\hline $\mathrm{PbZrO}_{3}(\mathrm{PZO})$ & Antiferroelétrico & 232 & - & - \\
\hline $\mathrm{PbZr}_{0.2} \mathrm{Ti}_{0.8} \mathrm{O}_{3}(\mathrm{PZT})$ & Ferroelétrico & 450 & - & 70 \\
\hline $\mathrm{NaNO}_{2}$ & Ferroelétrico & 164 & - & $10(140 \mathrm{~K})$ \\
\hline $\mathrm{KH}_{2} \mathrm{PO}_{4}$ & Ferroelétrico & -150 & - & $5.33(96 \mathrm{~K})$ \\
\hline $\mathrm{LiNbO}_{3}$ & Ferroelétrico & 937 & - & 70 \\
\hline $\mathrm{LiTaO}_{3}$ & Ferroelétrico & 347 & - & 50 \\
\hline $\mathrm{KNbO}_{3}$ & Ferroelétrico & 439 & - & $30(523 \mathrm{~K})$ \\
\hline $\mathrm{BiFeO}_{3}(\mathrm{BFO})$ & Multiferroico (Par isolado) & 830 & 370 & $\sim 100(\mathrm{RT})$ \\
\hline $\mathrm{LuFe}_{2} \mathrm{O}_{4}$ & Multiferroico (Ordenamento de carga) & 57 & -23 & 25 \\
\hline $\mathrm{Cr}_{2} \mathrm{BeO}_{4}$ & Multiferroico (Interação DM) & - & - & - \\
\hline $\mathrm{Cr}_{2} \mathrm{O}_{3}$ & Multiferroico & - & 34 & - \\
\hline $\mathrm{Cr}_{3} \mathrm{~B}_{7} \mathrm{O}_{13} \mathrm{Cl}$ & Multiferroico & - & - & - \\
\hline $\mathrm{GaFeO}_{3}$ & Multiferroico & - & - & - \\
\hline $\mathrm{LiCOPO}_{4}$ & Multiferroico & -- & - & - \\
\hline $\mathrm{NdCrTiO}_{5}$ & Multiferroico & - & - & - \\
\hline $\mathrm{TbPO}_{4}$ & Multiferroico & - & - & - \\
\hline YIG (Yttrium-Iron-Garnet) & Multiferroico & - & - & - \\
\hline $\mathrm{BiMnO}_{3}$ & Multiferroico (Par isolado) & 477 & -168 & - \\
\hline $\mathrm{CdCr}_{2} \mathrm{~S}_{4}$ & Multiferroico & - & - & - \\
\hline $\mathrm{RMnO}_{3}(\mathrm{R}=\mathrm{Y}, \mathrm{Sc}, \mathrm{In}, \mathrm{Dy}-\mathrm{Lu})$ & Multiferroico (Ordenamento geométrico) & 927 & -153 & 5.6 \\
\hline $\mathrm{TbMnO}_{3}$ & Multiferroico & -245 & -230 & $0.1-1.0$ \\
\hline $\mathrm{BaMnF}_{4}$ & Multiferroico & - & - & - \\
\hline $\mathrm{PbFeTiO}_{3}$ & Multiferroico & - & - & - \\
\hline
\end{tabular}

Nota: Alguns dos valores não foram mostrados na tabela por inconsistência ou ausência dos mesmos na literatura atual. 
2.6. $\mathrm{O}$ composto $\mathrm{BiFeO}_{3}$ como material multiferroico de temperatura ambiente

2.6.1. Estrutura cristalina e polarizabilidade do $\mathrm{BiFeO}_{3}$

Com estrutura cristalina do tipo Perovskita $\left(\mathrm{ABO}_{3}\right)$ de célula unitária trigonal reduzida da estrutura hexagonal, $\mathrm{o} \mathrm{BiFeO}_{3}$ apresenta, em temperatura ambiente, a fase ferroelétrica romboédrica de grupo pontual $R 3 c(161)$ com parâmetros de rede $a_{r b}=3,97 \AA$ e ângulo $\alpha_{r b}=89,3^{\circ}$.

A representação colunar do arranjo mostrado na Figura $12 a$ detalha o empacotamento de estrutura romboédrica ${ }^{4}$ derivada da sua célula unitária (Fig. 12b). A região evidenciada na base da representação colunar é destacada (Fig. 12c) pela união de duas células pseudo-cúbicas com uma pequena representação ao longo do eixo de polarização espontânea.

O comportamento ferroelétrico do BFO, devido aos pares de elétrons isolados dos íons $\mathrm{Bi}^{3+}$ localizados no sítio $\mathrm{A}$ da estrutura, apresenta maior contribuição de deslocamento de cargas ao longo do eixo [111] pc. Seu valor médio de polarização elétrica aproxima-se de $90 \mu \mathrm{C} . \mathrm{cm}^{-2}$.

\footnotetext{
${ }^{4}$ Informações do arquivo de coordenadas atômicas CIF usado como referência estão disponíveis no ANEXO A.
} 
Figura 12 - Representação estrutural do arranjo atômico do composto $\mathrm{BiFeO}_{3}$ ao longo da direção de polarização ferroelétrica [111] (a) extraído de uma célula unitária de estrutura cristalina trigonal $(R 3 c)$ (b) e sua representação romboédrica formada por duas células pseudo-cúbicas (c) e ao longo da direção [111] $]_{p c}$ de polarização espontânea.

a)
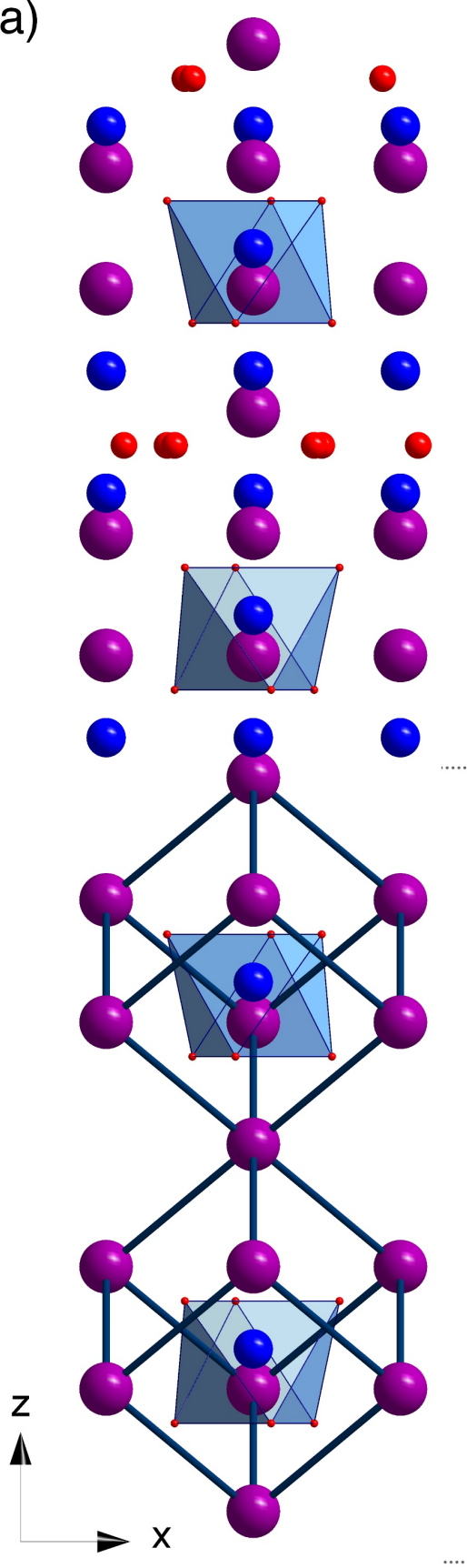

b)

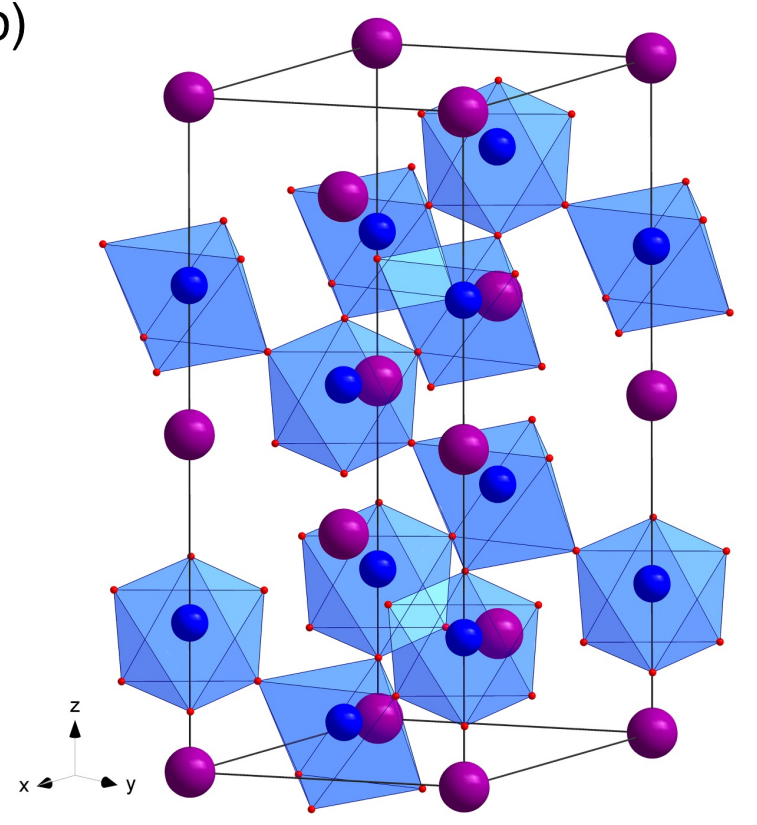

c)

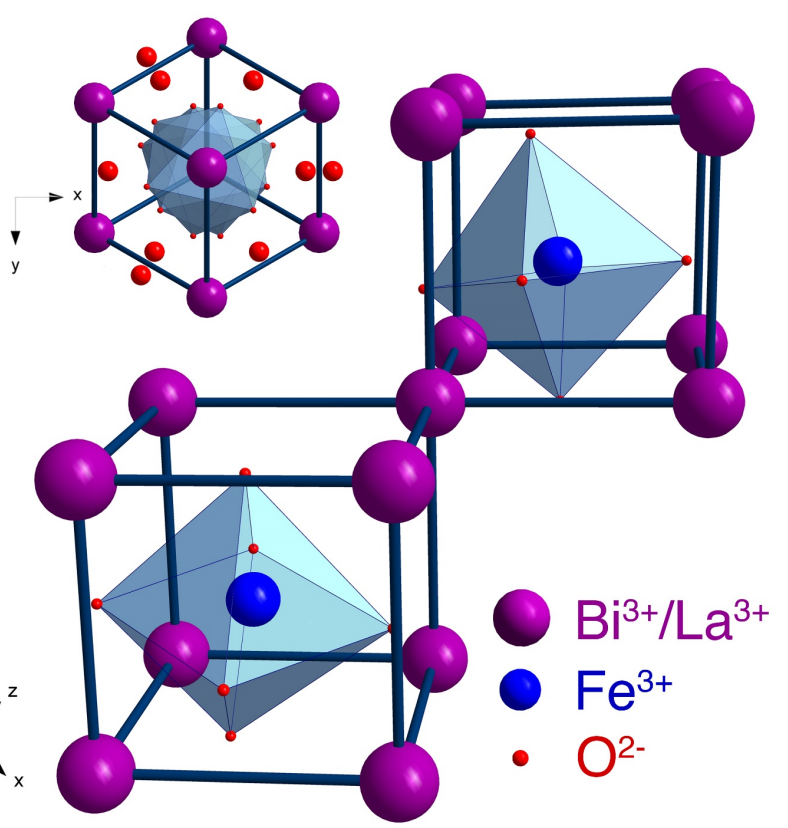

Fonte: O autor.

Nota: A estrutura apresentada foi elaborada de acordo com as informações do arquivo de coordenadas atômicas CIF 2102913 disponível em (PALEWICZ et al., 2007) e reproduzido no ANEXO A. 
As possíveis configurações das componentes de polarização da estrutura romboédrica do $\mathrm{BiFeO}_{3}$ somam-se 4 positivas $\left(P_{1}^{+}, P_{2}^{+}, P_{3}^{+}\right.$e $\left.P_{4}^{+}\right)$e suas respectivas componentes de sentido oposto $\left(P_{1}^{-}, P_{2}^{-}, P_{3}^{-}\right.$e $\left.P_{4}^{-}\right)$, como mostrado na Figura 13a.

Os mecanismos de polarização estão atrelados aos caminhos percorridos pela mudança dos vetores sob condições de histerese em torno das 8 possibilidades de estabilização. Sendo assim, os principais mecanismos de polarização sob campo elétrico podem ser consultados na Tabela 02.

Tabela 2 - Possíveis rotações de vetores de polarização elétrica do $\mathrm{BiFeO}_{3}$ de estrutura romboédrica.

\begin{tabular}{ccc}
\hline Rotação de $71^{\circ}$ & Rotação de $109^{\circ}$ & Rotação de $180^{\circ}$ \\
\hline$P_{1}^{+} \rightarrow P_{3}^{-}$ & $P_{1}^{+} \rightarrow P_{4}^{-}$ & $P_{1}^{+} \rightarrow P_{1}^{-}$ \\
$P_{2}^{+} \rightarrow P_{4}^{-}$ & $P_{1}^{+} \rightarrow P_{2}^{-}$ & $P_{2}^{+} \rightarrow P_{2}^{-}$ \\
$P_{3}^{+} \rightarrow P_{1}^{-}$ & $P_{2}^{+} \rightarrow P_{1}^{-}$ & $P_{3}^{+} \rightarrow P_{3}^{-}$ \\
$P_{4}^{+} \rightarrow P_{2}^{-}$ & $P_{2}^{+} \rightarrow P_{3}^{-}$ & $P_{4}^{+} \rightarrow P_{4}^{-}$ \\
$P_{3}^{-} \rightarrow P_{1}^{+}$ & $P_{3}^{+} \rightarrow P_{4}^{-}$ & $P_{1}^{-} \rightarrow P_{1}^{+}$ \\
$P_{4}^{-} \rightarrow P_{2}^{+}$ & $P_{3}^{+} \rightarrow P_{2}^{-}$ & $P_{2}^{-} \rightarrow P_{2}^{+}$ \\
$P_{1}^{-} \rightarrow P_{3}^{+}$ & $P_{4}^{+} \rightarrow P_{1}^{-}$ & $P_{3}^{-} \rightarrow P_{3}^{+}$ \\
$P_{2}^{-} \rightarrow P_{4}^{+}$ & $P_{4}^{-} \rightarrow P_{1}^{+}$ & $P_{4}^{-} \rightarrow P_{4}^{+}$ \\
& $P_{4}^{-} \rightarrow P_{3}^{+}$ & \\
& $P_{1}^{-} \rightarrow P_{2}^{+}$ & \\
& $P_{1}^{-} \rightarrow P_{4}^{+}$ & \\
& $P_{2}^{-} \rightarrow P_{3}^{+}$ & \\
& $P_{2}^{-} \rightarrow P_{1}^{+}$ & \\
& $P_{3}^{-} \rightarrow P_{4}^{+}$ & \\
& $P_{3}^{-} \rightarrow P_{2}^{+}$ &
\end{tabular}

Fonte: $\mathrm{O}$ autor. 
Figura 13 - Representação estrutural do arranjo atômico do composto $\mathrm{BiFeO}_{3}$ ao longo das possíveis direções de polarização ferroelétrica (a) e as três configurações de domínios ferroelétricos criados pela região de transição entre diferentes vetores $\mathrm{P}$, chamadas de paredes de domínios.

a)

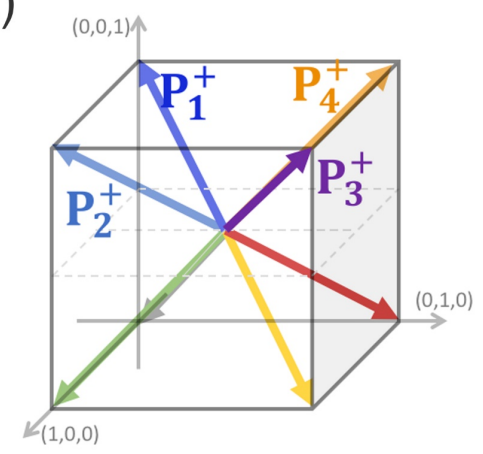

b)

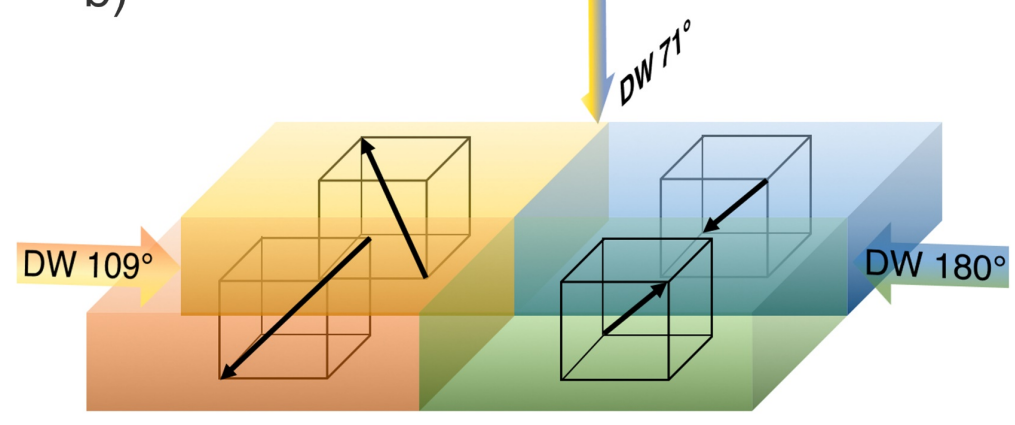

Fonte: $\mathrm{O}$ autor.

Uma vez que as possíveis rotações dos vetores de polarização ferroelétrica respeitam os caminhos indicados na tabela 2, a formação de paredes de domínios ferroelétricos também corresponderá as condições de cada vetor de contorno dos domínios adjacentes.

Todas as combinações de transição entre configurações de domínios se resumem aos três graus de liberdade permitidos para a polarização. Como é possível verificar na Figura 13b, as paredes de domínio corresponderão as regiões de transição entre estados de polarização dentro de uma das configurações possíveis, formando assim paredes de domínio do tipo 71,109 e $180^{\circ}$.

A estrutura magnética do $\mathrm{BiFeO}_{3}$ é determinada pela orientação dos momentos de spins nos planos cristalográficos formados pelos íons do sitio $\mathrm{B}\left(\mathrm{Fe}^{3+} / \mathrm{Fe}^{2+}\right)$ da estrutura $\mathrm{ABO}_{3}$. Seu comportamento apresenta ordenamento antiferromagnético do tipo $G$ com fraco momento ferromagnético $M$ de rede, momento este, perpendicular ao vetor de polarização $P$ (Fig. 14a) devido a interações entre os planos ferromagnéticos (111), de acordo com o vetor como mostrado na Figura 14b. (CATALAN; SCOTT, 2009; BAEK; EOM, 2012) 
Figura 14 - Estrutura cristalina do tipo Perovskita com célula unitária pseudo-cúbica e simetria romboédrica ferroelétrica do $\mathrm{BiFeO}_{3}$ indicando as direções pependiculares dos vetores de polarizabilidade e momento magnético $M(a)$, ordenamento antiferromagnético do tipo $G$ com planos ferromagnéticos (111) (b) e ilustração da interação Dzyaloshinskii-Moriya entre planos (111) na intensificação do momento ferromagnético fraco da estrutura (c).

a)

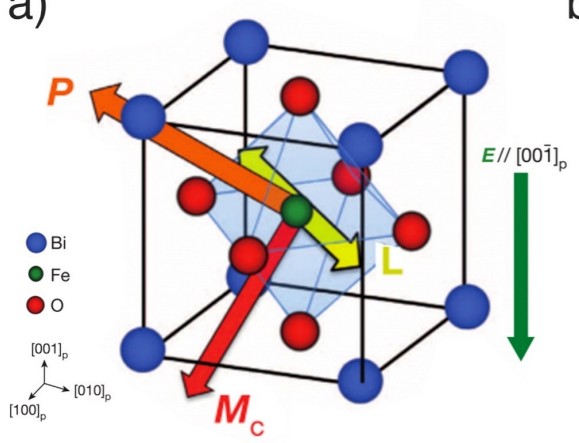

b)

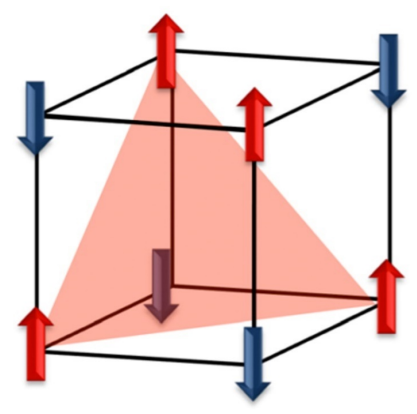

c)

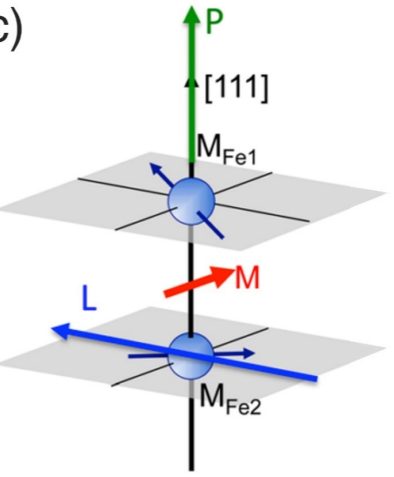

Fonte: Adaptado de (CATALAN; SCOTT, 2009; HERON; SCHLOM; RAMESH, 2014)

Devido ao acoplamento magnetoelétrico presente no BFO, as propriedades ferroelétricas controláveis por campo elétrico externo podem assumir papel fundamental no controle do momento magnético de rede formado pelas interações do tipo Dzyaloshinskii-Moriya (DM) como forma de reduzir a energia nos planos antiferromagnéticos da estrutura (Fig.14c). (HERON et al., 2014)

A presença desse acoplamento torna o BFO um componente de grande interesse na busca de novos materiais que permitam a manipulação de estados de spin por campos elétricos externos e nesse contexto, o estudo e controle das propriedades ferroelétricas impactam diretamente na eficiência deste material como base para a construção de dispositivos (FIEBIG et al., 2016; LORENZ et al., 2016). 
2.6.2. Sistema substitucional por dopagem isovalente com íons terras raras

A substituição de íons $\mathrm{Bi}^{3+}$ na estrutura do BFO por elementos isovalentes de dopagem, tais como íons trivalentes de terras-raras $\left(\mathrm{TR}^{3+}\right)$, é apresentada por alguns autores em diferentes abordagens para redução de polarização (CATALAN; SCOTT, 2009), aumento na contribuição de momento magnético de rede (XU et al., 2013) e também na busca por fenômenos ópticos e espectroscópicos (ZHANG et al., 2012; YI et al., 2015) que possam trazer ao BFO propriedades de interesse tecnológico (YANG et al., 2012).

Mecanismos de dopagem isovalente cuidadosamente estudados pelas regras de substituição determinadas pelos fatores de tolerância Goldschmidt, em óxidos, principalmente aqueles com propriedades multiferroicas, obedecem rigorosos parâmetros de controle de distorção da rede cristalina, influenciando significativamente as propriedades eletromecânicas e consequentemente as interações de campo cristalino, induzindo ou suprimindo fenômenos como ferroeletricidade, magnetoelasticidade, magnetoeletricidade e outros acoplamentos de ordenamento de longa distância fundamentais para a engenharia nanotecnológica (JIA et al., 2002; VAILIONIS et al., 2011; DAMODARAN et al., 2016; HEO et al., 2016).

Características bem conhecidas do composto $\mathrm{BiFeO}_{3}$ como a alta corrente de fuga e a sua elevada coercividade indicam a necessidade de diferentes abordagens físicas e químicas para a busca de um composto multiferroico de baixo coeficiente eletromecânico que permita a implementação do mesmo em nanodispositivos de baixo consumo energético. Estudos mostram a relação da dopagem do sitio $A$ de estruturas cristalinas de filmes finos como o BFO, trazendo grande controle de diversas respostas da estrutura a interações ferroicas.

Como mostrado no trabalho de Yang et al., a substituição de íons de $\mathrm{Bi}^{3+}(\sim 1,36$ $\AA$ ) por elementos de raio iônico semelhante, como o $\mathrm{La}^{3+}(\sim 1,36 \AA$ ), tem a capacidade de promover alterações na transição entre as fases ferroelétrica-paraelétrica do composto (Fig.15a,b), ao passo que, respeitando o limite de substituição, a fase 
ferroelétrica é estabilizada, com a redução nos coeficientes piezoelétricos (YANG et al., 2012).

A análise dos diagramas de fase calculados mostrados na Figura $15(a, b)$ é essencial para a compreensão dos mecanismos e concentrações de dopagem limite na manutenção das fases desejadas dos sistemas multiferroicos deste trabalho.

É possível observar na sequência de curvas de histerese elétrica (Fig.15c) o surgimento de curvas de histerese dupla acima das concentrações de $12 \%$ de substituição e a evolução da fase paraelétrica do $\mathrm{Bi}_{(1-x)} L a_{(x)} \mathrm{FeO}_{3}$ para valores de $x$ maiores que 0,20 . Estes comportamentos já foram estudados e comprovados em diversos outros trabalhos (SINGH; MARUYAMA; ISHIWARA, 2007; ZHANG et al., 2012; KUMAR; SHARMA; VARSHNEY, 2015; JANG et al., 2016; PAN et al., 2016).

Figura 15 - Esquema de diagrama de fases universal para dopagem por terras-raras na estrutura do $\mathrm{BiFeO}_{3}(\mathrm{a})$, esquema de diagrama de fases calculado na substituição por La ${ }^{3+}$ (b), e a evolução das curvas de histerese na transição de fase ferroelétrica e paraelétrica com diferentes concentrações de dopagem por Sm e La(c).

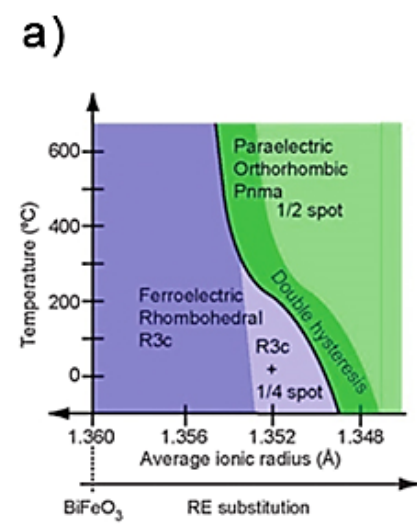

b) $R E=L a$
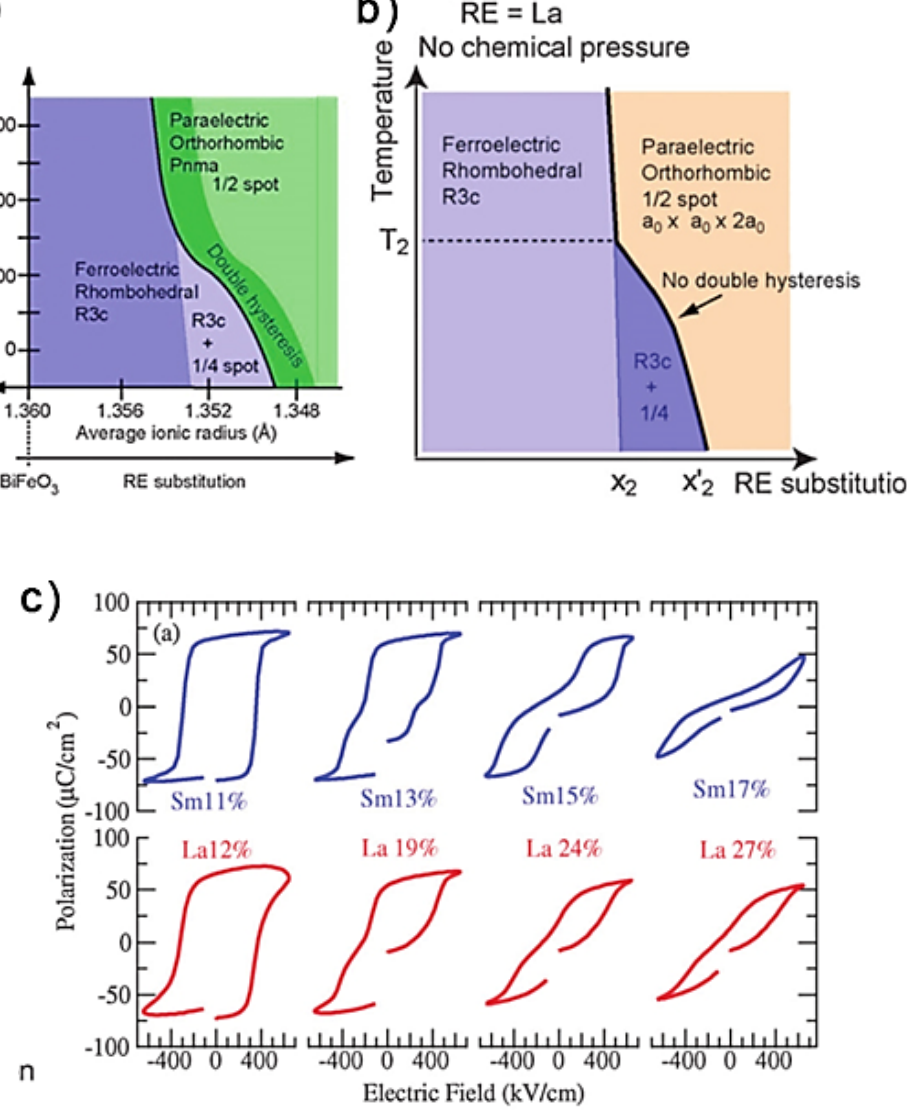


\subsubsection{Filmes finos multiferroicos}

Baseado em estudos que classificam $\mathrm{O} \mathrm{BiFeO}_{3}$ como um sistema de polarização elétrica por pares de elétrons isolados (6s lone-pair electrons) do bismuto (YUAN et al., 2007), a substituição deste íon também contribui para a redução de portadores de carga a serem deslocados nos eventos de troca, de forma a minimizar a energia total necessária para saturar os estados polarizados positivo (up) e negativo (down).

Sabe-se da necessidade de redução, ou pelo menos da manutenção da densidade de energia consumida por operação eletrônica, posto a exponencial elevação na demanda de recursos computacionais na era da eletrônica. Neste sentido, o tópico relacionado com a redução dos valores de coercividade de materiais ferroelétricos usados na produção de dispositivos de memória lógica compete com a importância na evolução das tecnologias de armazenamento e processamento de informações (CHANDRAKASAN; BRODERSEN, 1995; STOLICHNOV et al., 2000).

A engenharia nanotecnológica de filmes finos move-se pelos avanços das técnicas de crescimento de heteroestruturas epitaxiais de componentes ferroicos (e multiferroicos) com características únicas de acordo com as relações de integração com substratos específicos (baseados em silício, por exemplo). A abordagem de engenharia em escala atômica proporciona o avanço na obtenção de materiais multiferroicos com baixos valores de coercividade atrelados às suas interações de acoplamento entre ordenamentos de diferentes composições.(MUNDY et al., 2016)

Algumas abordagens na engenharia nanotecnológica relacionam-se com estudos mecânico-elastoelétricos, trabalhando com a relação de tensão entre estruturas com parâmetros de rede diferentes, o que causa distorções na estrutura cristalina de alguns compostos e que consequentemente promovem, por exemplo, a intensificação de propriedades ferroelétricas nestes. Outra abordagem, utilizada neste 
trabalho, é a obtenção de filmes ultrafinos, com dimensões de escalabilidade direta com as propriedades de interesse, no caso a ferroeletricidade.

Filmes finos ferroelétricos multiferroicos apresentam valores de coercividade elétrica que podem ser modulados pela espessura da camada FE, de acordo com a relação $E_{C} \sim d^{-\frac{2}{3}}$ para espessuras abaixo de 100 micrômetros (onde, $\mathrm{E}_{\mathrm{c}}=$ coercividade elétrica; $d$ = espessura da camada FE), onde os eventos de nucleação e crescimento de domínios ferroelétricos seguem princípios comuns para a classe de materiais ferroelétricos dielétricos entre capacitores (CHANDRA et al., 2004; JO et al., 2006).

Uma das aplicações de sistemas multiferroicos baseados em heteroestruturas de filmes finos é a criação de dispositivos de memória magnetoelétricos. As técnicas de crescimento de filmes finos, como o crescimento por laser pulsado (PLD), permitem a fabricação de estruturas intercaladas com camadas de filmes multiferroicos e filmes ferromagnéticos.

A interação entre uma estrutura de material multiferroico antiferromagnético sob acoplamento interfacial com um filme ferromagnético pode se tornar parte de uma arquitetura de memória baseada no controle de spins mediante aplicação de campo elétrico externo (Fig.16).(HERON, 2013; HERON et al., 2014; FIEBIG et al., 2016)

Figura 16 - Esquema de um dispositivo magnetoelétrico formado pela interação de uma camada multiferroica de $\mathrm{BiFeO}_{3}$ e uma camada de material ferromagnético CoFe (a), magnetoresistência anisotrópica alterada em função da aplicação de campo elétrico externo ao dispositivo com efeito magnetoelétrico.
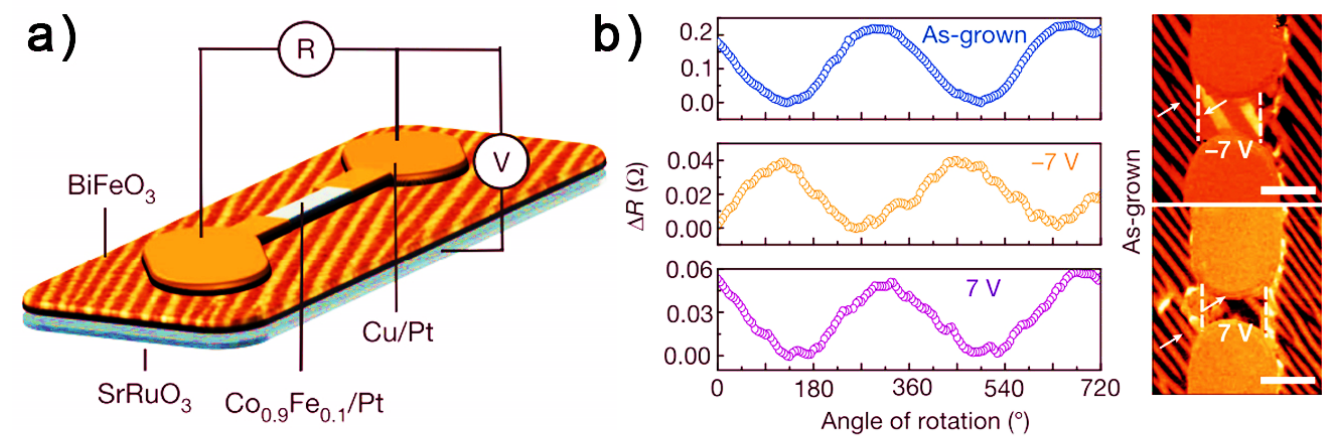

Fonte: Adaptado de (HERON et al., 2014) 
O estudo de filmes finos com propriedades multiferroicas de baixa coercividade e forte acoplamento magnetoelétrico proporcionará o avanço necessário para o desenvolvimento de dispositivos, como o mostrado na figura acima, com a capacidade de manipulação de momentos de spin, pela resposta de magnetorresistência anisotrópica, baseado em efeito hall (Fig.16b).

A possibilidade de controle e manipulação de estados de spin magnéticos usando campo elétrico em operações fundamentais unitárias de gravação de estados consumindo menos de 1 atoJoule de energia (MILLER, 2016) certamente influenciará a indústria eletrônica de processamento e armazenamento de informações em dispositivos baseados em spintrônica, mais eficientes, rápidos, não-voláteis e de baixo consumo energético.

2.7. Panorama geral de publicações relacionadas à área

Como forma de situar a pesquisa desenvolvida na área de materiais multiferroicos magnetoelétricos, uma busca nas bases de dados da Web of Knowledge pelas publicações relacionadas com as palavras-chave Thin film. Ferroelectric, Pulsed Laser Deposition (abreviado pela sigla PLD na figura) e Multiferroic retornaram o perfil de trabalhos publicados entre os anos de 1945 a 2017.

A análise das curvas mostradas na Figura 17a corrobora a linha evolutiva do desenvolvimento das tecnologias mencionadas e relacionadas com este trabalho, especialmente pelo início das tecnologias de materiais ferroelétricos a partir de 1960, o desenvolvimento da tecnologia de deposição por PLD a partir de 1990, como mencionado anteriormente e, segundo dados de publicação anual apontados no trabalho de (RAMESH; SPALDIN, 2007), um aumento exponencial de pesquisas voltadas para a classe de materiais multiferroicos que ocorreu a partir dos anos 2000 , 
devido a implementação e avanço nas técnicas de crescimento de monocristais filmes finos e na engenharia de materiais para novas arquiteturas de base.

Figura 17 - Perfil de publicações contabilizadas nos bancos de dados da Web of Knowledge entre os anos 1945 e 2017 para as palavras-chave a) Thin film. Ferroelectric, Pulsed Laser Deposition (abreviado pela sigla PLD na figura) e Multiferroic, b) Barium titanate, Lead zirconate titanate e $\mathrm{BiFeO}_{3}$ e para os principais gargalos tecnológicos da área da computação c) Data storage, spintronic, FeRAM e Moore's Law.
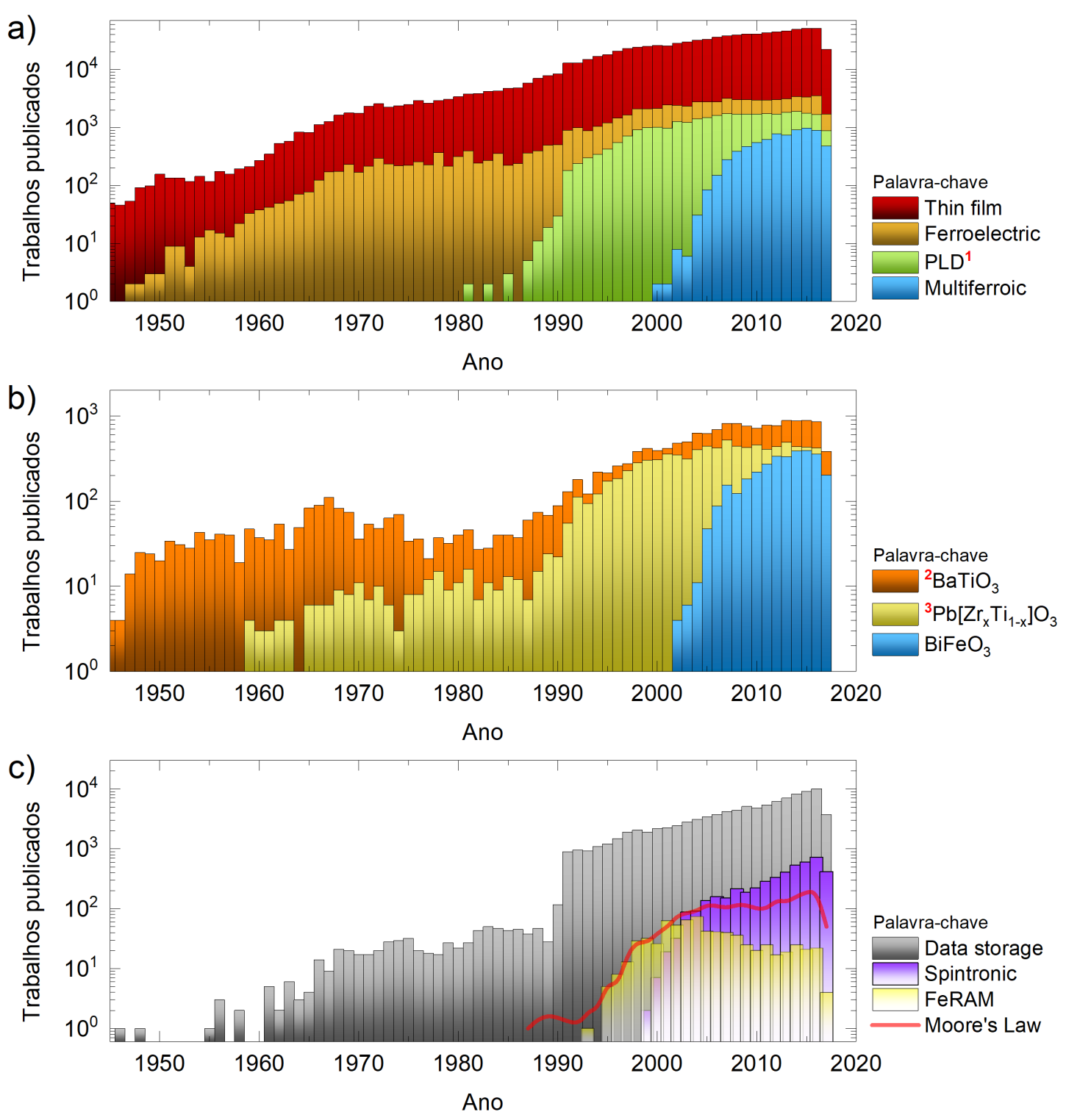

Fonte: $\mathrm{O}$ autor.

Nota: Dados extraidos de consultas a base de dados Web of Knowledge em $<$ https://www.webofknowledge.com/> 
Do ponto de vista histórico e da busca por novos materiais e suas propriedades, os trabalhos pioneiros sobre ferroeletricidade do titanato de $\mathrm{Bário}^{\mathrm{BaTiO}}{ }_{3}$ começaram anteriormente aos trabalhos com piezoeletricidade dos tão bem conhecidos compostos de $\mathrm{Pb}\left[\mathrm{Zr}_{\mathrm{x}} \mathrm{Ti}_{1-\mathrm{x}}\right] \mathrm{O}_{3}$ que surgiram após os anos de 1960, de acordo com o gráfico da Figura 17b. As palavras-chave usadas na busca pelas publicações sobre $\mathrm{BTO}^{2}$ e $\mathrm{PZT}^{3}$ foram feitas pelos seus respectivos nomes Barium titanate e Lead zirconate titanate, a fim de evitar a contabilização de trabalhos não relacionados com os materiais mencionados.

As pesquisas envolvendo as ferritas de bismuto começaram a aparecer nos textos científicos após os anos 2000. Como já mencionado nos trabalhos do professor R. Ramesh, somente após esforços no desenvolvimento de tecnologias para o crescimento de monocristais puros, os estudos sobre BFO começaram a avançar no campo da física de materiais multiferroicos. A estabilização necessária dos ordenamentos de carga e spin responsáveis pela manutenção do efeito magnetoelétrico presente no BFO só passaram a ser reprodutíveis após muitas tentativas na produção dos filmes finos de alta qualidade.

De forma geral, é evidente a recente abordagem tecnológica dos materiais multiferroicos que cresce juntamente com o aparecimento de novos dispositivos e tecnologias para atender à crescente demanda por poder de processamento eficiente e de baixo consumo energético (Fig. 17c). O domínio e controle de propriedades fundamentais de carga e spintrônica de elétrons, ferroeletricidade, ferromagnetismo e ferroelasticidade abre um campo imenso de possibilidades as quais os materiais multiferroicos podem ser aplicados (KHOMSKII, 2009). 


\section{OBJETIVOS 03}

\section{OBJETIVOS}

\subsection{Objetivo Geral}

Enquadra-se como objetivo central desta tese de doutorado a abordagem de diferentes parâmetros de controle na obtenção de um sistema de filmes ultrafinos heteroestruturados de $\mathrm{BiFeO}_{3}$ dopado com lantânio $\left(\mathrm{LaBiFeO}_{3}-\mathrm{LBFO}\right)$, tendo em vista a redução nos valores de coercividade elétrica e manutenção do acoplamento spin-órbita interfacial com estruturas ferromagnéticas.

\subsection{Objetivos Específicos}

- Realizar o crescimento de filmes finos heteroestruturados de alta qualidade do composto $\mathrm{BiFeO}_{3}$ dopado com lantânio e caracterizar de forma sistemática suas propriedades.

- Analisar o comportamento ferroelétrico/piezoelétrico dos filmes finos de LBFO crescidos com diferentes espessuras.

- Compreender os mecanismos de polarização elétrica de filmes finos de LBFO, especialmente aqueles com baixo valor de coercividade elétrica.

- Testar a robustez e fadiga de sistemas LBFO para aplicação como dispositivos de memória. 
- Avaliar o comportamento de acoplamento de troca entre filmes finos de LBFO e filmes ferromagnéticos de $\mathrm{Co}_{0,9} \mathrm{Fe}_{0,1}$.

\subsection{Justificativa}

Segundo as perspectivas indicadas na literatura, a evolução das tecnologias em armazenamento e processamento de dados tem como base o desenvolvimento de novos materiais para aplicação como memória e dispositivos lógicos (ITRS, 2015). Neste contexto, sustentado pelas diretrizes no âmbito tecnológico e energético, justifica-se o estudo e elaboração do estado-da-arte de materiais multiferroicos multifuncionais.

Os resultados obtidos e analisados neste trabalho proporcionaram o entendimento de novas características dos sistemas de filmes finos heteroestruturados de $\mathrm{LaBiFeO}_{3}$ para produção de memórias de baixo consumo energético. Os resultados apontam a viabilidade no uso deste material para produção de memórias FeRAM com coercividade elétrica de $\sim 0,5$ volt, sendo até o momento o primeiro relato deste tipo na literatura e indústria.

As análises das propriedades dos sistemas ferroelétricos obtidos elucidaram mecanismos de polarizabilidade elétrica estático e dinâmico de filmes ultrafinos de LBFO que serão de grande importância para o desenvolvimento de tecnologias no campo de data storage e novos dispositivos lógicos.

O estudo de acoplamento de troca entre os sistemas multiferroicos de baixa coercividade elétrica e filmes ferromagnéticos evidenciam a possibilidade no desenvolvimento de dispositivos lógicos mais eficientes baseados em princípios da spintrônica.

Com base nos avanços mencionados acima, o caráter inovador da pesquisa desenvolvida nos laboratórios da University of California - Berkeley em parceria com a Intel Corporation contribui significativamente para os setores de interesse da sociedade. 


\section{EXPERIMENTAL 03 MATERIAIS E MÉTODOS}

\section{EXPERIMENTAL}

Como um trabalho de múltiplas e complexas etapas e processos, os materiais usados e os procedimentos adotados no crescimento dos filmes epitaxiais, a caracterização estrutural, elétrica, magnética, polarizabilidade ferroelétrica e as séries de ensaios e medidas de acoplamento serão discutidas em cada item do capítulo de resultados. Neste item, uma descrição geral das etapas de desenvolvimento será apresentada.

\subsection{Materiais}

4.1.1. Principais materiais utilizados no processo de crescimento de filmes finos multiferroicos

- Alvo cerâmico comercial de $\mathrm{BiFeO}_{3}$, pureza de 99,90\% (Praxair comp.)

- Alvo cerâmico comercial de $\mathrm{Bi}_{0,80} \mathrm{La}_{0,20} \mathrm{FeO}_{3}$, pureza de 99,90\% (Praxair comp.)

- Alvo cerâmico comercial de $\mathrm{SrRuO}_{3}$, pureza de 99,90\% (Praxair comp.)

- Substrato comercial de $\mathrm{SrTiO}_{3}$, orientação cristalográfica (001), miscut 0,10 (CrysTec GmbH Inc.) 
- Substrato comercial de $\mathrm{DyScO}_{3}$, orientação cristalográfica (110), miscut $0,1^{\circ}$ (CrysTec GmbH Inc.)

- Álcool isopropílico PA

- Acetona PA

- Tinta de prata comercial

4.1.2. Materiais utilizados na preparação de amostras para ensaios elétricos e magnéticos

- Vidrarias de laboratório e conjunto de pinças

- Álcool isopropílico PA

- Resina fotossensível positiva comercial G-line

- Revelador comercial

- Lâmpada UV para fotolitografia

- Cantilever micromash HQ:NSC35/Pt

- Micromanipulador modelo 7B

4.1.3. Sistemas utilizados no crescimento de filmes finos

- Câmara de deposição selada;

- Excimer laser de $\mathrm{KrF}$ de alta potência pulsado (428 nm);

- Sistema óptico de focalização de feixe;

- Câmara de deposição por Sputtering; 


\subsection{Métodos}

\subsubsection{Deposição de filmes finos heteroestruturados}

No campo de estudos dos materiais multiferroicos, a ciência e engenharia de materiais tem um papel fundamental nos avanços conquistados nos últimos 20 anos. Uma das contribuições foi no desenvolvimento das técnicas de crescimento de cristais que proporcionaram um controle mais apurado das propriedades dos materiais. Uma das técnicas físicas mais usadas no crescimento de filmes finos é a deposição por laser pulsado (PLD). Esta popularidade deve-se especialmente a flexibilidade do sistema para crescimento de inúmeros materiais em diferentes condições.(MARTIN; CHU; RAMESH, 2010)

O sistema de deposição por laser pulsado (PLD) foi utilizado para o crescimento das camadas multiferroicas das amostras de $\mathrm{BiFeO}_{3}$ e $\mathrm{BiLaFeO}_{3}$ com parâmetros de controle adequados para cada composição. Um esquema de um sistema PLD é mostrado na Figura 18.

O processo de crescimento por PLD envolve a ablação de um alvo cerâmico por um feixe de laser pulsado com potência de alguns $\mathrm{mJ}$ a poucos $\mathrm{J}$, como mostrado na Figura 19. A fluência calculada pela densidade de energia entregue pelo feixe de laser foi calculada pela integração da área de cada perfil de interação do laser de acordo com a posição do conjunto óptico de focalização em função da superfície do alvo. Cada posição gera uma projeção diferente do laser sobre a superfície do alvo, como pode ser visto para cada tipo de spot medido e identificado na Figura 20.

A deposição de camadas metálicas ferromagnéticas de $\mathrm{CO}_{0,9} \mathrm{Fe}_{0,1}$ foi realizada por Sputtering catódico (Fig. 21) em temperatura ambiente e sob campo magnético de 200 Oe orientado paralelo a superfície de crescimento.

Os parâmetros de crescimento dos filmes multiferroicos e filmes metálicos ferromagnéticos pelas técnicas mencionadas acima estão detalhados nas tabelas 3 e 4, respectivamente. 
Figura 18 - Esquema ilustrativo de um sistema de deposição por laser pulsado (PLD).

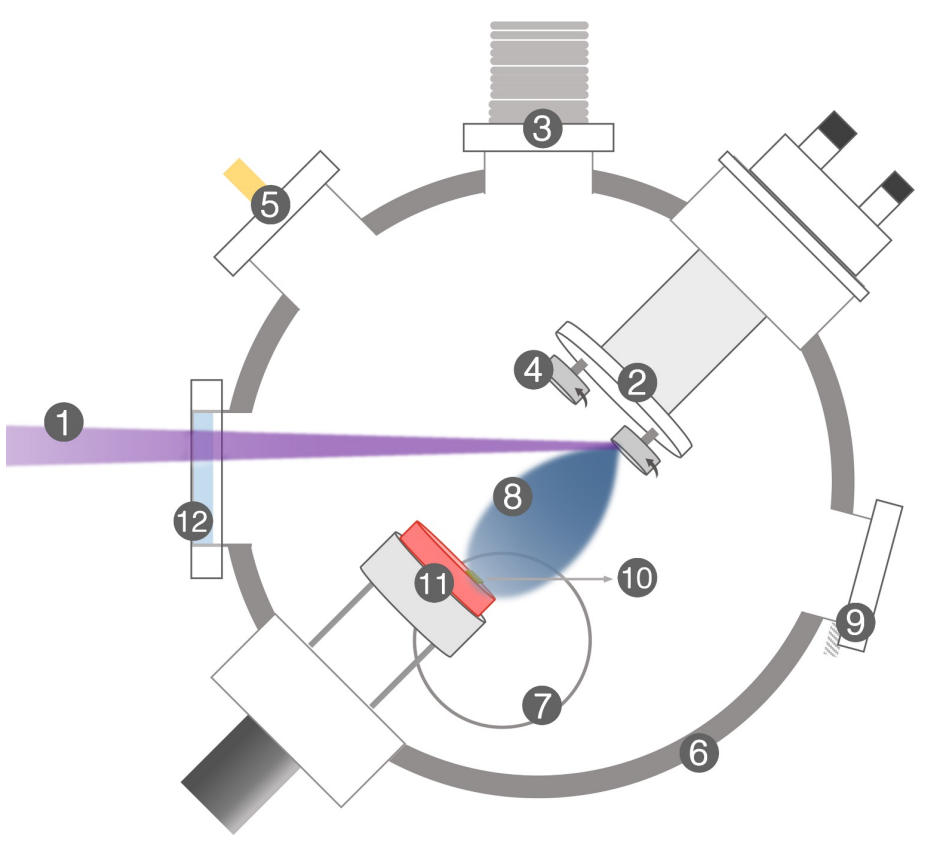

1. Laser pulsado de alta potência

2. Carrossel porta-alvos

3. Acesso da bomba de baixo vácuo

4. Alvo

5. Entrada de gás

6. Câmara de deposição

7. Acesso da bomba turbomolecular

8. Pluma de plasma

9. Válvula de controle de pressão

10. Substrato

11. Conjunto de aquecimento resistivo

12. Janela de quartzo

Fonte: $\mathrm{O}$ autor.

Figura 19 - Fotografia do processo de crescimento durante a ablasão do alvo em uma câmara de PLD (a) e o perfil de densidade de energia do feixe pulsado de laser do sistema de ablasão em função da posição do conjunto óptico sobre o ponto focal do sistema antes (energia total) e depois da janela de quartzo da câmara (energia atenuada) (b).

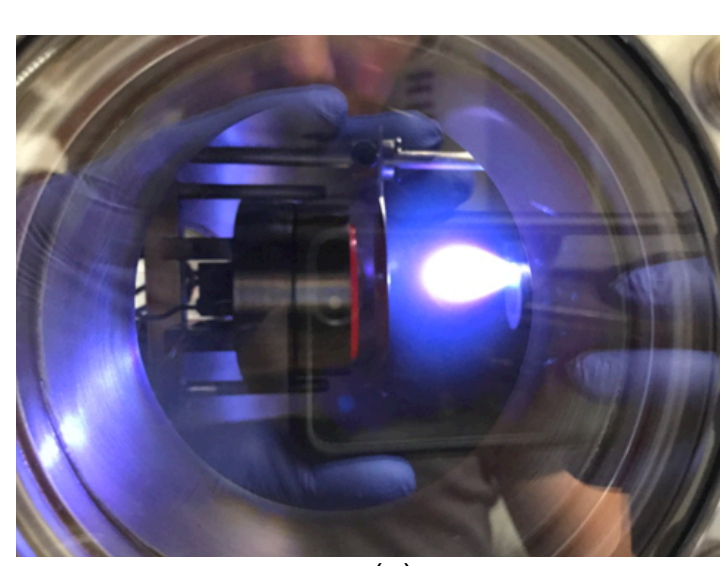

(a)

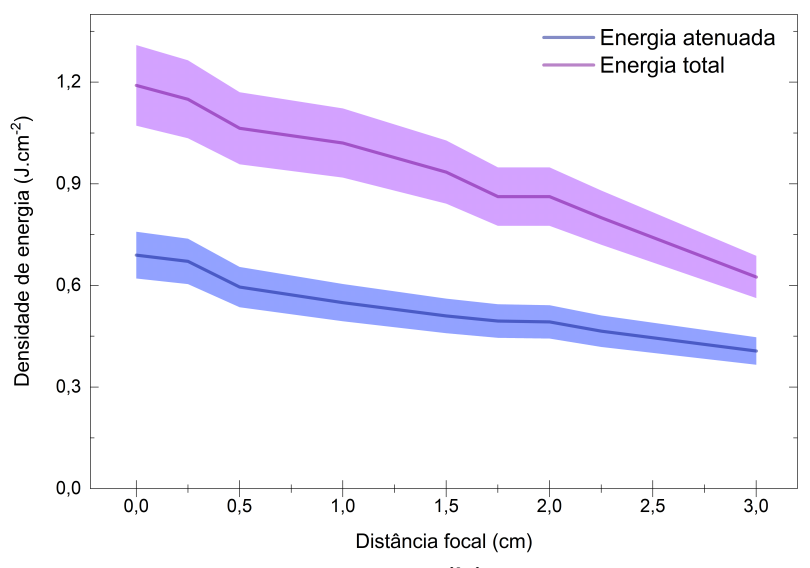

(b)

Fonte: O autor. 
Figura 20 - Representação do perfil e da área de interação do feixe de laser pulsado sobre a superfície do alvo cerâmico em função da posição relativa da lente focalizadora do conjunto óptico entre as marcações 0 e 2 (a-e).

a)

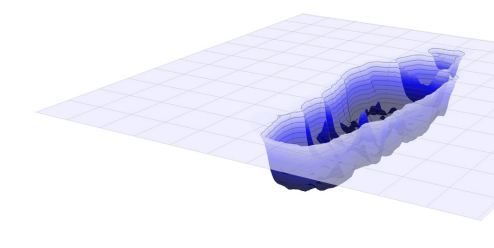

b)

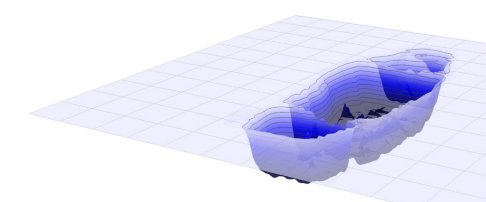

c)

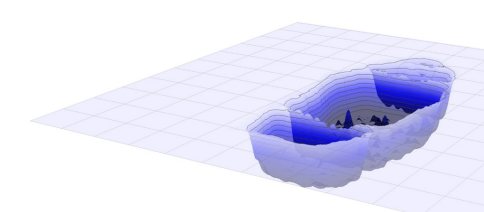

d)

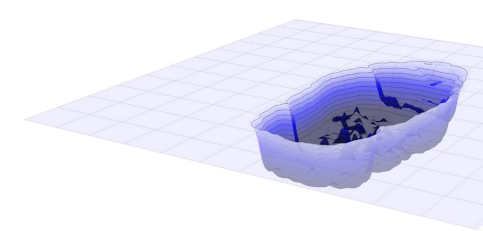

e)

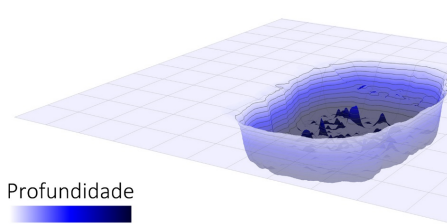

Projeção Lente focalizadora

Posição 0

Posição 0,5

Posição 1

Posição 1,5

Posição 2

Fonte: O autor.

Os valores calculados de densidade de energia mostrados no gráfico da Figura 19b foram obtidos pela integração das áreas das projeções mostradas na Figura 20 obtidas para 1 único pulso de $70 \mathrm{~mJ}$ do laser excimer UV sobre a superfície de um papel termossensível. As projeções do ponto focal do laser foram digitalizadas em alta resolução e processadas por software de imagem específico, onde a intensidade de 
cinza no papel termossensível representa indiretamente a intensidade do feixe de laser (representado pela escala "profundidade" na figura 20).

Figura 21 - Esquema ilustrativo de um sistema de deposição por pulverização catódica (Sputtering) (a), fotografia do porta-amostras na pré-câmara (b) e o processo de deposição pela formação do plasma acima da amostra (c).

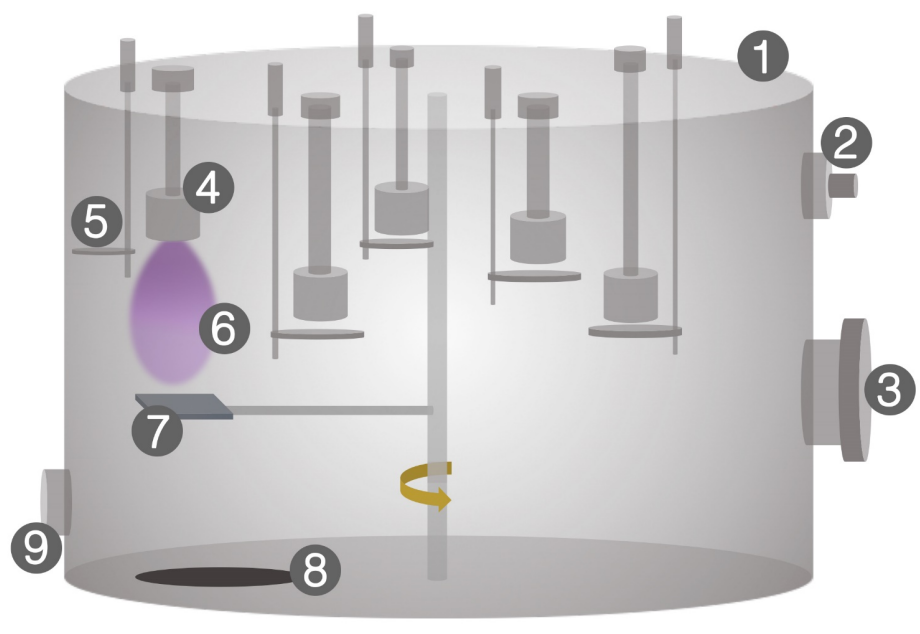

(a)
1. Câmara de deposição

2. Entrada de gás (Argônio)

3. Acesso do porta-amostra

4. Conjunto Alvo-Magnetron (sputter gun)

5. Anteparo (shutter) do alvo

6. Plasma

7. Porta-amostra móvel e eixo de rotação

8. Acesso da bomba turbomolecular

9. Acesso da bomba de baixo vácuo

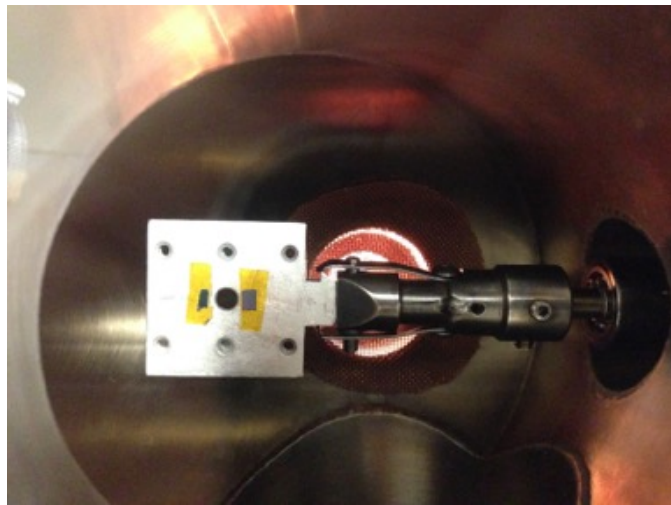

(b)

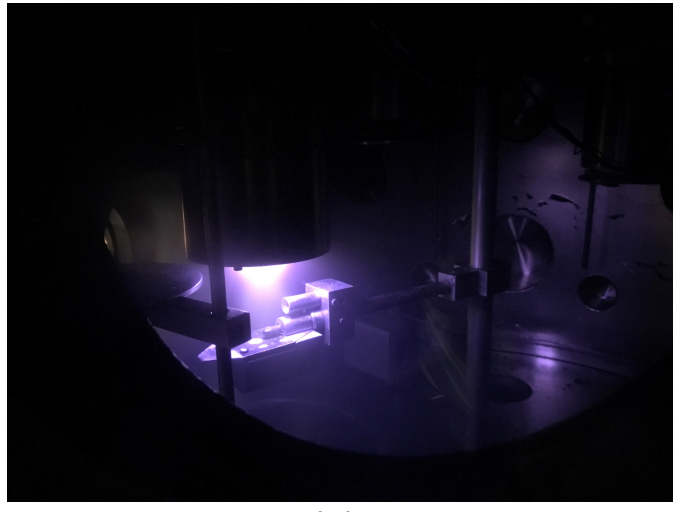

(c)

Fonte: $\mathrm{O}$ autor. 
Tabela 3- Parâmetros de deposição de filmes finos multiferroicos epitaxiais pela técnica de PLD.

\begin{tabular}{|lcc|}
\hline \multicolumn{1}{|c}{ Parâmetros } & $\mathbf{S r R u O}_{\mathbf{3}}$ & $\mathbf{B i F e O}_{3}$ \\
\hline Temperatura do substrato & $680{ }^{\circ} \mathrm{C}$ & $700{ }^{\circ} \mathrm{C}$ \\
\hline Energia do Laser & $100 \mathrm{~mJ}$ & $85 \mathrm{~mJ}$ \\
\hline Fluência do Laser & $1,5 \mathrm{J.cm}^{-2}$ & $1 \mathrm{J.cm}^{-2}$ \\
\hline Frequência do Laser & $05 \mathrm{~Hz}$ & $05 \mathrm{~Hz}$ \\
\hline Pressão de $\mathrm{O}_{2}$ & $100 \mathrm{mTorr}$ & $100 \mathrm{mTorr}$ \\
\hline Tempo & Variável & Variável \\
\hline Espessura (calib. por XRR) & Variável & Variável \\
\hline
\end{tabular}

Fonte: O autor.

Tabela 4 - Parâmetros de deposição de filmes metálicos ferromagnéticos por Sputtering.

\begin{tabular}{|lcc|}
\hline \multicolumn{1}{|c}{ Parâmetros } & $\mathbf{C o}_{0,9} F_{\mathbf{e}_{0,1}}$ & $\mathbf{P t}$ \\
\hline Temperatura do substrato & $\mathrm{RT}$ & $\mathrm{RT}$ \\
\hline Potência & 10 Watts & 25 Watts \\
\hline Pressão do Ar & $9 \times 10^{-3}$ Torr & $5 \times 10^{-3}$ Torr \\
\hline Tempo & $5 \mathrm{~s}$ & $26 \mathrm{~s}$ \\
\hline Espessura (calib. por XRR) & $2 \mathrm{~nm}$ & $5 \mathrm{~nm}$ \\
\hline
\end{tabular}

Fonte: O autor.

Os valores para os parâmetros de deposição tanto dos filmes ferroelétricos como dos filmes ferromagnéticos mostrados nas tabelas anteriores são algumas das melhores condições trabalhadas durante o projeto. Estes valores variam significativamente uma vez que os processos de deposição por PLD podem variar significativamente entre cada crescimento. Muitos fatores como a instabilidade do laser, a qualidade dos substratos e o posicionamento das amostras influenciam na qualidade dos crescimentos. Essa instabilidade exige por parte do pesquisador uma dinâmica nas condições de crescimento, sempre verificados pelas técnicas de caracterização mencionadas neste trabalho. 


\subsubsection{O processo de fotolitografia de microdispositivos}

Essencialmente, o processo de fotolitografia consiste na criação de padrões nano e microscópicos na superfície de uma amostra pela exposição à luz UV de uma resina fotossensível depositada previamente (Figura 22). O primeiro passo deste processo consiste na produção de uma máscara, no caso da fotolitografia por contato $^{5}$, geralmente de vidro transparente, onde são impressos padrões específicos para o dispositivo que se deseja criar sobre a amostra. Essas máscaras são gravadas à laser para produção de dois tipos de padrões: a) impressão por sombra e b) impressão por exposição. Basicamente no modelo (a), a forma do padrão a ser impresso na máscara será escura, projetando a sombra desta geometria sobre a superfície de uma resina fotossensível, ao passo que no modelo (b), a geometria dos padrões será transparente, permitindo que a luz ultravioleta atravesse o padrão e atinja a resina onde o dispositivo será criado.

Uma vez com a máscara selecionada, o passo seguinte é a deposição de um monômero sensível a radiação ultravioleta, também conhecido como resina fotossensível ou fotoresistor (marca G-line), pela técnica de spin-coating sobre a superfície da amostra que será padronizada. Após a deposição, a amostra com uma fina camada de resina sobre a superfície é aquecida para acelerar a cura do material. Essa etapa geralmente é feita usando uma chapa de aquecimento a $90{ }^{\circ} \mathrm{C}$ por 3 minutos.

A seguir, a amostra é precisamente posicionada sob um equipamento de luz ultravioleta e a máscara é colocada cuidadosamente sobre a amostra, atentando para que a posição das marcações dos dispositivos impressos no vidro esteja sobre a área correta da amostra. Com a máscara posicionada e fixada, a amostra é exposta a radiação ultravioleta por 2 minutos. Após a exposição, a amostra é lavada em uma

\footnotetext{
${ }^{5}$ Fotolitografia pode ser realizada em modo de contato ou em modo de projeção. Processos mais complexos e precisos como DUV e EUV são detalhados na referência $(C A O, 2004)$
} 
solução reveladora para remoção das áreas não padronizadas da resina dependendo da natureza positiva ou negativa da resina usada.

Explicado pelos princípios físicos da difração, o processo de litografia apresenta limitação quanto ao tamanho dos dispositivos padronizados sobre uma amostra. $\mathrm{O}$ fator de limite dimensional de um padrão exposto a radiação UV passa a depender de as geometria e distância entre as marcações, uma vez que a luz que passa entre elas sofrerá difração, gerando padrões distribuídos de difração na região de sombra do dispositivo (CAO, 2004). A equação 4 mostra a relação entre a distância entre os dispositivos impressos na máscara e do comprimento de onda da fonte UV usada.

$$
2 b_{\text {min }}=3 \sqrt{\lambda\left(s+\frac{d}{2}\right)}
$$

onde $2 \mathrm{~b}$ é o período da grade de difração, $\lambda \circ$ comprimento de onda a radiação incidente, s o espaço entre a máscara e a superfície da amostra e d a espessura do filme de resina fotossensível.

O processo geral de litografia usando luz ultravioleta semelhante ao processo usado para preparação das amostras deste trabalho é mostrado na Figura 22.

Figura 22 - Esquema ilustrativo do processo de litografia por luz ultravioleta e ablação iônica para criação de microdispositivos em filmes finos heteroestruturados.

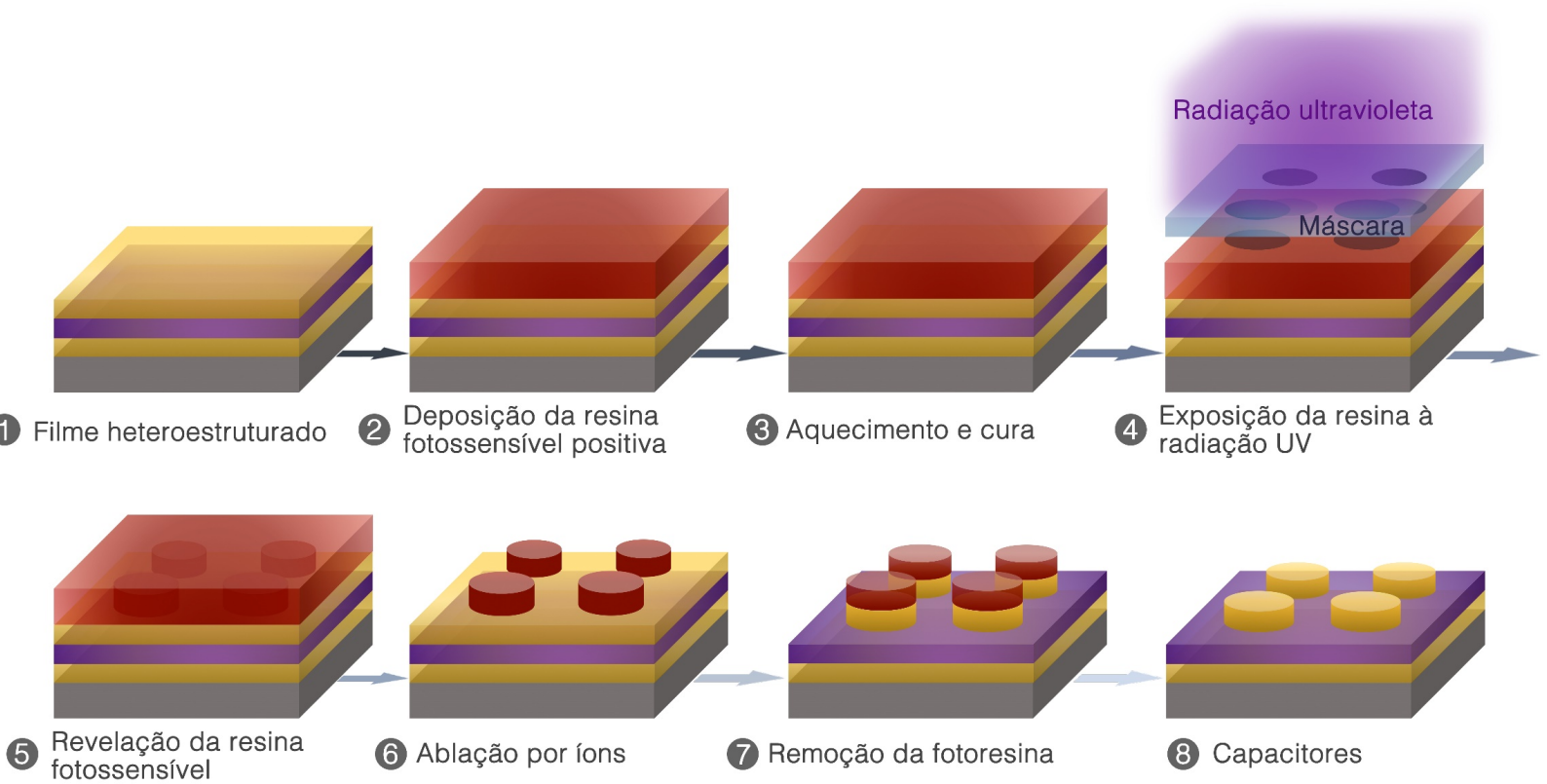


Fonte: O autor.

Em sistemas heteroestruturados e multicamadas, a fotolitografia é uma técnica essencial para preparação de microdispositivos, e em alguns casos nanodispositivos, sobre a superfície de uma amostra. As etapas 6, 7 e 8 da figura acima correspondem ao processo de gravura dos padrões criados por fotolitografia pelo uso de um sistema chamado de ion-milling, onde um feixe de íons de Argônio é projetado sobre a superfície da amostra em uma câmara de baixa pressão para a remoção dos átomos dessa superfície por colisões diretas entre íons e átomos.

4.2.3. Caracterização de filmes finos multiferroicos e microdispositivos

Caracterizações de superfície (topografia e piezoresposta) foram realizadas em dois microscópios de força atômica Multimode Nanoscope da Bruker adaptados com dois lock-in amplifiers para ensaios do tipo PFM (Piezoresponse Force Microscopy).

A técnica de Microscopia de Força Atômica está entre os métodos de caracterização de nanoestrutura de filmes finos mais usados para análises de rotina, com a verificação de superfícies, como para ensaios mais robustos e complexos, com por exemplo, medidas de condutividade, ensaios mecânicos, eletrostáticos, impedância, respostas magnéticas entre outros.

Dentro das diversas classes de microscopia do tipo SPM (Scanning Probe Microscopy), o modo de operação em AFM (Atomic Force Microscopy), mostrado na Figura 23, opera com o uso de uma ponteira do tipo cantilever com um tip de contato de aproximadamente 5-10 nm (de acordo com as definições do fabricante) que é posta em interação com a superfície da amostra (modo de contato, não contato ou contato intermitente "tapping mode") (VOIGTLÄNDER, 2015). 
A superfície da amostra é varrida pela ponteira com o auxílio de atuadores cerâmicos piezoelétricos que movimentam a amostra nos três eixos ( $x, y$ e $z$ ) enquanto mede a deflexão do cantilever pela leitura, por meio de um sensor fotodiodo, dos movimentos da reflexão de um laser direcionado sobre sua superfície polida. Ao varrer a superfície de uma amostra, as deflexões da ponteira causam modificação da posição do laser refletido nos quadrantes do fotodiodo, o sistema elétrico então ajusta a voltagem aplicada ao atuador cerâmico sob a amostra para retornar ao ponto central da posição $z$ da superfície. Esse processo gera um sinal elétrico interpretado pelo computador que cria uma imagem de cada ponto (pixel) escaneado pelo microscópio (KHOLKIN et al., 2007; VOIGTLÄNDER, 2015).

Figura 23 - Esquema de funcionamento de um microscópio de força atômica (AFM).

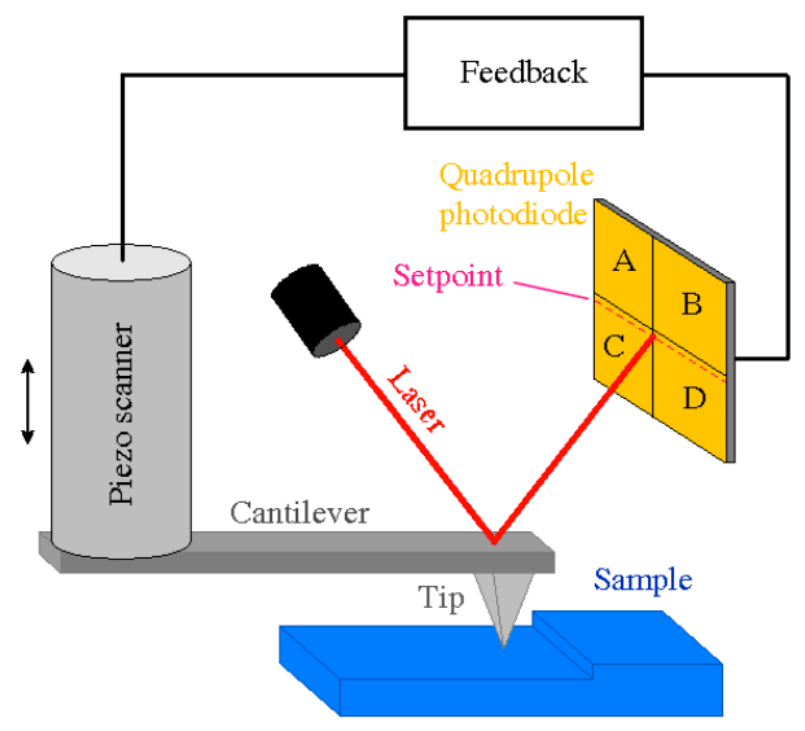

Fonte: (MORELLI, 2009)

Limitações em cada modo de operação são determinantes na escolha da técnica para a correta caracterização topográfica da amostra, como é o caso de superfícies muito rugosas ou sensíveis, onde o modo intermitente pode ajudar a contornar os problemas de distorção de imagem devido ao atrito e consequentemente dados à ponteira.

A análise de topografia feita por AFM, além de uma etapa fundamental da caracterização dos filmes finos, é também uma técnica multifuncional, uma vez que, com a ponteira (cantilever) em contato com a superfície da amostra, medidas 
adicionais de outras propriedades podem ser tomadas durante a varredura do sistema, como é o caso do imageamento de domínios ferroelétricos.

Realizada em modo de contato, as medidas de PFM (Piezoresponse Force Microscopy) fazem a varredura de domínios ferroelétricos pela aplicação de campo elétrico entre a ponteira (cantilever) e a superfície do material, seguindo pela leitura das respostas piezoelétricas do material ponto-a-ponto (Fig. 24). Uma vez que a resposta piezoelétrica depende do tipo de domínio ferroelétrico presente no material, é possível identificar a estrutura de domínios de uma amostra ferroelétrica, como é caso dos filmes finos estudados neste trabalho (VOIGTLÄNDER, 2015).

Figura 24 -Esquema ilustrativo de um PFM com os principais componentes e arranjos (a) e a distribuição do campo elétrico aplicado em modo local (esquerda) quando um eletrodo abaixo da camada ferroelétrica permite o circuito entre ponteira e superfície da amostra e em campo elétrico global quando um eletrodo superior entre a superfície ferroelétrica e a ponteira distribui uniformemente o campo aplicado (b).

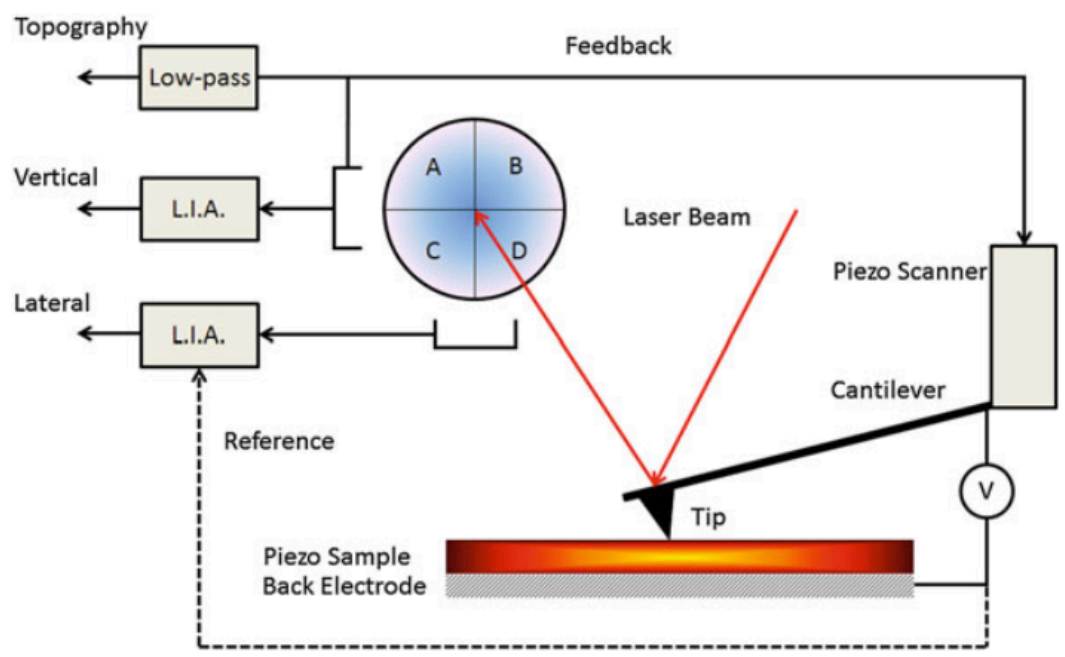

(a)
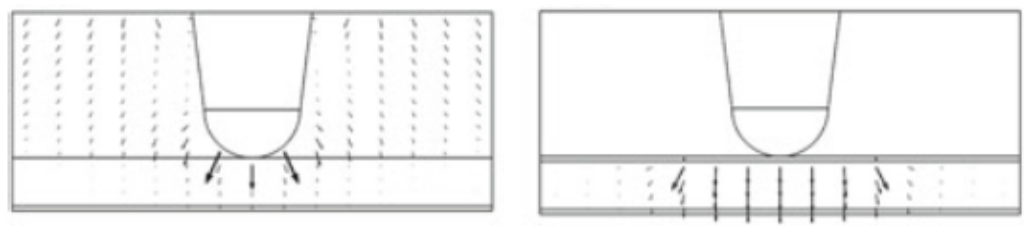

(b)

Fonte: (MARKYS, 2014) 
As medidas de PFM são feitas com o cantilever em contato direto com a superfície da amostra, uma baixa tensão alternada ( $A C$ voltage) é aplicada entre a ponteira e o material enquanto a deflexão do cantilever, causada pelo efeito inverso da piezoeletricidade, é medida e amplificada pelo uso de amplificadores do tipo lockin.

O uso de amplificadores lock-in é essencial para a distinção entre os sinais de topografia e de deslocamento vertical e lateral causados pelo comportamento piezoelétrico da amostra. Outra função fundamental desses componentes eletrônicos é a capacidade de filtrar os sinais e remover os ruídos gerados pelo sistema, assim, medidas da ordem de picometros podem ser coletadas e interpretadas (MARKYS, 2014).

A primeira abordagem de caracterização estrutural feita nos filmes finos deste trabalho foi pelo uso da técnica de Difração de raios $\mathbf{X}$. As medidas de difração de raios $\mathrm{x}$ foram feitas mediante o uso de um sistema de difratômetros de raios $\mathrm{X}$ modelo X'Pert MRD da marca Panalytical (Fig. 25) com geometria e óptica de alinhamento para filmes finos.

Figura 25 - Difratômetro X'Pert3 MRD Panalytical para filmes finos.
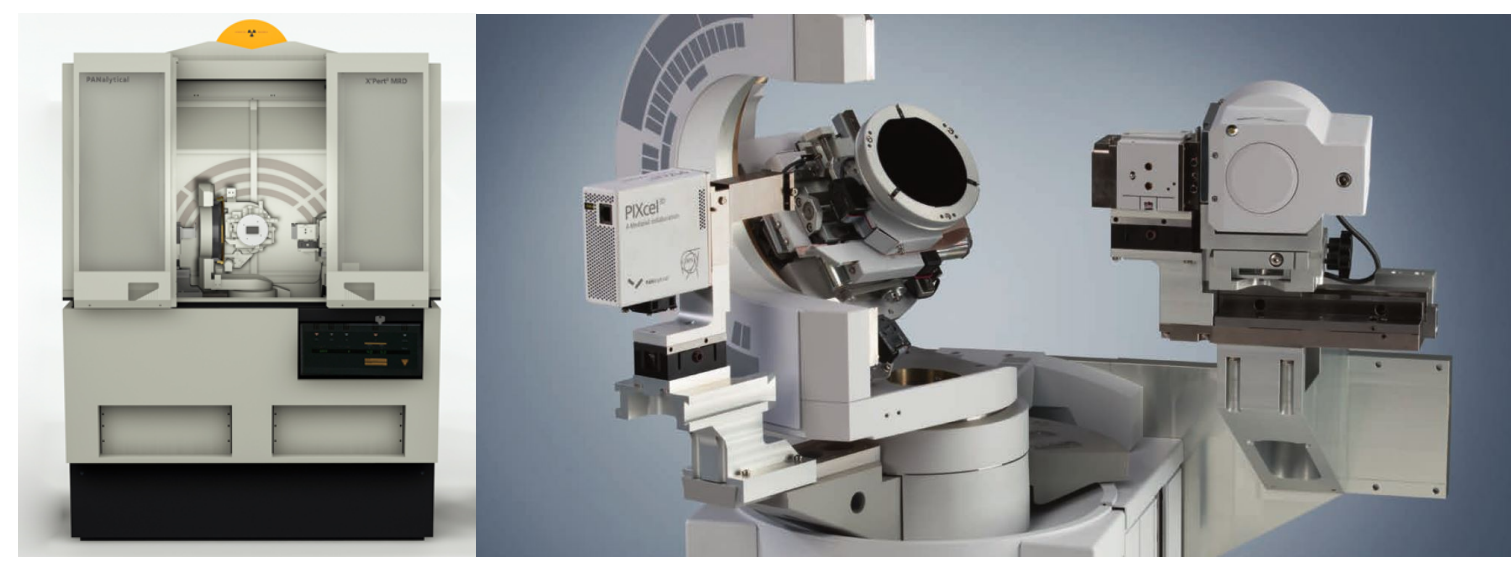

Fonte: (PANALYTICAL, 2016) 
Durante as medidas de difração ${ }^{6}$, um feixe de raios $\mathrm{X}$ monocromático (Cu Ka) é direcionado sobre a superfície da amostra, provocando espalhamento elástico devido ao arranjo atômico da estrutura cristalina do material. Uma vez que a posição do feixe incidente sobre a amostra em relação ao detector satisfazem a condição de difração de Bragg, a formação de um espalhamento com interferência construtiva é detectada e registrada pelo equipamento em função do ângulo, criando um padrão na forma de um difratograma (HASEK, 1987).

No caso de materiais filmes finos heteroestruturados, o uso da difração de raios $X$ é uma etapa fundamental para a análise de fases, a qualidade estrutural das amostras em termos de epitaxia e em alguns casos, detalhes estruturais mais sutis como a formação de domínios ferroelétricos, vórtices e distorções periódicas causadas pelas próprias propriedades intrínsecas do material (SUWAS; RAY, 2014).

Geralmente o escaneamento convencional 20- $\omega$ é a opção escolhida para a análise da posição dos picos de reflexão do filme fino crescido em relação aos picos de reflexão do substrato monocristalino, o que nos dá informações importantes sobre a qualidade do crescimento do filme, condições de tensão e compressão entre as estruturas depositadas e o substrato, fases secundárias etc.

Nos casos onde a confirmação da espessura do filme é preciso ser verificada, o modo de varredura por reflexão (Reflectivity mode) é usado para identificação dos padrões de reflexão dos raiox $X$ incidentes em baixos ângulos, onde a interação da radiação com a variação de densidade eletrônica dos átomos da superfície produz os padrões de interferência de Kiessig (Kiessig fringes).

A técnica de Microscopia Eletrônica de Transmissão de Alta Resolução (HRTEM) foi empregada na avaliação da qualidade dos filmes crescidos epitaxialmente e sua estrutura cristalina local. O equipamento usado neste Doutorado foi o TEAM I (FEI Titan 80-300 modificado com correção de aberração duplo) do centro de microscopia do Lawrence Berkeley National Laboratory. As técnicas de microscopia eletrônica fazem uso de um feixe de elétrons acelerados através de uma coluna ajustada por uma diferença de potencial definida pelo usuário. Como parte do conjunto desta coluna, lentes eletromagnéticas condensadoras convergindo o feixe de elétrons a um ponto comum próximo a superfície da amostra. Parte dos elétrons

\footnotetext{
${ }^{6}$ Maiores detalhes sobre a técnica estão descritos no ANEXO B.
} 
direcionados para a amostra são transmitidos através da estrutura cristalina sofrendo colisões elásticas e inelásticas, após a amostra, lentes objetivas produzem as primeiras imagens que são ampliadas e projetadas pelas lentes de projeção sobre uma tela fosforescente (THOMAS; GEMMING, 2014; DEEPAK; MAYORAL; ARENAL, 2015; MOORTHY, 2015).

Os ensaios elétricos foram realizados em amostras preparadas por litografia UV convencional. Este processo é utilizado em indústria de fabricação de dispositivos eletrônicos como microchips e memórias para criação de padrões micrografados na superfície da amostra. As amostras fabricadas neste trabalho foram preparadas com padrões circulares na forma de capacitores de 8 e 16 micrômetros de diâmetro (Fig. 26) como contatos elétricos juntamente com a camada condutora de $\mathrm{SrRuO}_{3}$ sobre a qual a composição multiferroica foi crescida.

Figura 26 - Representação tridimensional da estrutura de um contato elétrico superior (esquerda) e sua imagem obtida por microscopia de força atômica (AFM).
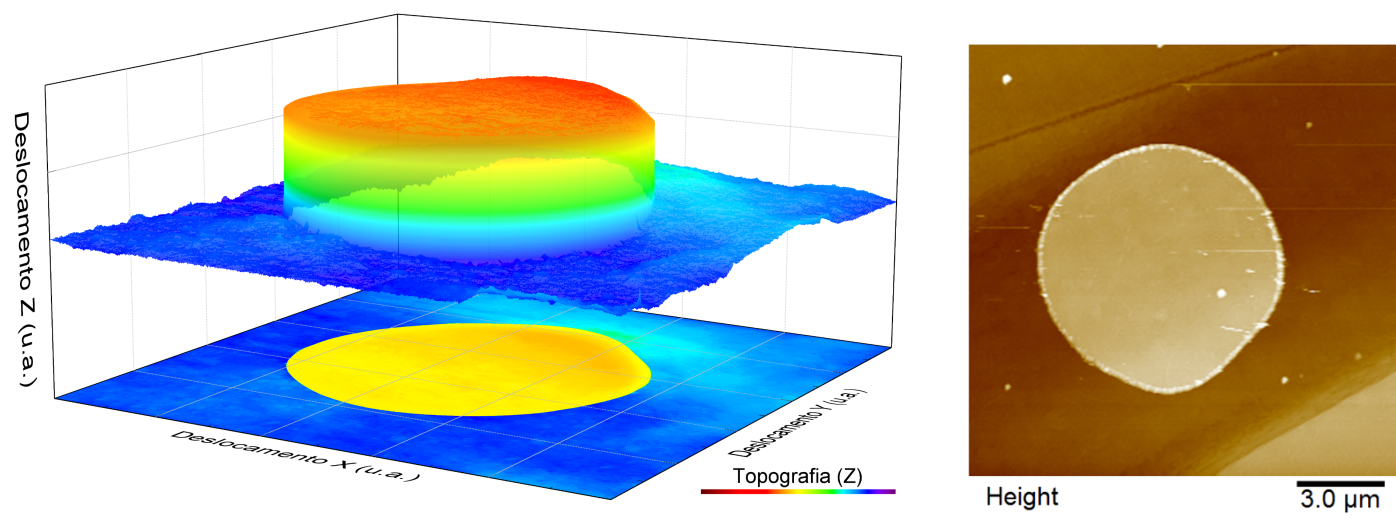

$160.0 \mathrm{~nm}$

Fonte: $\mathrm{O}$ autor.

As sequências de pulso elétrico foram realizadas em estações de teste especiais para medidas ferroelétricas. Um sistema de teste da empresa Radiant Technology de modelo Multiferroic // foi utilizado para obtenção de curvas de histerese elétrica e medidas dinâmicas de polarização pelo método PUND (Positive-UP Negative-DOWN). As configurações de pulso utilizadas nas medidas PUND e nos testes de gravação e leitura ferroelétrica estão detalhadas na Figura 27. 
O perfil de polarização elétrica em cada estágio da curva de histerese ferroelétrica, de acordo com as configurações de pulso usadas, é mostrado em uma sequência partindo do campo elétrico negativo em um ciclo completo da curva de histerese (Fig. 28).

Figura 27 - Esquema de configuração dos padrões de pulso elétrico para as análises de polarização dinâmica pelo método PUND (a) e ensaios de gravação e leitura de estados ferroelétricos (write and read) (b).

a)

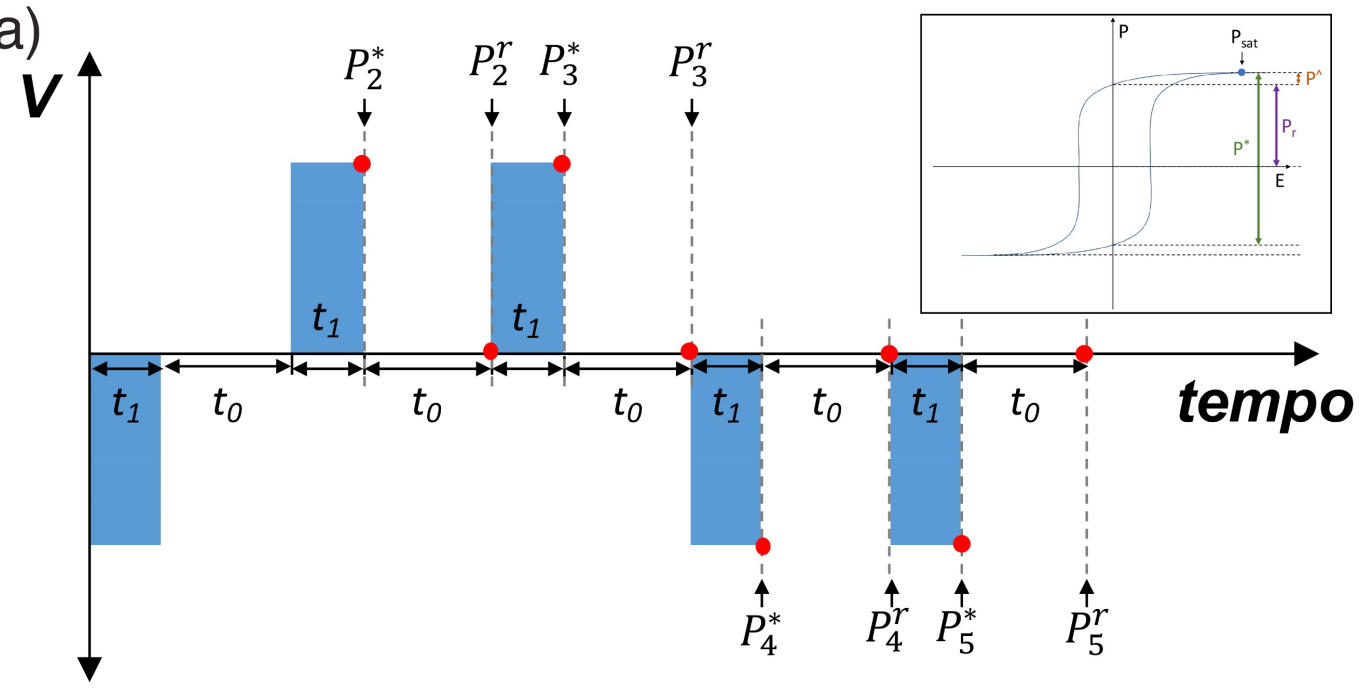

b)

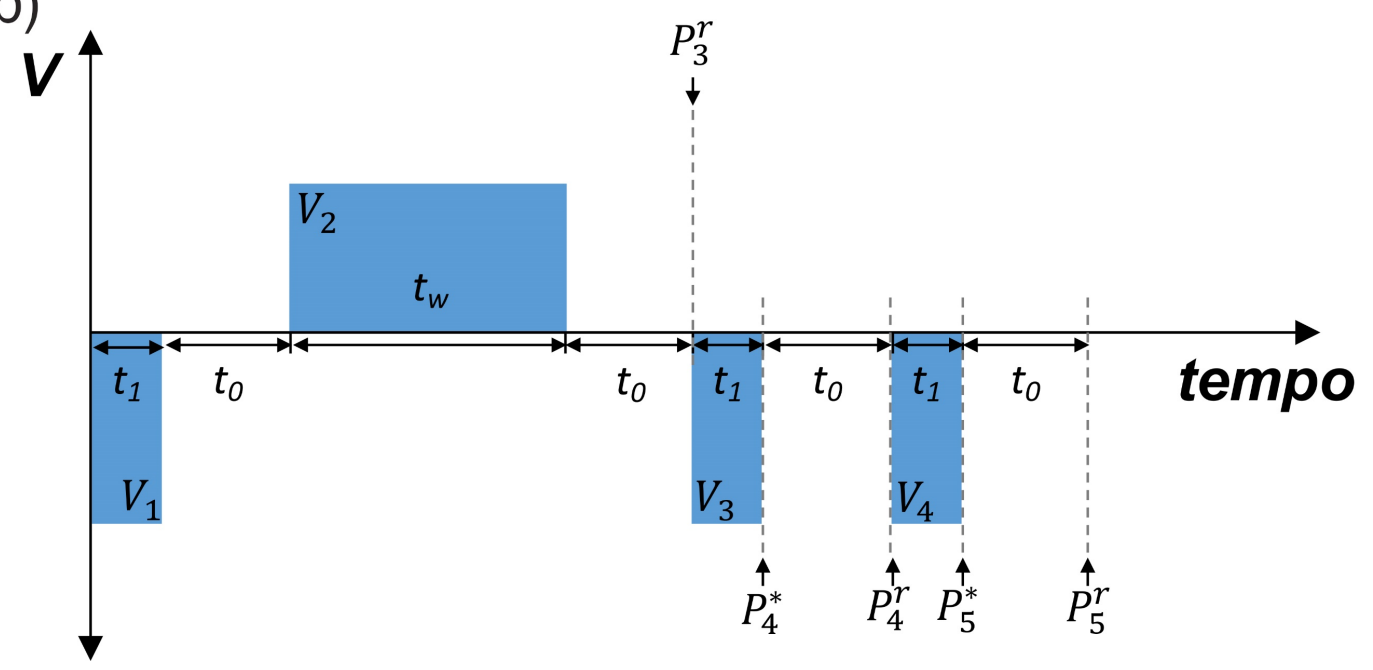

Fonte: O autor. 
Figura 28 - Sequência (a-i) de alteração de estados ferroelétricos nos ensaios PUND para determinação da polarização dinâmica PUND.
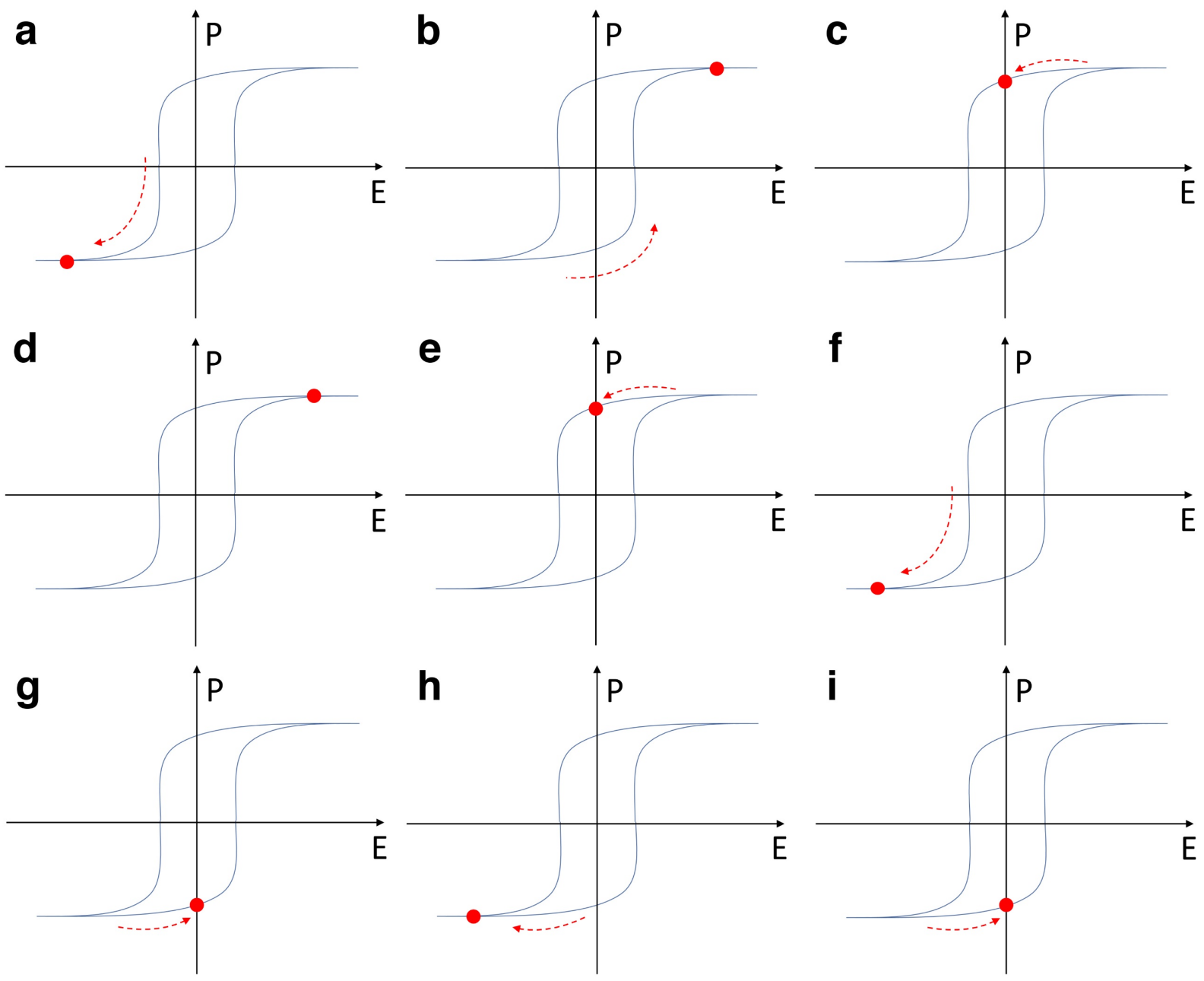

Fonte: O autor.

Dado o comportamento magnético dos filmes finos produzidos neste trabalho, as técnicas de Espectroscopia de raios X por Dicroísmo Linear Magnético (XMLD) e Dicroísmo Circular Magnético (XMCD) foram usadas para determinação do ordenamento de spins na estrutura do $\mathrm{LaBiFeO}_{3}$. De forma geral, a absorção de raios $X$ polarizados é fortemente dependente da anisotropia de estados não ocupados. XMLD é uma técnica particularmente usada para medir o ordenamento de cargas magnéticas e tem grande apelo em sistemas antiferromagnéticos como o BFO (QUITMANN et al., 2010; RAMANATHAN, 2010). 
Ensaios de histerese magnética em temperatura ambiente foram realizados sob variação de campo magnético em um magnetômetro de amostra vibrante, do inglês Vibrating Sample Magnetometer VSM, para determinação do comportamento $\mathrm{M}-\mathrm{H}$ no eixo de magnetização e fora do plano.

Algumas medidas preliminares e complementares de magnetorresistência anisotrópica foram realizadas nas amostras de $\mathrm{Pt} / \mathrm{CoFe} / \mathrm{LaBiFeO}_{3} / \mathrm{SrRuO}_{3} / \mathrm{SrTiO}_{3} \mathrm{com}$ o objetivo de avaliar a qualidade dos filmes ferromagnéticos e a possibilidade de manipulação dos domínios magnéticos deste filme pela alteração nos estados de polarização do filme multiferroico.

Os microdispositivos (Fig. 29a) para medidas de magnetorresistência foram padronizados por uma série de processos de microfabricação envolvendo a técnica de fotolitografia multi sequencial.

As interconexões elétricas (Fig. 29b) entre os sistemas AMR e os microdispositivos padronizados sobre as amostras foram realizadas nos laboratórios de microfabricação com o auxílio de equipamentos específicos para o processo de wire bonding. 
Figura 29 - Representação gráfica (a) e imagem de microscopia otica (b) dos dispositivos e conexões para medidas de magnetoresistência anisotrópica.

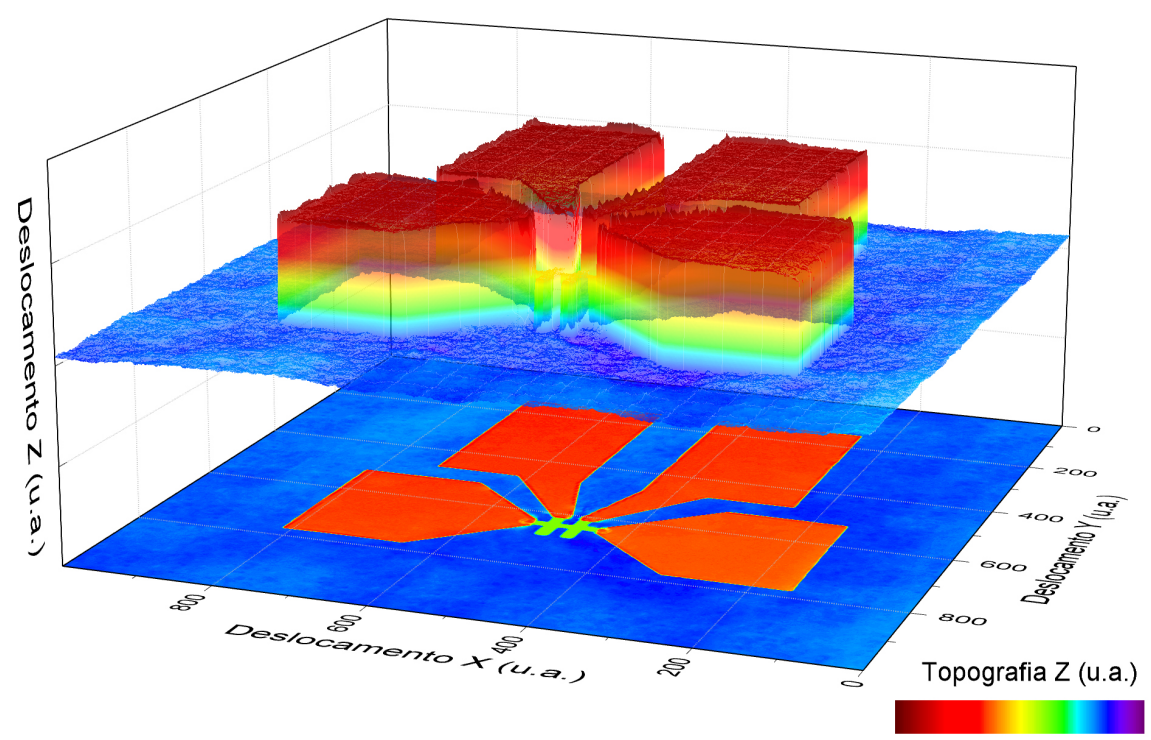

(a)

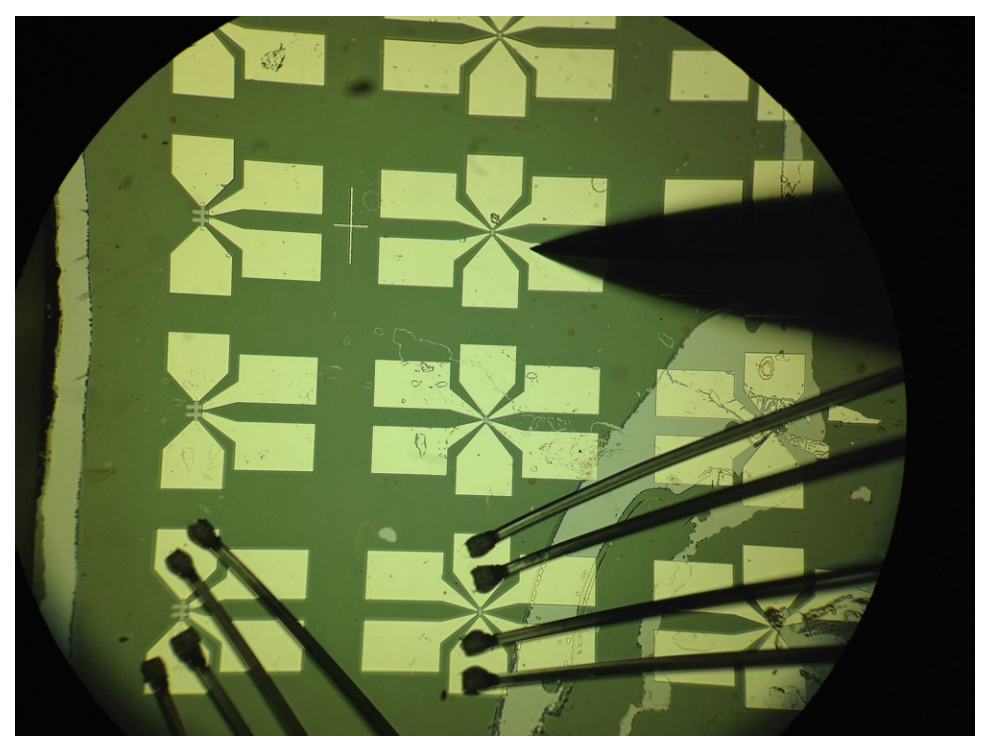

(b)

Fonte: $\mathrm{O}$ autor. 


\section{RESULTADOS 05 \\ E DISCUSSÃO}

\section{RESULTADOS E DISCUSSÃO}

Os dados apresentados e discutidos a seguir representam, de forma ordenada para cada etapa de desenvolvimento experimental, as características de um sistema de heteroestruturas crescidas epitaxialmente pela técnica de deposição física a vapor por laser pulsado PLD (Fig. 30).

Inicialmente os filmes finos de $\mathrm{SrRuO}_{3}(\mathrm{SRO})$ usados como eletrodo inferior foram depositados sobre a superfície dos substratos de interesse em uma sequência de testes com diferentes parâmetros de crescimento. Uma vez encontrada a zona de crescimento adequada às condições satisfatórias para a obtenção de bons filmes com características como espessura adequada, fase cristalina pura e baixa rugosidade, a sequência de crescimentos passa para a próxima composição depositada sobre o eletrodo, o filme fino de $\mathrm{BiFeO}_{3}$.

A obtenção inicial de filmes finos de $\mathrm{BiFeO}_{3}$ (BFO) tem por objetivo testar as condições de crescimento na sua influência sobre as características ferroelétricas das amostras produzidas. Uma vez estabelecida a região de crescimento para obtenção de filmes finos ferroelétricos com propriedades adequadas, os experimentos evoluíram para o crescimento das composições de interesse neste trabalho, os filmes finos de $\mathrm{La}_{0,10} \mathrm{Bi}_{0,90} \mathrm{FeO}_{3}$ (LBFO). 
Após os estudos estruturais, elétricos e magnéticos dos filmes ferroelétricos, segue-se para a etapa de deposição dos filmes ferromagnéticos de $\mathrm{Co}_{0,90} \mathrm{Fe}_{0,10}$ depositados sobre esta estrutura para avaliação das condições de acoplamento interfacial FE/FM.

Figura 30 - Esquema de crescimento das amostras heteroestruturadas em multimadas de filmes finos de $\mathrm{BiFeO}_{3}$ e $\mathrm{SrRuO}_{3}$ sobre um substrato monocristalino.

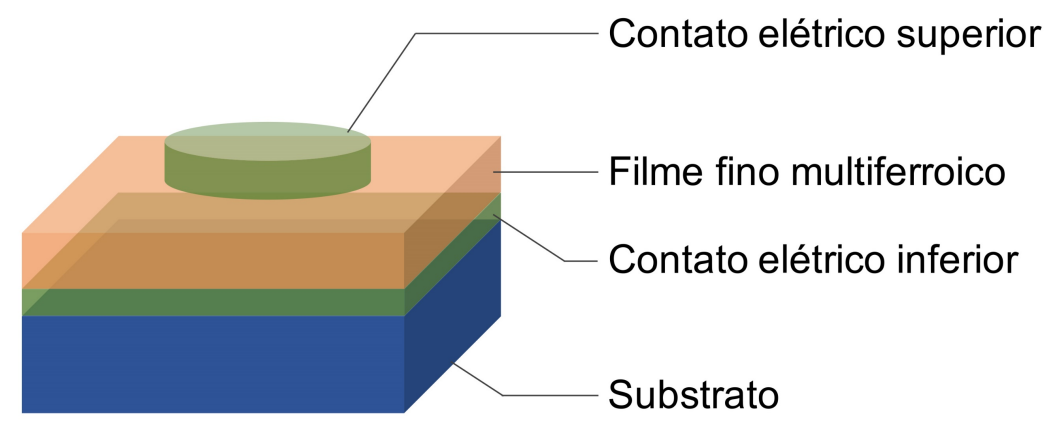

Fonte: $\mathrm{O}$ autor.

5.1. Crescimento e caracterização de filmes finos de $\mathrm{BiFeO}_{3}$

5.1.1. Topografia e imagem de domínios ferroelétricos por microscopia de força atômica e PFM

Inicialmente, as amostras são constituídas de uma camada inicial de material condutor (óxido) depositada diretamente sobre a superfície de um monocristal de orientação cristalina conhecida, a camada inicial condutora também é chamada de buffer layer e sua espessura varia entre 10 e $20 \mathrm{~nm}$ e em seguida, a camada de material multiferroico, no caso o $\mathrm{BFO}$, foi depositada sobre a superfície da primeira camada buffer atomicamente distribuída e acomodada no substrato, de acordo com a representação mostrada na Figura 30. A composição estequiométrica do óxido $\mathrm{SrRuO}_{3}$ foi escolhida como camada buffer para todas as amostras. 
Figura 31 - Imagens de microscopia de força atômica dos filmes finos de $\mathrm{SrRuO}_{3} \quad(\sim 10 \mathrm{~nm}$ de espessura) sobre substratos de $\mathrm{SrTiO}_{3}(100)$ e $\mathrm{DyScO}_{3}(110)$ em função da energia de ablação do laser pulsado (a) e da temperatura do substrato durante o crescimento (b).

a)
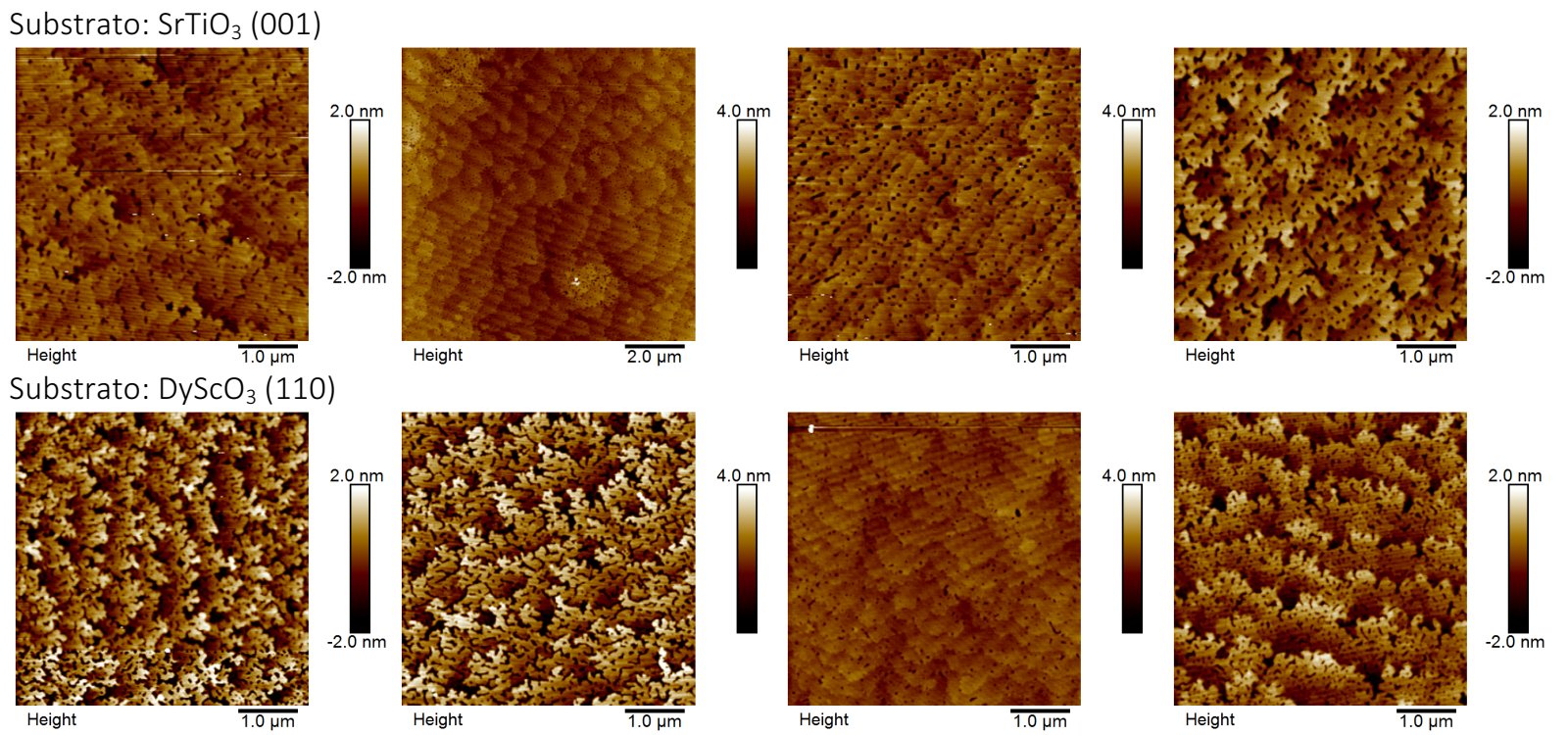

Energia do Laser

80

b)

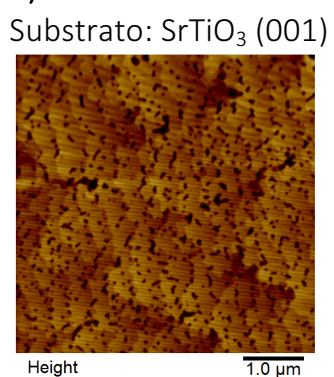

Substrato: $\mathrm{DyScO}_{3}$ (110)

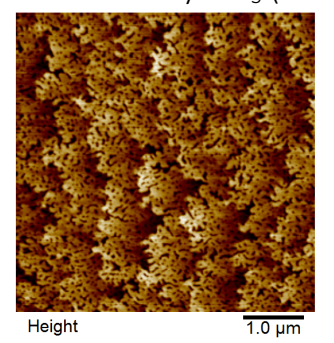

Temperatura do substrato
90

Parâmetros invariáveis:
$100 \mathrm{~mJ}$

Temperatura: $660^{\circ} \mathrm{C}$ Frequência: $05 \mathrm{~Hz}$

Pressão parcial de $\mathrm{O}_{2}: 100$ mTorr

Tempo de deposição: 5 min
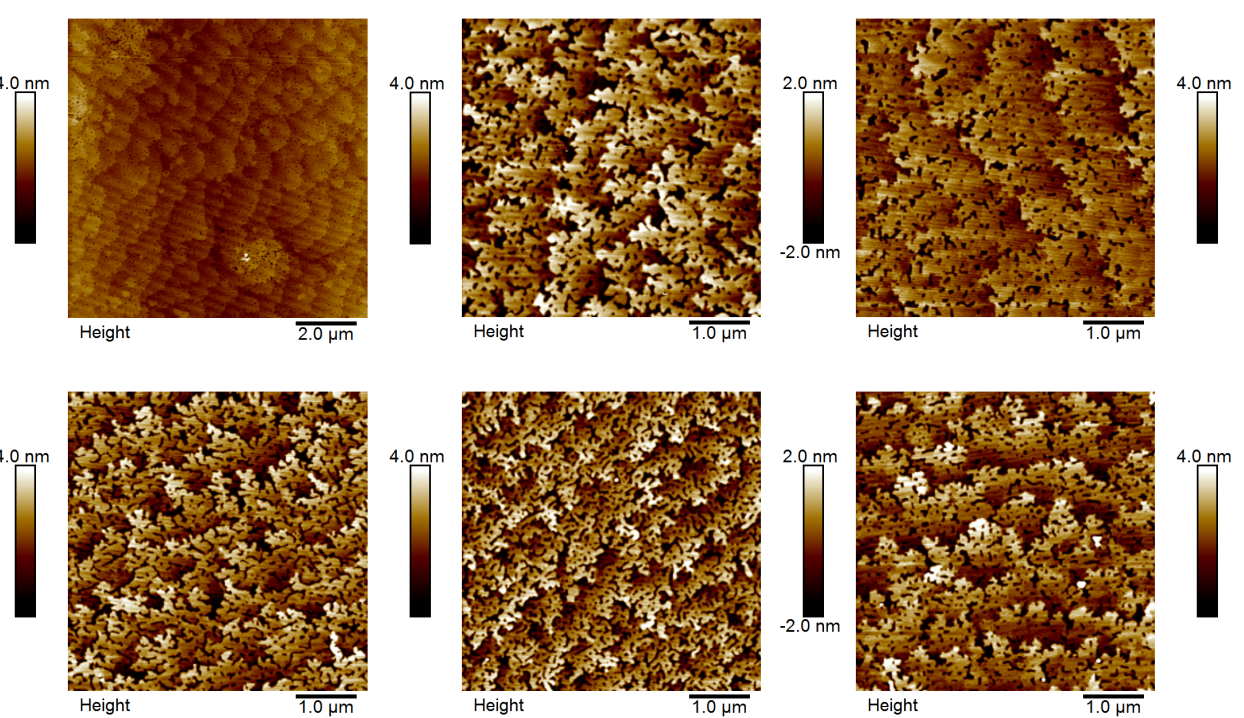

650

660

670

$700^{\circ} \mathrm{C}$

Parâmetros invariáveis:

Energia do laser: $90 \mathrm{~mJ}$

Frequência: $05 \mathrm{~Hz}$

Pressão parcial de $\mathrm{O}_{2}: 100$ mTorr

Tempo de deposição: 5 min 
As condições de crescimento de filmes de $\mathrm{SrRuO}_{3}$, bem como de qualquer outra composição, dependem de diversos fatores e podem não ser reprodutíveis, o que demanda constante calibração e reconfiguração dos parâmetros de deposição. Sendo assim, apenas algumas das condições trabalhadas para a deposição da camada buffer em substratos de DSO e STO estão mostradas na Figura 31. Com área de varredura de $5 \mu^{2}$, os valores de rugosidade das camadas de eletrodo inferior depositadas apresentaram valores em torno de 0,2 $\mathrm{nm}$.

\section{$\mathrm{BiFeO}_{3}$}

A interpretação das imagens de microscopia de força por piezoresposta (PFM) no plano é obtida e analisada de acordo com a direção de deslocamento do vetor de polarização dos domínios ferroelétricos presentes na amostra, como mostrado na figura 32.

Amostras de filmes finos de $\mathrm{BiFeO}_{3}$ (BFO) foram obtidas pela técnica de deposição física por laser pulsado com diferentes valores de espessura, variando entre 10 e $100 \mathrm{~nm}$. As imagens de microscopia de força atômica mostradas na Figura 33 referem-se a topografia (imagens superiores) e aos domínios ferroelétricos horizontais no plano (imagens inferiores) da estrutura cristalina para diferentes espessuras da camada de BFO. 
Figura 32 - Esquema de funcionamento da varredura no plano (in-plane, IP) por microscopia de força de piezoresposta no sistema $\mathrm{BiFeO}_{3}$ de domínio ferrolétricos.

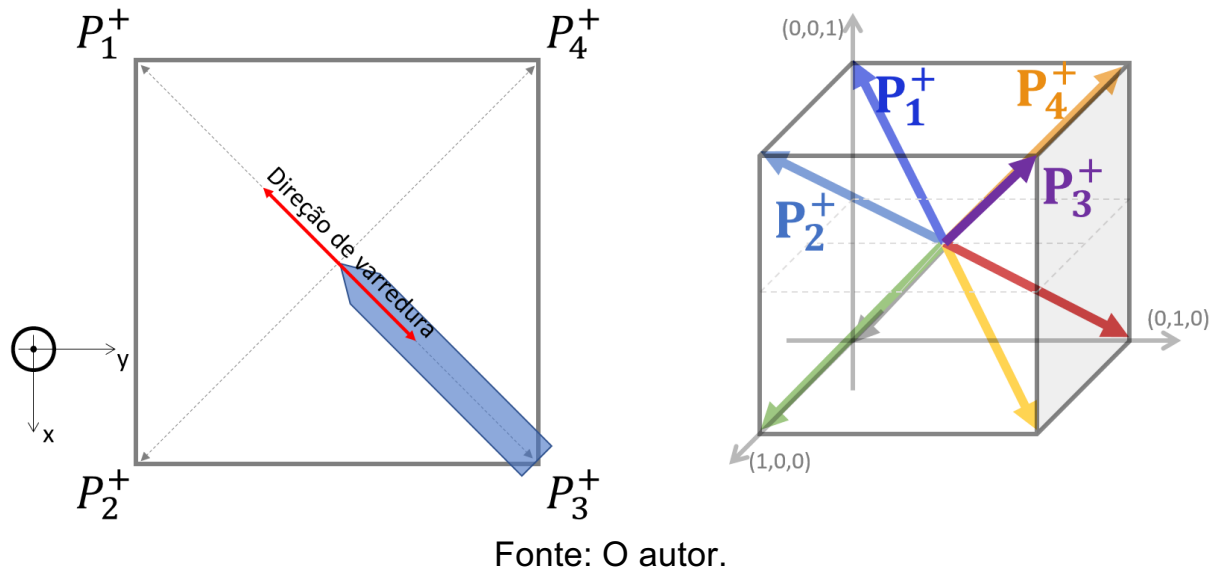

Fica evidenciado pelas imagens topográficas dos filmes de $\mathrm{BiFeO}_{3}$ (Fig. 33, superior) a baixa rugosidade das superfícies analisadas (valores medidos apontaram rugosidades entre 0,2 e 0,5 $\mathrm{nm}$ ), o que corresponde diretamente a boa qualidade e uniformidade durante o processo de transferência de massa entre alvo e substrato e o mecanismo de crescimento dos filmes epitaxiais sobre o substrato.

Figura 33 - Imagens de microscopia de força atômica (AFM - imagens superiores e IPPFM - imagens inferiores) de filmes finos de $\mathrm{BiFeO}_{3}$ crescidos com diferentes espessuras sobre $10 \mathrm{~nm}$ de $\mathrm{SrRuO}_{3}$ em substratos de $\mathrm{DyScO}_{3}$ (110).
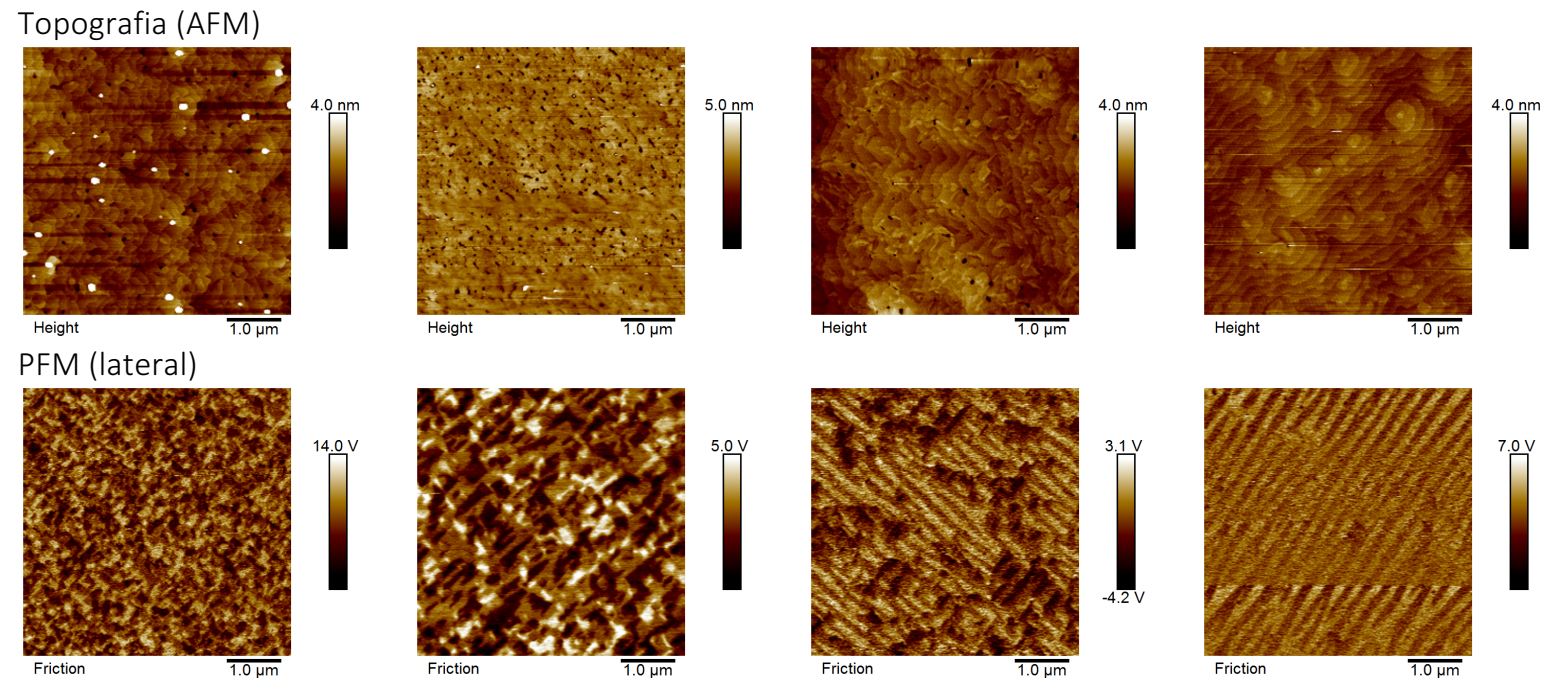

Espessura da camada ferroelétrica
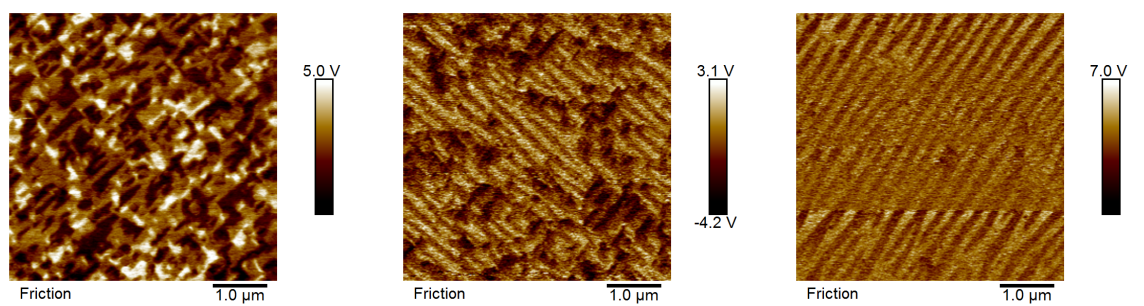

10

20

50

$100 \mathrm{~nm}$ 
A geometria de domínios ferroelétricos em materiais como o $\mathrm{BiFeO}_{3}$ e outros exemplos como $\mathrm{PbZrTiO}_{3}, \mathrm{BaTiO}_{3}$ etc, variam de acordo com uma série de parâmetros de crescimento, tensão, espessura entre outros.(MARTIN, 2008; DAMODARAN et al., 2016) As imagens de microscopia em modo PFM (in-plane PFM - IPPFM) mostradas na Figura 33 inferior corroboram com as informações de outros autores para sistemas com espessuras diferentes.

As amostras com a camada de BFO com espessura entre 100 e $20 \mathrm{~nm}$ apresentam domínios ferroelétricos do tipo linha (stripe-like), caracterizando domínios ferroelétricos de $71^{\circ}$. Dentre o grupo de amostras trabalhadas, apenas as amostras com $100 \mathrm{~nm}$ de espessura apresentaram domínios de $71^{\circ} \mathrm{com}$ duas variantes (Fig. 34a), as demais amostras (para espessuras menores que $100 \mathrm{~nm}$ ) identificamse com domínios orientados aleatoriamente com 4 variantes (Fig. 34b).

A formação de domínios ferroelétricos em sistemas como o BFO pode ser bastante complexa devido a distribuição de cargas e rearranjo espacial das espécies envolvidas nas estruturas cristalinas. Muitos trabalhos enfatizam a importância da engenharia e do controle da formação de domínios ferroelétricos em sistemas com possível aplicação tecnológica.(MERZ, 1954; SHIN et al., 2007; GUYONNET, 2014) 
Figura 34 - Distribuição das coordenadas de domínios ferroelétricos stripe-like com 2 variantes (a) e 4 variantes (b) obtidos pela análise dos vetores das imagens de microscopia de força atômica (IPPFM) de filmes finos de $\mathrm{BiFeO}_{3}\left(100 \mathrm{~nm}\right.$ e $50 \mathrm{~nm}$, respectivamente) crescidos sobre $10 \mathrm{~nm}$ de $\mathrm{SrRuO}_{3}$ em substratos de $\mathrm{DyScO}_{3}(110)$.
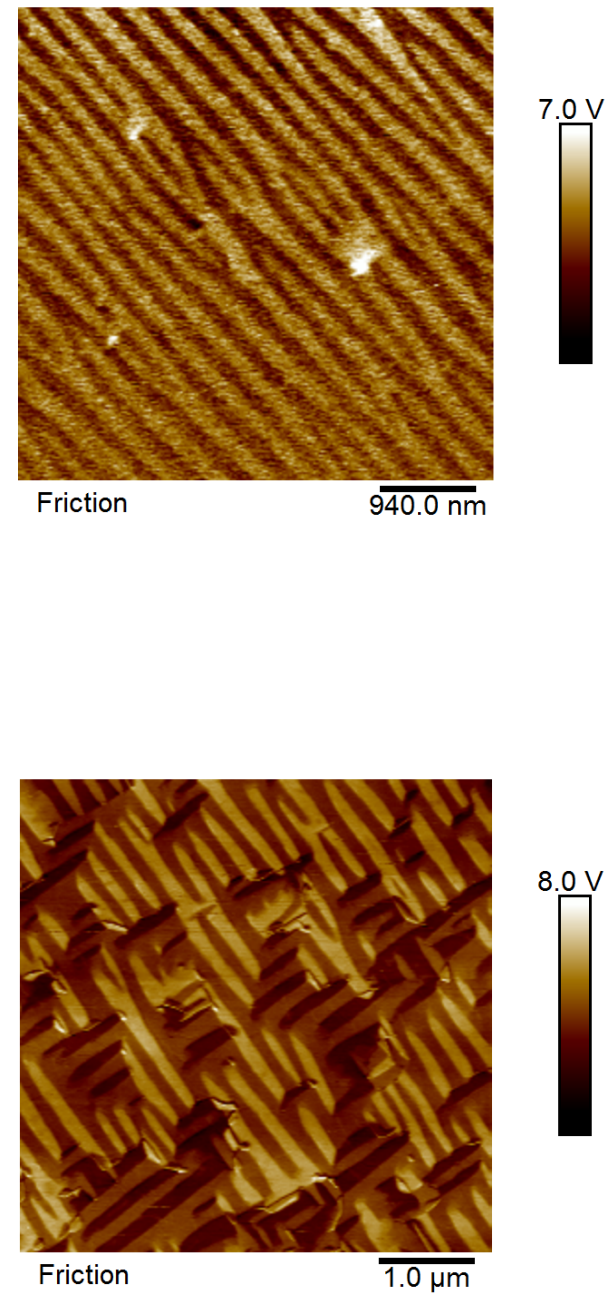

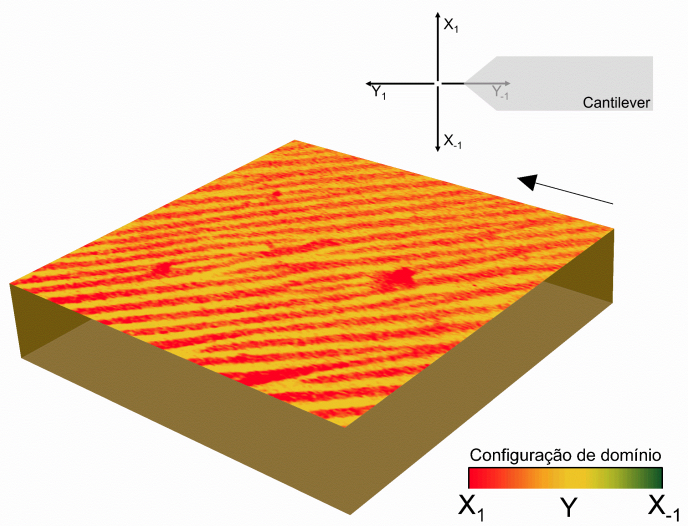

(a)

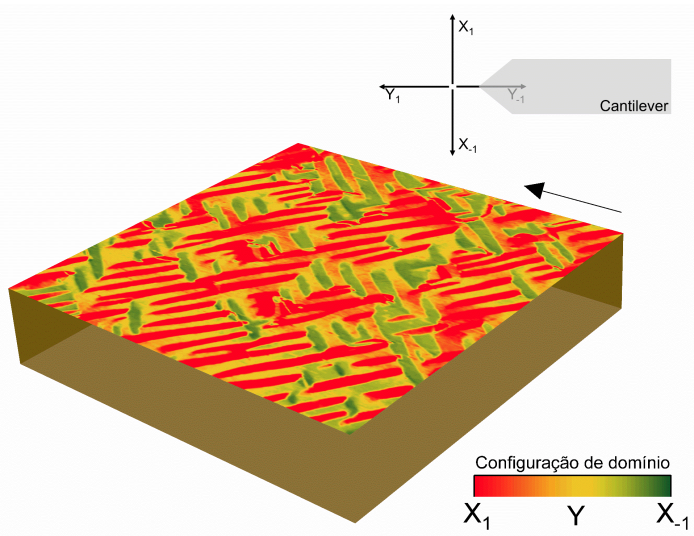

(b)

De acordo com as imagens de microscopia de força atômica e a partir do entendimento da geometria e distribuição dos domínios ferroelétricos nas estruturas de $\mathrm{BFO}$ crescidas sobre substratos de $\mathrm{DyScO}_{3}$ (110) foi possível determinar a espessura mínima da camada multiferroica para as demais caracterizações, uma vez que a amostra com $20 \mathrm{~nm}$ ainda apresenta domínios de $71^{\circ}$ distribuídos aleatoriamente, o que não ocorre de forma clara na amostra com $10 \mathrm{~nm}$ (Fig. 33) de espessura. A partir deste ponto, as amostras para avaliação estrutural, elétrica e magnética foram crescidas com $20 \mathrm{~nm}$ de espessura para a camada de LBFO. 
5.1.2. Perfil cristalográfico dos filmes finos de $\mathrm{BiFeO}_{3}$

Uma das características fundamentais do crescimento de filmes por PLD é a possibilidade de obtenção de estruturas heteroepitaxiais, ou seja, com diferentes composições, camadas de óxidos se intercalam com a mesma orientação cristalográfica do seu substrato base. Nesse sentido, as amostras de $\mathrm{BiFeO}_{3} / \mathrm{SrRuO}_{3} / \mathrm{DyScO}_{3}$ (filme multiferroico/eletrodo inferior/substrato) comportaramse de forma a acomodar a estrutura cristalina das camadas $\mathrm{SrRuO}_{3}(10 \mathrm{~nm})$ e $\mathrm{BiFeO}_{3}$ (10-100 nm) de forma epitaxial ao ordenamento cristalográfico do substrato de $\mathrm{DyScO}_{3}$ (110), como pode ser analisado nos difratogramas de raios $\mathrm{X}$ da Figura 35.

A distribuição cristalina evidenciada pelos difratogramas corrobora para o perfil limpo das fases presentes neste sistema. O perfil dos picos estreitos para a distribuição do substrato e dos filmes indica que as amostras crescidas epitaxialmente apresentam boa qualidade e perfil cristalino orientado.

Apesar do foco deste trabalho estar voltado para sistemas finos menores que $50 \mathrm{~nm}$ de espessura, amostras de $\mathrm{BiFeO}_{3} \mathrm{com} 100 \mathrm{~nm}$ de espessura também foram crescidas e analisadas por difração de raios $\mathrm{X}$, conforme mostrado no difratograma da Figura 35. O mapeamento de espaço recíproco (Fig. 36) corrobora com o perfil do difratograma, deixando claro a continuidade do parâmetro de rede do substrato nos picos de reflexão (334) e (203) dos filmes $\mathrm{BiFeO}_{3}$ e $\mathrm{SrRuO}_{3}$, respectivamente. 
Figura 35 - Difratograma de raios $X$ (a) das amostras de $\mathrm{BiFeO}_{3}(10-100 \mathrm{~nm}) / \mathrm{SrRuO}_{3} / \mathrm{DyScO}_{3}$ com ênfase na reflexão 110 do substrato de $\mathrm{DyScO}_{3}$ (b) e com ênfase na reflexão 220 do substrato de $\mathrm{DyScO}_{3}$ (c).
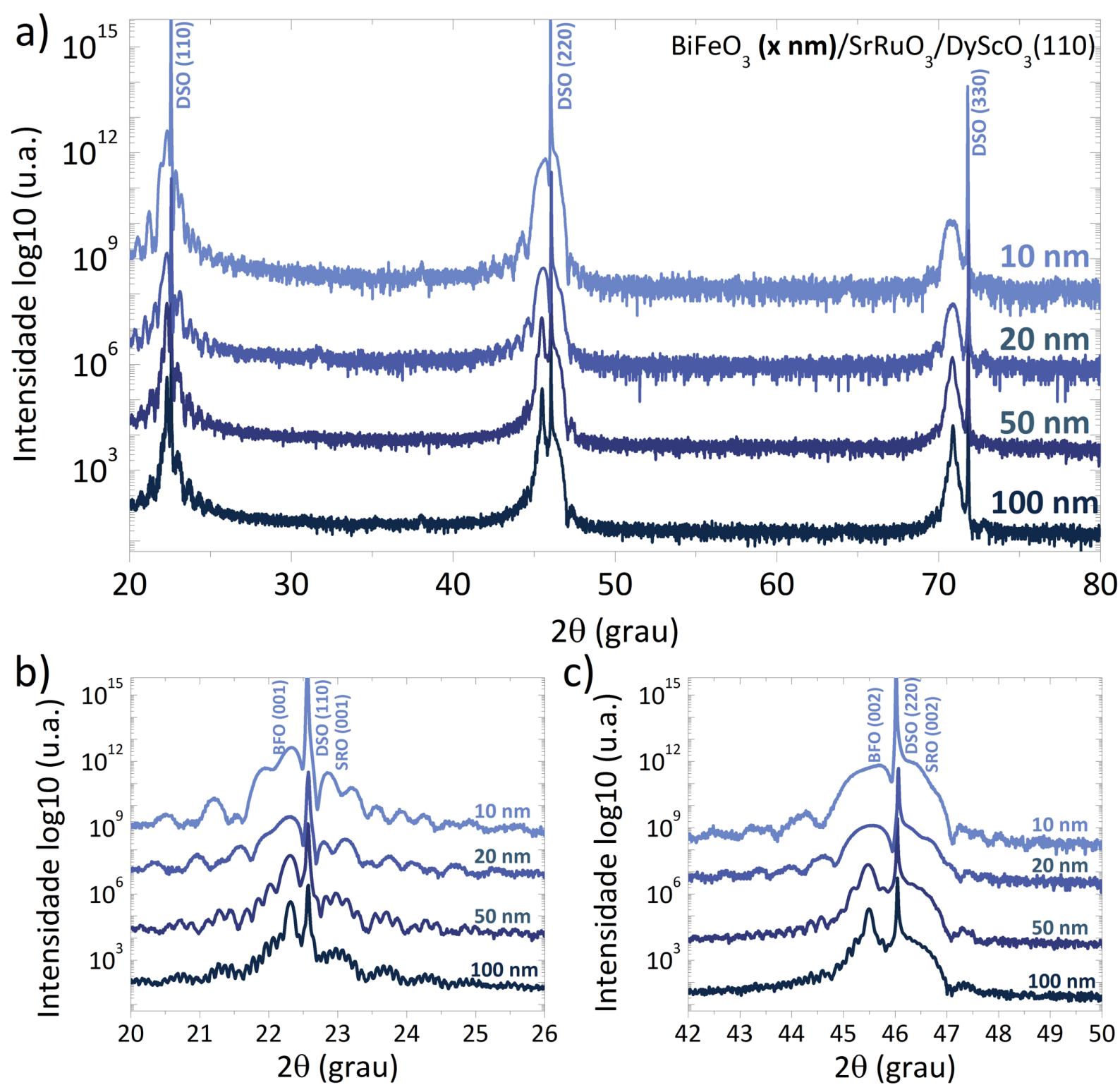

c)

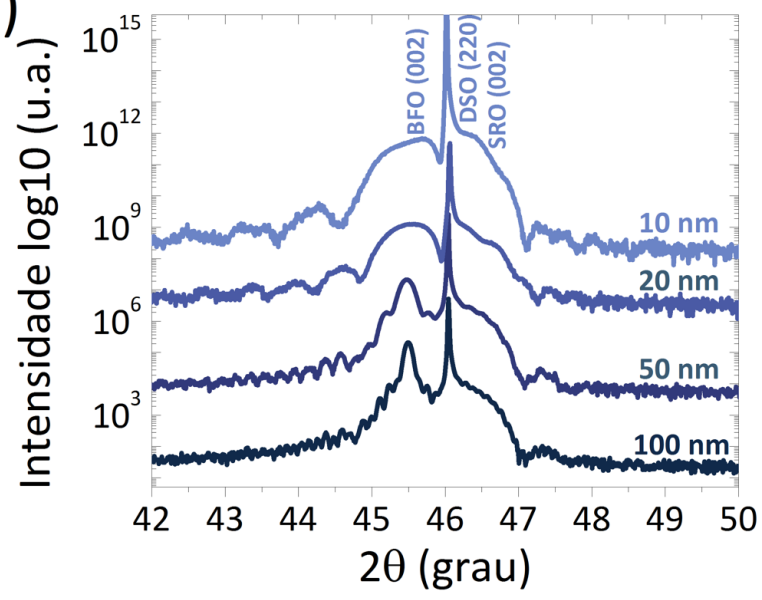


Figura 36 - Mapeamento de espaço recíproco de raios $\mathrm{X}$ da amostra $\mathrm{BiFeO}_{3}(100 \mathrm{~nm}) / \mathrm{SrRuO}_{3} / \mathrm{DyScO}_{3}$ (a) com ênfase nas reflexões (334) do substrato e (203)pc do filme de $\mathrm{BiFeO}_{3}(100 \mathrm{~nm})$.

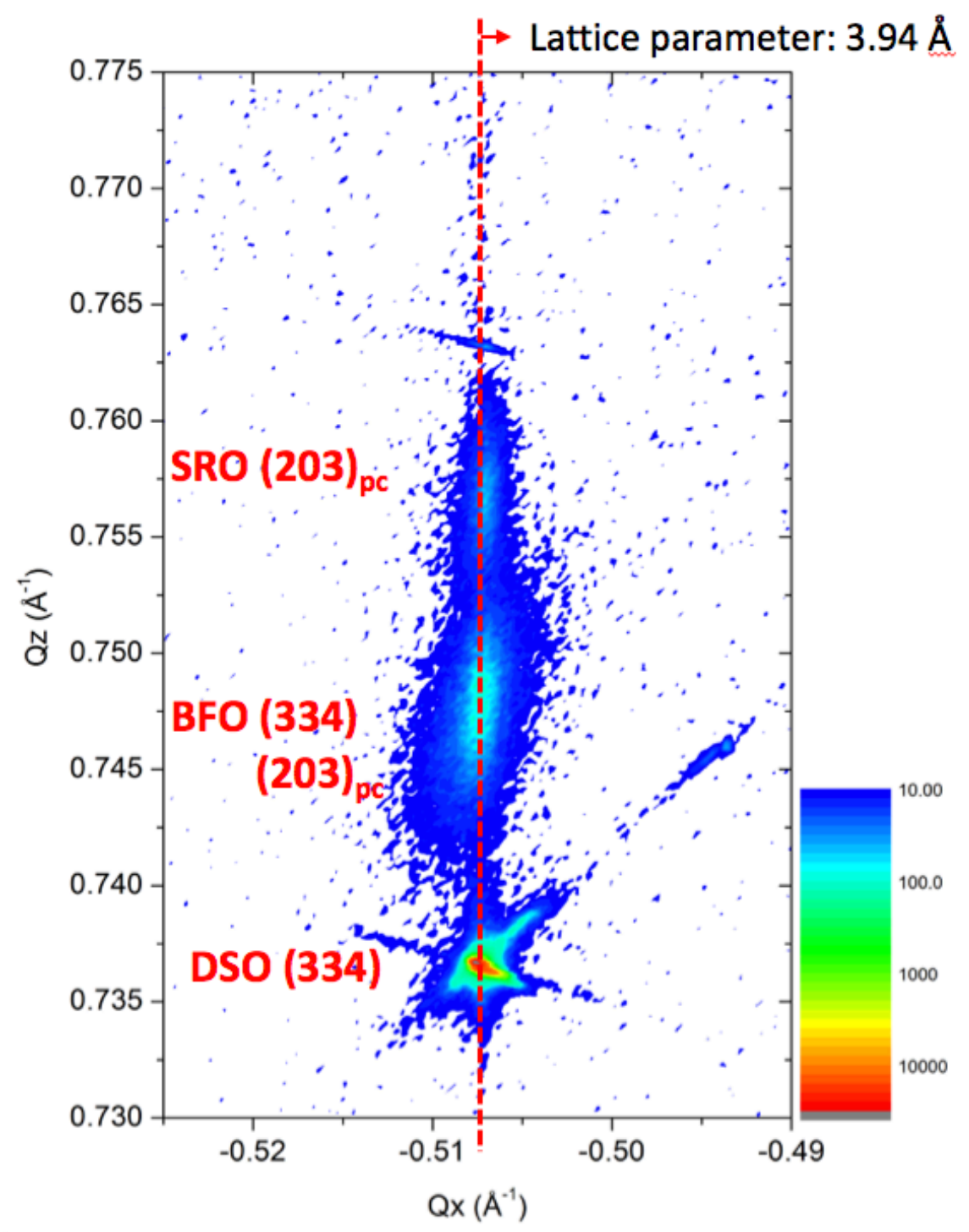




\section{$\mathrm{LaBiFeO}_{3}$}

5.2. Crescimento e caracterização de filmes finos de $\mathrm{LaBiFeO}_{3}$

5.2.1. Topografia e imagem de domínios ferroelétricos por microscopia de força atômica e PFM

A partir da obtenção das informações principais de comportamento e crescimento dos filmes de $\mathrm{BiFeO}_{3}$ pela técnica de deposição por laser pulsado e pela definição de espessura mínima para manutenção de parâmetros epitaxiais e de formação de domínio ferroelétricos, a dopagem destes filmes passou a ser realizada para o estudo da modificação de propriedades elétricas com base na substituição de íons $\mathrm{Bi}^{3+}$ por íons $\mathrm{La}^{3+}$ na estrutura romboédrica da composição multiferroica.

O perfil topográfico das amostras de $\mathrm{Bi}_{0,9} \mathrm{La}_{0,1} \mathrm{FeO}_{3}$ (Fig. 37), crescidas na mesma configuração já descrita para as amostras de $\mathrm{BiFeO}_{3}$, apresenta rugosidade em torno de $0,3 \mathrm{~nm}$, valores da ordem de deslocamentos entre planos atômicos. Uma vez que a presença de domínios no plano pode ser observada pela imagem PFM-IP (Fig. 37), as possibilidades de controle das propriedades ferroelétricas se tornam viáveis do ponto de vista nanotecnológico. 
Figura 37 - Imagens de microscopia de força atômica da topografia, piezoresposta vertical e piezoresposta horizontal de filmes finos de $\mathrm{Bi}_{0,9} \mathrm{La}_{0,1} \mathrm{FeO}_{3}$ com espessura de $20 \mathrm{~nm}$ crescido sobre 10 $\mathrm{nm}$ de $\mathrm{SrRuO}_{3}$ em substratos de $\mathrm{DyScO}_{3}(110)$.

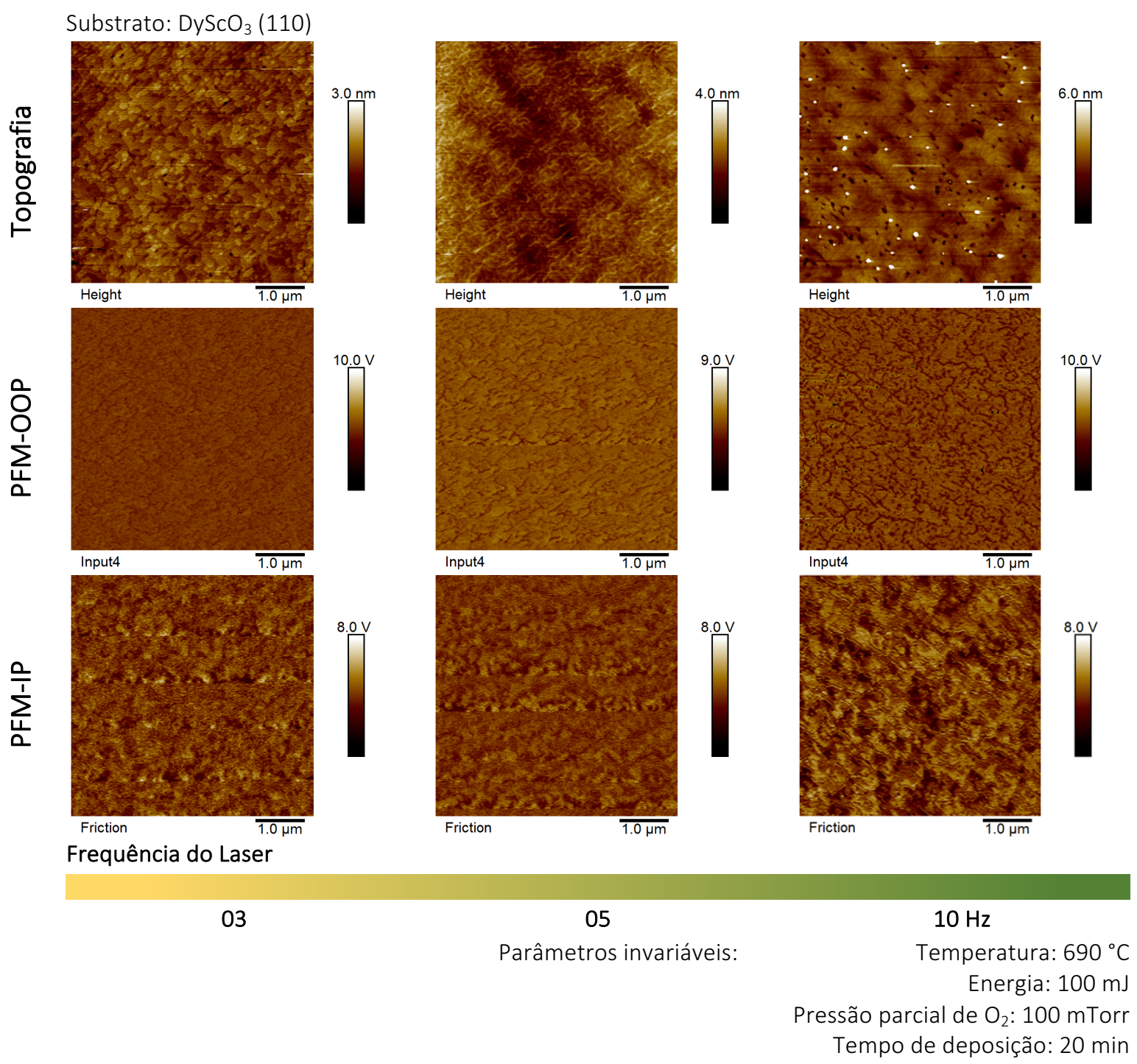

5.2.2. Perfil cristalográfico das amostras de $\mathrm{LaBiFeO}_{3}$

Da mesma forma como observado para as amostras de $\mathrm{BiFeO}_{3}$, as amostras dopadas com lantânio também apresentaram padrões de difração característicos de filmes finos epitaxiais (Fig. 38), mesmo para diferentes parâmetros de crescimento, como no caso da velocidade de deposição pela frequência de pulsos do laser de ablação. 
Figura 38 - Difratogramas de raios $\mathrm{X}$ das amostras de $\mathrm{Bi}_{0,90} \mathrm{La}_{0,10} \mathrm{FeO}_{3} / \mathrm{SrRuO}_{3} / \mathrm{DyScO}_{3}$ crescidos com diferentes frequências de pulso do laser $\left(03,05\right.$ e $10 \mathrm{~Hz}$ ) entre 20 e $80^{\circ} 2 \theta$ (a) e uma ampliação dos picos em torno da reflexão (220) do substrato (b).
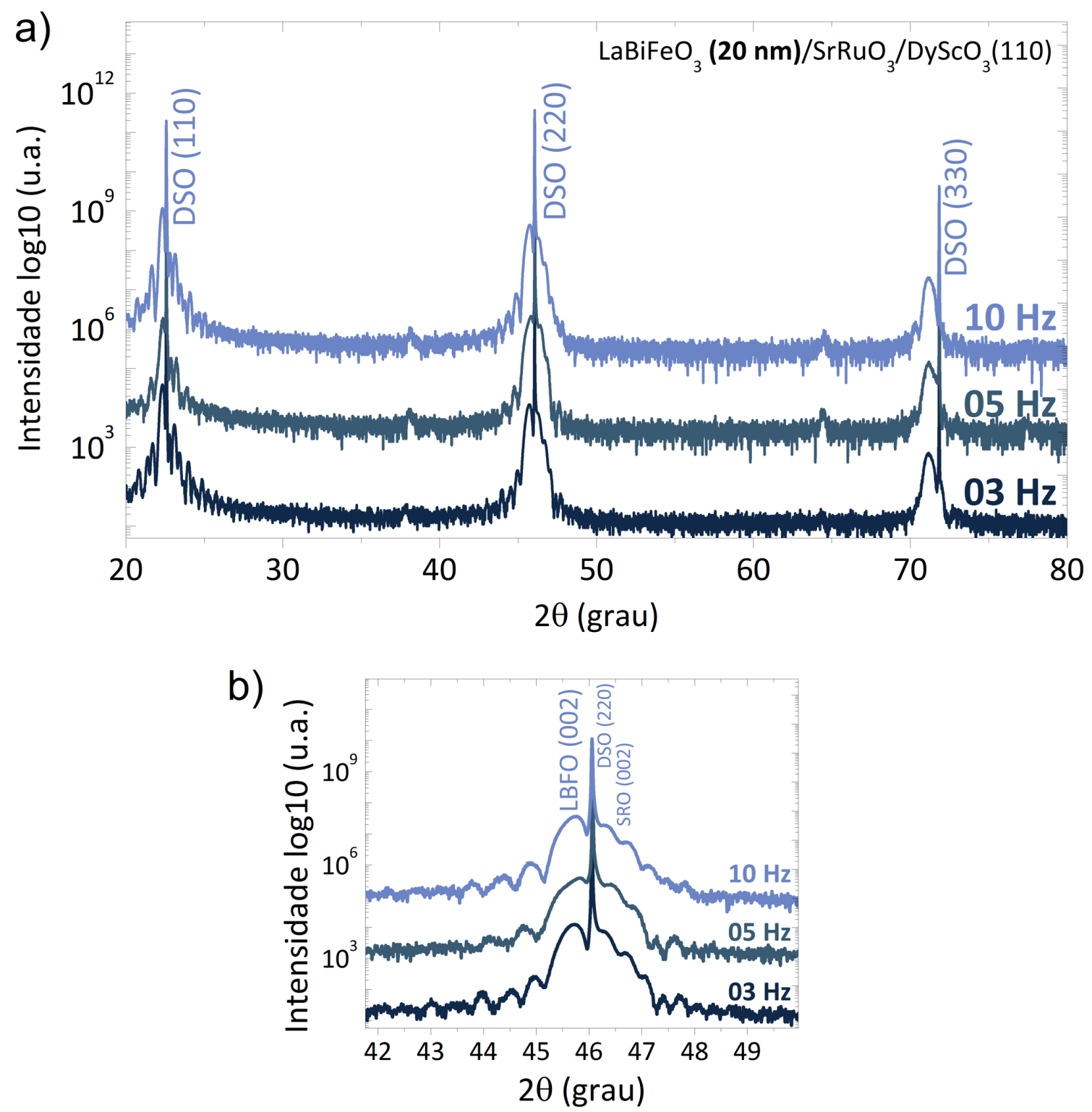

Como forma de testar as condições de epitaxia dos filmes finos obtidos, algumas amostras foram submetidas a diferentes temperaturas de tratamento térmico em forno resistivo após o crescimento sob atmosfera dinâmica de $\mathrm{O}_{2}$. Os resultados de difração por mapeamento de espaço recíproco (Fig. 39) deixam claro o perfil dos sistemas não modificados após cada tratamento, o que pode ser visualizado nas imagens de AFM e PFM da Figura 40. 
Figura 39 - Mapeamento de espaço recíproco (RSM) de raios $X$ das amostra de $\mathrm{Bi}_{0,90} \mathrm{La}_{0,10} \mathrm{FeO}_{3} / \mathrm{SrRuO}_{3} / \mathrm{DyScO}_{3}$ crescidos e posteriormente tratados em diferentes temperaturas após o crescimento sob atmosfera dinâmica de $\mathrm{O}_{2}$.
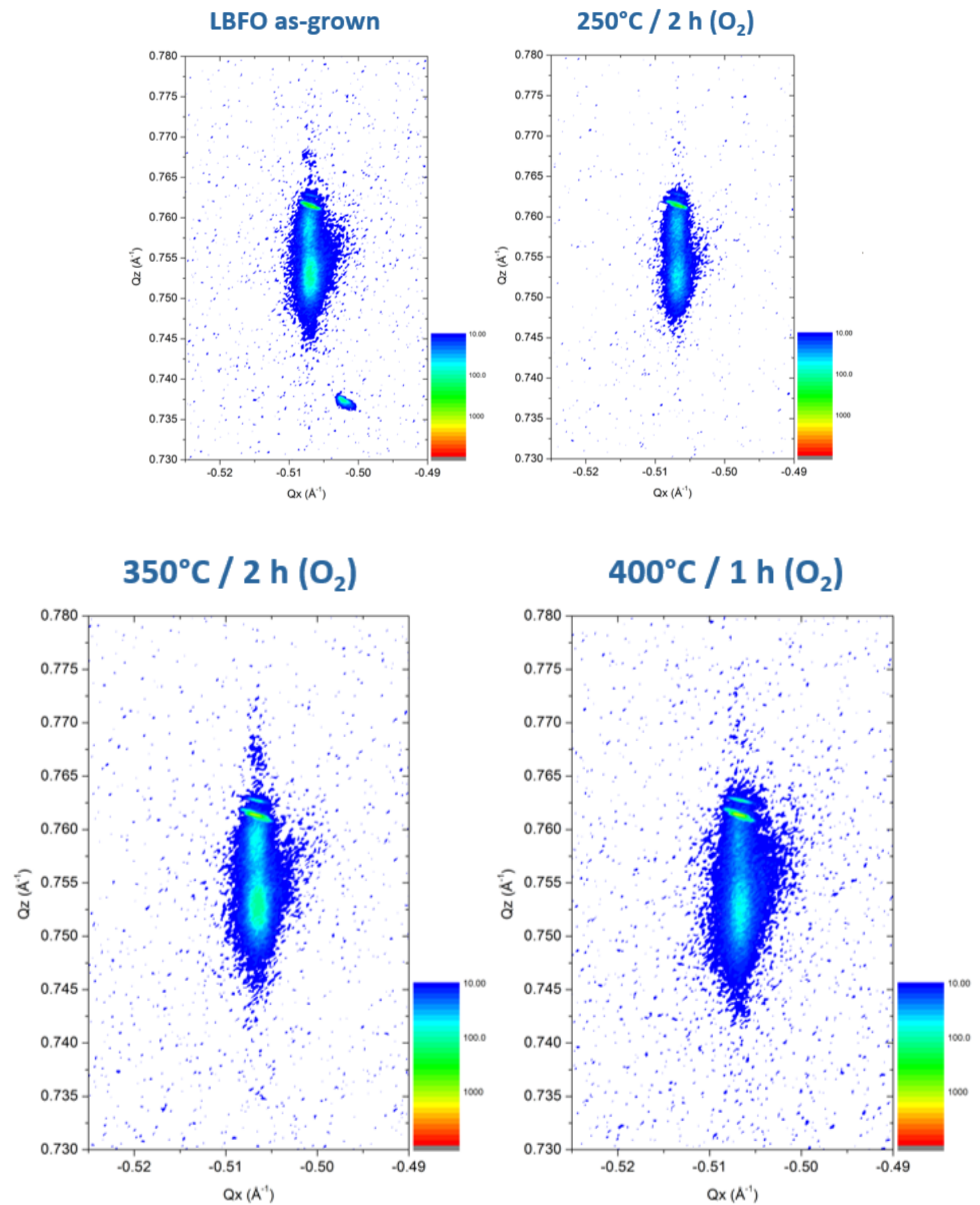
Figura 40 - Imagens de microscopia de força atômica das amostras de $\mathrm{Bi}_{0,90} \mathrm{La}_{0,10} \mathrm{FeO}_{3}$ após diferentes condições de tratamento térmico.

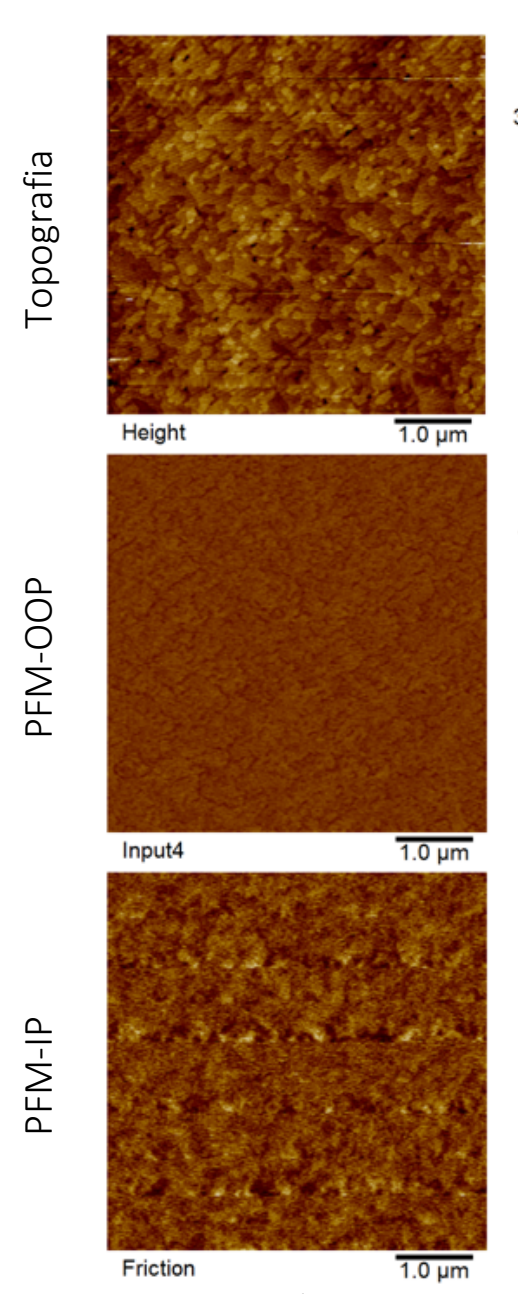

Temperatura de tratamento térmico
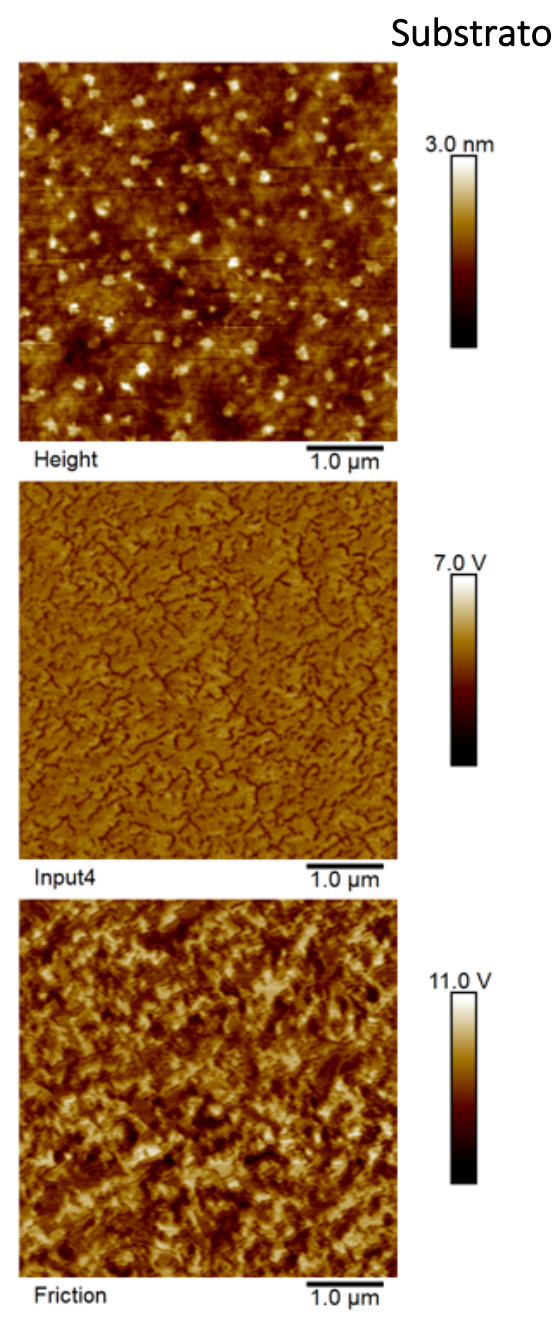
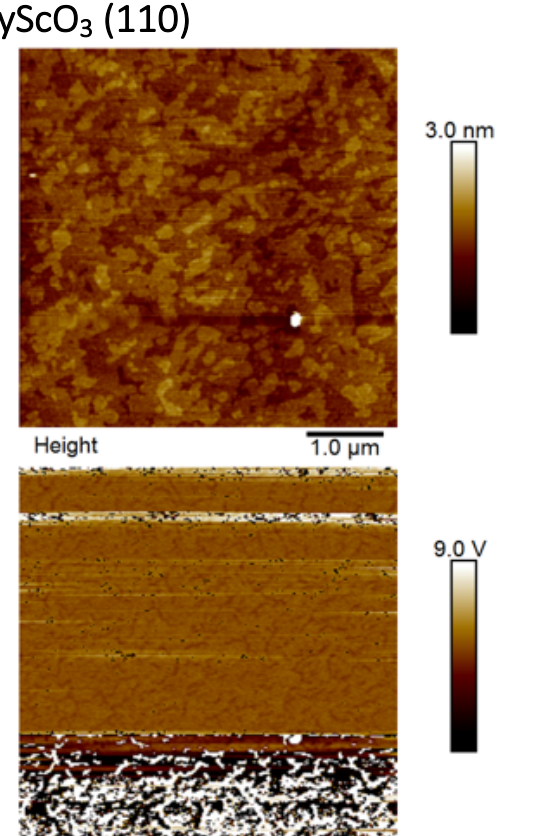

Input4

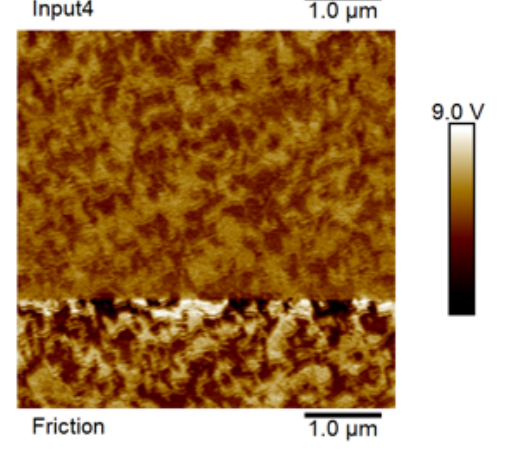

$350^{\circ} \mathrm{C} / 2 \mathrm{~h}$
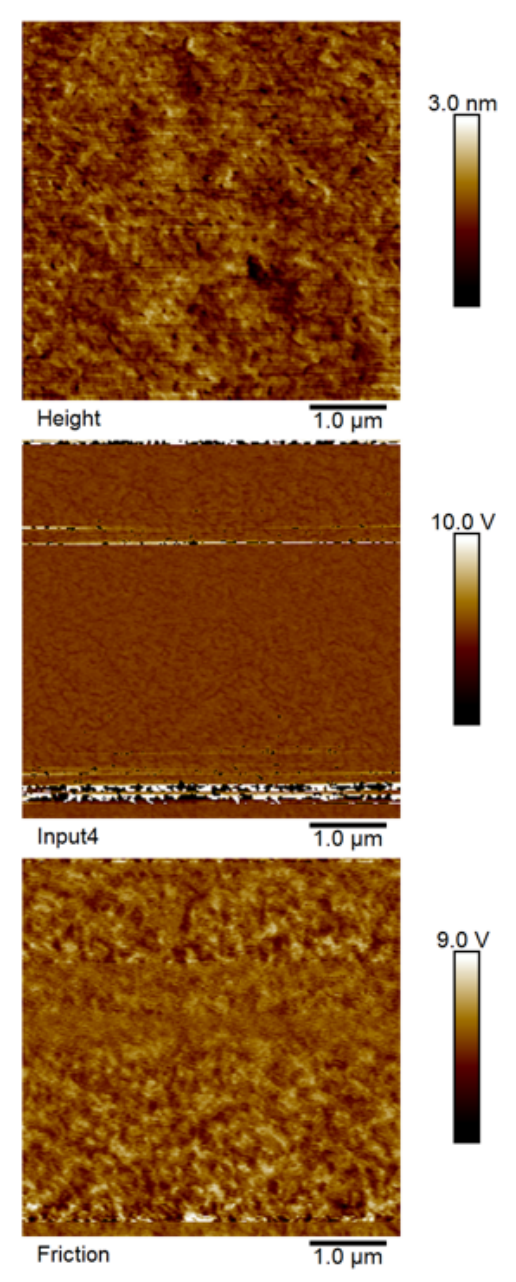

$400^{\circ} \mathrm{C} / 1 \mathrm{~h}$ 
5.2.3. Microscopia eletrônica de transmissão dos filmes de $\mathrm{LaBiFeO}_{3}$

Uma avaliação mais detalhada da estrutura cristalina dos filmes crescidos sobre o substrato faz-se necessária para compreensão e verificação da formação adequada do ordenamento atômico de cada estrutura. É possível observar pelas micrografias de microscopia eletrônica de transmissão (Fig. 41a) e por STEM-HAADF (Fig. 41b) que a formação das camadas é constante, sem a presença de buracos ou defeitos de empilhamento, que são capazes de alterar ou até anular propriedades ferroicas importantes da estrutura cristalina do LBFO. Diferentes magnificações das imagens HAADF podem ser vistas na Figura 42.

A representação da célula unitária de LBFO é apresentada como forma de ilustrar as posições atômicas identificadas pelos contrastes claros da imagem de microscopia eletrônica de transmissão por varredura em modo de campo escuro anular de alto ângulo (HAADF) (Fig. 43a). Fica evidente a polarização da estrutura pela descentralização do átomo de Fe localizado no sítio $\mathrm{B}$, pelo deslocamento dos pares isolados do $\mathrm{Bi}$ e da rotação do octaedro de oxigênio da estrutura, como mostrado na Figura 43b e ilustrado na Fig. 43c.

A polarização espontânea característica de materiais ferroicos deve-se a fatores estruturais e de simetria que permitem o deslocamento do átomo central da célula unitária para uma das posições menos energéticas e distorções de campo cristalino entre os orbitais $p$ dos átomos de oxigênio no octaedro e os orbitais $d$ do átomo metálico central. No caso do $\mathrm{BiFeO}_{3}$, o principal mecanismo de polarização deve-se ao deslocamento das nuvens eletrônicas dos pares isolados do $\mathrm{Bi}^{3+}$ no sítio A da estrutura.(YANG et al., 2014) 
Figura 41 - Micrografia de microscopia eletrônica de transmissão de alta resolução da seção transversal da amostra de $\mathrm{Bi}_{0,90} \mathrm{La}_{0,10} \mathrm{FeO}_{3} / \mathrm{SrRuO}_{3} / \mathrm{DyScO}_{3}(\mathrm{a})$ e imagem de STEM em modo HAADF da estrutura cristalina do filme $\mathrm{Bi}_{0,90} \mathrm{La}_{0,10} \mathrm{FeO}_{3}$ (b)

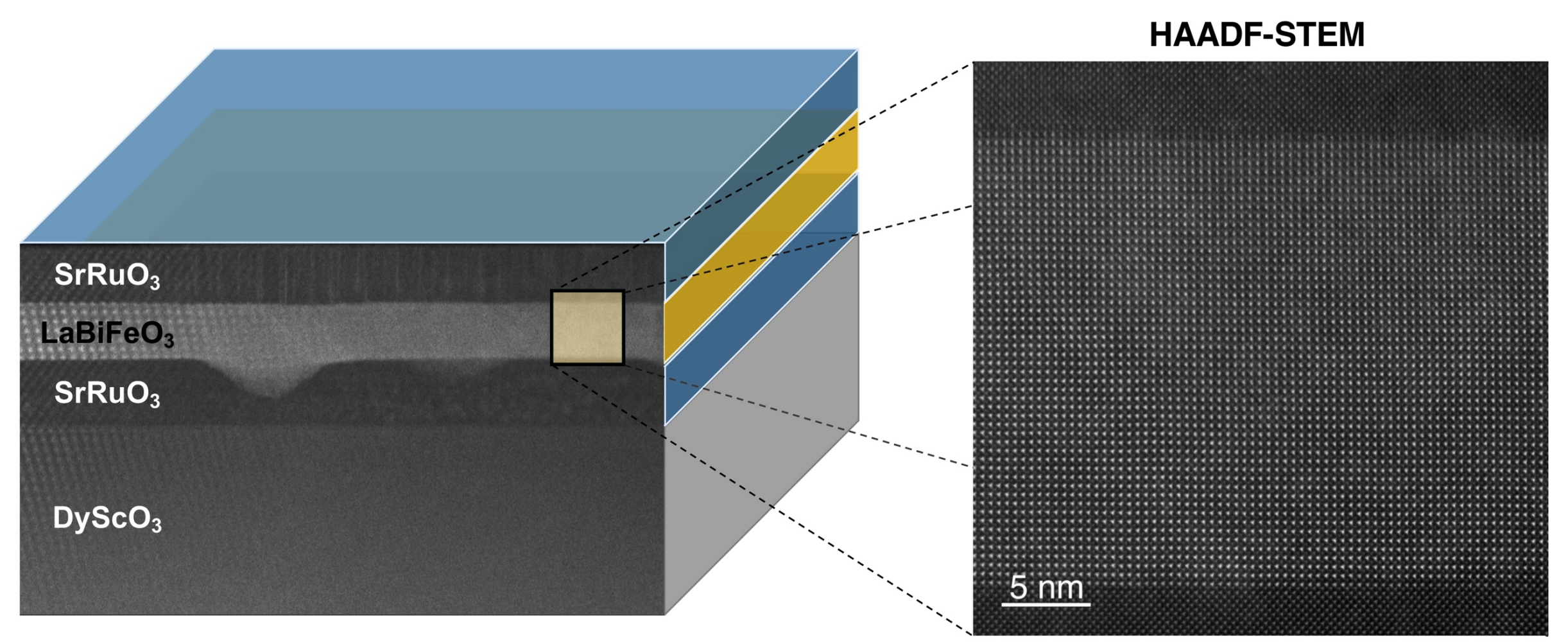

(a)

(b) 
Figura 42 - Micrografia de microscopia eletrônica de transmissão de alta resolução da seção transversal da amostra de $\mathrm{Bi}_{0,90} \mathrm{La}_{0,10} \mathrm{FeO}_{3} / \mathrm{SrRuO}_{3} / \mathrm{DyScO}_{3}$ em diferentes magnificações.
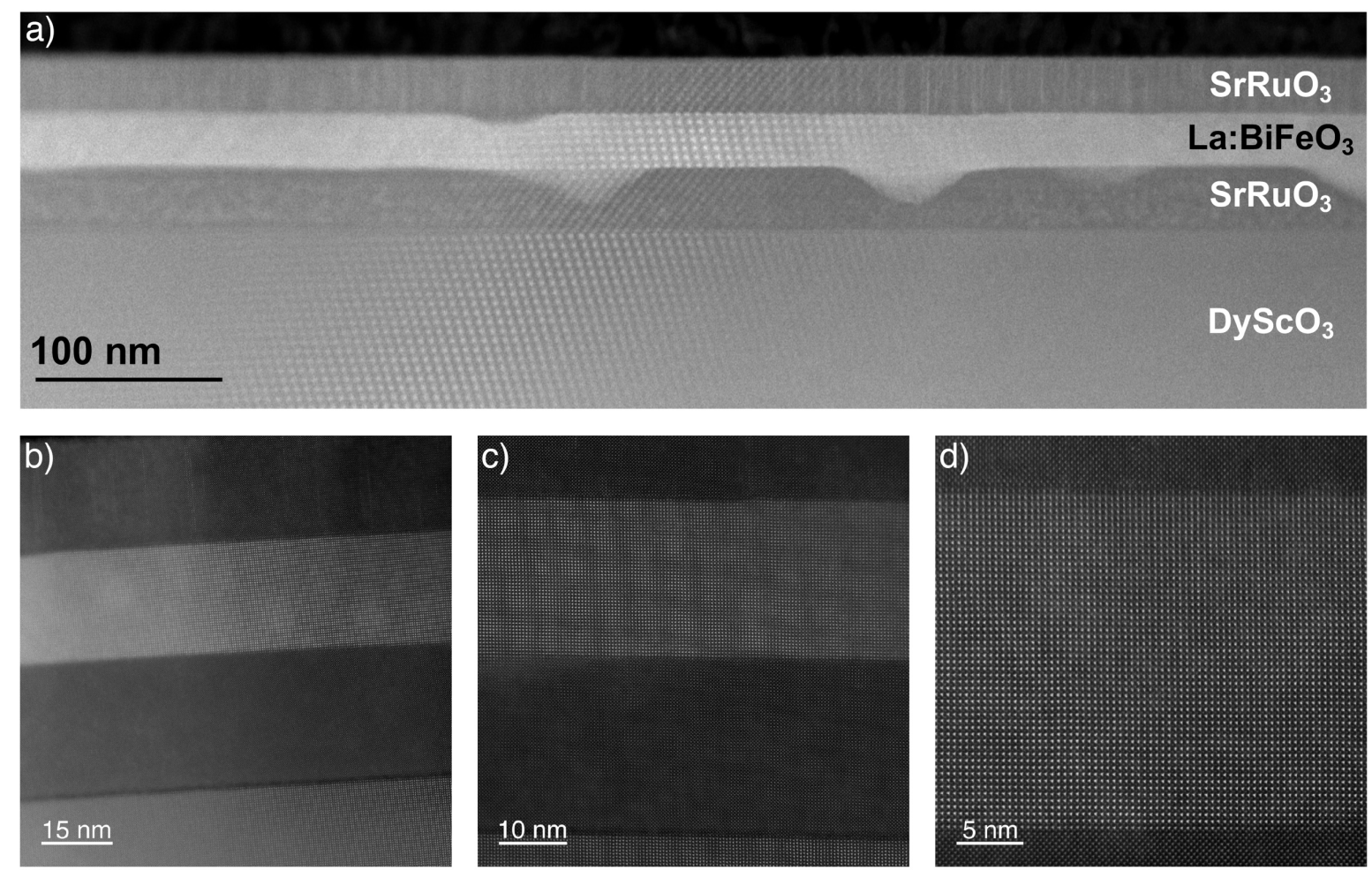

Figura 43 - Micrografia de microscopia eletrônica de transmissão de alta resolução da seção transversal da amostra de $\mathrm{Bi}_{0,90} \mathrm{La}_{0,10} \mathrm{FeO}_{3} / \mathrm{SrRuO}_{3} / \mathrm{DyScO}_{3}(\mathrm{a})$, imagem de STEM em modo HAADF da estrutura cristalina do filme $\mathrm{Bi}_{0,90} \mathrm{La}_{0,10} \mathrm{FeO}_{3}$ (b) e sua respectiva representação de célula unitária (c).

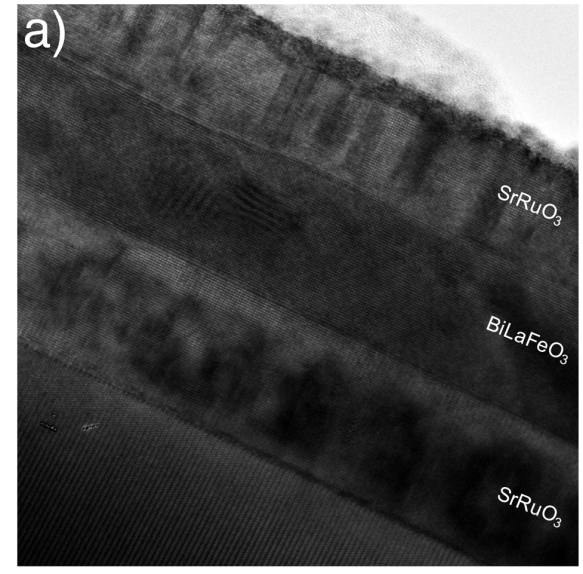

(a)

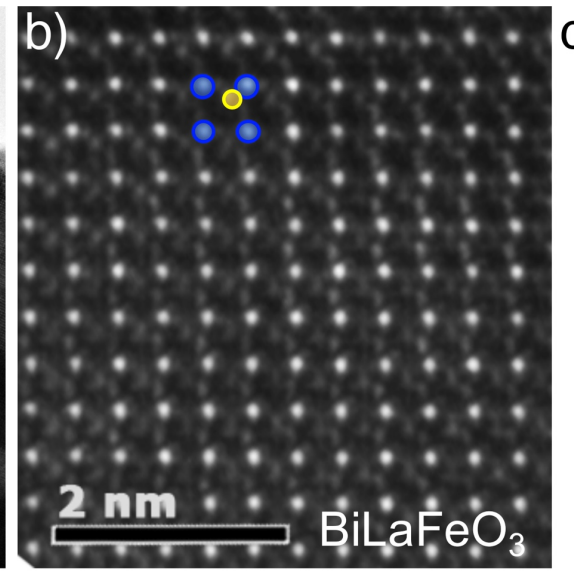

(b)

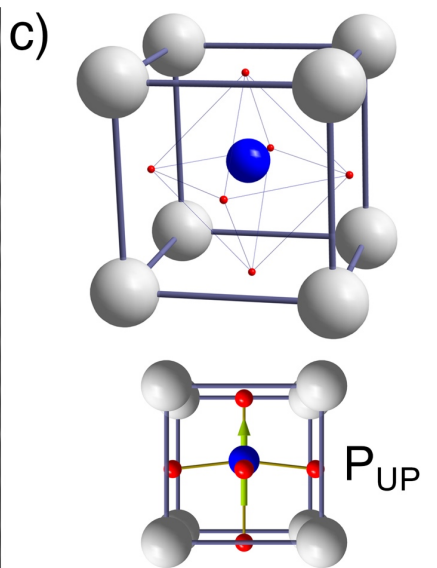

(c) 
5.2.4. Piezo deslocamento medido por coeficiente de piezoresposta do tensor $d_{33}$

Como forma de provar a existência de ferroicidade na estrutura do LBFO com $20 \mathrm{~nm}$ de espessura, ensaios de piezoeletricidade foram realizados com o auxílio de um microscópio de força atômica adaptado para medidas elétricas de coeficiente $d_{33}$. Curvas de piezoresposta foram obtidas nas amostras com capacitores de 8 micrômetros (Fig. 26) de diâmetro mostrando valores de coercividade em frequências baixas em torno de 0,15-0,18 V, como pode ser observado nas Figuras 44-46.

De forma clara, estes valores de coercividade indicam a possibilidade de alteração de estados de polarização (up e down) extremamente baixos (<0,2 V). Estes dados são uma das maiores contribuições deste trabalho até o momento, uma vez que valores de coercividade para materiais multiferroicos convencionais publicados até o momento são da ordem de 2 a 6 volts.

Como mencionado na introdução desse trabalho, a busca por materiais BFO com propriedades multiferroicas que possam se acoplar e controlar sistemas magnéticos com o uso de campo elétrico é a chave para a criação de novos dispositivos de memória lógica.

O comportamento piezoelétrico das amostras LBFO de $20 \mathrm{~nm}$ de espessura sob excitação com aplicação de corrente $\mathrm{AC}$ de $0,1 \mathrm{~V}$ e 0,03 V, ambos usando $2 \mathrm{kHz}$, indicou valores muito interessantes de voltagem coerciva. Esta é a primeira vez que valores de coercividade elétrica, próximos da ordem de 0,15 V foram observados nos sistemas multiferroicos de $\mathrm{LaBiFeO}_{3}$ (Fig. 46). 
Figura 44 - Curvas de resposta piezoelétrica por coeficiente $d_{33}$ registrados em fase $(a, c, e, g)$ e amplitude de deslocamento (b,d,f,h) do sistema $\mathrm{Bi}_{0,90} \mathrm{La}_{0,10} \mathrm{FeO}_{3}(20 \mathrm{~nm}) / \mathrm{SrRuO}_{3}(10 \mathrm{~nm}) / \mathrm{DyScO}_{3}$ variando passo de aquisição entre $0,2 \mathrm{~V}$ e 0,01 V.

a)

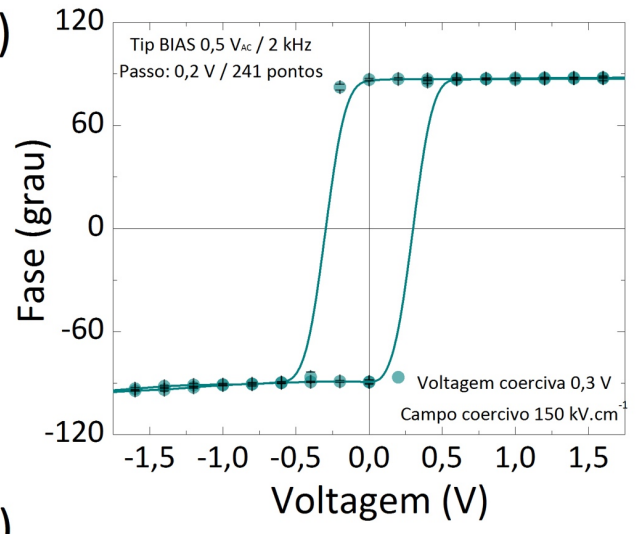

b)

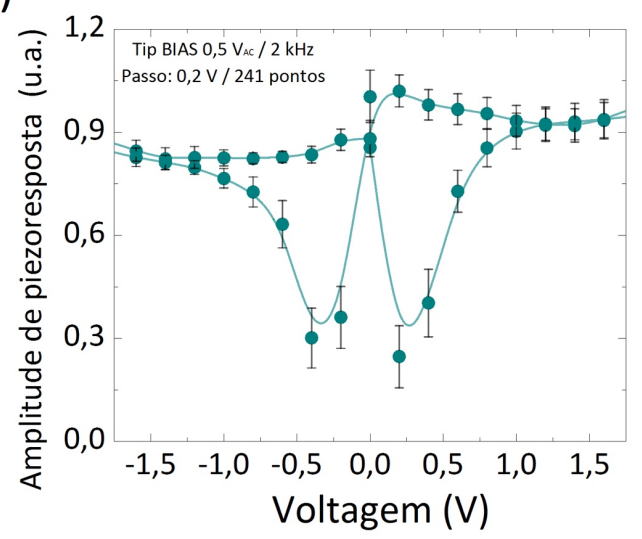

e)

$120 \operatorname{T}_{\text {Tip BIAS 0,5 Vac } / 2 \mathrm{kHz}}^{\text {Passo: } 0,05 \mathrm{~V} / 401 \text { ponto }}$

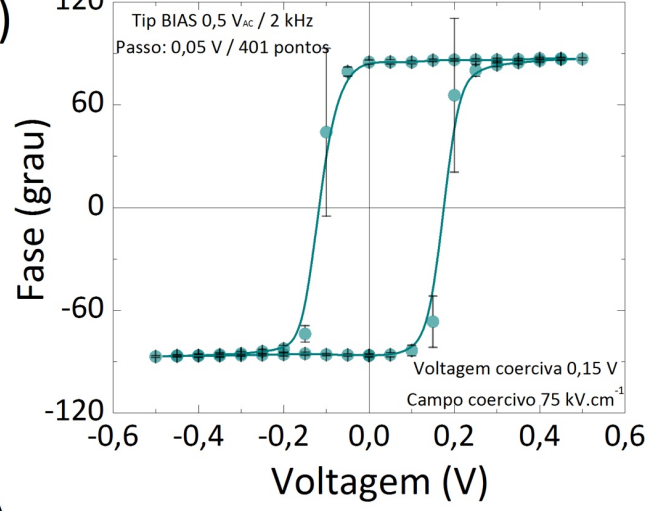

f)

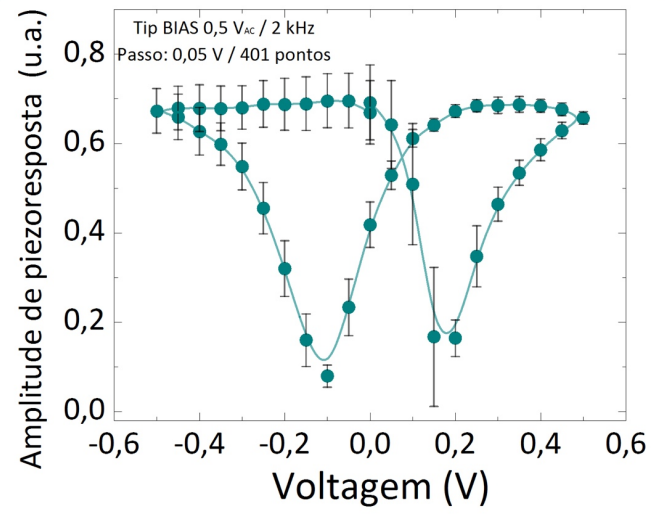

c)

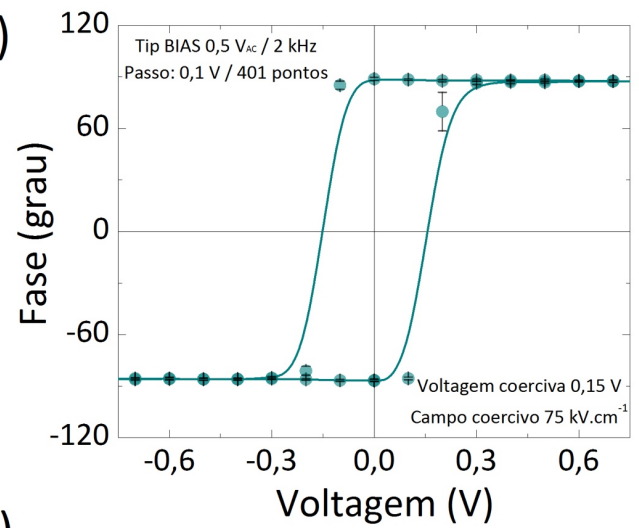

d)

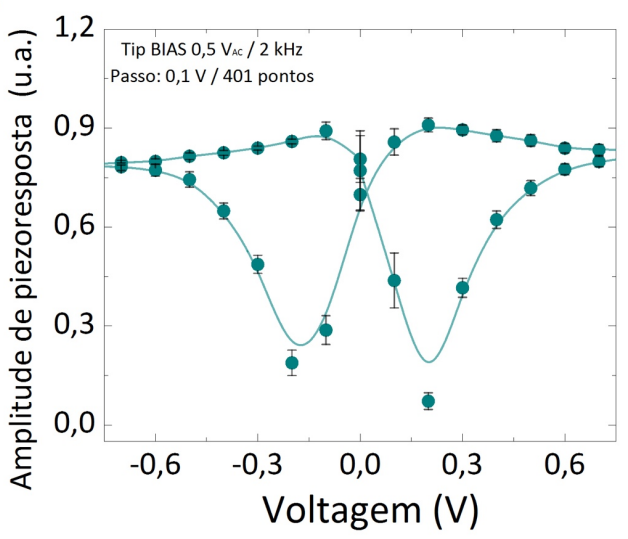

g)

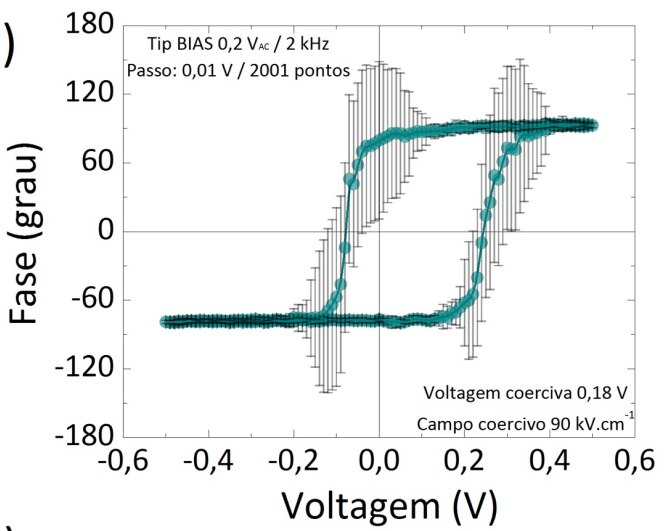

h)

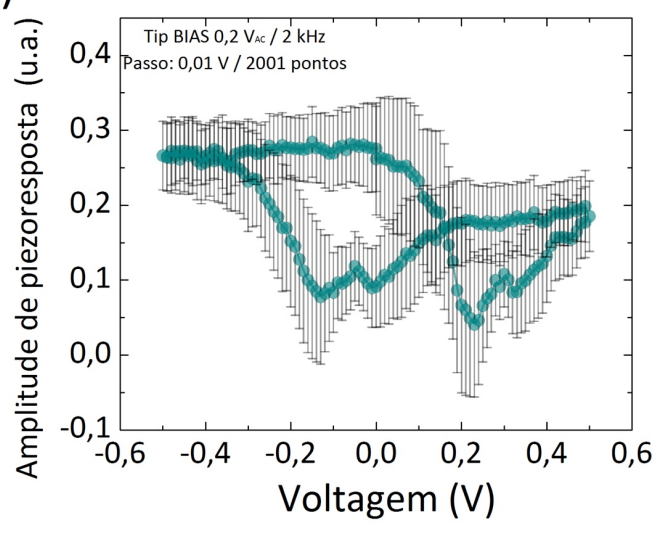


Figura 45 - Curvas de resposta piezoelétrica por coeficiente $d_{33}$ registrados em fase $(a, c)$ e amplitude de deslocamento (b,d) do sistema $\mathrm{Bi}_{0,90} \mathrm{La}_{0,10} \mathrm{FeO}_{3}(20 \mathrm{~nm}) / \mathrm{SrRuO}_{3}(10 \mathrm{~nm}) / \mathrm{DyScO}_{3}$ variando tensão $\mathrm{AC}$ senoidal de $0,4 \vee$ e $0,3 \vee$ aplicadas ao cantilever.
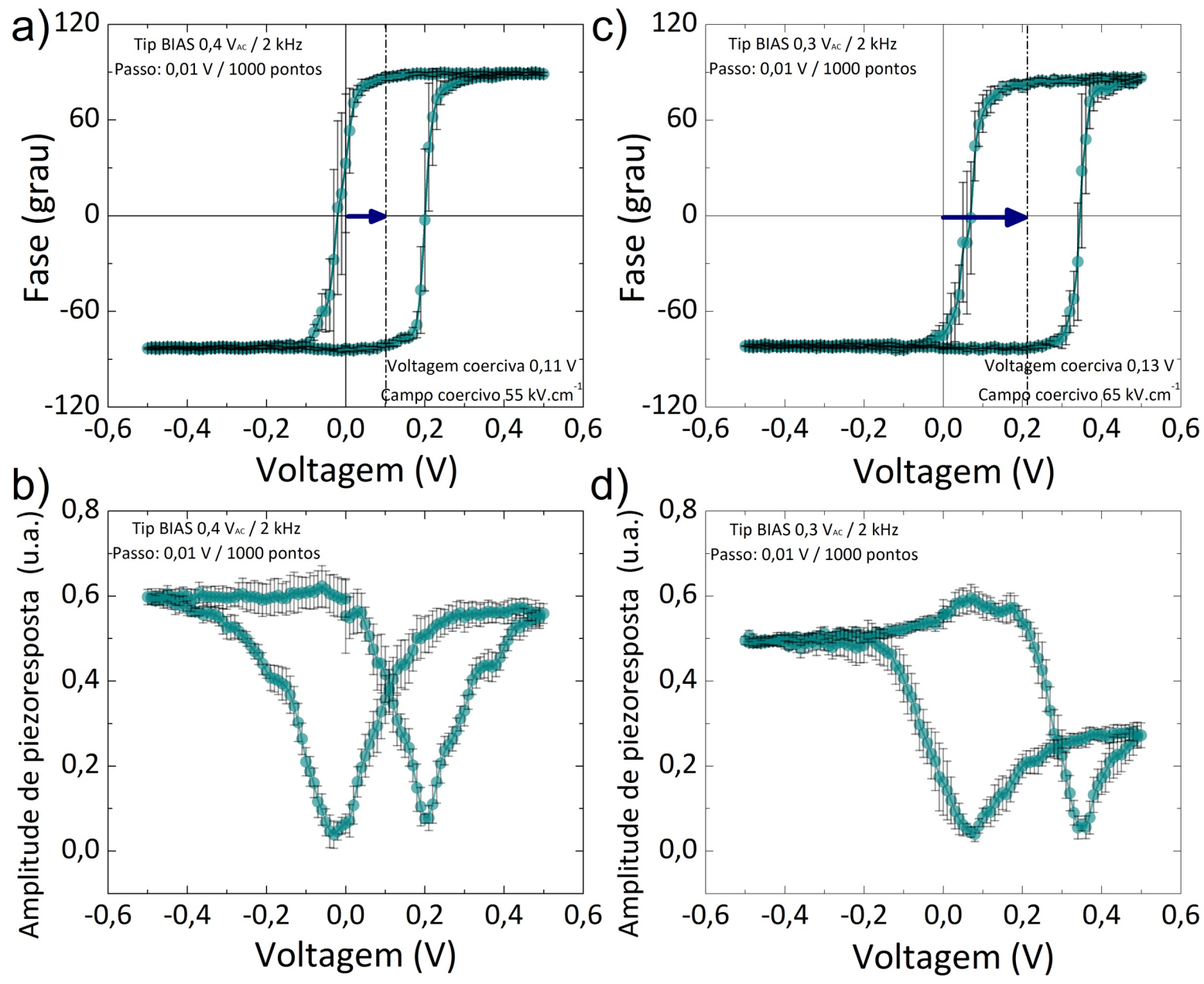


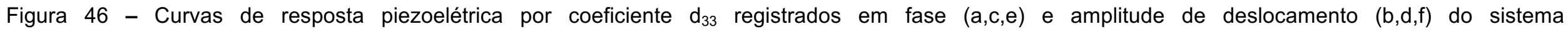
$\mathrm{Bi}_{0,90} \mathrm{La}_{0,10} \mathrm{FeO}_{3}(20 \mathrm{~nm}) / \mathrm{SrRuO}_{3}(10 \mathrm{~nm}) / \mathrm{DyScO}_{3}$ variando a voltagem $\mathrm{AC}$ bias aplicada ao cantilever.
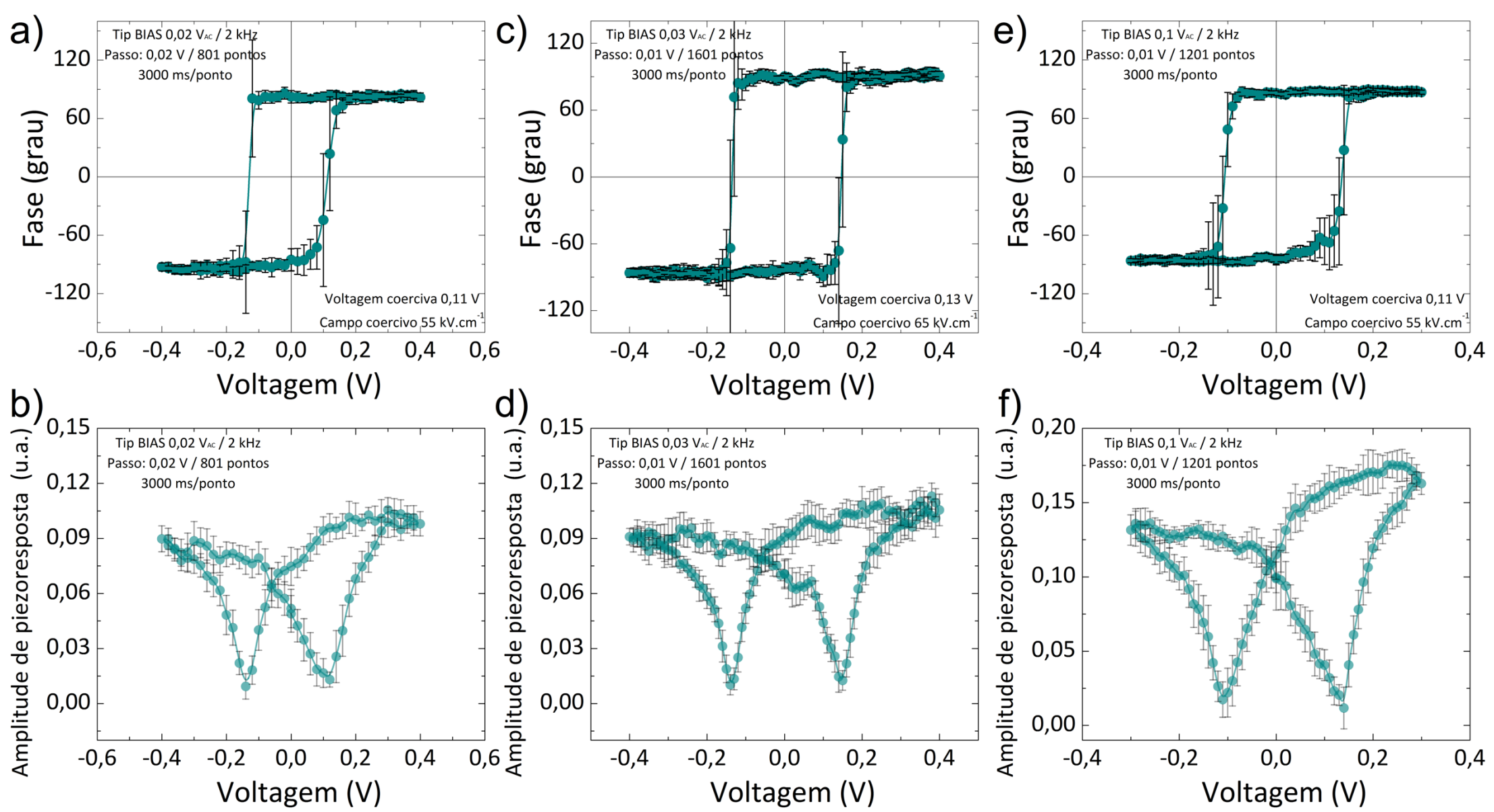
5.2.5. Dicroísmo circular magnético de raios $X$ e dicroísmo linear magnético de raios $X(X M C D$ e XMLD)

As amostras de filmes finos de $\mathrm{LaBiFeO}_{3}$ foram avaliadas por dicroísmo linear e circular medido por XMLD e XMCD. Todas as medidas foram realizadas em diferentes temperaturas em ângulo rasante para $20 \mathrm{~nm}$ de camada multiferroica na banda $L_{2}$ e $L_{3}$ do ferro.

Entende-se como material multiferroico aquele com o acoplamento entre pelo menos duas ordens ferroicas, no caso do $\mathrm{BiFeO}_{3}$, sabemos que a polarização elétrica está intimamente relacionada com a polarização magnética pelas equações 2 e 3 citadas anteriormente. Como parte deste trabalho, foi verificado a estrutura magnética destes compostos e como pode ser observado pelos espectros de absorção na borda $L_{2}$ e $L_{3}$ do $\mathrm{Fe}$, a resposta assimétrica do dicroísmo linear confirma o ordenamento antiferromagnético para a estrutura do $\mathrm{LaBiFeO}_{3}$ (Fig. 47a).

Calculando a integração dos picos de assimetria "A" (Fig. 47b) nos espectros para a amostra de LBFO, foi possível encontrar uma aproximação da temperatura de Néel para esta composição da ordem de 543 a 566 K (Fig. 47c), bem acima da temperatura de outros materiais antiferromagnéticos da classe dos materiais multiferroicos.

A presença do ordenamento magnético em temperatura ambiente na estrutura de filmes finos de LBFO torna-os atrativos para aplicação em dispositivos eletrônicos. 
Figura 47 Espectros de absorção de raios $X$ na borda $L_{2}$ e $L_{3}$ do Fe sob dicroismo linear (a) e circular (c) magnético de raios $\mathrm{X}$ para a amostra de $\mathrm{LaBiFeO}_{3}$, o perfil de assimetria de XMLD (b) e a curva de comportamento antiferromagnético em função da temperatura (d) obtida pelo ajuste e integração do pico A indicado na imagem.
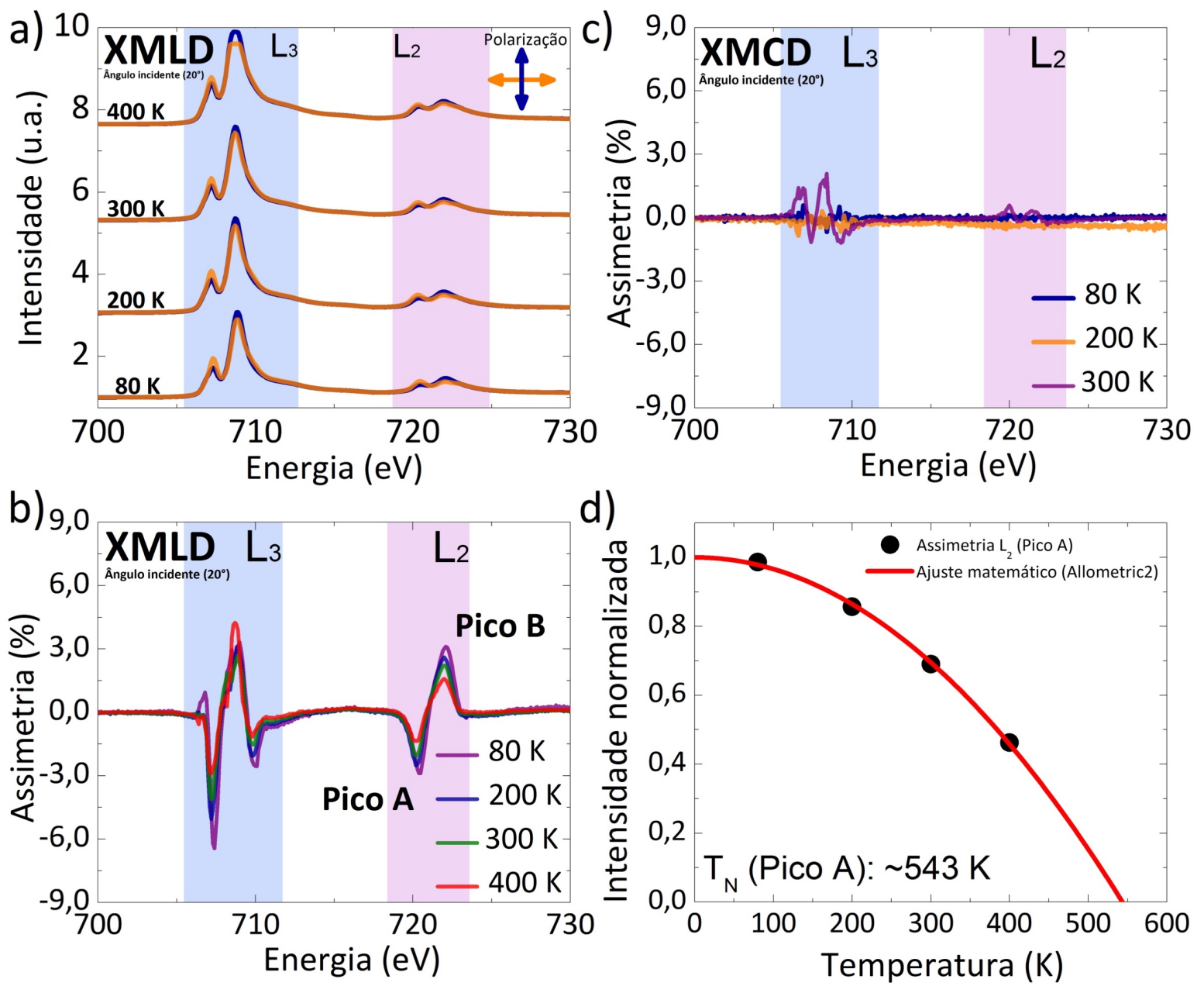

d)

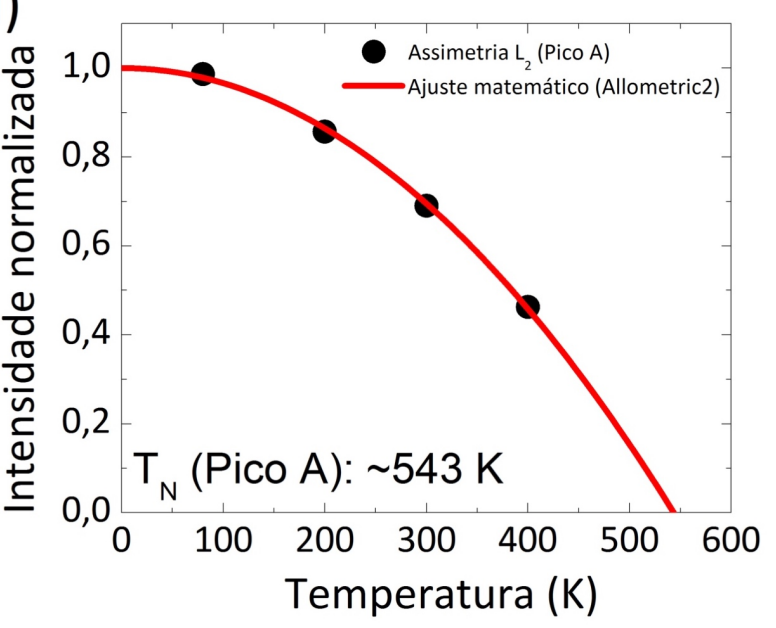


Assim como é importante observar a resposta do comportamento de absorção do ferro sob diferentes polarizações lineares de raios $X$ para identificação de fase antiferroelétrica no sistema LBFO, a falta de resposta de absorção na presença de polarização circular $(\mathrm{XMCD})$ garante que não há presença de comportamento ferroelétrico, o que corrobora para os resultados obtidos por XMLD e os cálculos de aproximação de temperatura de Néel.

5.2.6. Polarização elétrica de filmes finos de $\mathrm{Bi}_{0,90} \mathrm{La}_{0,10} \mathrm{FeO}_{3}$

\subsubsection{Ensaios de histerese elétrica por curvas P-E}

Todos os ensaios elétricos realizados nas amostras de LBFO foram submetidos a tratamentos estatísticos convencionais, as curvas de histerese ferroelétrica para filmes com espessuras $20 \mathrm{~nm}$ medidas em diferentes frequências estão mostradas na Figura 48(a-e). Medidas de corrente de fuga também foram realizadas nos mesmos capacitores usados para as medidas ferroelétricas (Fig. 48f). 
Figura 48 - Curvas de histerese ferroelétrica das amostras de LBFO $(20 \mathrm{~nm})$ em diferentes frequências.
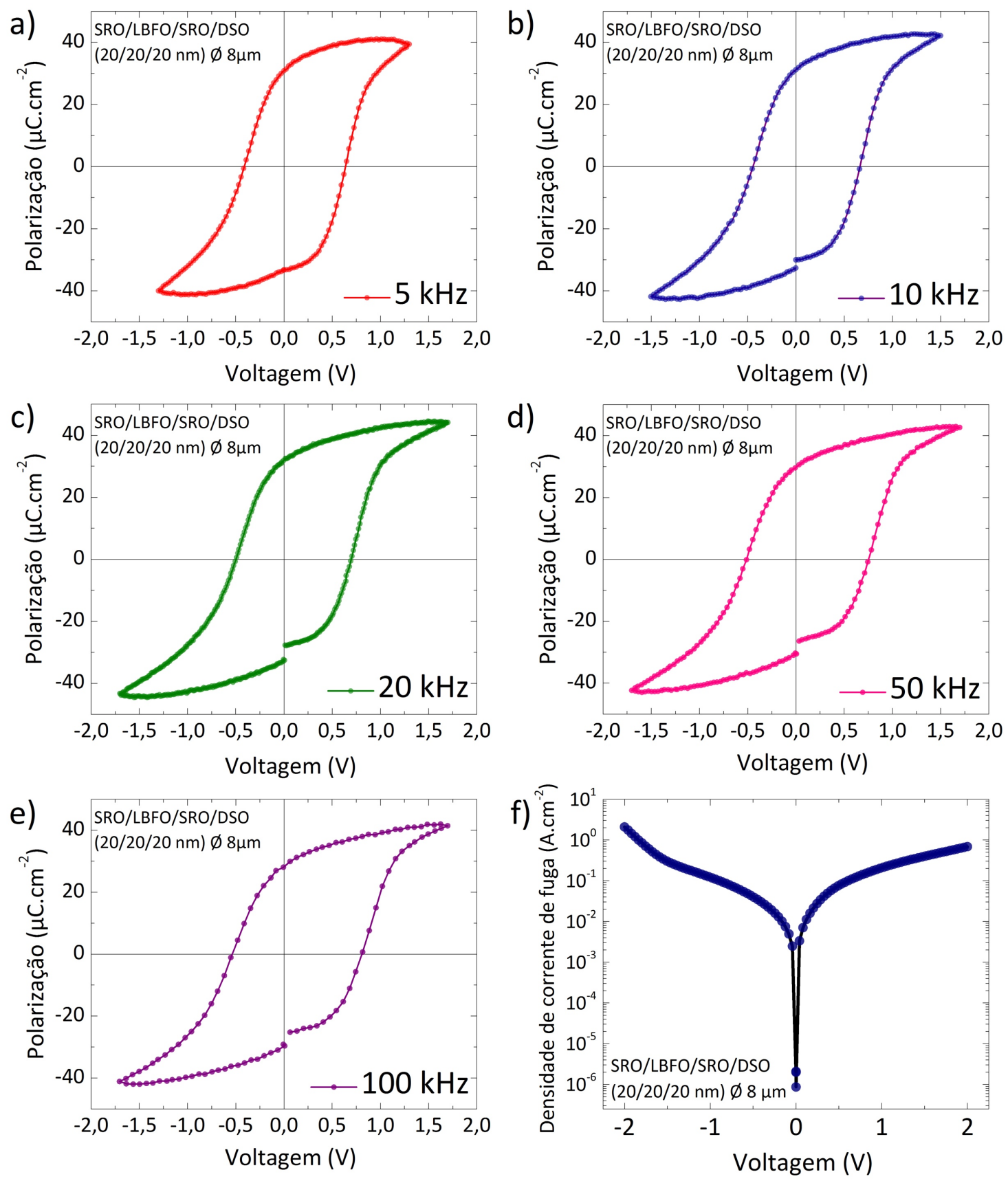

Com comportamento característico de material ferroelétrico, as curvas de histerese do LBFO (20 nm) apresentaram polarização de saturação próximo de $40 \mu \mathrm{C} . \mathrm{cm}^{-2}$ e coercividade elétrica $V_{C}$ próxima de $0,5 \mathrm{~V}$, muito abaixo dos valores convencionais da ordem de 2 a $6 \mathrm{~V}$ encontrados para materiais ferroelétricos. 


\subsubsection{Ensaios de polarização elétrica dinâmica por (PUND)}

Ensaios de polarização elétrica dinâmicos (PUND - Positive UP Negative DOWN) foram realizados em estações de teste com sistemas do tipo Radiant tester. As configurações de pulso aplicadas em cada teste estão descritas nos esquemas apresentados no capítulo Materiais e Métodos.

Os valores de polarização dinâmicos em função da tensão aplicada através do filme podem ser vistos na Figura 49. A dinâmica de saturação dos estados polarizados torna-se mais rápida a medida que o valor de campo elétrico aumenta.

Figura 49 - Gráfico do ensaio de PUND da polarização 2P para diferentes durações de pulsos com diferentes valores de tensão da amostra LBFO de $20 \mathrm{~nm}$.

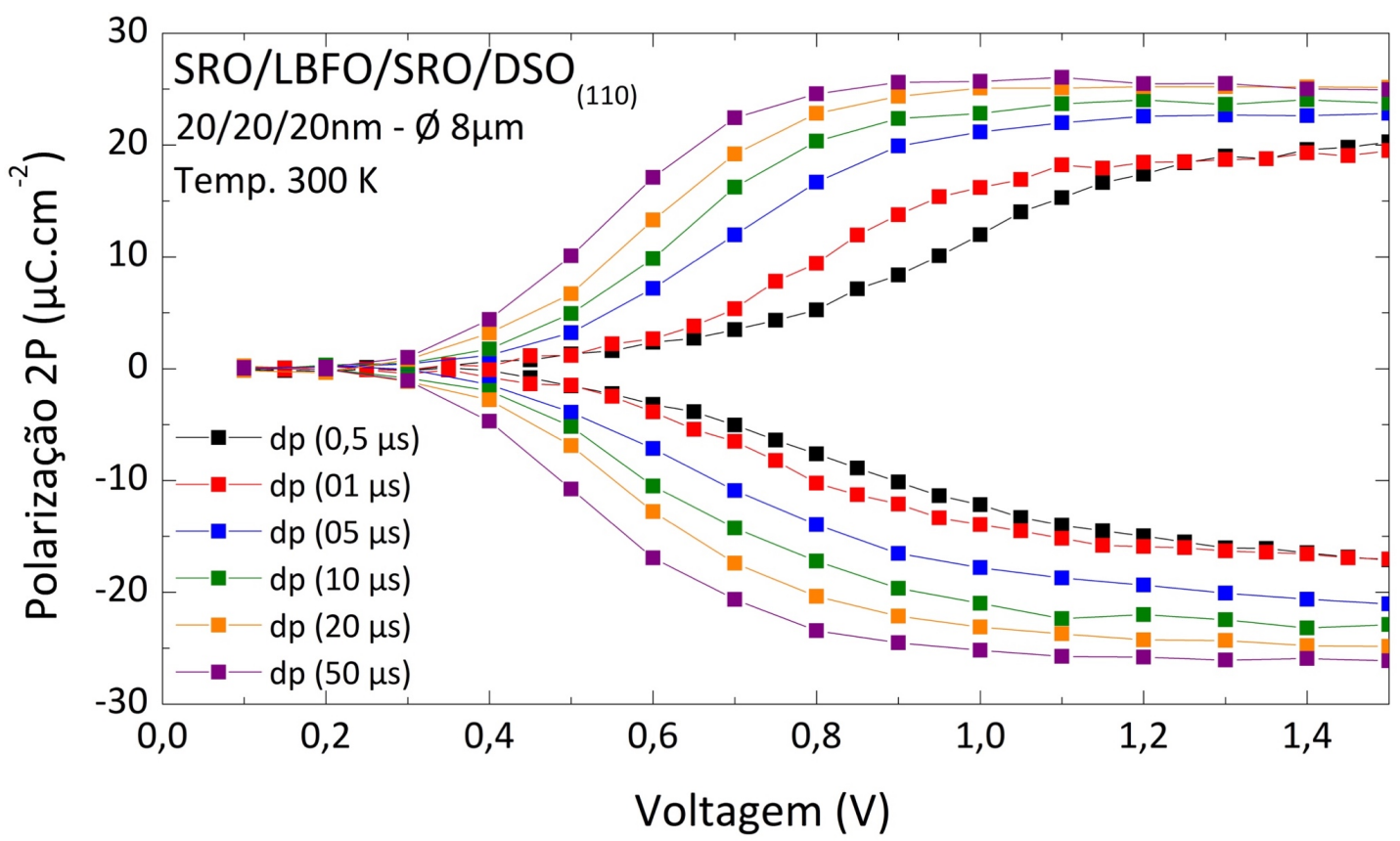

Medidas de polarização elétrica em função da temperatura também foram realizadas nas amostras de LBFO $(20 \mathrm{~nm})$, como indicado na Figura 50. 
Como já observado na literatura, a dependência do comportamento ferroelétrico em função da temperatura está intimamente ligada às características da estrutura cristalina e sua resposta à energia de fônon no sistema.

Figura 50 - Curvas de histerese ferroelétrica tomadas nas frequências de 10, 20 e $100 \mathrm{kHz}$ das amostras de LBFO $(20 \mathrm{~nm})$ em diferentes temperaturas.
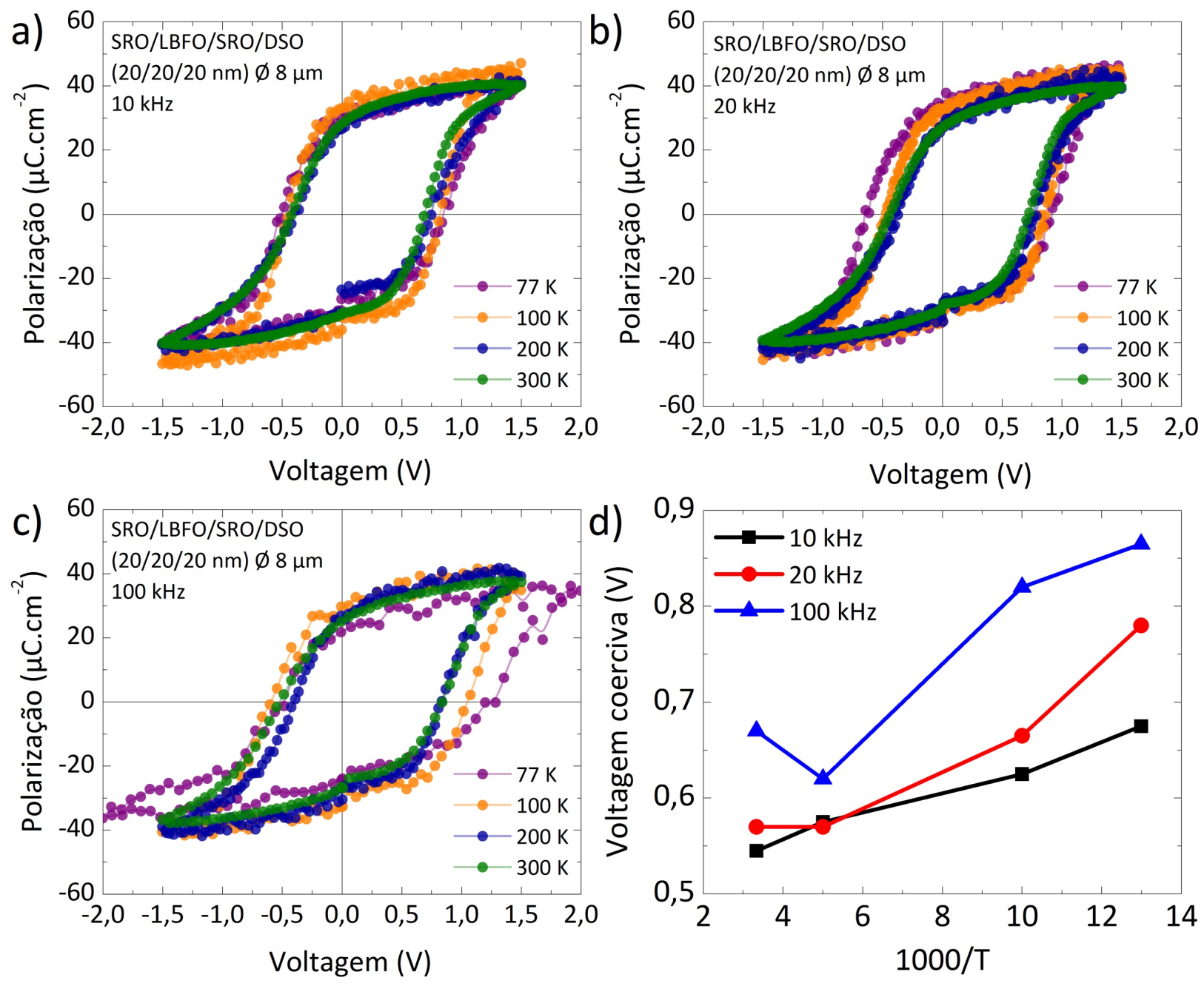

Os valores obtidos em diferentes temperaturas estão próximos daqueles encontrados nas medidas de histerese em temperatura ambiente, com exceção do comportamento mais estável das medidas pelo aumento da resistividade da amostra com o decréscimo da temperatura. 
5.2.6.3. Medidas de fadiga das amostras de LBFO com $20 \mathrm{~nm}$.

As medidas de fadiga ferroelétrica (Fig. 52) foram tomadas em temperatura ambiente com a amostra de $20 \mathrm{~nm}$ de espessura sob a configuração do sistema de ciclagem determinada pelo esquema apresentado na Figura 51.

Medidas de curva de histerese (a $100 \mathrm{kHz}$ ) foram tomadas antes e após o processo de fadiga (Fig. 53) para determinação da estabilidade em resposta a ciclagem elétrica dos ensaios de fadiga. Em ambos os dados, as amostras não mostraram significativa alteração nas curvas de histerese durante este processo, mesmo após 10 bilhões de ciclos ( 10 anos de operação de um dispositivo "writeread").

Figura 51 - Esquema da configuração do sistema de ciclagem ferroelétrica aplicada nas amostras de $\mathrm{LaBiFeO}_{3}$
a) Sequência de pulsos de ciclagem
b) Sequência de pulsos PUND
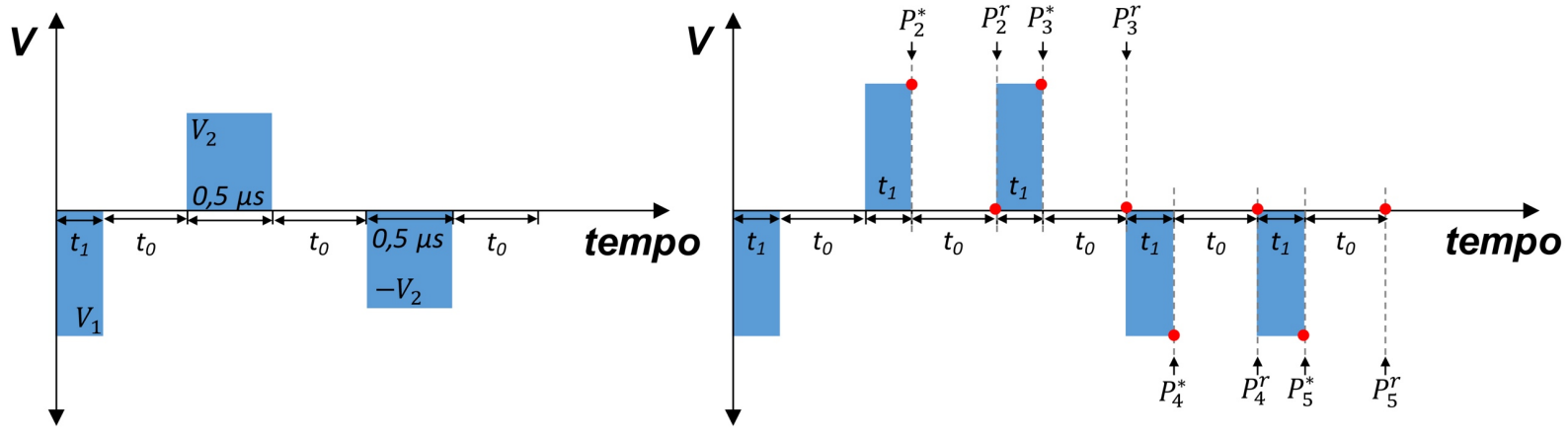

Figura 52 - Medidas de fadiga elétrica das amostras de LBFO com 20 nm de espessura. 


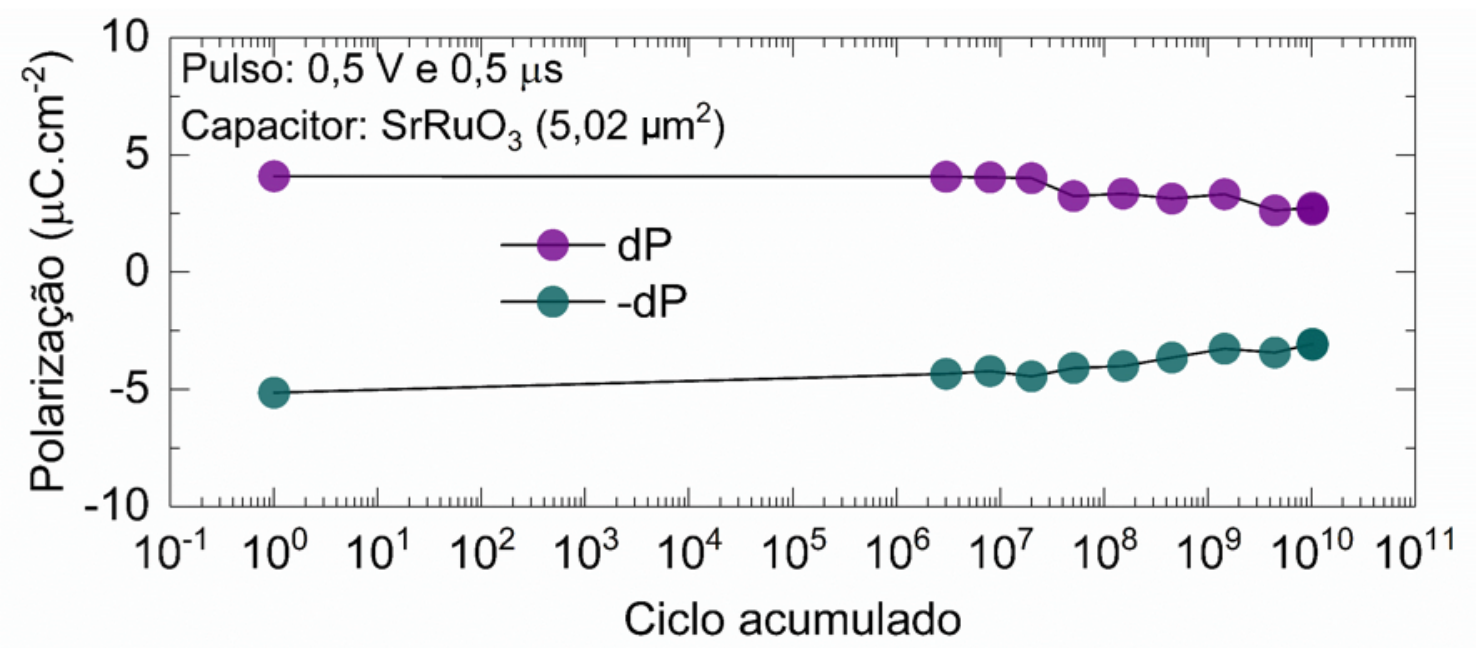

Figura 53- Curvas de histerese elétrica das amostras de LBFO com 20 nm de espessura antese após as medidas de fadiga.
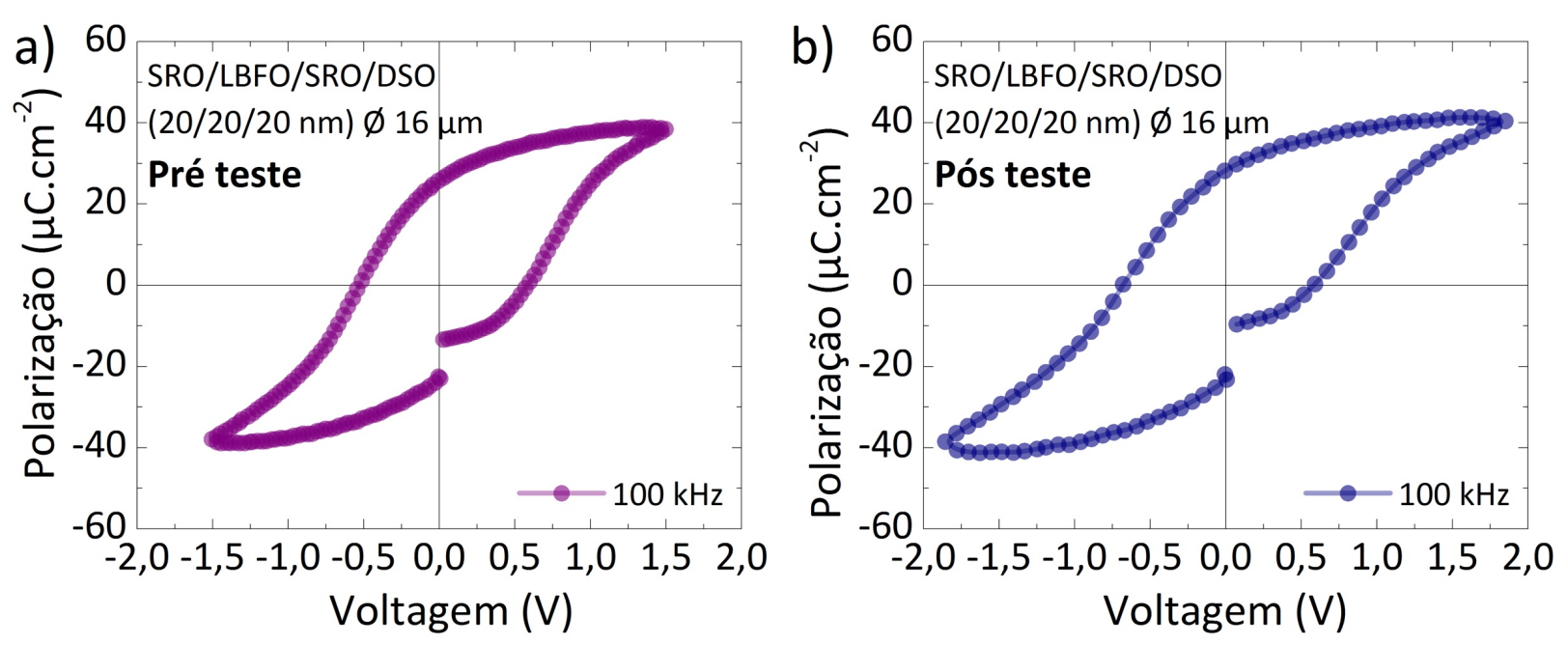

Devido a baixa voltagem aplicada a cada pulso, definida previamente pelo comportamento de histerese deste sistema, e devido a duração de pulso de 0,5 $\mu \mathrm{s}$, os valores de polarização $2 \mathrm{P}(\mathrm{dP})$ foram da ordem de apenas $4 \mu \mathrm{C} . \mathrm{cm}^{-2}$.

5.2.6.4. Polarização elétrica ultra rápida medida por curvas de corrente e campo elétrico em função da duração de pulso

Fica evidente pelos dados apresentados na Figura 52 que o filme fino de LBFO (20 nm) supera uma sequência de pulsos elétricos (gravação e leitura) da ordem de $10^{10}$ ciclos, o que corresponde a uma vida útil de operação da ordem de 10 anos, de acordo com os parâmetros comerciais. 
As amostras de LBFO com $20 \mathrm{~nm}$ de espessura foram analisadas quanto ao comportamento ferroelétrico em regime ultra rápido de polarização e deslocamento de cargas.

As medidas foram realizadas nos laboratórios de circuitos e dispositivos da Intel e são mostrados com tempo de pulso de 100 nano segundos (Fig. 54). 
Figura 54 - Curvas de polarização das amostras de LBFO com $20 \mathrm{~nm}$ de espessura em regime ultra rápido com duração de pulso de 100 ns.
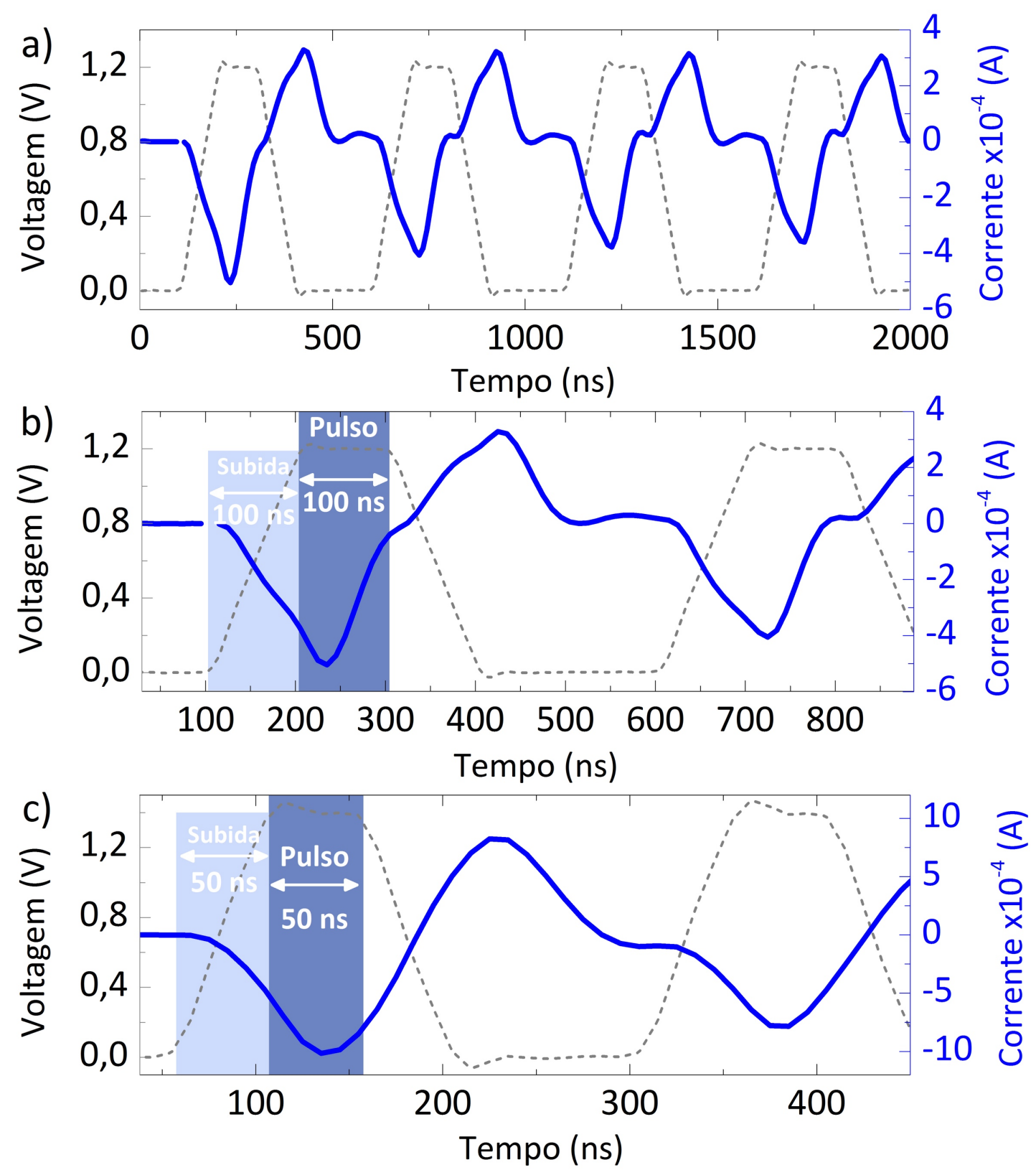

Com a análise das medidas de pulso ultra rápidos, as curvas de polarização foram ajustadas pelo modelo de KAI para evolução do comportamento ferroelétrico na escala de nano segundos (Fig. 55). Os valores resultantes do ajuste da curva ao modelo indicaram boa correlação estatística para $n$ (dimensionalidade) igual a 3 , indicando processos de nucleação e crescimento de domínios tridimensionais nesta escala de tempo. 
Figura 55 - Curvas de polarização das amostras de LBFO com $20 \mathrm{~nm}$ de espessura em regime ultra rápido com duração de pulso de 100 ns para perfil de Ps diferentes (a) e cálculo de parâmetros de dinâmica de polarização pelo modelo KAI (b, c).
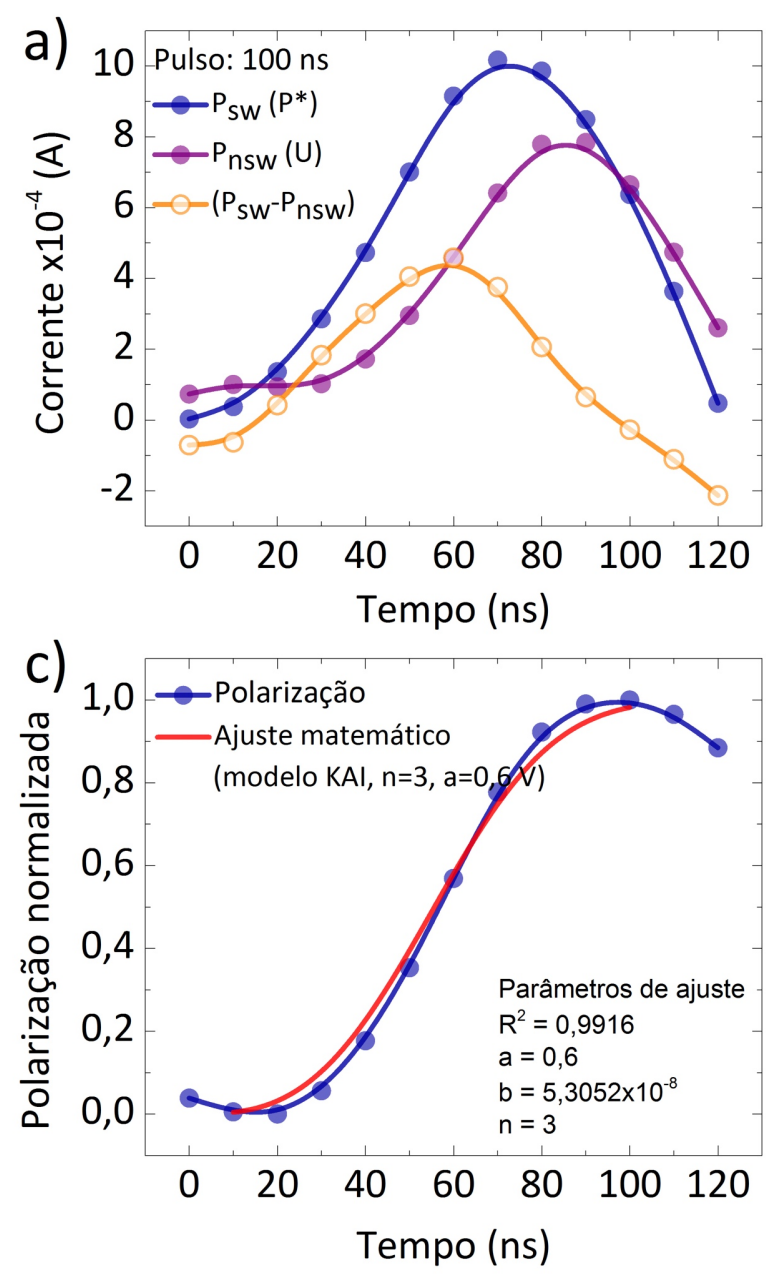

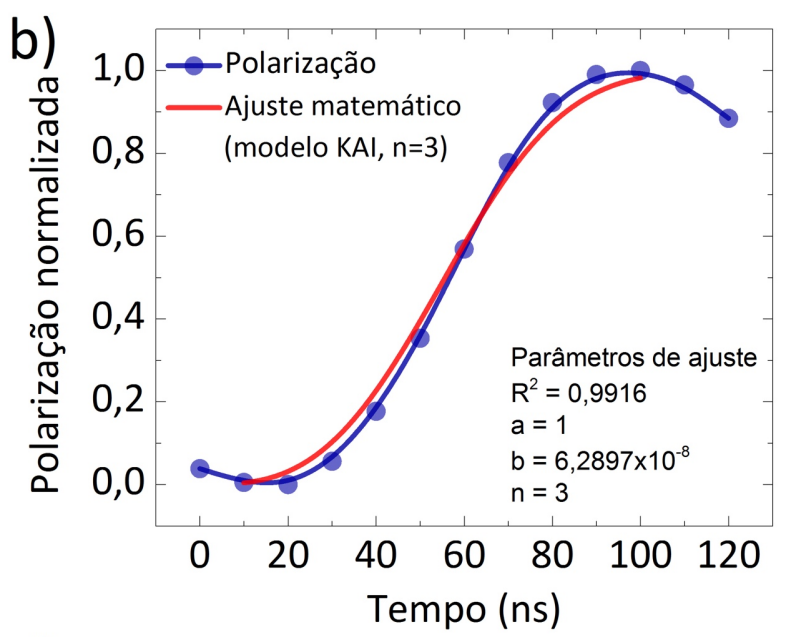

d) Modelo KAI* é descrito por

(*Kolmogorov-Avrami-Ishibashi (KAI) model)

$$
\Delta \mathrm{P}_{(\mathrm{t})}=2 P_{S}\left[1-A e^{\left.-\left({ }^{t} / t_{0}\right)^{n}\right]}\right.
$$

onde $t_{0}$ é o tempo característico de troca e $n$ é a dimensionalidade do processo de nucleação.
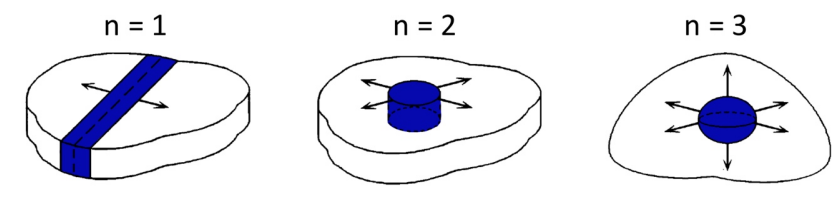

5.3. Crescimento e caracterização de filmes de $\mathrm{LaBiFeO}_{3}$ ultrafinos (10 nm)

\subsubsection{Estrutura cristalográfica e ensaios de polarização elétrica}


As amostras de LBFO foram também crescidas com $10 \mathrm{~nm}$ de espessura, da ordem de poucas células unitárias. O comportamento destes materiais ultrafinos pode ser visto nos resultados a seguir.

Como parte da avaliação estrutural, os difratogramas das amostras de LBFO $(10 \mathrm{~nm})$ são mostrados na Figura 56.

Figura 56 - Difratograma da amostra de LBFO $(10 \mathrm{~nm})$ crescido sobre SRO e DSO (110) como substrato.

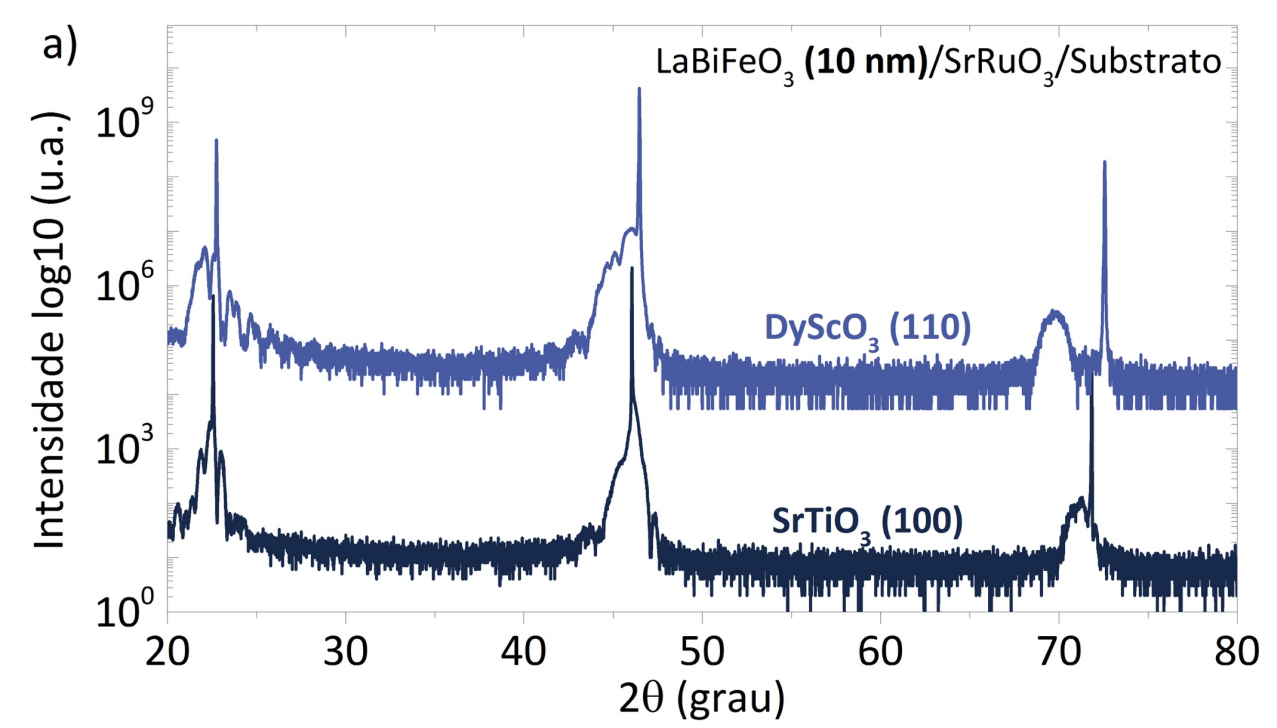

b)

c)
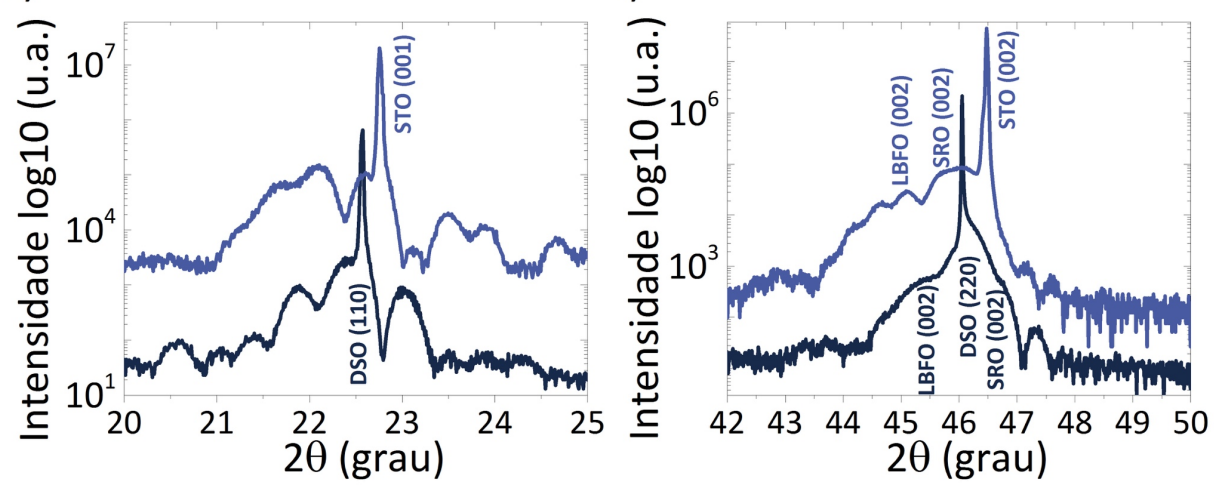

Amostras de $\mathrm{LaBiFeO}_{3}$ com $10 \mathrm{~nm}$ de espessura foram crescidos sobre SRO em DSO (110) e suas curvas de histerese foram registradas em diferentes frequências (Fig. 57). Dada a baixa resistência elétrica devido a espessura, medidas de polarização remanescente também foram realizadas (Fig. 58). 
Figura 57 - Curvas de histerese ferroelétrica das amostras de LBFO $(10 \mathrm{~nm})$ em diferentes frequências.
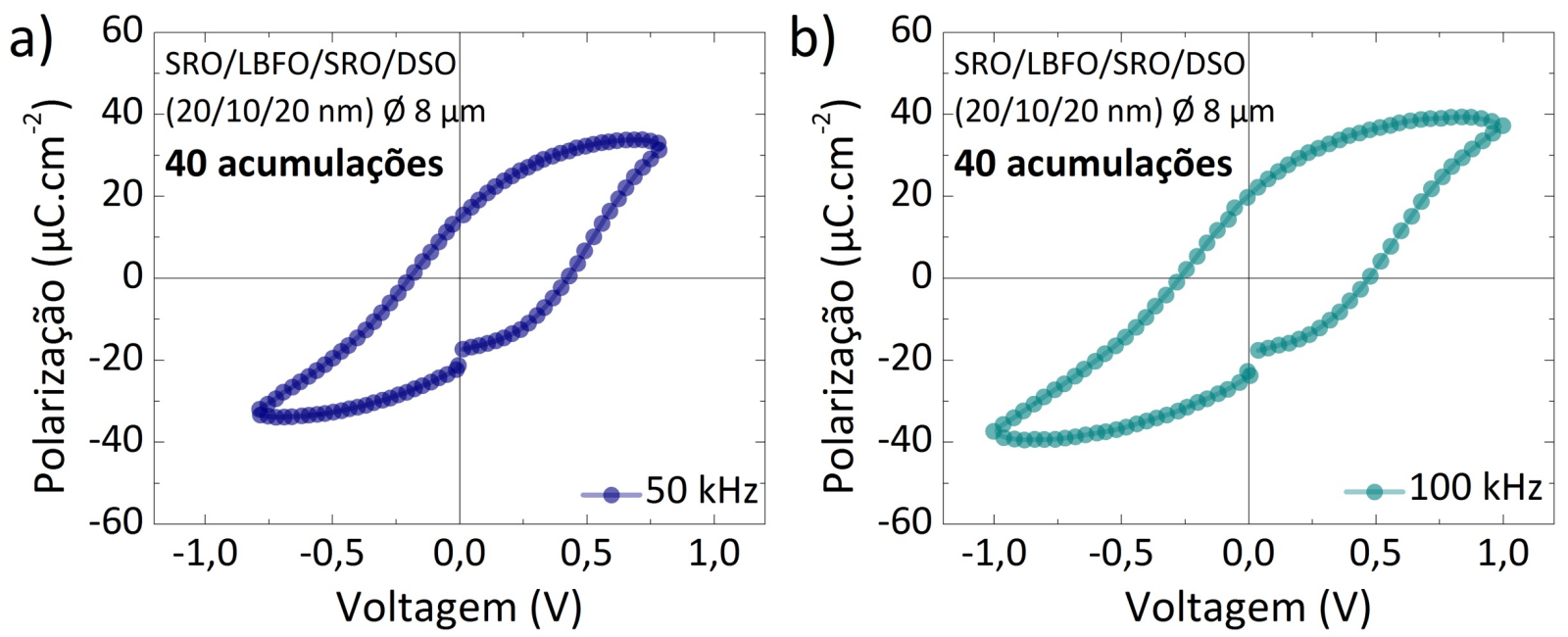

Figura 58 - Curvas de histerese ferroelétrica remanescente das amostras de LBFO (10 nm) sob campo elétrico de 0,8 $\mathrm{V}$ e duração de pulso de $0,1 \mathrm{~ms}$.
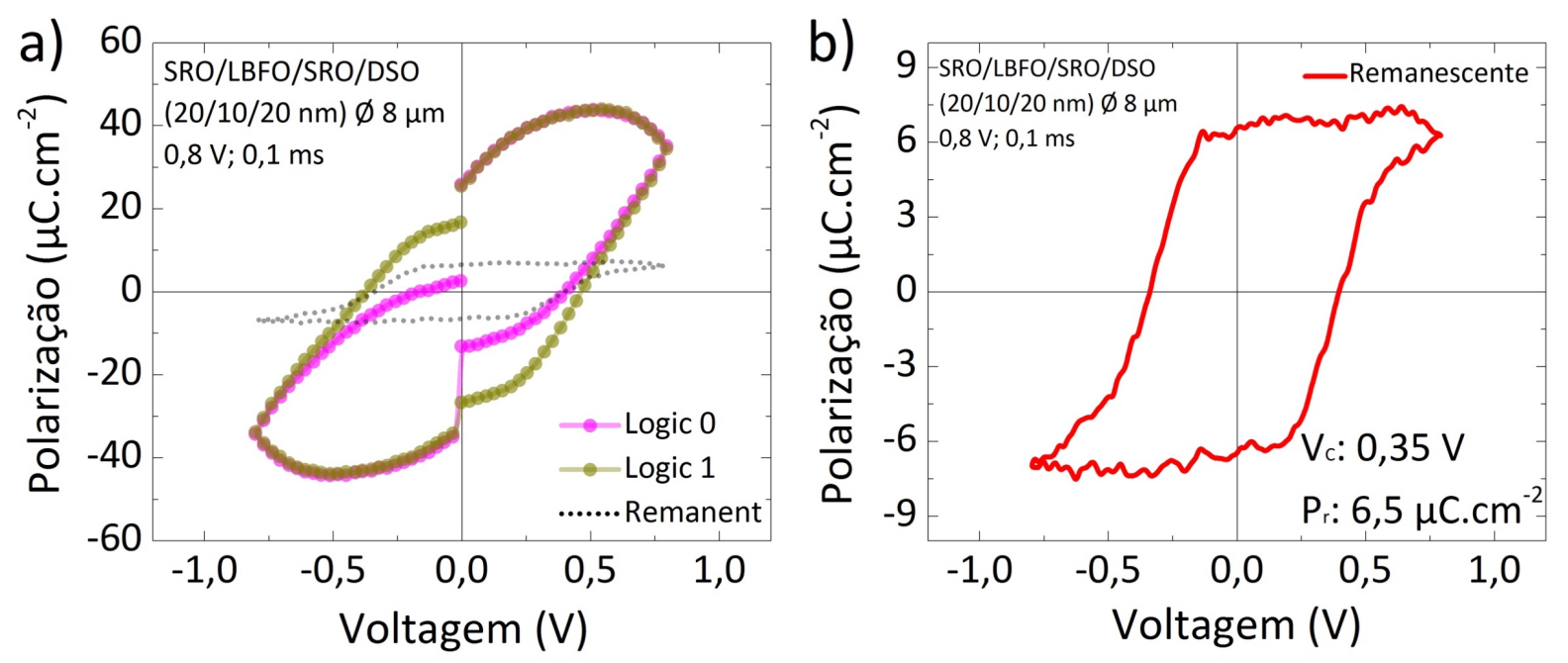

É possível observar que mesmo para filmes da ordem de $10 \mathrm{~nm}$ de espessura, onde a resistência elétrica se torna muito baixa, o comportamento ferroelétrico é significativamente mensurável. As medidas de histerese ferroelétrica remanescente ajudam a identificar os componentes ferroelétricos uma vez que os componentes de perda elétrica são extraídos da curva final. 
Ensaios PUND também foram realizados nas amostras mencionadas acima. Os valores se mostram razoáveis para a espessura das amostras. Contudo, estudos mais cuidadosos precisam ser realizados para reduzir a corrente de fuga (Fig. 59).

Figura 59 - Gráfico da polarização $2 \mathrm{P}$ do ensaio PUND para diferentes durações de pulsos com diferentes valores de tensão da amostra LBFO de10 nm seus respectivos valores de $T_{0}$ em função do campo elétrico aplicado calculado com base no modelo KAl (b,c).

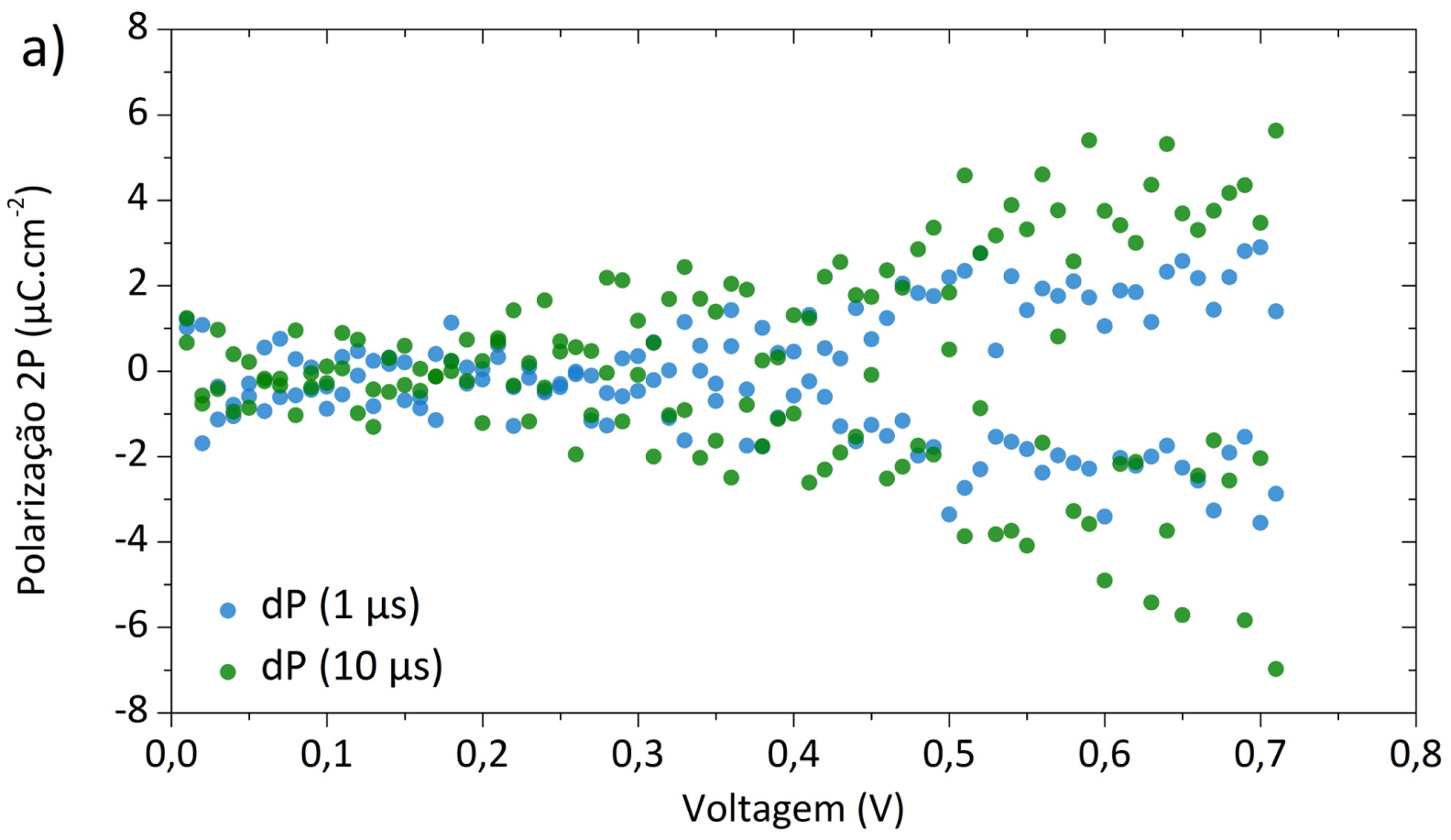

b)

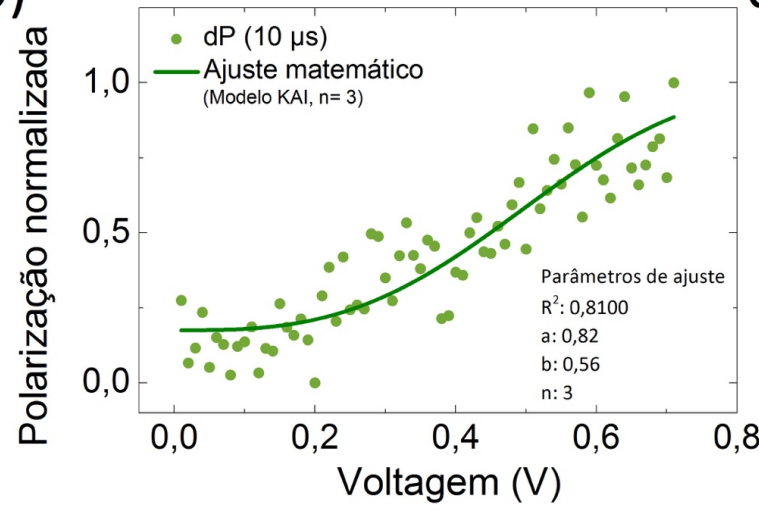

c)

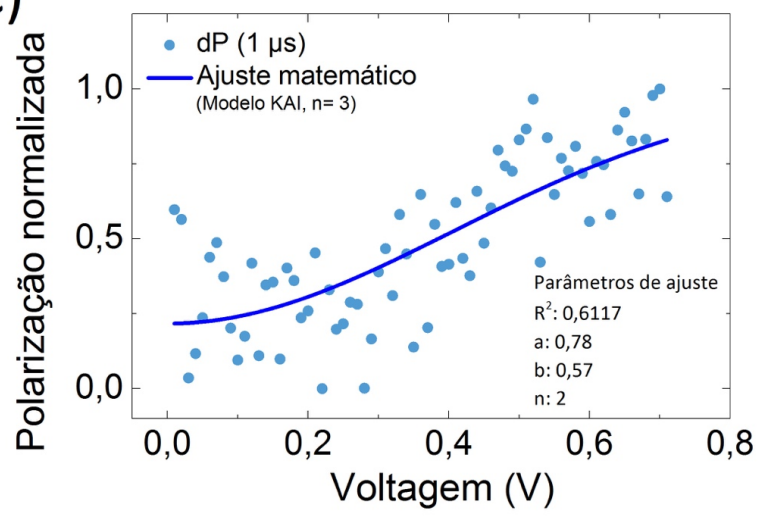


5.4. Propriedades ferrolétricas das amostras $\mathrm{LaBiFeO}_{3}$ em função da espessura.

Como já apontado por outros autores como Chandra et al. e Scott (SCOTT, 1995; CHANDRA et al., 2004), os processos de nucleação e movimentação de paredes de domínios ferroelétricos segue processos de interação Coulombiana e de interações ferroelásticas que determinam a velocidade na formação de domínios, bem como a sua relação com a espessura do material como modelado na forma de capacitores planos paralelos.

As curvas de histerese ferroelétrica para as amostras com diferentes espessuras são mostradas na Figura 60. É possível observar o escalonamento das características de cada curva em função da espessura da camada ferroelétrica.

De acordo com os valores de coercividade obtidos para cada amostra com espessura diferente, foi possível observar que o sistema LBFO também segue a forma semi-empírica onde $E_{c} \propto d^{-2 / 3}$, como mostrado e discutido por Scott (1995) e Chandra et al. (2004) e exemplificada na Figura 60. 
Figura 60 - Curvas de histerese ferroelétrica das amostras de LBFO em diferentes espessuras para a frequência de $100 \mathrm{kHz}(\mathrm{a})$, curvas de histerese remanescente (b), e curva de relação entre os valores de coercividade $\mathrm{E}_{\mathrm{C}}$ e polarização remanescente $\operatorname{Pr}(\mathrm{d})$ em função da espessura da camada ferroelétrica.
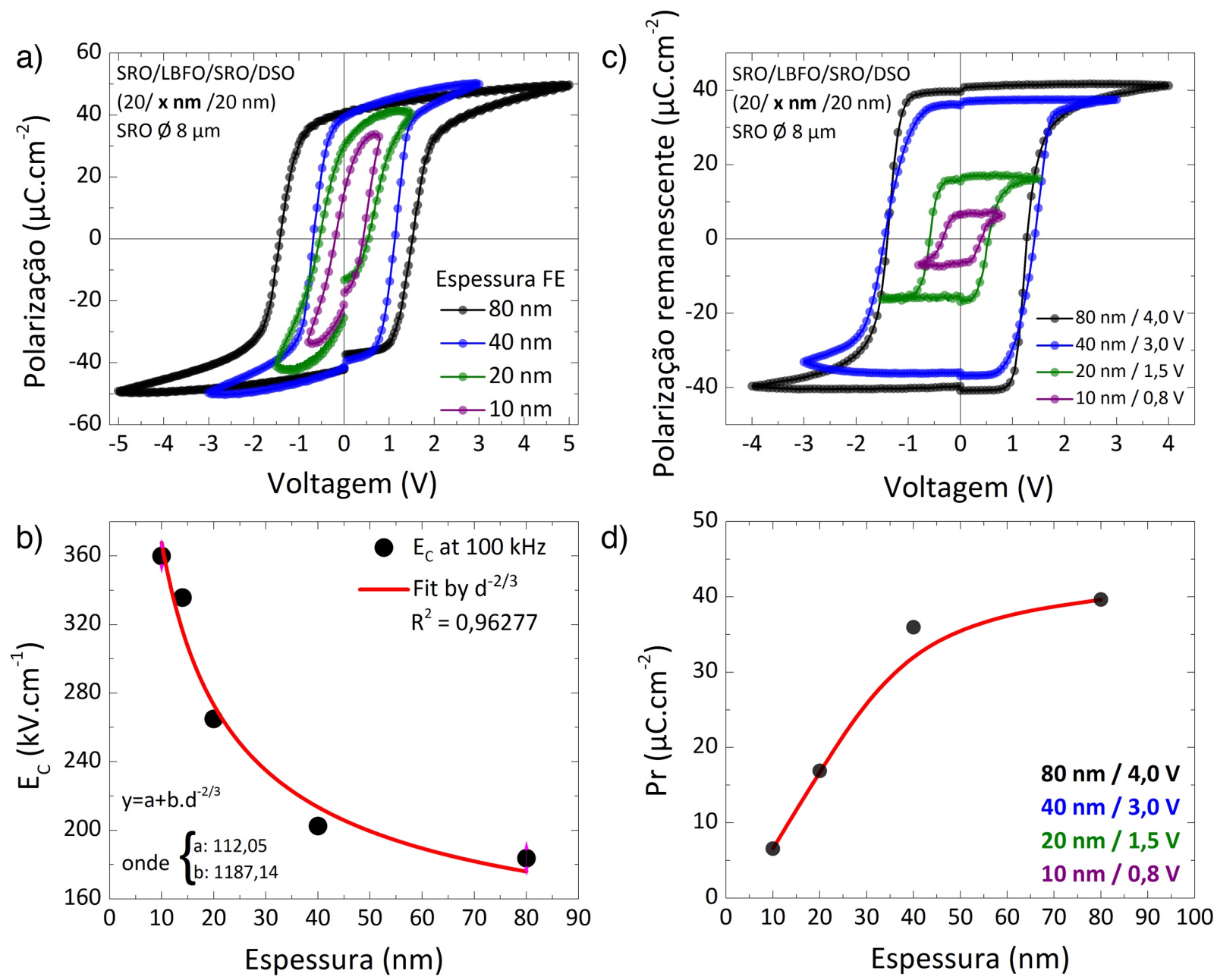

Fica evidente a relação de escala de espessura com a coercividade apresentada para cada amostra e é exatamente este comportamento, já estudado por outros pesquisadores (MERZ, 1954), e que também foi provado nos resultados mostrados para o sistema $\mathrm{LaBiFeO}_{3}$.

Para cada curva de histerese em diferentes frequências para cada uma das espessuras obtidas acima, os valores de campo coercivo são mostrados na Figura 61. Medidas de histerese ferroelétrica e histerese remanescente foram realizadas a fim de se obter o maior número de pontos para frequências altas e baixas. 
Figura 61 - Gráfico da coercividade elétrica das amostras de LBFO para espessuras de 10 (a), 20 (b), 40 (c) e $80 \mathrm{~nm}$ (d) da camada ferroelétrica em função da frequência de eventos de polarização obtida por histerese convencional e remanescente.

a)

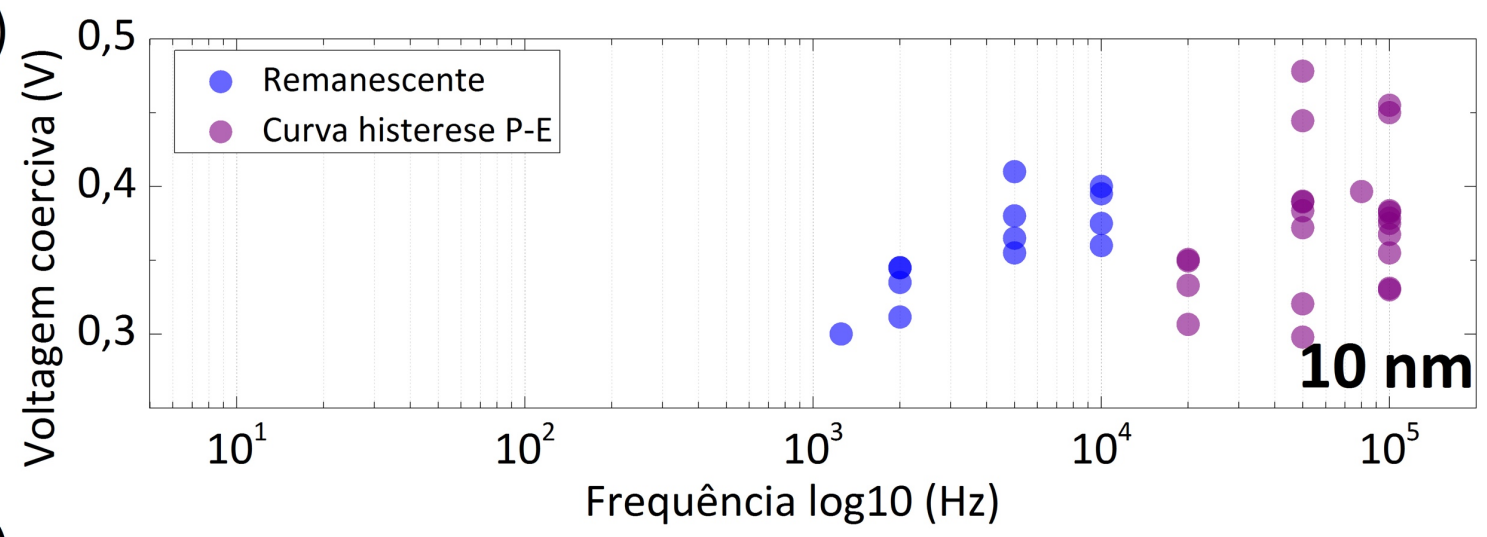

b)

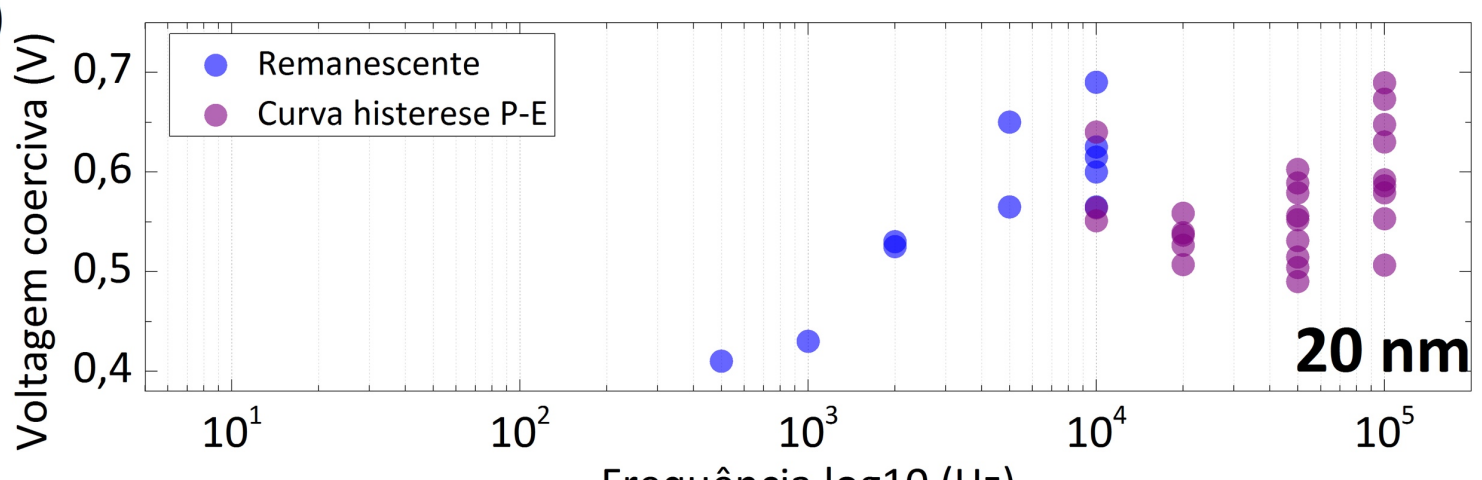

c)

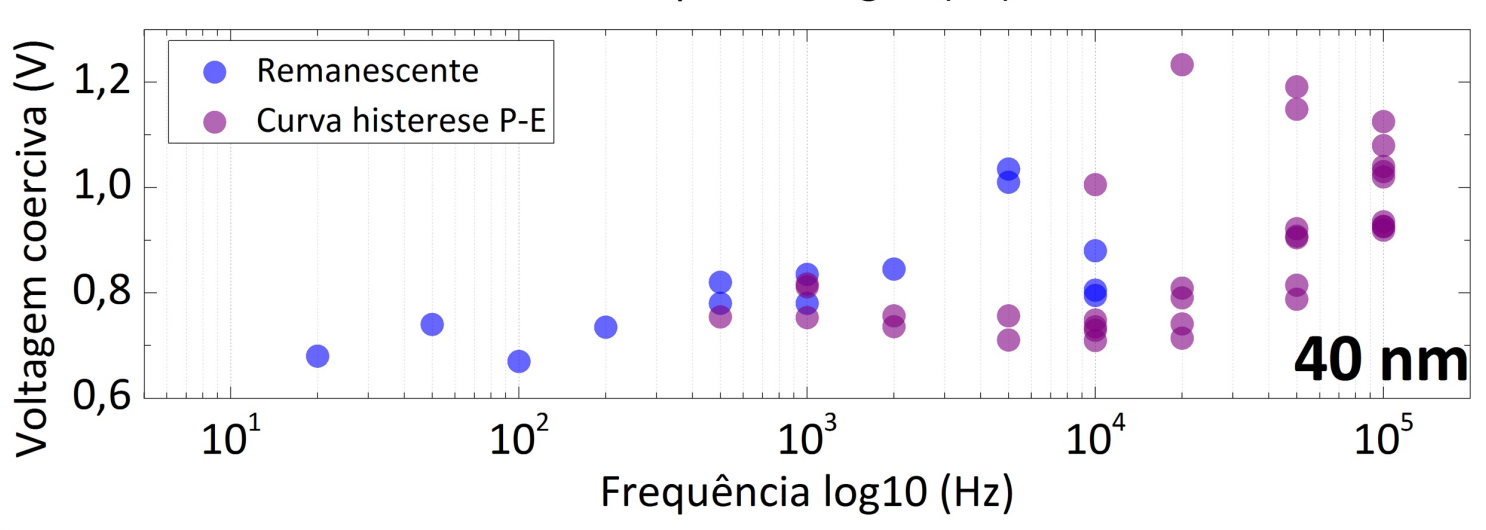

d)

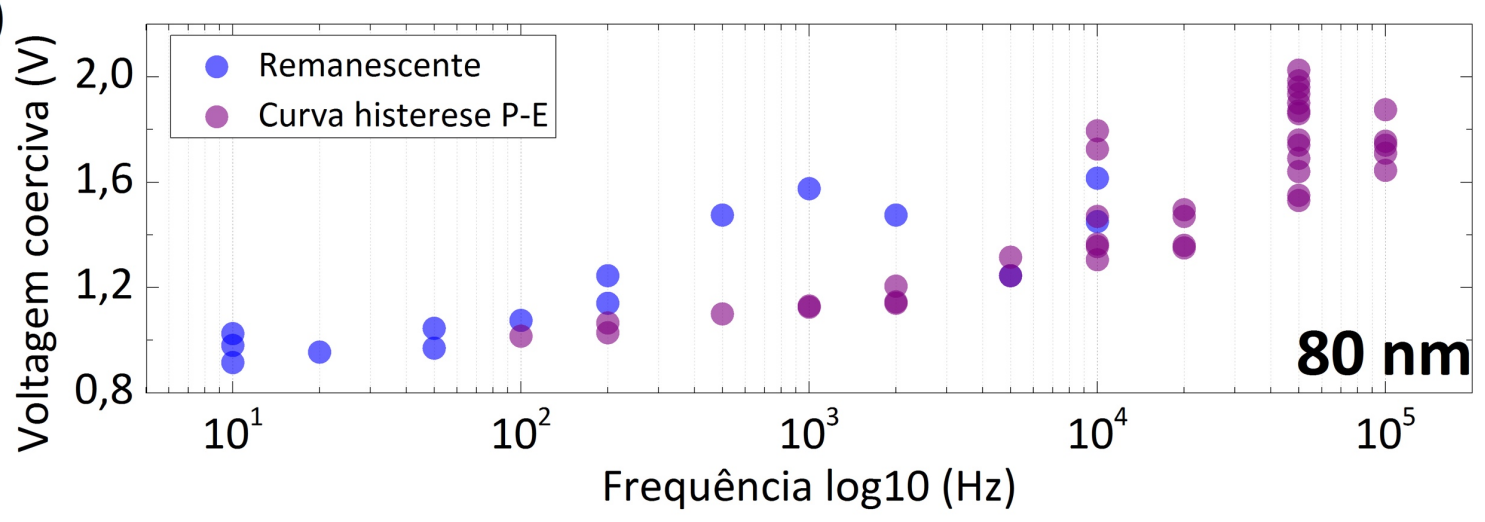


Segundo teorias de crescimento e movimentação de domínios ferroelétricos (MERZ, 1954), que define o comportamento energético do fenômeno de polarização, a observação dos valores de coercividade, energia mínima necessária para transitar entre estados polarizados opostos, descrevem o comportamento fundamental e dinâmico dos fenômenos de deslocamento de portadores de carga e íons na estrutura ferroelétrica de matérias como o $\mathrm{BiFeO}_{3}$.

É possível observar pelos valores do gráfico na Fig. 62 e Fig. 63 que a região de baixa frequência se comporta como um estado mínimo de energia, onde, provavelmente, processos ferroelétricos adiabáticos (sem perda de energia) determinam os estados de polarização, bem como, os valores de coercividade para frequências maiores determinam os mecanismos de crescimento de domínios ferroelásticos.

Figura 62 - Gráfico da coercividade elétrica das amostras de LBFO para diferentes espessuras da camada ferroelétrica em função da frequência de eventos de polarização.

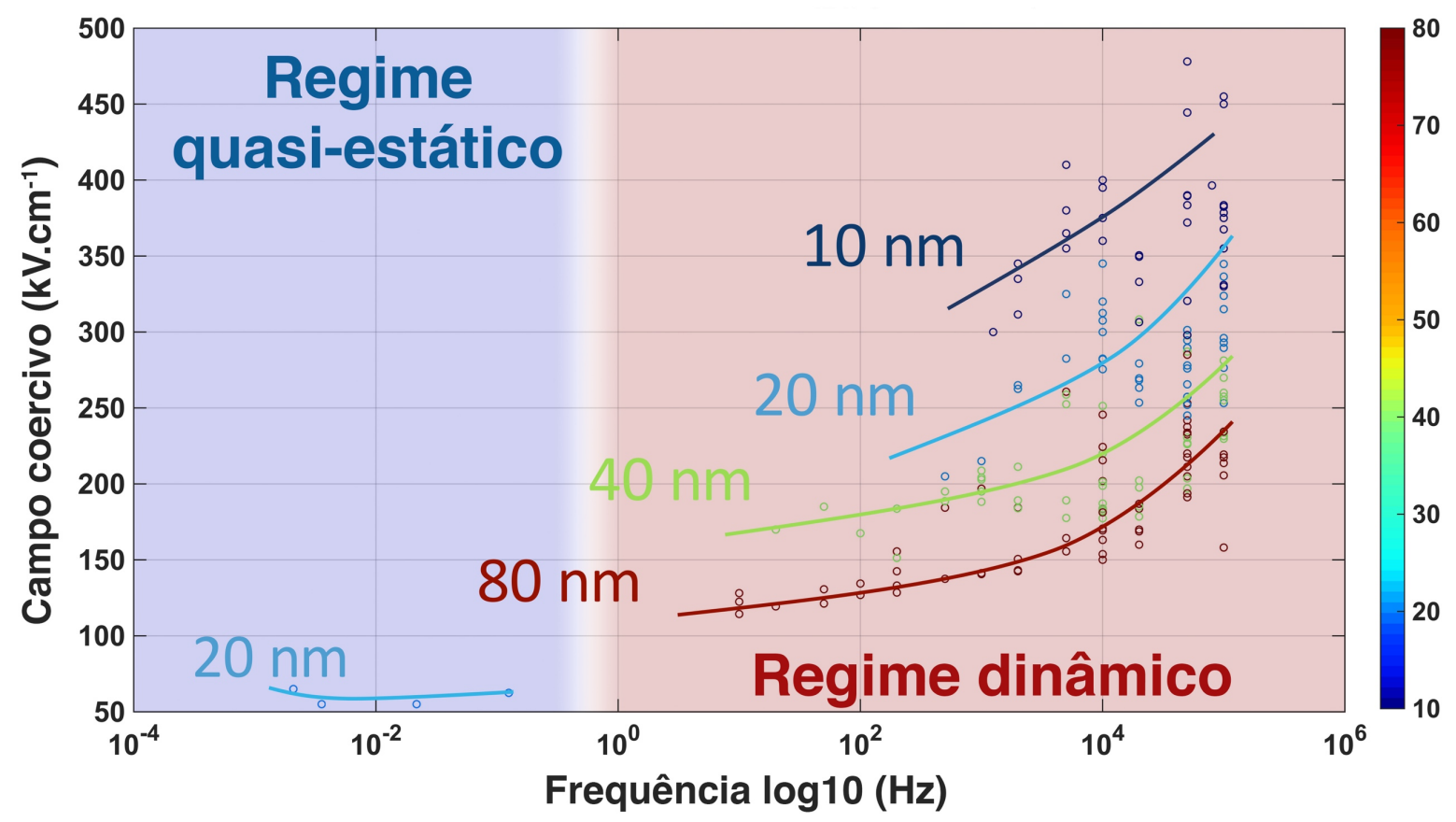


Figura 63 - Resposta de polarização elétrica em função do campo elétrico aplicado em uma dada frequência de variação de campo no intervalo entre os regimes quase-estático e dinâmico para diferentes espessuras 10, 20, 40 e $80 \mathrm{~nm}$.

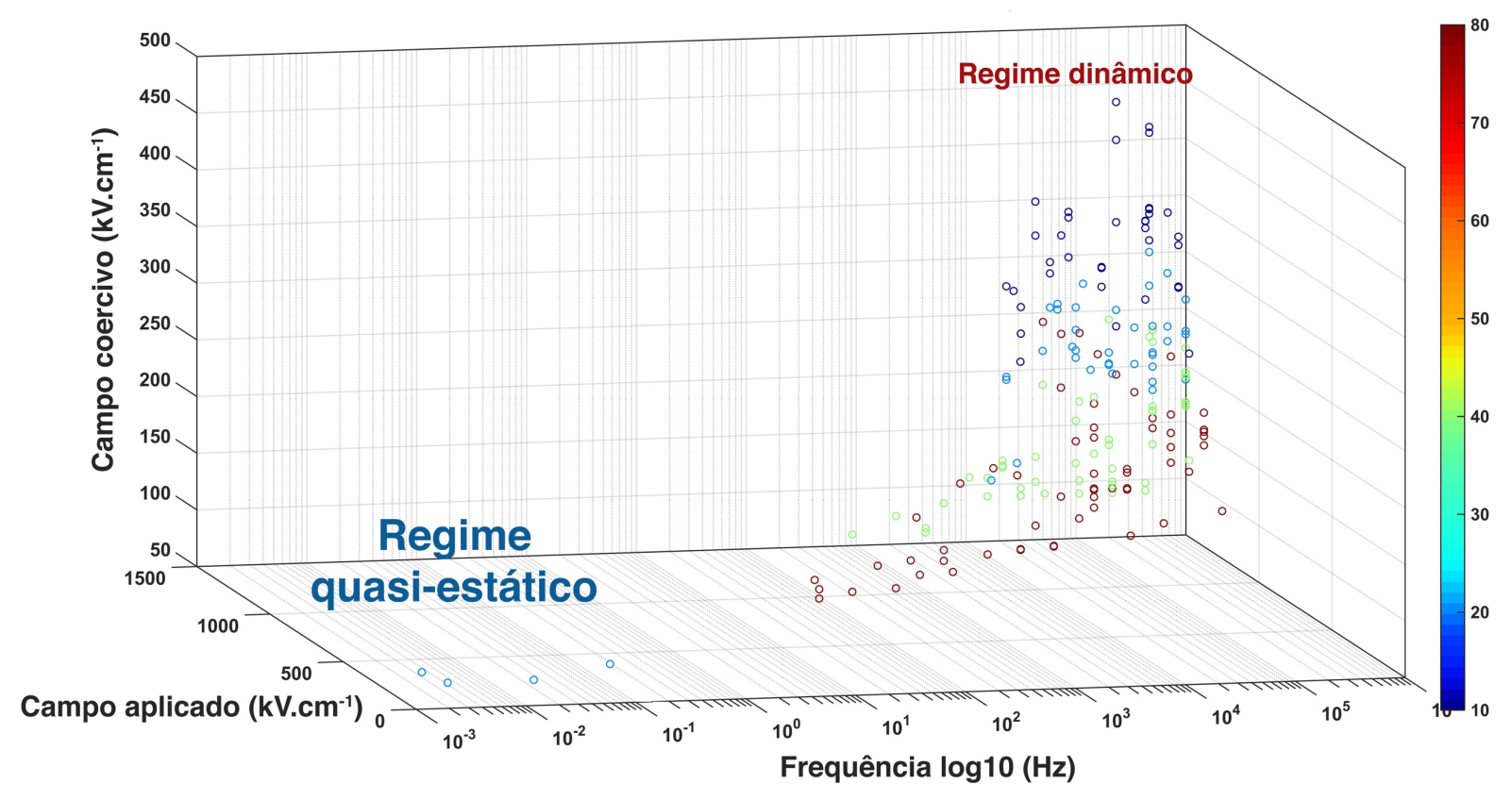


Figura 64 - Gráfico de superfície da resposta de polarização elétrica em função do campo elétrico aplicado em uma dada frequência de variação de campo no intervalo entre os regimes quase-estático e dinâmico.

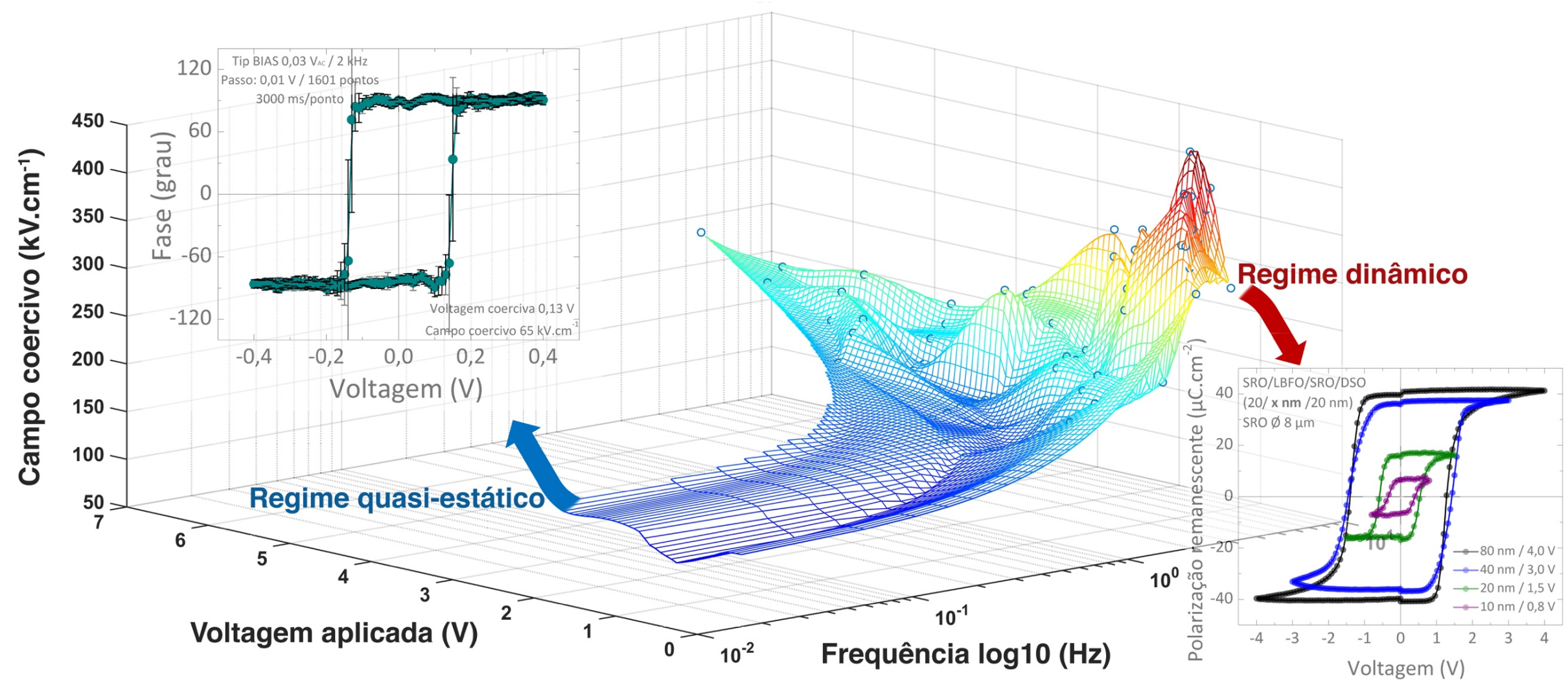


O entendimento dos fenômenos que dominam a polarizabilidade da estrutura em frequências de regime quase-estático podem esclarecer as interações naturais e fundamentais dos fenômenos ferroelétricos nesta estrutura.

O gráfico de superfície (Fig. 64) criada a partir dos dados de polarização para diferentes frequências e campos elétricos aplicados mostra claramente a superfície de energia que rege o comportamento ferroelétrico do sistema $\mathrm{BiLaFeO}_{3}$ nas amostras deste trabalho.

Cálculos teóricos podem fornecer informações precisas sobre as curvas de energia potencial para cada estado de polarização e a manipulação destas curvas traria a possibilidade de avançar na engenharia nanotecnológica da produção de materiais funcionais com configurações eletrônicas controláveis.

5.5. Ensaios de gravação e leitura (Write-Read)

Ensaios de gravação e leitura de estados polarizáveis também foram obtidos para amostras com espessuras de 40 e $80 \mathrm{~nm}$. Os dados podem ser vistos na Figura 65.

A configuração dos pulsos aplicados para os ensaios de gravação e leitura está detalhada na Figura 27b. As medidas foram realizadas apenas nas amostras com espessuras de 80 e $40 \mathrm{~nm}$ devido ao comportamento condutivo das amostras de menor espessura impedirem o estado de saturação. 
Figura 65 - Gráfico do ensaio de PUND da polarização 2P normalizada para diferentes valores de tensão com diferentes valores de duração de pulso da amostra LBFO de $40 \mathrm{~nm}$ (a) e $80 \mathrm{~nm}$ (d) e seus respectivos valores de $\mathrm{T}_{0}$ em função do campo elétrico aplicado (b,c $\left.-40 \mathrm{~nm}\right)(\mathrm{e}, \mathrm{f}-80 \mathrm{~nm})$.
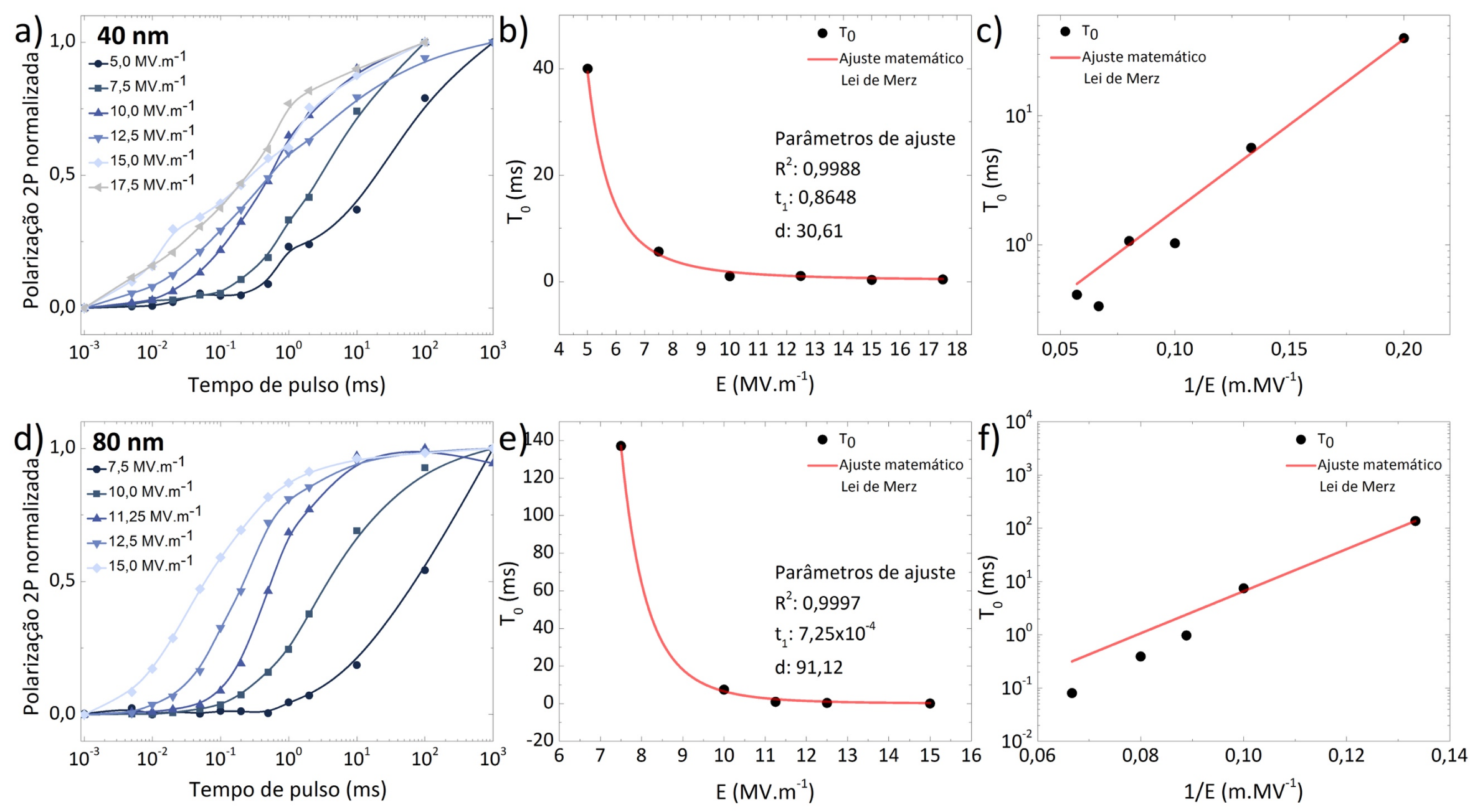
Alguns coeficientes extraídos de equações modeladas por outros autores podem representar fenômenos físicos distintos em cada sistema, como o caso dos valores de dimensionalidade $\mathrm{n}$ que se relacionam com diferentes geometrias de nucleação de domínios ferroelétricos.

Os valores de menores que 1 para as amostras estudadas neste trabalho ainda precisam ser interpretados. Apesar de alguns autores apenas definirem valores inteiros para $n$, alguns trabalhos na literatura apresentam valores decimais de $n$, como é o caso das amostras de LBFO (Fig. 66).

Figura 66 - Gráfico dos valores de dimensionalidade $n(a)$ e $T_{\infty}$ (b) calculados por ajuste usando os modelos KAI e Lei de Merz dos dados medidos pelos ensaios PUND das amostras com espessuras de 40 e $80 \mathrm{~nm}$.
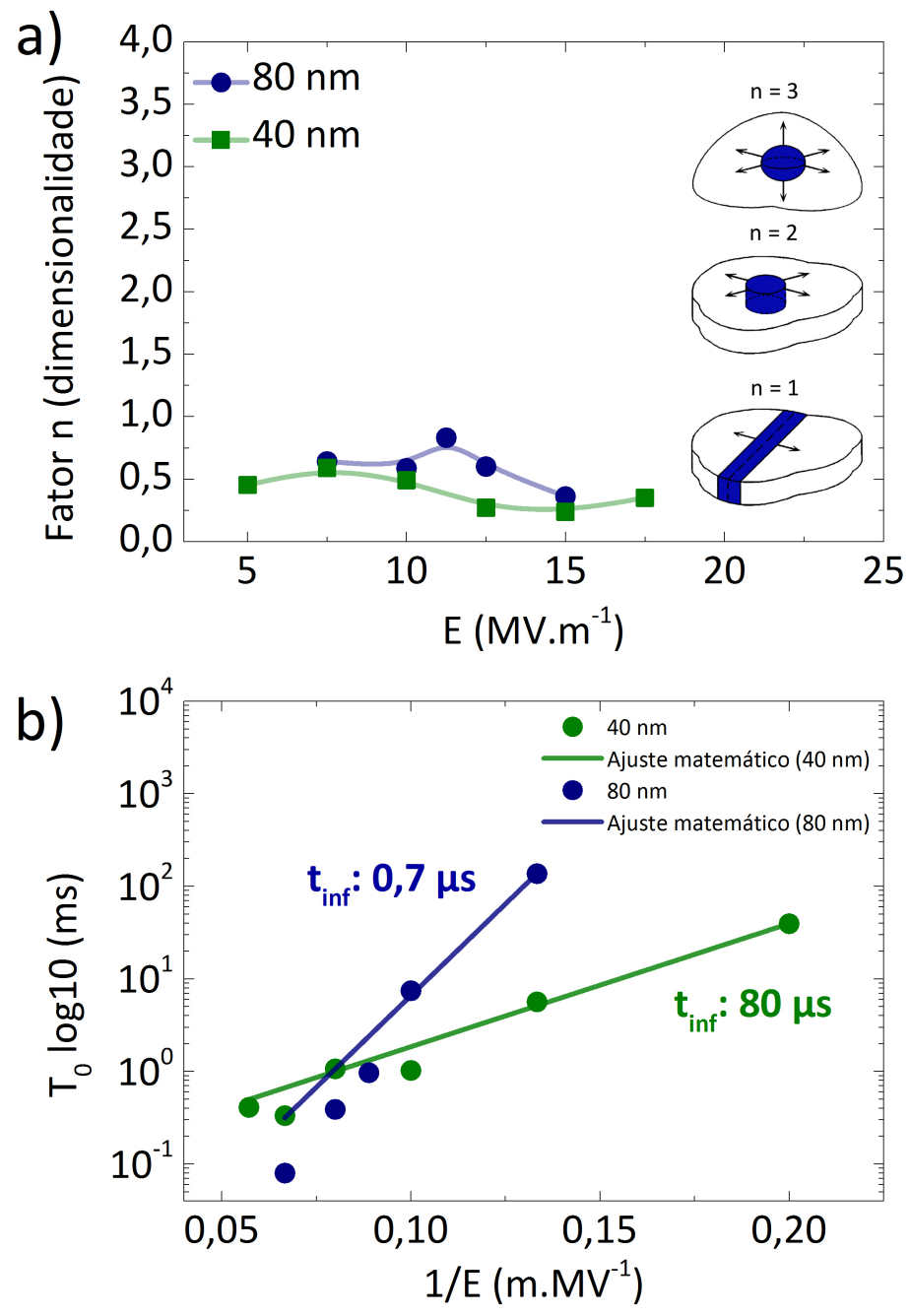
5.6. Acoplamento spin-órbita de interface entre filmes finos antiferromagnéticos de $\mathrm{BiFeO}_{3}$ e ferromagnéticos de $\mathrm{Co}_{0,9} \mathrm{Fe}_{0,1}$.

Uma das etapas mais importantes deste trabalho foi o estudo de acoplamento entre filmes finos antiferromagnéticos e filmes ferromagnéticos por interação spinorbital de interface entre dois sistemas, um ferroelétrico (FE) e outro ferromagnético (FM), como ilustrado na Figura 67.

Figura 67 - Esquema representativo da interface e interação spin-órbita entre os domínios ferromagnéticos da camada FM e os planos antiferromagnéticos com momento ferromagnético de rede da camada AFM do $\mathrm{BiFeO}_{3}$.

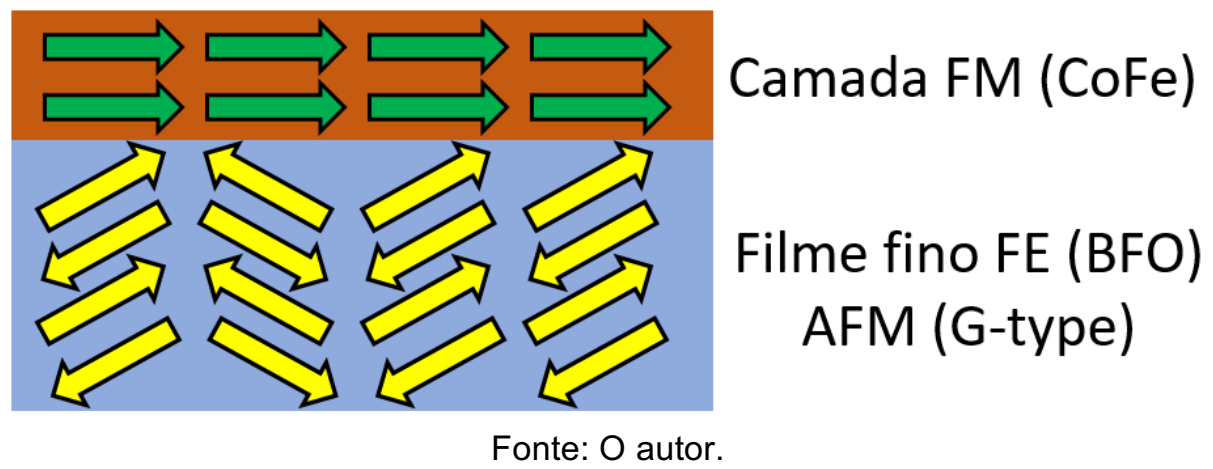

Imagens de microscopia de força atômica e PFM (Fig. 68) foram obtidas para verificação da superfície das amostras FE antes do processo de deposição da camada FM de $\mathrm{Co}_{0,90} \mathrm{Fe}_{0,10}$.

Figura 68 - Imagens de microscopia AFM e PFM (no plano) das amostras de BFO crescidas sobre SRO em substratos de STO/Si.
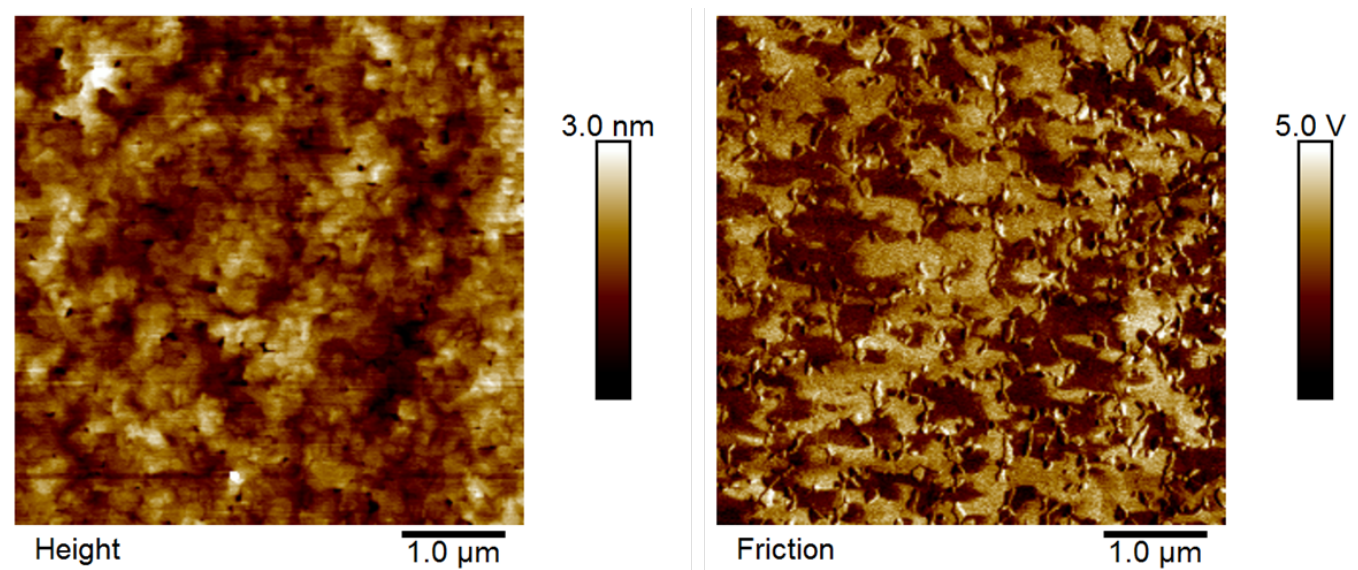
As amostras para estudos de integração FE/FM em sistemas suportados em silício foram crescidas sobre substrato de STO/Si(100). A caracterização estrutural dos filmes pode ser vista no difratograma mostrado na Figura 69.

Como a espessura das camadas ferromagnéticas determinam a intensidade das interações interfaciais de acoplamento, medidas de refletividade por raios $X(X R R)$ foram adotadas para verificação e calibração da espessura dessas camadas (Fig. 70).

Figura 69 - Difratograma da amostra de BFO crescidas sobre SRO em substratos de STO/Si.

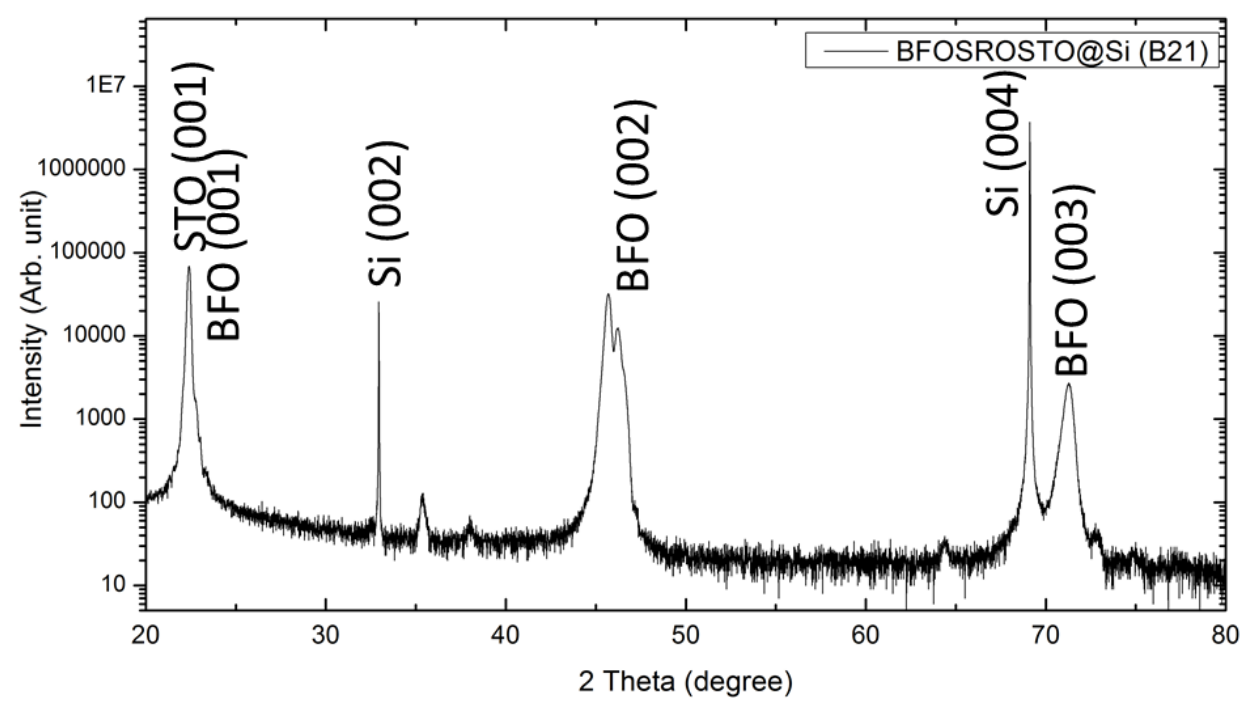


Figura 70 - Difratometria em modo de reflectância XRR (a) e histerese magnética (b) de uma amostra de CoFe crescido sobre STO(100)

Thickness calibration by XRR

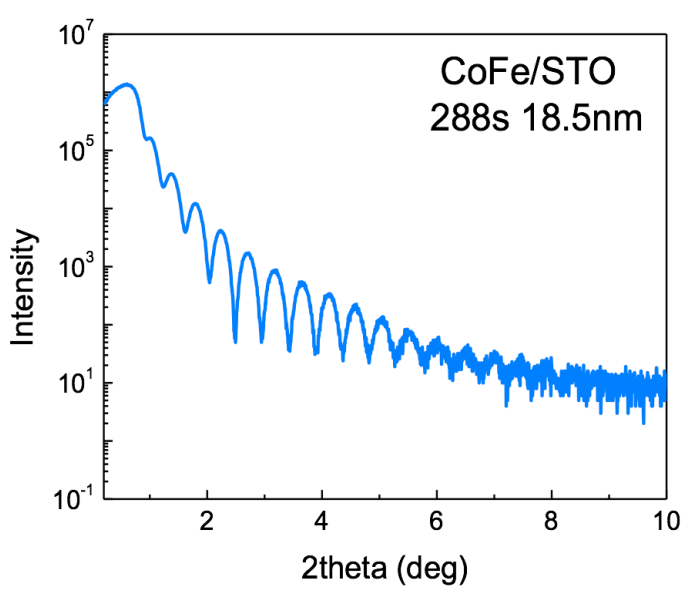

(a)
$\mathrm{M}-\mathrm{H}$ loop of $\mathrm{Co}_{0.9} \mathrm{Fe}_{0.1} / \mathrm{STO}(001)$

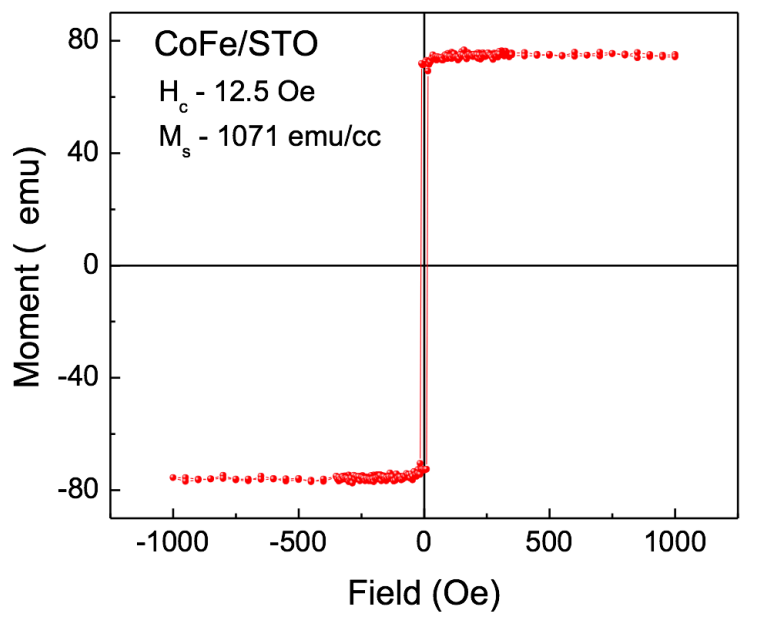

(b)

De forma clara, as medidas de histerese magnética mostraram um aumento nos valores de campo coercivo $\mathrm{H}_{\mathrm{C}}$ de 12 Oe dos filmes ferromagnéticos de $\mathrm{Co}_{0,90} \mathrm{Fe}_{0,10}$ para 80 Oe quando este é depositado sobre uma camada antiferromagnética de $\mathrm{BiFeO}_{3}$ (Fig. 71).

Figura 71 - Histerese magnética de uma amostra de CoFe de 2,3 nm (a) e 3,2 nm (b) crescido sobre BFO/SRO/STO/Si(100)

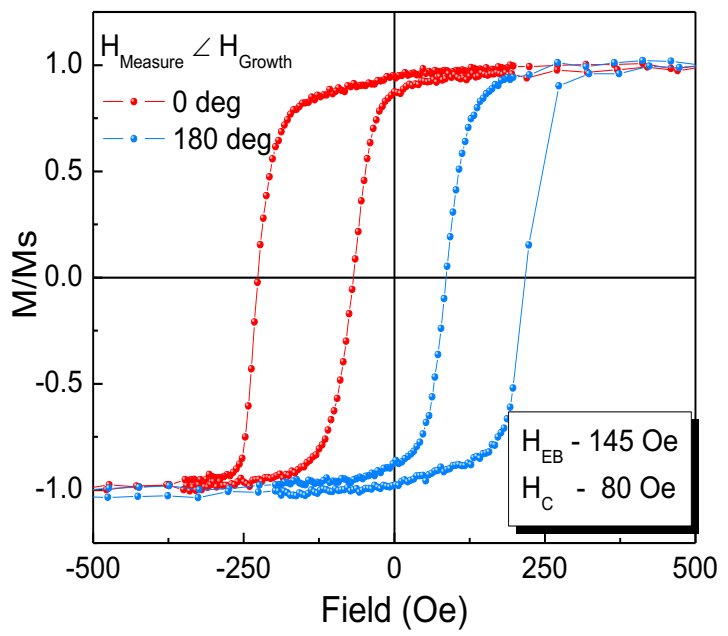

(a)

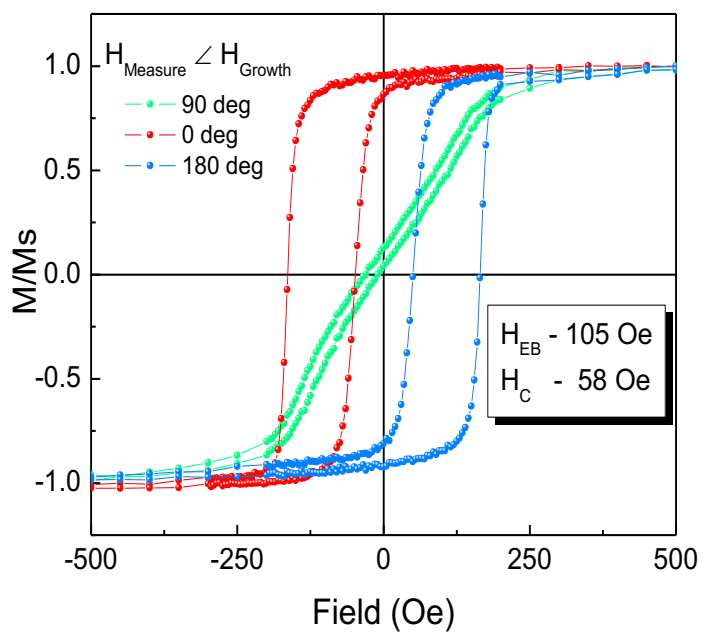

(b) 
Figura 72 - Histerese magnética de uma amostra de CoFe de 2,3 nm crescido sobre BFO/SRO/STO/Si(100) obtido por VSM em diferentes ângulos da amostra como indicado na figura central.
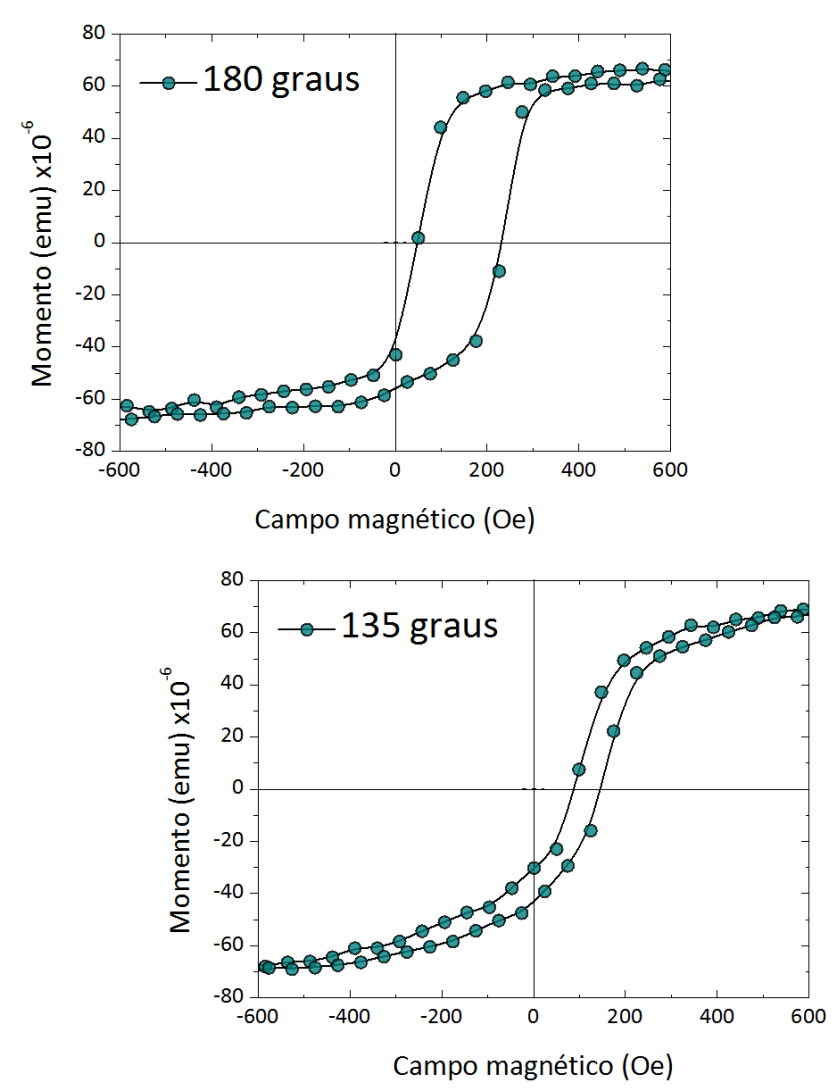
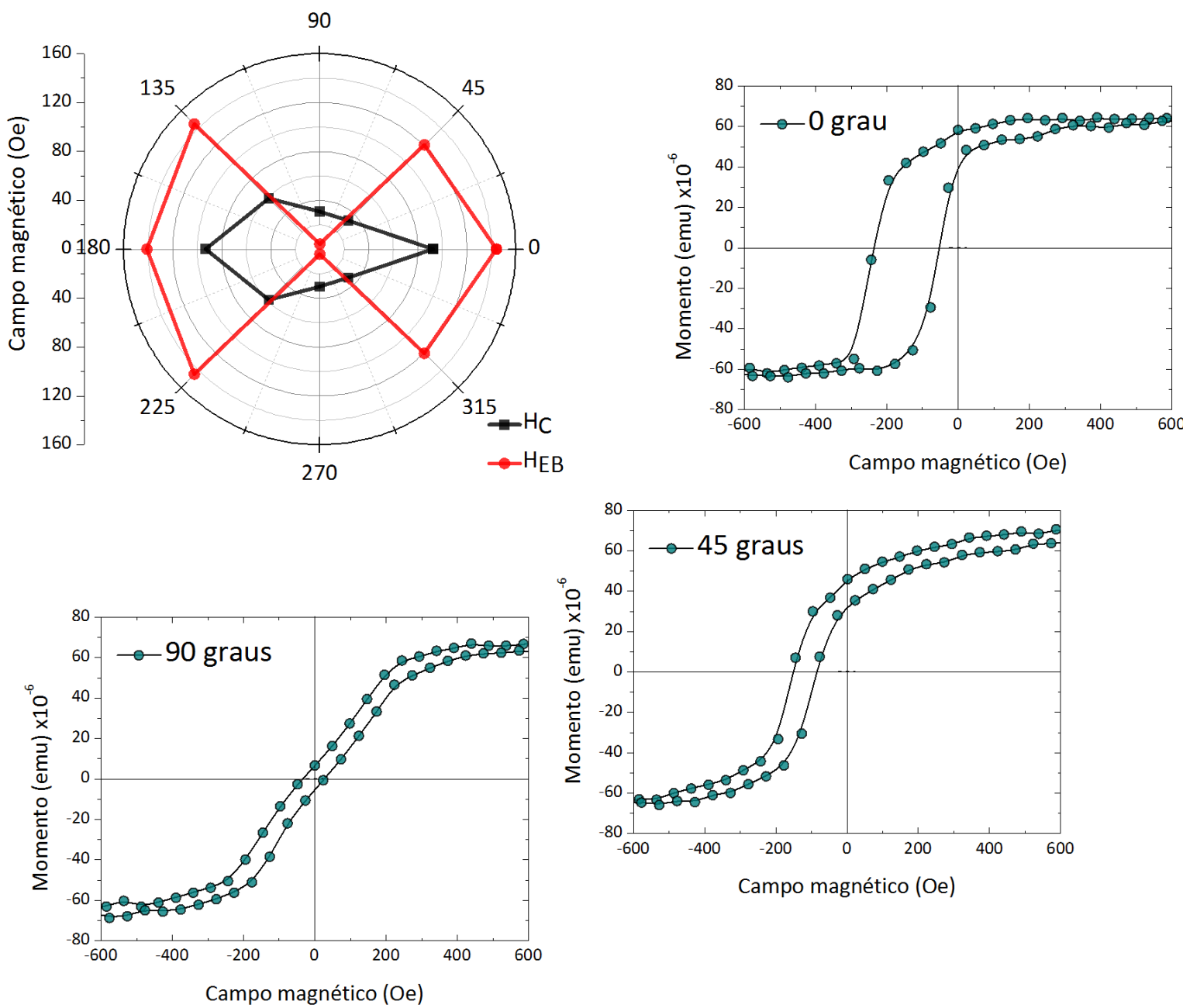
O comportamento de anisotropia magnética pode ser constatado pelas curvas de histerese $\mathrm{M}-\mathrm{H}$ em diferentes posições de rotação da amostra em função da bobina magnética, como mostrado pelas marcações da Figura 72.

Uma vez acoplado, o sistema FE/FM passou por análise de ciclagem onde um campo magnético foi aplicado à amostra a fim de analisar a estabilidade do acoplamento entre os domínios ferromagnéticos do filme $\mathrm{Co}_{0,9} \mathrm{Fe}_{0,1}$ e os momentos magnéticos de rede da estrutura FE (Fig. 73).

Mesmo após 100 ciclos completos sob campo máximo de 1000 Oe, as amostras mantiverem o acoplamento de troca.

Figura 73 - Histerese magnética de uma amostra de CoFe de 2,3 crescido sobre $\mathrm{BFO} / \mathrm{SRO} / \mathrm{STO} / \mathrm{Si}(100)$ obtido por VSM por diferentes ciclos de campo magnético.

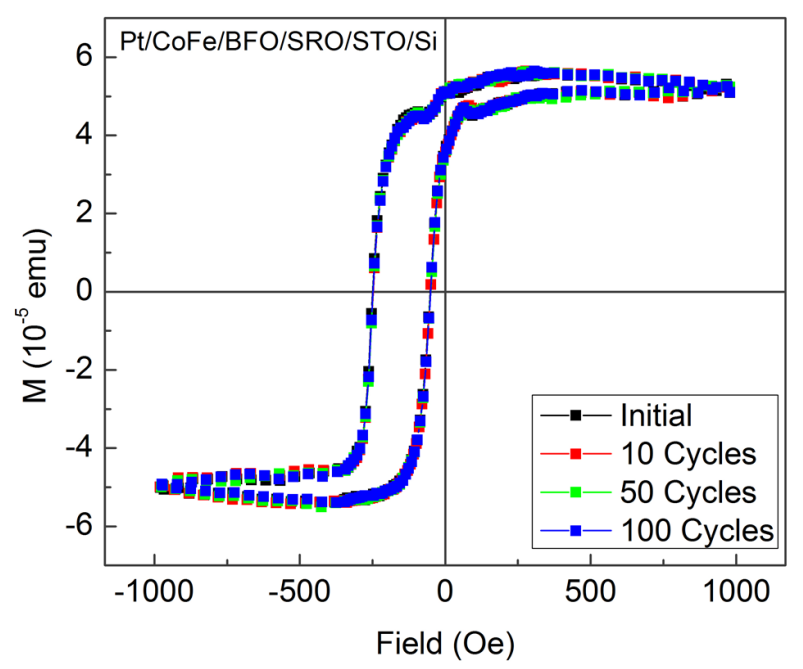

(a)

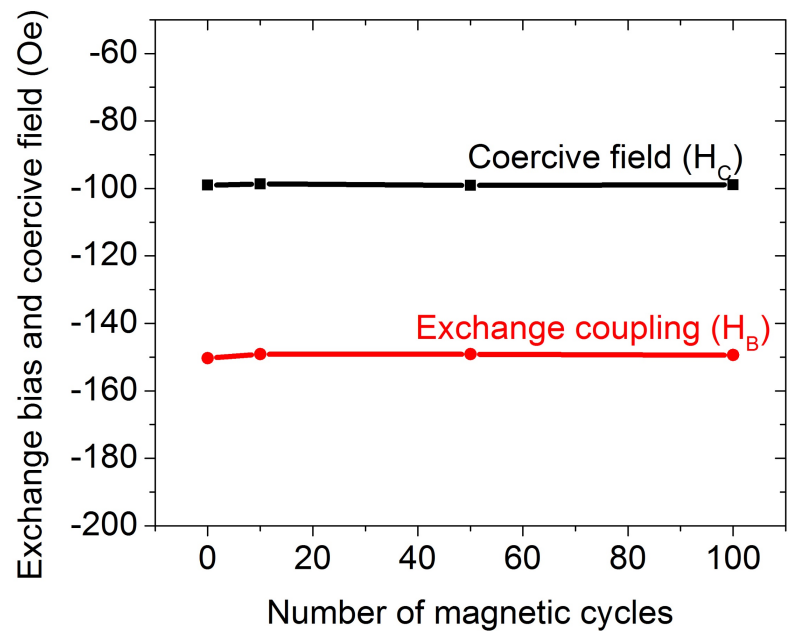

(b) 
5.7. Acoplamento spin-órbita de interface entre filmes finos antiferromagnéticos de $\mathrm{Bi}_{0,90} \mathrm{La}_{0,10} \mathrm{FeO}_{3}$ e ferromagnéticos de $\mathrm{Co}_{0,90} \mathrm{Fe}_{0,10}$.

Assim como foram feitas as caracterizações de acoplamento entre os filmes de BFO e $\mathrm{Co}_{0,9} \mathrm{Fe}_{0,1}$, medidas de acoplamento magnético de troca também foram realizadas para amostras usando uma camada de filme fino de $20 \mathrm{~nm}$ de $\mathrm{LaBiFeO}_{3}$ sobre a qual foi depositada a camada ferromagnética de $\mathrm{Co}_{0,9} \mathrm{Fe}_{0,1}$.

Da mesma forma, medidas de espessura foram feitas para calibração das camadas de $\mathrm{Co}_{0,9} \mathrm{Fe}_{0,1}$ e LBFO (Fig. 74a) e como forma de avaliar o comportamento ferromagnético da camada de $\mathrm{Co}_{0,9} \mathrm{Fe}_{0,1}$, medidas de histerese magnética $\mathrm{M}$ - $\mathrm{H}$ foram feitas em um VSM (Fig. 74b).

Figura 74 - Difratometria em modo de reflectância (a) e histerese magnética (b) de uma amostra de $\mathrm{Co}_{0,9} \mathrm{Fe}_{0,1}$ crescido sobre STO(100)

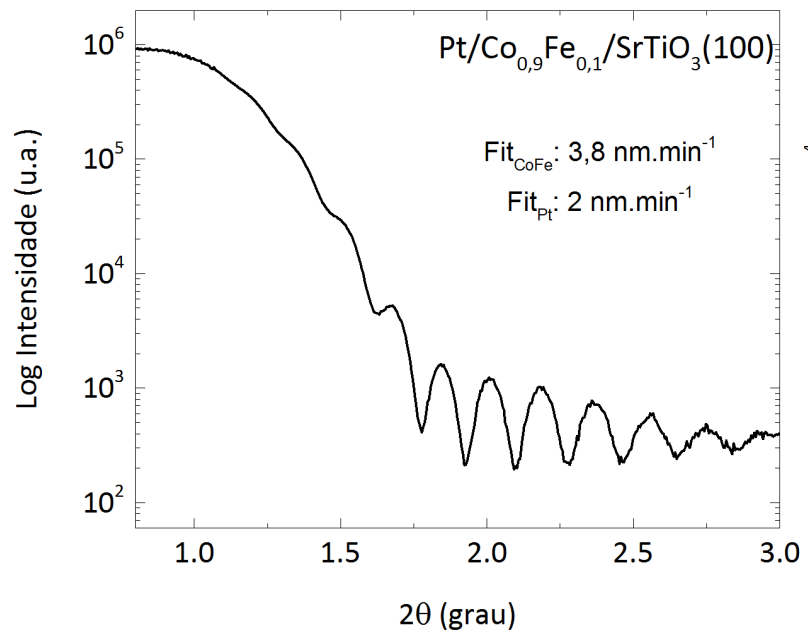

(a)

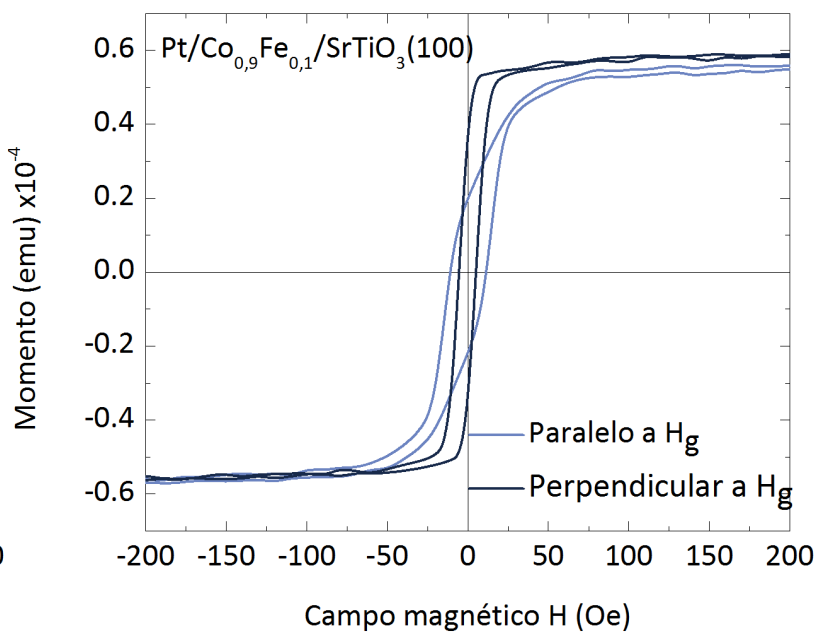

(b)

Qualquer impureza entre estes dois filmes inevitavelmente diminui ou destrói a interação puramente interfacial entre os momentos de spin da estrutura 
ferromagnética do filme de $\mathrm{Co}_{0,9} \mathrm{Fe}_{0,1}$ e os orbitais do filme antiferromagnético de LBFO.

Nesse sentido, imagens de microscopia eletrônica de transmissão de alta resolução (Fig. 75a) e imagens de microscopia eletrônica de transmissão por varredura em modo HAADF (Fig. 75b) foram feitas para a verificação transversal dos filmes obtidos.

Figura 75 - Micrografia de microscopia eletrônica de transmissão de alta resolução da seção transversal da amostra de $\mathrm{Pt} / \mathrm{Co}_{0,90} \mathrm{Fe}_{0,10} / \mathrm{Bi}_{0,90} \mathrm{La}_{0,10} \mathrm{FeO}_{3} / \mathrm{SrRuO}_{3} / \mathrm{SrTiO}_{3}$ (a), imagem de STEM em modo HAADF da interfaec entre as estruturas cristalinas do filme $\mathrm{Bi}_{0,90} \mathrm{La}_{0,10} \mathrm{FeO}_{3}$ e do filme $\mathrm{Co}_{0,90} \mathrm{Fe}_{0,10}$ (b).

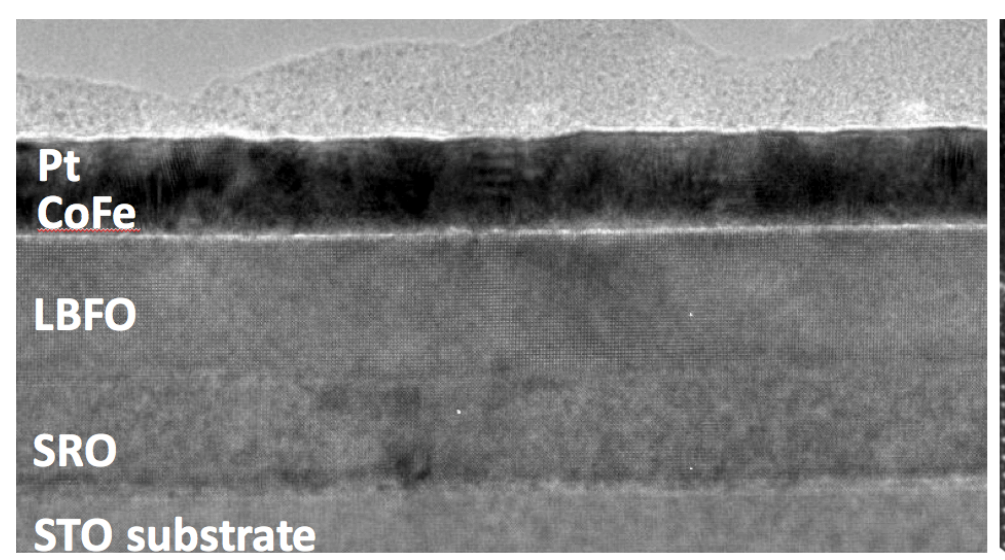

(a)

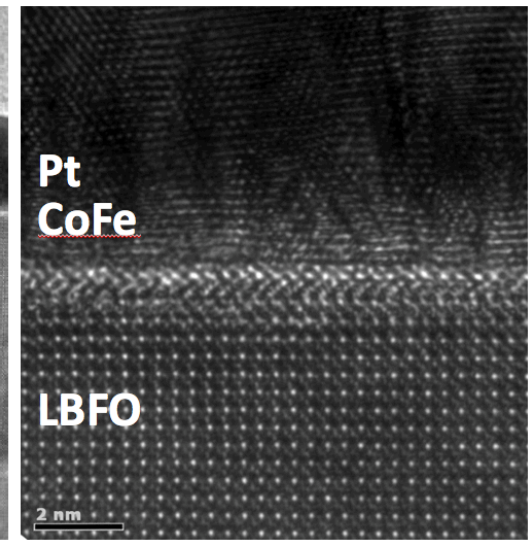

(b)

$\mathrm{O}$ acoplamento criado entre a estrutura do filme LBFO e o filme de $\mathrm{Co}_{0,9} \mathrm{Fe}_{0,1}$ dá-se exclusivamente pelos spins dos últimos planos ferromagnéticos da estrutura antiferromagnética do LBFO. Por ser fortemente ferromagnético, o filme de $\mathrm{Co}_{0,9} \mathrm{Fe}_{0,1}$ apresenta um eixo preferencial de magnetização (easy axis) com valores de coercividade em torno de 5 Oe (Fig. 74b).

Com a interação dos spins desta estrutura com a estrutura do filme multiferroico, devido ao acoplamento criado, valores de coercividade para a estrutura passam para valores da ordem de 80 Oe para amostras crescidas sobre substratos de $\mathrm{SrTiO}_{3}$ e para 180 Oe quando a amostra foi crescida sobre STO/Si, como pode ser observado na Figura 76. 
Figura 76 - Curvas de histerese magnética $\mathrm{MH}$ da amostra $\mathrm{Pt} / \mathrm{Co}_{0,90} \mathrm{Fe}_{0,10} / \mathrm{Bi}_{0,90} \mathrm{La}_{0,10} \mathrm{FeO}_{3} / \mathrm{SrRuO}_{3}$ crescida em dois diferentes substratos $\mathrm{SrTiO}_{3}$ e $\mathrm{SrTiO}_{3} / \mathrm{Si}$.

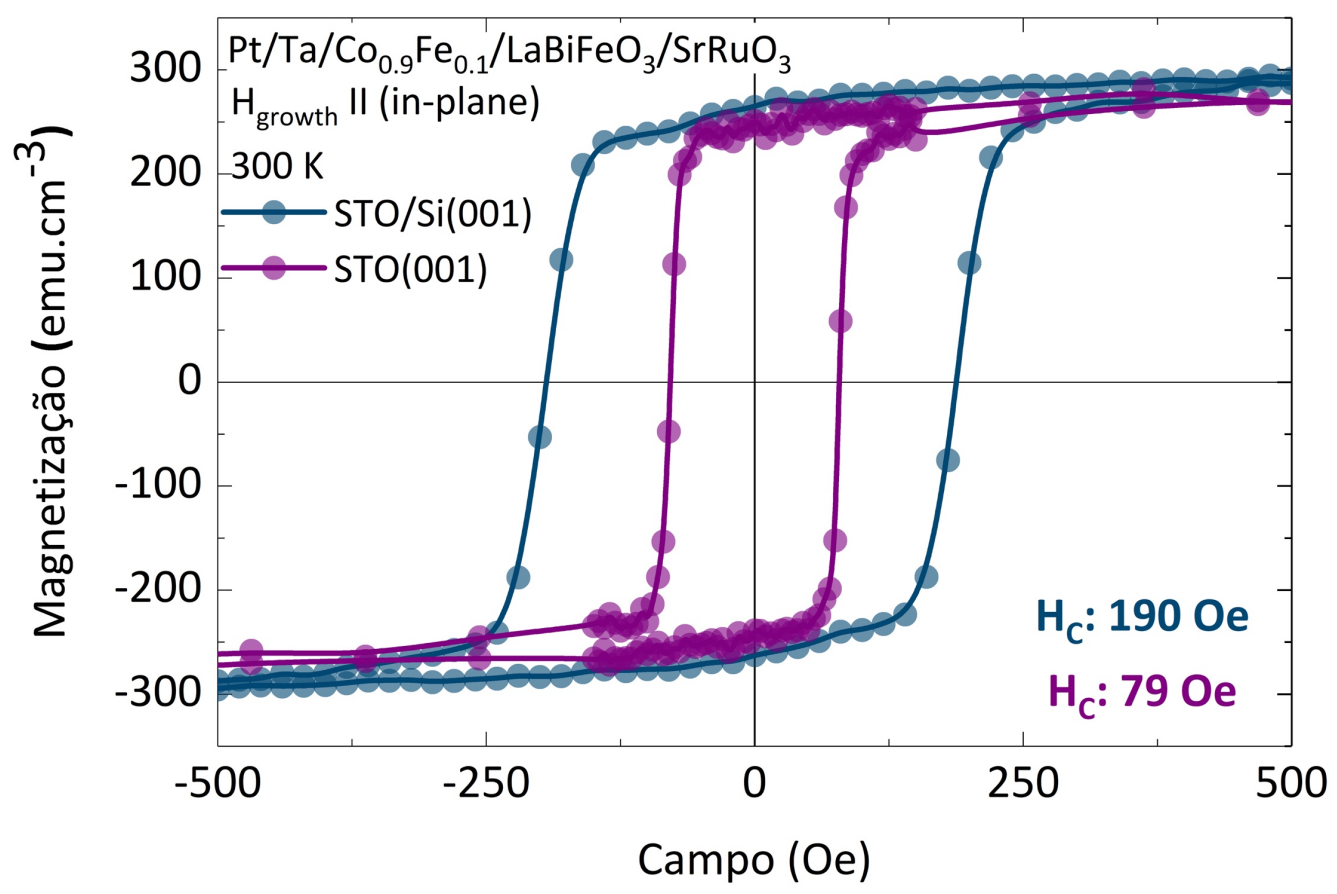

Exatamente pela diferença entre os valores de coercividade indicados anteriormente (5 Oe de coercividade para o filme $\mathrm{Co}_{0,9} \mathrm{Fe}_{0,1}$ puro crescido sobre STO e 190 Oe para o filme de $\mathrm{Co}_{0,9} \mathrm{Fe}_{0,1}$ crescido sobre LBFO) que é possível comprovar o acoplamento entre as estruturas antiferromagnética e ferromagnética dos filmes finos crescidos epitaxialmente sobre silício (STO/Si), tornando esse sistema adaptável para as atuais tecnologias de produção de dispositivos eletrônicos.

Lembrando que as estruturas dos demais filmes e substratos das amostras trabalhadas aqui apresentam comportamento paramagnético, o que não pode justificar um aumento na contribuição dos valores de coercividade mostrados nas curvas de histerese magnética.

Outras condições foram usadas para o crescimento de sistemas FM/AFM com filmes BFO e LBFO, duas dessas melhores condições foram mostradas na Figura 76 e os valores de coercividade magnética das demais condições podem ser consultados na Tabela 5. 
Tabela 5 - Descrição dos valores de coercividade e shift magnético no plano e fora do plano para diferentes amostras de BFO e LBFO crescidas em diferentes condições e diferentes substratos.

\begin{tabular}{|c|c|c|c|c|}
\hline & $\mathrm{IP}-\mathrm{H}_{\mathrm{C}}$ & $\mathrm{IP}-\mathrm{H}_{\mathrm{EB}}$ & $\mathrm{OOP}-\mathrm{H}_{\mathrm{C}}$ & $\mathrm{OOP}-\mathrm{H}_{\mathrm{EB}}$ \\
\hline \multicolumn{5}{|l|}{ Composição } \\
\hline BFO $100 \mathrm{~nm}$ & $51 \mathrm{Oe}$ & $20 \mathrm{Oe}$ & 248 Oe & $16 \mathrm{Oe}$ \\
\hline LBFO $100 \mathrm{~nm}$ & $46.5 \mathrm{Oe}$ & $28 \mathrm{Oe}$ & $135 \mathrm{Oe}$ & $42 \mathrm{Oe}$ \\
\hline LBFO 20 nm (estequiométrico) & $78 \mathrm{Oe}$ & $\mathrm{O} O \mathrm{Oe}$ & 132 Oe & $50 \mathrm{Oe}$ \\
\hline LBFO $20 \mathrm{~nm}$ (excesso de 20\% Bi) & $120 \mathrm{Oe}$ & 0 Oe & $140 \mathrm{Oe}$ & $36 \mathrm{Oe}$ \\
\hline \multicolumn{5}{|l|}{ Espessura } \\
\hline LBFO $20 \mathrm{~nm}$ & $78 \mathrm{Oe}$ & $\mathrm{O} \mathrm{Oe}$ & 132 Oe & $50 \mathrm{Oe}$ \\
\hline LBFO $100 \mathrm{~nm}$ & $46.5 \mathrm{Oe}$ & $28 \mathrm{Oe}$ & $135 \mathrm{Oe}$ & $42 \mathrm{Oe}$ \\
\hline \multicolumn{5}{|l|}{ Frequência de crescimento } \\
\hline LBFO 20 nm (3 Hz) & $94 \mathrm{Oe}$ & $12 \mathrm{Oe}$ & $45 \mathrm{Oe}$ & $25 \mathrm{Oe}$ \\
\hline LBFO 20 nm (5 Hz) & $78 \mathrm{Oe}$ & $\mathrm{OOe}$ & $132 \mathrm{Oe}$ & $50 \mathrm{Oe}$ \\
\hline \multicolumn{5}{|l|}{ Substrato } \\
\hline LBFO 20 nm/STO(001) & $78 \mathrm{Oe}$ & O Oe & $132 \mathrm{Oe}$ & $50 \mathrm{Oe}$ \\
\hline LBFO 20 nm/STO/Si(001) & 189 Oe & $0 \mathrm{Oe}$ & $103 \mathrm{Oe}$ & $25 \mathrm{Oe}$ \\
\hline
\end{tabular}




\section{CONCLUSÃO 06}

\section{CONCLUSÃO}

De forma breve, este trabalho apresenta uma proposta de estudo, controle e manipulação de novos materiais multiferroicos baseados em ferrita de bismuto dopados com íons terra raras. Valores baixos de coercividade elétrica tornaram o estudo do $\mathrm{LaBiFeO}_{3}$ foco deste projeto para sua integração como material funcional eficiente.

Filmes finos epitaxiais multiferroicos de diferentes espessuras foram obtidos pela técnica de deposição a vapor por laser pulsado (PLD) com excelentes características estruturais e topográficas. Os filmes finos com $20 \mathrm{~nm}$ de espessura apresentaram rugosidade em uma área de $5 \mu \mathrm{m}^{2}$ de aproximadamente $0,2 \mathrm{~nm}$ e estrutura de domínios ferroelétricos desordenados.

Foi possível obter valores de piezoeletricidade das amostras de LBFO com 20 $\mathrm{nm}$ de espessura da ordem de $0,1 \mathrm{~V}$ em regime quase-estático (baixa frequência) e seu comportamento ferroelétrico com coercividade da ordem de $0,5 \mathrm{~V}$ para operação em regimes dinâmicos.

Mesmo com dopagem com 10\% de La, o ordenamento antiferromagnético da estrutura do $\mathrm{BiFeO}_{3}$ se manteve estável em temperatura ambiente, apresentando 
temperatura de Néel próximo de valores característicos para a composição de $\mathrm{BiFeO}_{3}$ não dopada.

As condições de crescimento, tanto dos filmes ferroelétricos como dos filmes ferromagnéticos deste trabalho, foram optimizadas para evitar a formação de fases secundárias ou impurezas nos filmes obtidos tanto por PLD como por sputtering.

Os fenômenos de polarização elétrica das amostras de LBFO seguiram um padrão de comportamento semelhante a lei de relação entre coercividade e espessura de camadas ferroelétricas dada pela expressão $\mathrm{d}^{-2 / 3}$. Ao passo que em filmes ultrafinos da ordem de $20 \mathrm{~nm}$, um limiar de energia mínimo determina os fenômenos fundamentais de polarização.

Ensaios de fadiga ferroelétrica provaram a estabilidade da estrutura ferroelétrica de filmes finos de LBFO $(20 \mathrm{~nm})$ para operação de leitura e gravação acima de 10 anos $\left(10^{10}\right.$ ciclos).

O acoplamento interfacial entre a estrutura antiferromagnética do LBFO e o comportamento ferromagnético da liga metálica de $\mathrm{Co}_{0,90} \mathrm{Fe}_{0,10}$ foi verificado por medidas de histerese $\mathrm{M}-\mathrm{H}$, com aumento no campo coercivo da ordem de 8 vezes ( $80 \mathrm{Oe}$ ) comparado com os valores da estrutura ferromagnética ( 10 Oe).

O conjunto de informações apresentadas indicam a viabilidade do uso da composição de $\mathrm{LaBiFeO}_{3}$ como um material candidato a aplicações em dispositivos de memória lógica e spintrônica de baixíssimo consumo energético por operação. 


\section{PERSPECTIVAS 06}

\section{PERSPECTIVAS}

Dentro das perspectivas deste trabalho, o estudo e controle das propriedades multiferroicas de filmes finos de $\mathrm{LaBiFeO}_{3}$ também permite a integração dos sistemas ferroelétricos e ferromagnéticos para o desenvolvimento de dispositivos baseados em spintrônica, sendo a magnetorresistência anisotrópica uma das vertentes deste projeto.

O desenvolvimento de dispositivos lógicos operados por efeito Hall (JUNGWIRTH; WUNDERLICH; OLEJNÍK, 2012) tem grandes chances de alcançar a escala comercial para fabricação de novas tecnologias mais eficientes. O controle de operações lógicas dada pela variação de resistência elétrica em transistores dada pela manipulação de spins acoplados a uma estrutura ferroelétrica permite que a alteração de estados on/off seja feita pela aplicação de campos elétricos externos, o que reduz consideravelmente o consumo elétrico de cada dispositivo.

Os estudos sobre as aplicações do efeito Hall e de spin-transfer torque na manipulação de sistemas magnetoelétricos acoplados têm sido alvo de investigação e como parte das perspectivas deste trabalho, o desenvolvimento de um dispositivo (Fig. 78) baseado nesses fenômenos tem sido desenvolvido para fabricação de uma nova classe de heteroestruturas funcionais para aplicação como dispositivos lógicos (MCGUIRE; POTTER, 1975; BRATAAS; KENT; OHNO, 2012; HERON et al., 2014; 
MEENA et al., 2014; MATSUKURA; TOKURA; OHNO, 2015; RISINGGÅRD; KULAGINA; LINDER, 2016; BHUKTARE et al., 2017).

Figura 77 - Dispositivo Hall formado por filme ultrafino de $\mathrm{LaBiFeO}_{3}(20 \mathrm{~nm})$ e filme ferromagnético de CoFe $(2 \mathrm{~nm})$ crescidos sobre DSO(110).

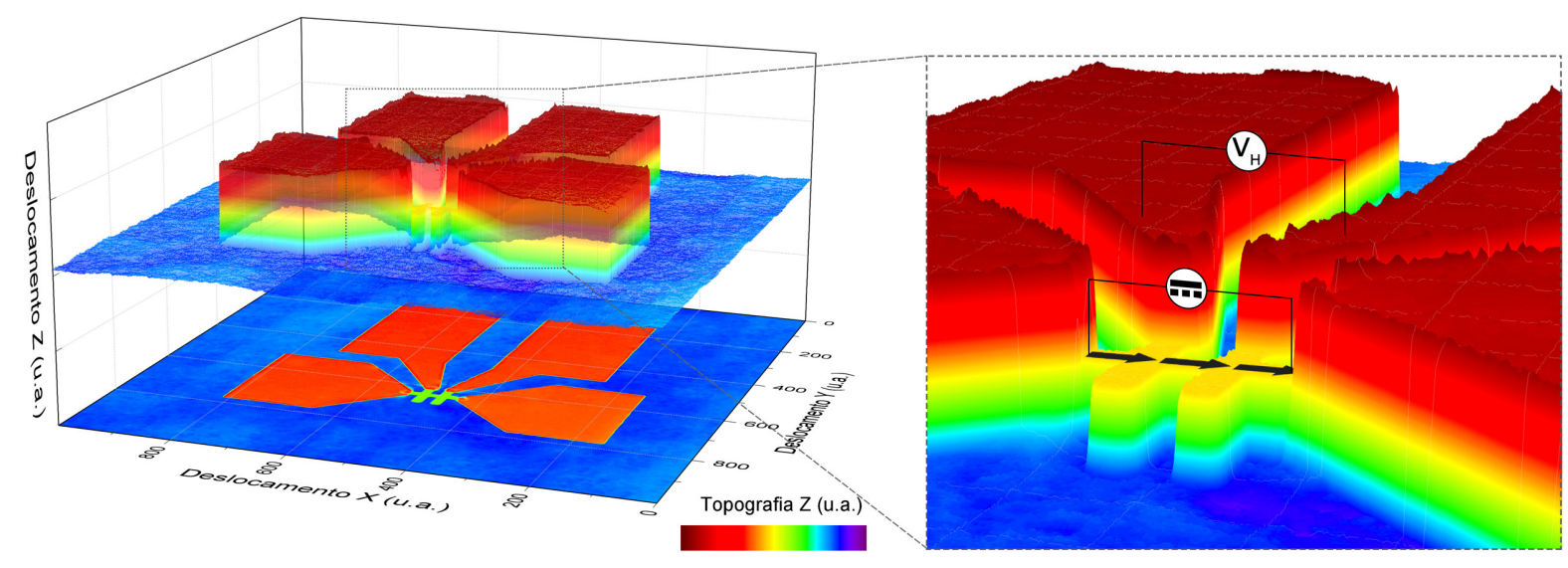

Fonte: $\mathrm{O}$ autor.

Os dispositivos de magnetorresistência anisotrópica (AMR) são formados pelo crescimento epitaxial de uma cada ferroelétrica de material multiferroico (LBFO) sobre o qual é depositado uma camada ferromagnética de $\mathrm{Co}_{0,9} \mathrm{Fe}_{0,1}$ em uma geometria do tipo Hall bar, como mostrado na Figura 78.

A passagem de corrente elétrica entre as extremidades do filme ferromagnético do dispositivo varia de acordo com os princípios da resistência hall (JUNGWIRTH; WUNDERLICH; OLEJNÍK, 2012). Dados preliminares mostram o efeito Hall anisotrópico presente nos dispositivos crescidos sobre filmes de LBFO (Fig. 79)

Uma vez alcançada a possibilidade de desenvolver a magnetorresistência sobre o conjunto de filmes finos de $\mathrm{LBFO}$ e $\mathrm{Co}_{0,9} \mathrm{Fe}_{0,1}$, as etapas seguintes a serem alcançadas são a manipulação ferroelétrica da camada multiferroicos e os estudos de acoplamento entre os filmes para a manipulação de spins magnéticos da estrutura FM, alterando e modulando resistência aplicada através do dispositivo. 
Figura 78 - Magnetoresistência anisotrópica do sistema $\mathrm{Co}_{0,9} \mathrm{Fe}_{0,1} / \mathrm{LBFO}$ crescido sobre DSO.

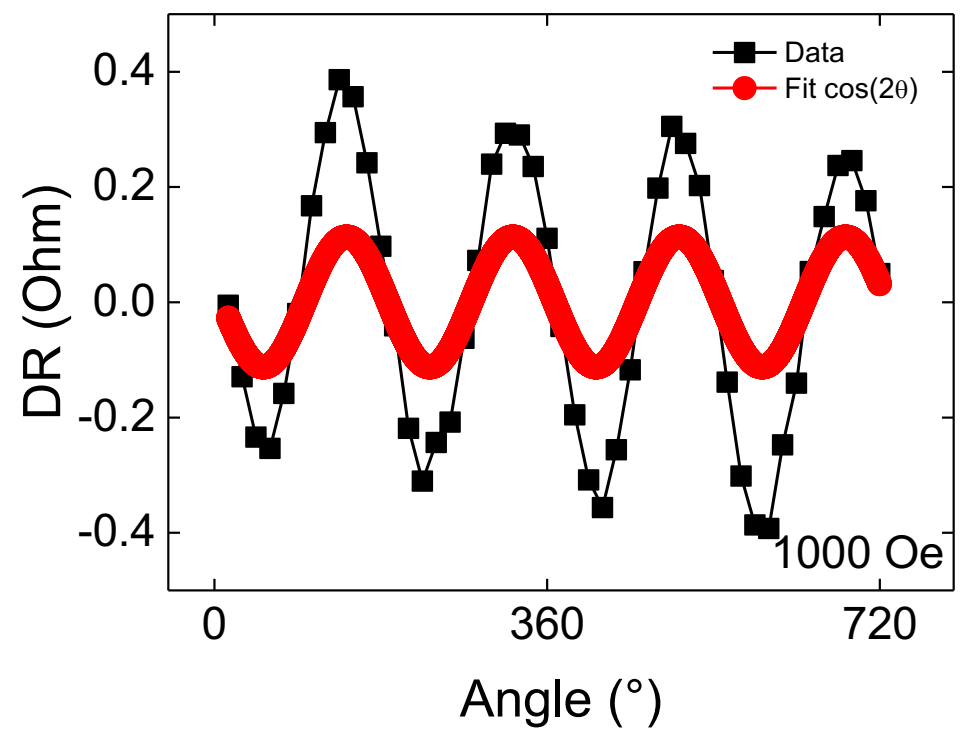

Uma vez alcançada a manipulação do acoplamento entre os filmes e a modulação da resistência Hall, uma nova classe de dispositivos pode ser criada para produção de novos transistores mais eficientes. 


\section{REFERÊNCIAS BIBLIOGRÁFICAS}

AGAR, J. C.; PANDYA, S.; XU, R.; YADAV, A. K.; LIU, Z.; ANGSTEN, T.; SAREMI, S.; ASTA, M.; RAMESH, R.; MARTIN, L. W. Frontiers in strain-engineered multifunctional ferroic materials. MRS Communications, p. 1-16, 2016. Disponível em: <https://www.cambridge.org/core/article/frontiers-in-strain-engineeredmultifunctional-ferroic-materials/95E71B1B18C06C02A60359A580051DA3>.

ALGUERÓ, M.; GREGG, J. M. Nanoscale Ferroelectrics and Multiferroics. [s.I: S.n.]v. 1

ASKELAND, D. R.; FULAY, P. P.; WRIGHT, W. J. The science and engineering of Materials. 6. ed. [s.I.] Cengage Learning, Inc., 2010.

BAEK, S. H.; EOM, C. B. Reliable polarization switching of BiFeO3. Philosophical transactions. Series A, Mathematical, physical, and engineering sciences, $v$. 370, n. 1977, p. 4872-89, 2012. Disponível em: <http://www.ncbi.nlm.nih.gov/pubmed/22987033>.

BARDEEN, J. John Bardeen - Nobel Lecture: Semiconductor Research Leading to the Point Contact Transistor. Disponível em:

<http://www.nobelprize.org/nobel_prizes/physics/laureates/1956/bardeenlecture.html\%5Cnhttp://scitation.aip.org/content/aapt/journal/ajp/33/5/10.1119/1.1971 617>. Acesso em: 1 jan. 2017.

BHUKTARE, S.; SINGH, H.; BOSE, A.; TULAPURKAR, A. A. Spintronic Oscillator Based on Spin-Current Feedback Using the Spin Hall Effect. Physical Review Applied, v. 7, n. 1, p. 14022, 27 jan. 2017. Disponível em:

<https://link.aps.org/doi/10.1103/PhysRevApplied.7.014022>.

BRATAAS, A.; KENT, A. D.; OHNO, H. Current-induced torques in magnetic materials. Nature Materials, v. 11, n. 5, p. 372-381, 23 abr. 2012. Disponível em: <http://dx.doi.org/10.1038/nmat3311>.

BUSCH, G. Early history of the physics and chemistry of semiconductors-from doubts to fact in a hundred years. European Journal of Physics, v. 10, n. 4, p. 254-264, 1 out. 1989. Disponível em: <http://stacks.iop.org/01430807/10/i=4/a=002?key=crossref.45b2a59e4b5d8aff8fdcfe2b818d3e41>.

CAO, G. Nanostructures and Nanomaterials: Synthesis, properties and applications. London: Imperial College Press, 2004.

CATALAN, G.; SCOTT, J. F. Physics and applications of bismuth ferrite. Advanced Materials, v. 21, n. 24, p. 2463-2485, 2009. 
CHANDRA, P.; DAWBER, M.; LITTLEWOOD, P. B.; SCOTT, J. F. Scaling of the Coercive Field with Thickness in Thin-Film Ferroelectrics. Ferroelectrics, v. 313, n. 1, p. 7-13, 2004.

CHANDRAKASAN, A. P.; BRODERSEN, R. W. LOW POWER DIGITAL CMOS DESIGN. [s.I.] Springer Science+Business Media New York, 1995.

CHOI, A. Y.; LEE, C. J.; PARK, J.; KIM, D.; KIM, Y. T. Corrugated Textile based Triboelectric Generator for Wearable Energy Harvesting. Scientific Reports, v. 7, p. 45583, 2017. Disponível em: <http://www.nature.com/articles/srep45583>.

CHRISTEN, H. M.; ERES, G. Recent advances in pulsed-laser deposition of complex oxides. Journal of Physics: Condensed Matter, v. 20, p. 1-16, 2008.

CURIE, P.; CURIE, J. Developpement, par pression, de l'électricité polaire dans les cristaux hémièdres à faces inclinées. Comptes Rendus, v. 91, p. 294-295, 1880.

CURIE, P.; CURIE, J. Contractions et dilatations produites par des tensions électriques dans les cristaux hémièdres à faces inclinées. Comptes Rendus, v. 93, p. 1137-1140, 1881.

DAMODARAN, A. R.; AGAR, J. C.; PANDYA, S.; CHEN, Z.; DEDON, L.; XU, R.; APGAR, B.; SAREMI, S.; MARTIN, L. W. New modalities of strain-control of ferroelectric thin films. Journal of Physics: Condensed Matter, v. 28, n. 26, p. 263001, 2016. Disponível em: <http://stacks.iop.org/09538984/28/i=26/a=263001? key=crossref.4847587df3d1f72d509769297bab84ee>.

DEEPAK, F. L.; MAYORAL, A.; ARENAL, R. Advanced Transmission Electron Microscopy: Applications to Nanomaterials. [s.l.] Springer International Publishing Switzerland, 2015.

DINEVA, P. et al. Piezoelectric Materials. In: SolidMechanics and Its Applications. [s.I.] Springer International Publishing Switzerland, 2014.

DREISMANN, A.; OHADI, H.; REDONDO, Y. V.; BALILI, R.; RUBO, Y. G.; TSINTZOS, S. I.; DELIGEORGIS, G.; HATZOPOULOS, Z.; SAVVIDIS, P. G.; BAUMBERG, J. J.; DEL VALLE-INCLAN REDONDO, Y.; BALILI, R.; RUBO, Y. G.; TSINTZOS, S. I.; DELIGEORGIS, G.; HATZOPOULOS, Z.; SAVVIDIS, P. G.; BAUMBERG, J. J. A sub-femtojoule electrical spin-switch based on optically trapped polariton condensates. Nature Materials, v. 15, n. 10, p. 1074-1078, 8 ago. 2016. Disponível em: <http://www.nature.com/doifinder/10.1038/nmat4722>.

EASON, R. Pulsed Laser Deposition of Thin Films. [s.I: s.n.]

EERENSTEIN, W.; MATHUR, N. D.; SCOTT, J. F.; F, J. Multiferroic and magnetoelectric materials. Nature, v. 442759, n. August, p. 759-765, 2006.

FIEBIG, M.; LOTTERMOSER, T.; MEIER, D.; TRASSIN, M. The evolution of multiferroics. Nature Reviews Materials, v. 1, n. 8, p. 16046, 5 jul. 2016. Disponível em: <http://e-citations.ethbib.ethz.ch/view/pub:179879>.

FURUKAWA, Y. History of semiconductors. Bulletin of the Japan Institute of 
Metals, v. 29, n. 1, p. 18-21, 1990. Disponível em:

<http://joi.jlc.jst.go.jp/JST.Journalarchive/materia1962/29.18?from=CrossRef>.

GRAY, S. A Letter to Cromwell Mortimer, M. D. Secr. R. S. Containing Several Experiments concerning Electricity; By Mr. Stephen Gray. Philosophical

Transactions of the Royal Society of London, v. 37, n. 417-426, p. 18-44, 1 jan. 1731. Disponível em:

<http://rstl.royalsocietypublishing.org/cgi/doi/10.1098/rstl.1731.0005>.

GUYONNET, J. Ferroelectric Domain Walls: Statics, Dynamics and

Functionalities revealed by atomics force microscopy. 2014. University of Geneva, 2014.

HASEK, J. (ed.). X-Ray and Neutron Structure Analysis in Materials Science. New York and London: Plenum Press, 1987.

HEO, Y.; HONG LEE, J.; XIE, L.; PAN, X.; YANG, C.-H.; SEIDEL, J. Enhanced conductivity at orthorhombic-rhombohedral phase boundaries in $\mathrm{BiFeO} 3$ thin films. NPG Asia Materials, v. 8, n. 8, p. e297, 2016. Disponível em:

$<$ http://www.nature.com/doifinder/10.1038/am.2016.120>.

HERON, J. T. Electric Field Control of Ferromagnetism and Magnetic Devices Using Multiferroics. 2013. Universisty of California, Berkeley, 2013.

HERON, J. T.; BOSSE, J. L.; HE, Q.; GAO, Y.; TRASSIN, M.; YE, L.; CLARKSON, J. D.; WANG, C.; LIU, J.; SALAHUDDIN, S.; RALPH, D. C.; SCHLOM, D. G.; IÑIGUEZ, J.; HUEY, B. D.; RAMESH, R. Deterministic switching of ferromagnetism at room temperature using an electric field. Nature, v. 516, n. 7531, p. 370-3, 2014.

Disponível em: <http://dx.doi.org/10.1038/nature14004>.

HERON, J. T.; SCHLOM, D. G.; RAMESH, R. Electric field control of magnetism using BiFeO3-based heterostructures. APPLIED PHYSICS REVIEWS, v. 1, n. 21303, p. 1-18, 2014.

HUMMEL, R. E. Understanding Materials Science. 2. ed. [s.I.] Springer-Verlag New York, LLC., 2004.

INTEL. 7th Generation Intel ® Processor Families for S Platforms (Document Number:335195-001). [s.I: s.n.].

ITRS. International Technology Roadmap for Semiconductors 2.0: Executive Report. International technology roadmap for semiconductors, p. 79, 2015. Disponível em: <http://www.semiconductors.org/main/

2015_international_technology_roadmap_for_semiconductors_itrs/>.

JANG, B.-K.; LEE, J. H.; CHU, K.; SHARMA, P.; KIM, G.-Y.; KO, K.-T.; KIM, K.-E.; KIM, Y.-J.; KANG, K.; JANG, H.-B.; JANG, H.; JUNG, M. H.; SONG, K.; KOO, T. Y.; CHOI, S.-Y.; SEIDEL, J.; JEONG, Y. H.; OHLDAG, H.; LEE, J.-S.; YANG, C.-H. Electric-field-induced spin disorder-to-order transition near a multiferroic triple phase point. Nature Physics, v. 13, n. October 2016, 2016. Disponível em:

<http://www.nature.com/doifinder/10.1038/nphys3902>. 
JIA, C. L.; CONTRERAS, J. R.; POPPE, U.; KOHLSTEDT, H.; WASER, R.; URBAN, $\mathrm{K}$. Lattice strain and lattice expansion of the SrRuO 3 layers in SrRuO 3/PbZr 0.52Ti 0.480 3/SrRuO 3 multilayer thin films. Journal of Applied Physics, v. 92, n. 1, p. 101-105, 2002.

JO, J. Y.; KIM, Y. S.; NOH, T. W.; YOON, J.-G.; SONG, T. K. Coercive fields in ultrathin BaTiO3 capacitors. Applied Physics Letters, v. 89, n. 23, p. 232909, 4 dez. 2006. Disponível em: <http://aip.scitation.org/doi/10.1063/1.2402238>.

JR., W. D. C.; RETHWISCH, D. G. Materials Science and Engineering: An Introduction. 9. ed. [s.I.] Wiley-VCH GmbH \& Co. KGaA, 2013.

JUNGWIRTH, T.; WUNDERLICH, J.; OLEJNÍK, K. Spin Hall effect devices. Nature Materials, v. 11, n. 5, p. 382-390, 23 abr. 2012. Disponível em:

$<$ http://dx.doi.org/10.1038/nmat3279>.

KEYES, R. W. Physical limits of silicon transistors and circuits. Reports on Progress in Physics, v. 68, n. 12, p. 2701-2746, 2005.

KHOLKIN, A.; KALININ, S.; ROELOFS, A.; GRUVERMAN, A. Review of Ferroelectric Domain Imaging by Piezoresponse Force Microscopy. Scanning probe microscopy electrical and electromechanical phenomena at the nanoscale, v. 1, p. 173-214, 2007. Disponível em: <http://www.springerlink.com/index/k731272704126051.pdf>.

KHOMSKII, D. Classifying multiferroics: Mechanisms and effects. Physics, v. 2, n. 20, 2009. Disponível em: <http://link.aps.org/doi/10.1103/Physics.2.20>.

KUMAR, A.; SHARMA, P.; VARSHNEY, D. Structural and Ferroic Properties of La , Nd , and Dy Doped BiFeO 3 Ceramics. Ceramics International, v. 2015, 2015.

LORENZ, M.; RAO, M. S. R.; VENKATESAN, T.; FORTUNATO, E.; BARQUINHA, P.; BRANQUINHO, R.; SALGUEIRO, D.; MARTINS, R.; CARLOS, E.; LIU, A.; SHAN, F. K.; GRUNDMANN, M.; BOSCHKER, H.; MUKHERJEE, J.; PRIYADARSHINI, M.; DASGUPTA, N.; ROGERS, D. J.; TEHERANI, F. H.; SANDANA, E. V.; BOVE, P.; RIETWYK, K.; ZABAN, A.; VEZIRIDIS, A.; WEIDENKAFF, A.; MURALIDHAR, M.; MURAKAMI, M.; ABEL, S.; FOMPEYRINE, J.; ZUNIGA-PEREZ, J.; RAMESH, R.; SPALDIN, N. A.; OSTANIN, S.; BORISOV, V.; MERTIG, I.; LAZENKA, V.;

SRINIVASAN, G.; PRELLIER, W.; UCHIDA, M.; KAWASAKI, M.; PENTCHEVA, R.; GEGENWART, P.; GRANOZIO, F. M.; FONTCUBERTA, J.; PRYDS, N. The 2016 oxide electronic materials and oxide interfaces roadmap. Journal of Physics D: Applied Physics, v. 49, n. 433001, p. 1-53, 2016.

LYTOVCHENKO, V. G.; STRIKHA, M. V. 100 years of semiconductor science.

Europhysics News, v. 45, n. 1, p. 15-18, 5 jan. 2014. Disponível em:

<http://www.europhysicsnews.org/10.1051/epn/2014101>.

MARKOV, I. L. Limits on fundamental limits to computation. Nature, v. 512, n. 7513, p. 147-154, 2014. Disponível em:

<http://dx.doi.org/10.1038/nature13570\%5Cnhttp://www.nature.com/doifinder/10.103 8/nature13570\%5Cnhttp://dx.doi.org/10.1038/nature13570\$\%5C\$nhttp://www.nature. com/doifinder/10.1038/nature13570>. 
MARKYS, G. Characterisation of Ferroelectric Bulk Materials and Thin Films. Dordrecht: Springer Netherlands, 2014. v. 2

\section{MARTIN, L. W. Engineering Multiferroic Materials and New Functionalities in} Materials. 2008. University of California, Berkeley, 2008.

MARTIN, L. W.; CHU, Y. H.; RAMESH, R. Advances in the growth and characterization of magnetic, ferroelectric, and multiferroic oxide thin films. Materials Science and Engineering R: Reports, v. 68, n. 4-6, p. 89-133, 2010.

MARTIN, L. W.; CRANE, S. P.; CHU, Y.-H.; HOLCOMB, M. B.; GAJEK, M.; HUIJBEN, M.; YANG, C.-H.; BALKE, N.; RAMESH, R. Multiferroics and magnetoelectrics: thin films and nanostructures. Journal of Physics: Condensed Matter, v. 20, n. 43, p. 434220, 29 out. 2008. Disponível em:

<http://stacks.iop.org/0953-

8984/20/i=43/a=434220?key=crossref. $f 9 e b a c 8 d 0 f 94636 f 6 b 597 e c 0 f c a 4 a a 35>$.

MARTIN, L. W.; RAPPE, A. M. Thin-film ferroelectric materials and their applications. Nature Reviews Materials, v. 2, n. 2, p. 16087, 15 nov. 2016. Disponível em: <http://www.nature.com/articles/natrevmats201687>.

MATSUKURA, F.; TOKURA, Y.; OHNO, H. Control of magnetism by electric fields. Nature Nanotechnology, v. 10, n. 3, p. 209-220, 5 mar. 2015. Disponível em: <http://www.nature.com/doifinder/10.1038/nnano.2015.22>.

MCGUIRE, T. R.; POTTER, R. I. Anisotropic Magnetoresistance in Ferromagnetic 3D Alloys. IEEE Transactions on Magnetics, v. 11, n. 4, p. 1018-1038, 1975.

MEENA, J.; SZE, S.; CHAND, U.; TSENG, T.-Y. Overview of emerging nonvolatile memory technologies. Nanoscale Research Letters, v. 9, n. 1, p. 526, 2014. Disponível em:

<http://www.pubmedcentral.nih.gov/articlerender.fcgi?artid=4182445\&tool=pmcentre z\&rendertype=abstract $\% 5 C$ nhttp://nanoscalereslett.springeropen.com/articles/10.118 6/1556-276X-9-526>.

MERZ, W. J. Domain formation and domain wall motions in ferroelectric BaTiO3 single crystals. Physical Review, v. 95, n. 3, p. 690-698, 1954.

MILLER, D. A. B. Attojoule Optoelectronics for Low-Energy Information Processing and Communications: a Tutorial Review. Journal of Lightwave Technology, v. 35, n. 3, p. 346-396, 18 set. 2016. Disponível em: <http://arxiv.org/abs/1609.05510>.

MISTRY, K. Leading at the edge $10 \mathrm{~nm}$ technology leadership. [s.I: s.n.]. Disponível em: <https://newsroom.intel.com/newsroom/wpcontent/uploads/sites/11/2017/03/Kaizad-Mistry-2017-Manufacturing.pdf>.

MOORE, G. E. Cramming More Components Onto Integrated Circuits. Electronics, v. 38, n. 8, p. 1-4, 1965.

MOORE, G. E. Progress in Digital Integrated Electronics. Electron Devices Meetings, 1975 International, v. 21, p. 11-13, 1975. 
MOORTHY, S. B. K. Thin film structures in energy applications. [s.I: s.n.]

MORELLI, A. Piezoresponse force microscopy of ferroelectric thin

filmsGroningenUniversity of Groningen/UMCG, , 2009. .

MUNDY, J. A.; BROOKS, C. M.; HOLTZ, M. E.; MOYER, J. A.; DAS, H.; RÉBOLA, A. F.; HERON, J. T.; CLARKSON, J. D.; DISSELER, S. M.; LIU, Z.; FARHAN, A.; HELD, R.; HOVDEN, R.; PADGETT, E.; MAO, Q.; PAIK, H.; MISRA, R.;

KOURKOUTIS, L. F.; ARENHOLZ, E.; SCHOLL, A.; BORCHERS, J. A.; RATCLIFF, W. D.; RAMESH, R.; FENNIE, C. J.; SCHIFFER, P.; MULLER, D. A.; SCHLOM, D. $\mathrm{G}$. Atomically engineered ferroic layers yield a room-temperature magnetoelectric multiferroic. Nature, v. 537, n. 7621, p. 523-527, 21 set. 2016. Disponível em: <http://www.nature.com/doifinder/10.1038/nature19343>.

NAGARAJAN, V.; GANPULE, C. S.; ROYTBURD, A.; RAMESH, R. Nanoscale Phenomena in Ferroelectric Thin Films. [s.I: s.n.]v. 42

NGO, C.; VAN DE VOORDE, M. Nanomaterials: doing more with less. In: Nanotechnolog in a Nutshell: From Simple to Complex Systems. [s.I.] Springer US, 2014. p. 67-83.

OTA, H.; MIGITA, S.; HATTORI, J.; FUKUDA, K.; TORIUMI, A. Structural advantages of silicon-on-insulator FETs over FinFETs in steep subthreshold-swing operation in ferroelectric-gate FETs. Japanese Journal of Applied Physics, v. 56, n. 4S, p. 04CD10, 1 abr. 2017. Disponível em: <http://stacks.iop.org/13474065/56/i=4S/a=04CD10?key=crossref.896da19178a4bf057a90179f039c95b3>.

PALEWICZ, A.; PRZENIOSŁO, R.; SOSNOWSKA, I.; HEWAT, A. W. Atomic displacements in BiFeO 3 as a function of temperature: neutron diffraction study. Acta Crystallographica Section B Structural Science, v. 63, n. 4, p. 537-544, 1 ago. 2007. Disponível em: <http://scripts.iucr.org/cgibin/paper?S0108768107023956>.

PAN, D.-F.; ZHOU, M.-X.; LU, Z.-X.; ZHANG, H.; LIU, J.-M.; WANG, G.-H.; WAN, J.G. Local Magnetoelectric Effect in La-Doped BiFeO3 Multiferroic Thin Films Revealed by Magnetic-Field-Assisted Scanning Probe Microscopy. Nanoscale Research Letters, v. 11, n. 1, p. 318, 2016. Disponível em: <http://nanoscalereslett.springeropen.com/articles/10.1186/s11671-016-1534-2>.

PANALYTICAL. X'Pert 3 MRD family. [s.I: s.n.].

PEÑA, M. A.; FIERRO, J. L. G. Chemical structures and performance of perovskite oxides. Chemical Reviews, v. 101, n. 7, p. 1981-2017, jul. 2001. Disponível em: <http://pubs.acs.org/doi/abs/10.1021/cr980129f>.

PETROVIĆ, M.; CHELLAPPAN, V.; RAMAKRISHNA, S. Perovskites: Solar cells \& engineering applications - materials and device developments. Solar Energy, v. 122, p. 678-699, dez. 2015. Disponível em: <http://linkinghub.elsevier.com/retrieve/pii/S0038092X15005277>.

POWELL, R. C.; BEIGLBÖCK, W.; EHLERS, J.; HEPP, K.; WEIDENMÜLLER, H. Symmetry, Group Theory, and the Physical Properties of Crystals. [s.l: s.n.] 
QUITMANN, C.; RAABE, J.; PUZIC, A.; KUEPPER, K.; WINTZ, S. Dynamics of Mesoscopic Magnetic Objects. [s.I: s.n.]v. 133

RAMANATHAN, S. Thin Film Metal-Oxides. Boston, MA: Springer US, 2010.

RAMESH, R.; SPALDIN, N. A. Multiferroics: progress and prospects in thin films. Nature Materials, v. 6, n. 1, p. 21-29, 2007. Disponível em: <http://www.nature.com/doifinder/10.1038/nmat1805>.

RANUÁREZ, J. C.; DEEN, M. J.; CHEN, C.-H. A review of gate tunneling current in MOS devices. Microelectronics Reliability, v. 46, n. 12, p. 1939-1956, dez. 2006. Disponível em: <http://linkinghub.elsevier.com/retrieve/pii/S0026271406000205>.

RIORDAN, M. The Lost History of the Transistor. Disponível em: $<$ http://spectrum.ieee.org/biomedical/devices/the-lost-history-of-the-transistor>. Acesso em: 1 jan. 2017.

RIORDAN, M.; HODDESON, L. The origins of the pn junction. IEEE Spectrum, v. 34, n. 6, p. 46-51, jun. 1997. Disponível em:

<http://ieeexplore.ieee.org/document/591664/>.

RISINGGÅRD, V.; KULAGINA, I.; LINDER, J. Electric field control of magnoninduced magnetization dynamics in multiferroics. Scientific Reports, v. 6, n. Dmi, p. 31800, 2016. Disponível em: <http://arxiv.org/abs/1606.00007>.

ROCKETT, A. The materials science of semiconductors. [s.l: s.n.]

SARASWAT. Thin Dielectrics for MOS Gate, 1996. .

SARWAR, A. Cmos power consumption and cpd calculationProceeding: Design Considerations for Logic Products. [s.I: s.n.]. Disponível em:

<http://www.ti.com/lit/an/scaa035b/scaa035b.pdf>.

SCOTT, J. F. Ferroelectric Memories. Physics World, p. 46-50, 1995. Disponível em: <http://opt.zju.edu.cn/eclass/attachments/2012-02/01-1329898747-

92686.pdf\%0Ahttp://ocean.scihub.cc/2145c3986e0aa49a085a87060b46597f/scott1989.pdf>.

SENGUPTA, A.; SARKAR, C. K. Introduction to Nano Basics to Nanoscience and Nanotechnology. [s.l: s.n.]

SETTER, N.; DAMJANOVIC, D.; ENG, L.; FOX, G.; GEVORGIAN, S.; HONG, S.; KINGON, A.; KOHLSTEDT, H.; PARK, N. Y.; STEPHENSON, G. B.;

STOLITCHNOV, I.; TAGANSTEV, A. K.; TAYLOR, D. V.; YAMADA, T.; STREIFFER, $S$. Ferroelectric thin films: Review of materials, properties, and applications. Journal of Applied Physics, v. 100, n. 5, 2006.

SHIN, Y.-H.; GRINBERG, I.; CHEN, I.-W.; RAPPE, A. M. Nucleation and growth mechanism of ferroelectric domain-wall motion. Nature, v. 449, n. 7164, p. 881-884, 2007.

SINGH, S. K.; MARUYAMA, K.; ISHIWARA, H. The influence of La-substitution on the micro-structure and ferroelectric properties of chemical-solution-deposited BiFeO 
3 thin films. Journal of Physics D: Applied Physics, v. 40, n. 9, p. 2705-2709, 2007. Disponível em: <http://stacks.iop.org/0022-

3727/40/i=9/a=004?key=crossref. $79 c 60630991 f 89 d 2 d 2 c f a f b e c 0 f 6 a 2 c 6>$.

SOCIETY OF LONDON, R. Philosophical Transactions of the Royal Society of London. [s.I.] W. Bowyer and J. Nichols, 1833.

STOLICHNOV, I.; TAGANTSEV, a.; COLLA, E.; GENTIL, S.; HIBOUX, S.; BABOROWSKI, J.; MURALT, P.; SETTER, N. Downscaling of Pb(Zr,Ti)O[sub 3] film thickness for low-voltage ferroelectric capacitors: Effect of charge relaxation at the interfaces. Journal of Applied Physics, v. 88, n. 4, p. 2154, 2000. Disponível em: $<$ http://scitation.aip.org/content/aip/journal/jap/88/4/10.1063/1.1305854>.

SUN, H.; ZHANG, Y.; ZHANG, J.; SUN, X.; PENG, H. Energy harvesting and storage in 1D devices. Nature Reviews Materials, v. 2, n. 6, p. 17023, 25 abr. 2017. Disponível em: <http://www.nature.com/articles/natrevmats201723>.

SUWAS, S.; RAY, R. K. Crystallographic Texture of Materials. [s.l: s.n.]

THOMAS, J.; GEMMING, T. Analytical Transmission Electron Microscopy. [s.l: s.n.]v. 78

TRASSIN, M. Low energy consumption spintronics using multiferroic heterostructures. Journal of Physics: Condensed Matter, v. 28, n. 3, p. 33001, 27 jan. 2016. Disponível em:

<http://www.ncbi.nlm.nih.gov/pubmed/26703387\%5Cnhttp://stacks.iop.org/09538984/28/i=3/a=033001?key=crossref.cee06f6301f7c74b480930731f2efca8>.

ULRICH, R.; SCHAPER, L.; NELMS, D.; LEFTWICH, M. Comparison of Paraelectric and Ferroelectric Materials for Applications as Dielectrics in Thin Film Integrated Capacitors. The International Journal of Microcircuits and Electronic Packaging, v. 23, p. $172-181,2000$.

VAILIONIS, A.; BOSCHKER, H.; SIEMONS, W.; HOUWMAN, E. P.; BLANK, D. H. A.; RIJNDERS, G.; KOSTER, G. Misfit strain accommodation in epitaxial ABO3 perovskites: Lattice rotations and lattice modulations. Physical Review B -

Condensed Matter and Materials Physics, v. 83, n. 6, p. 1-13, 2011.

VOIGTLÄNDER, B. Scanning Probe Microscopy. Berlin, Heidelberg: Springer Berlin Heidelberg, 2015.

WHATMORE, R.; ABRAHAMS, S. C.; NASSAU, K. FERROELECTRIC MATERIALS. 2007. 10 2007. Disponível em:

<http://www.sciencedirect.com/science/article/pii/B9780080347240500457>.

XU, X.; GUOQIANG, T.; HUIJUN, R.; AO, X. Structural, electric and multiferroic properties of $\mathrm{Sm}$-doped $\mathrm{BiFeO} 3$ thin films prepared by the sol-gelprocess. Ceramics International, v. 39, n. 6, p. 6223-6228, 2013.

XU, Y. Ferroelectric Materials and Their Applications. North-Holland: Elseviver Science Publishers B. V., 1991. 
YANG, C.-H.; KAN, D.; TAKEUCHI, I.; NAGARAJAN, V.; SEIDEL, J. Doping BiFeO3: approaches and enhanced functionality. Physical chemistry chemical physics : PCCP, v. 14, n. 46, p. 15953-62, 2012. Disponível em:

<http://www.ncbi.nlm.nih.gov/pubmed/23108014>.

YANG, J.-C.; HE, Q.; YU, P.; CHU, Y.-H. BiFeO 3 Thin Films: A Playground for Exploring Electric-Field Control of Multifunctionalities. Annual Review of Materials Research, v. 45, n. 1, p. 150203175635006, 2014. Disponível em:

<http://www.annualreviews.org/doi/abs/10.1146/annurev-matsci-070214-020837>.

YASUDA, N.; MURAYAMA, H.; FUKUYAMA, Y.; KIM, J.; KIMURA, S.; TORIUMI, K.; TANAKA, Y.; MORITOMO, Y.; KUROIWA, Y.; KATO, K.; TANAKA, H.; TAKATA, M. $X$-ray diffractometry for the structure determination of a submicrometre single powder grain. Journal of Synchrotron Radiation, v. 16, n. 3, p. 352-357, 1 maio 2009. Disponível em: <http://scripts.iucr.org/cgi-bin/paper?S090904950900675X>.

YI, M. L.; WANG, C. B.; LI, L.; WANG, J. M.; SHEN, Q.; ZHANG, L. M. Influence of $\mathrm{Tb}$ doping on structure and multiferroic properties of BiFeO3 films prepared by pulsed laser deposition. Applied Surface Science, v. 344, p. 47-51, 2015. Disponível em:

<http://www.sciencedirect.com/science/article/pii/S0169433215006984>.

YUAN, G. L.; OR, S. W.; CHAN, H. L. W.; LIU, Z. G. Reduced ferroelectric coercivity in multiferroic Bi0.825 Nd0.175 Fe O3 thin film. Journal of Applied Physics, v. 101, n. 2, p. 1-5, 2007.

ZHANG, H. Ultrathin Two-Dimensional Nanomaterials. ACS Nano, v. 9, n. 10, p. 9451-9469, 27 out. 2015. Disponível em:

<http://pubs.acs.org/doi/10.1021/acsnano.5b05040>.

ZHANG, Z.; LIU, H.; LIN, Y.; WEI, Y.; NAN, C. W.; DENG, X. Influence of la doping on magnetic and optical properties of bismuth ferrite nanofibers. Journal of

Nanomaterials, v. 2012, 2012. 


\section{ANEXO A: Arquivo CIF 2102913 da estrutura cristalina do $\mathrm{BiFeO}_{3}$}

$\begin{array}{ll}\begin{array}{l}\text { Origin } \\ \text { Code }\end{array} & \text { COD } \\ \text { Database dates } & 2102913 \\ \text { Common name } & \\ \begin{array}{l}\text { Systematic name } \\ \text { Structural formula }\end{array} & \text { Bismuth ferrite } \\ \begin{array}{l}\text { Analytical formula } \\ \text { Ana } 3\end{array} & \end{array}$

Author(s)

Publication title Citation

Mineral name

Compound source

Structure type

Creation method

Comments
General

Bibliographic data

Palewicz, Andrzej; Przenioslo, Radoslaw; Sosnowska, Izabela; Hewat, Alan Atomic displacements in $\mathrm{BiFeO}_{3}$ as a function of temperature: neutron diffraction study
Phase data

$$
\text { Bi } \mathrm{Fe} \mathrm{O} 3
$$

trigonal

R 3 C (161)

$a=5.5977(1) \AA c=13.9354(2) \AA$

$\mathrm{a} / \mathrm{b}=1.0000 \mathrm{~b} / \mathrm{c}=0.4017 \mathrm{c} / \mathrm{a}=2.4895$

$378.16(1) \AA^{3}$

6

hR10

NOP3

ba2

Atomic parameters

\begin{tabular}{cccccccc} 
Atom ox. & Wyck. & Site & S.O.F. & $\mathbf{x} / \mathbf{a}$ & $\mathbf{y} / \mathbf{b}$ & \multicolumn{1}{c}{$z / \mathbf{c}$} & $\mathbf{U}\left[\AA^{2}\right]$ \\
$\mathrm{BI}$ & $6 \mathrm{a}$ & 3. & & 0 & 0 & 0 \\
$\mathrm{FE}$ & $6 \mathrm{a}$ & 3. & & 0 & 0 & $0.22125(11)$ \\
$\mathrm{O} 1$ & $18 \mathrm{~b}$ & 1 & 1.00001 & $0.4481(3)$ & $0.0171(4)$ & $0.95308(16)$
\end{tabular}

Anisotropic displacement parameters, in $\AA^{2}$

\begin{tabular}{ccccccc} 
Atom & $\mathbf{U}_{\mathbf{1 1}}$ & $\mathbf{U}_{\mathbf{2 2}}$ & $\mathbf{U}_{\mathbf{3 3}}$ & $\mathbf{U}_{\mathbf{1 2}}$ & $\mathbf{U}_{\mathbf{1 3}}$ & \multicolumn{1}{c}{$\mathbf{U}_{\mathbf{2 3}}$} \\
$\mathrm{BI}$ & $0.0219(9)$ & $0.0219(9)$ & $0.0075(10)$ & $0.0110(9)$ & 0.00000 & 0.00000 \\
$\mathrm{FE}$ & $0.0099(6)$ & $0.0099(6)$ & $0.0121(10)$ & $0.0050(6)$ & 0.00000 & 0.00000 \\
$\mathrm{O} 1$ & $0.0232(3)$ & $0.0149(4)$ & $0.0125(3)$ & $0.0079(3)$ & $0.0023(3)$ & $-0.0038(3)$
\end{tabular}


Selected geometric informations

\begin{tabular}{|c|c|c|c|}
\hline Atoms 1,2 & d $1,2[\AA]$ & \multicolumn{2}{|c|}{ Atoms 1,2} \\
\hline $\mathrm{BI}-\mathrm{BI}^{\mathrm{i}}$ & $3.9798(0)$ & $\mathrm{BI}-\mathrm{FE}^{\mathrm{xi}}$ & $3.5895(7)$ \\
\hline $\mathrm{BI}-\mathrm{BI}^{\mathrm{ii}}$ & $3.9798(0)$ & $\mathrm{BI}-\mathrm{FE}^{\mathrm{xii}}$ & $3.5895(7)$ \\
\hline $\mathrm{BI}-\mathrm{BI}^{\mathrm{iii}}$ & $6.8683(0)$ & $\mathrm{FE}-\mathrm{O} 1^{\mathrm{xiii}}$ & $2.1132(25)$ \\
\hline $\mathrm{BI}-\mathrm{BI}^{\mathrm{iv}}$ & $6.8683(1)$ & $\mathrm{FE}-\mathrm{O} 1^{\mathrm{xiv}}$ & $2.1132(24)$ \\
\hline $\mathrm{FE}-\mathrm{FE}^{\mathrm{v}}$ & $6.9677(22)$ & $\mathrm{FE}-\mathrm{O} 1^{\mathrm{xv}}$ & $1.9558(25)$ \\
\hline $\mathrm{BI}-\mathrm{BI}^{\mathrm{v}}$ & $6.9677(1)$ & $\mathrm{FE}-\mathrm{O} 1^{\mathrm{xvi}}$ & $1.9558(19)$ \\
\hline $\mathrm{BI}-\mathrm{FE}$ & $3.0832(15)$ & $\mathrm{BI}-\mathrm{FE}^{\mathrm{xvii}}$ & $8.3769(14)$ \\
\hline $\mathrm{BI}-\mathrm{FE}^{\mathrm{vi}}$ & $3.8845(15)$ & $\mathrm{BI}-\mathrm{BI}^{\mathrm{ix}}$ & $3.9798(0)$ \\
\hline $\mathrm{BI}-\mathrm{FE}^{\mathrm{vii}}$ & $3.3201(4)$ & $\mathrm{BI}-\mathrm{BI}^{\text {vii }}$ & $3.9798(0)$ \\
\hline $\mathrm{BI}-\mathrm{FE}^{\text {viii }}$ & $3.5895(7)$ & $\mathrm{BI}-\mathrm{BI}^{\mathrm{xv}} \mathrm{iii}$ & $3.9798(0)$ \\
\hline $\mathrm{BI}-\mathrm{FE}^{\mathrm{ix}}$ & $3.3201(4)$ & $\mathrm{BI}-\mathrm{BI}^{\mathrm{xix}}$ & $6.8683(0)$ \\
\hline $\mathrm{BI}-\mathrm{FE}^{\mathrm{x}}$ & $3.3201(4)$ & & \\
\hline $\begin{array}{l}\text { (i) }-0.66667-\mathrm{x}+\mathrm{y},- \\
\text { (iii) } 0.66667-\mathrm{x}+\mathrm{y},- \\
\text { (v) }-\mathrm{x}+\mathrm{y}, \mathrm{y}, 0.5+\mathrm{z} \text {; } \\
\text { (viii) } 0.33333+\mathrm{x},-0 \\
\text { (ix) }-0.33333-\mathrm{x}+\mathrm{y}, \\
\text { (xi) }-0.66667+\mathrm{x},-0 \\
\text { (xiii) }-0.66667+\mathrm{x},- \\
\text { (xv) }-0.33333-\mathrm{y},-0 \\
\text { (xvii) }-0.33333+\mathrm{x}, \\
\text { (xix) } 1.33333-\mathrm{x}+\mathrm{y},\end{array}$ & $\begin{array}{l}333+y, 0.166 \\
667+y,-0.16 \\
-x+y, y,-0.5 \\
33+y,-0.333 \\
333+y,-0.16 \\
33+y,-0.333 \\
333+x-y,-0 . \\
67+x-y,-0.6 \\
333+y, 0.333 \\
667+y, 0.16\end{array}$ & $\begin{array}{l}333-x+y, \\
66667-x+ \\
67-x+y, 0 . \\
33333-x+y \\
3333+x, 0 \\
0.33333-x \\
.66667-x- \\
33333-x+\end{array}$ & $\begin{array}{l}6667+z ; \\
.16667+z ; \\
667+z ; \\
0.16667+z ; \\
3333+z ; \\
-0.83333+z ; \\
0.66667+z ; \\
.16667+z ;\end{array}$ \\
\hline
\end{tabular}

Selected hydrogen bonds

Extended geometric informations 


\section{ANEXO B: Princípios da técnica de Difração de raios $X$}

A importância de se conhecer a estrutura cristalina de um determinado material faz parte da base para avaliação de uma série de propriedades referente àquela determinada distribuição. A técnica de difratometria de raios $X(D R X)$ é capaz de fornecer as ferramentas necessárias para realizar esta tarefa. ${ }^{(1-3)}$

A difração de raios $X$ é um fenômeno promovido pela interação da radiação eletromagnética, de faixas de comprimento de onda característicos para os raios $\mathrm{X}$, sobre a estrutura atômica do material de estudo, seja ele amorfo ou cristalino.

A geração de raios $X$ acontece num tubo de alto vácuo, onde ocorre a aceleração de elétrons contra um alvo metálico (cobre, molibdênio, etc) (Figura 1) e o resultado da interação elétron-átomo (alvo). O deslocamento dos elétrons mais internos do átomo do alvo promove a transição de elétrons de camadas mais externas da eletrosfera, liberando energia na forma de fótons característicos de raios $X .{ }^{(1-3)}$

A incidência de feixes de raios $X$ sobre a superfície de um material pode proporcionar interferência construtiva das ondas eletromagnéticas, pela eletrosfera dos átomos da amostra, e consequentemente, provocar difração das mesmas, dando origem aos feixes difratados que serão contabilizados por um detector em um equipamento chamado difratômetro. ${ }^{(1-3)}$

$\mathrm{Na}$ figura 2 podemos observar a geometria que satisfaz a condição de Bragg pela interação da radiação eletromagnética de raios $\mathrm{X}$ incidente com os átomos de um material cristalino com planos (hkl), com distância interplanar $d_{h k l}$. 
Figura 79 - Esquema de geração de raios $X$ : (a) foto de um tubo de raios $X$; (b) representação esquemática de um tubo de raios $X$ e seus principais componentes; (c) emissão de fótons pela interação de elétrons incidentes sobre um átomo de um elemento metálico.

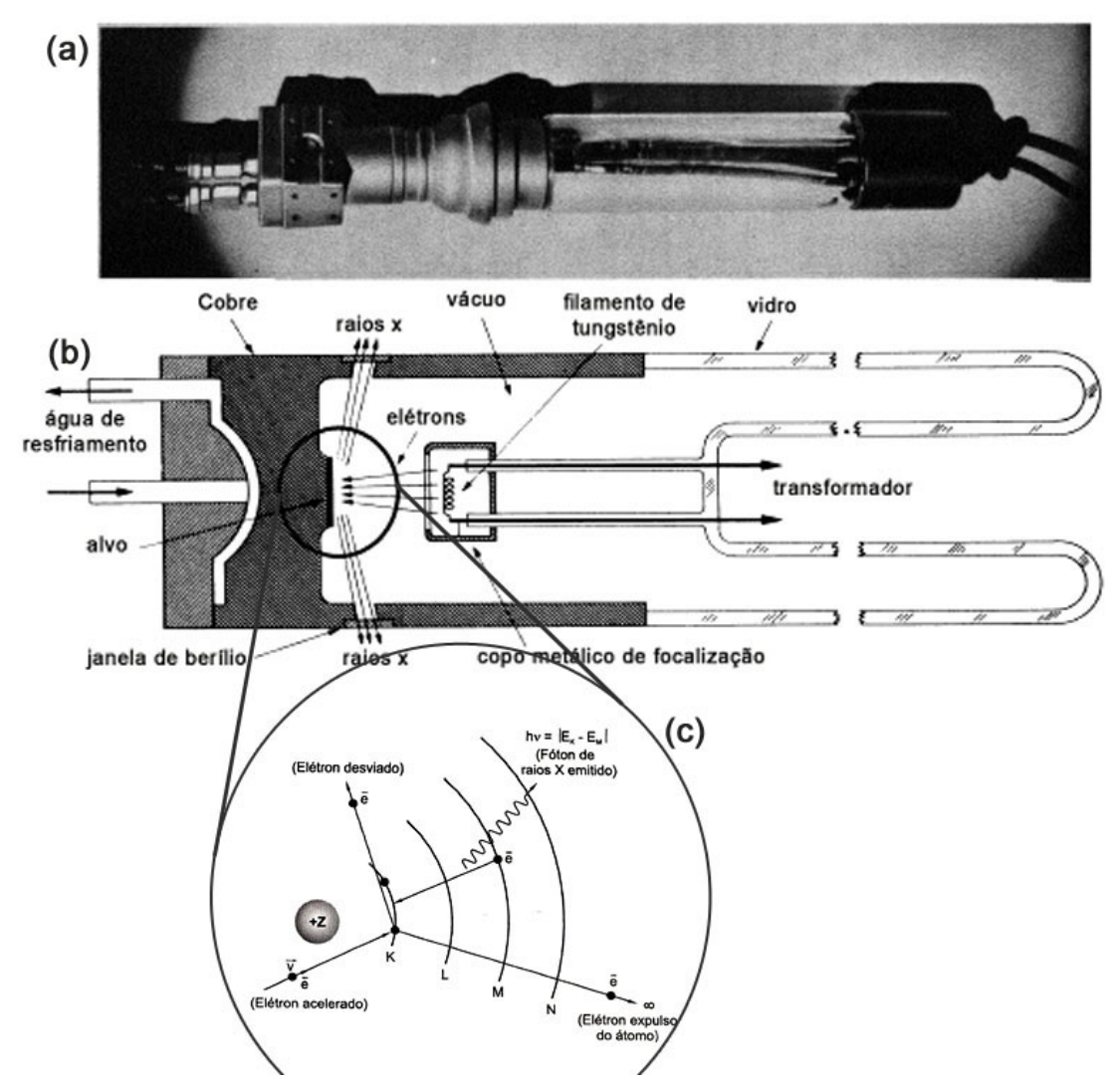

Fonte: Adaptado de $(2,3)$

Figura 80 - Representação esquemática da interação de feixes de raios $X$ com planos $A$ e $B$ de um material cristalino, promovendo sua difração.

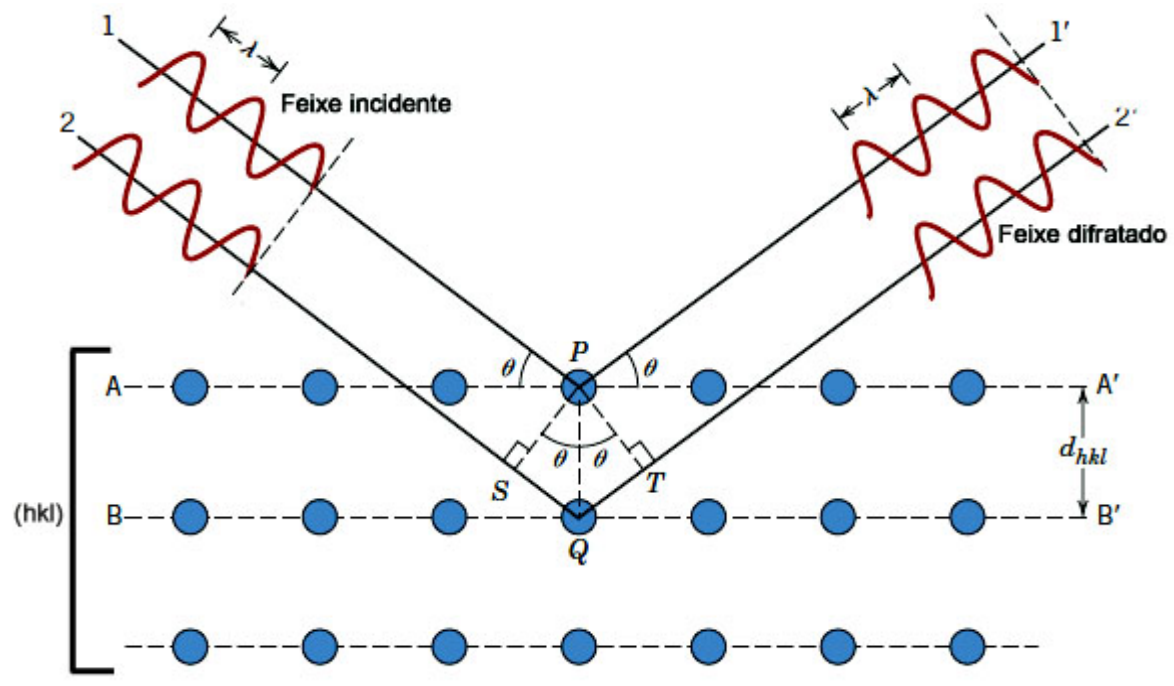

Fonte: Adaptado de (4). 
De acordo com a geometria da rede dos planos cristalinos atingidos pelos feixes incidentes, existe uma relação entre o comprimento de onda $(\lambda)$ incidente e a distância interplanar $d_{h k l}$, sob um ângulo $\theta$ na superfície do plano. Essa relação é expressa pela equação 1. ${ }^{(1-3)}$

$$
\mathrm{n} \cdot \lambda=2 \cdot \mathrm{d}_{\mathrm{hk} \mid} \cdot \operatorname{sen}(\theta)
$$

onde $\mathrm{n}$ é um número inteiro, representando a ordem de difração, $\lambda$ é o comprimento de onda incidente, $d_{h k l}$ é a distância interplanar e $\theta$ é o ângulo de incidência dos raios $X^{(1-3)}$

Essa relação geométrica favorece a formação de difração dos os raios $X$ usados na técnica, essa relação é chamada de Lei de Bragg. Ainda assim, ela não é o fator único que garante a ocorrência do fenômeno mencionado. Apesar de importante, as demais condições a serem satisfeitas para que ocorra o fenômeno de difração em planos (hkl) não serão discutidos neste trabalho. ${ }^{(1-3)}$

A seguir, satisfazendo as condições de Bragg, o feixe incidente difrata, a presença de feixes difratados chegando ao detector é medida por unidade de tempo, em segundos, o que gera um número de contagens para um determinado tempo e em um determinado ângulo. A varredura da superfície da amostra é feita em ângulos $\theta, 0$ que chamamos de ângulo de Bragg, enquanto que o registro feito no equipamento define o ângulo de difração, dado em $2 \theta$. Sempre que o feixe sofrer difração em algum ângulo $2 \theta$, o equipamento registrará o número de contagens naquele ângulo (contagens por segundo - cps), criando assim um pico em um difratograma, característico de determinado plano cristalino presente naqueles ângulos específicos, como pode ser visto na figura $3 .^{(1-3,5)}$ 
Figura 81 - Modelo de difratograma do metal molibdênio.

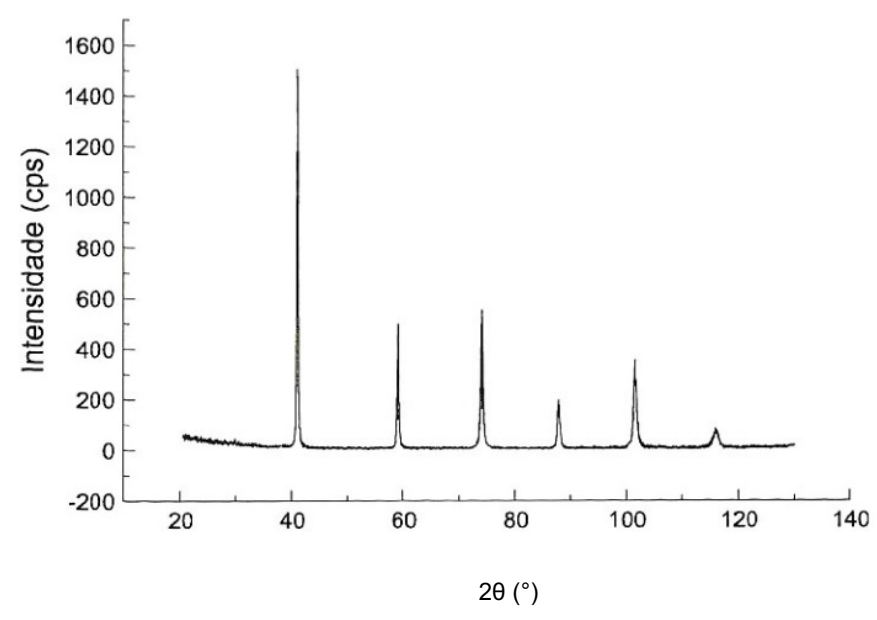

Fonte: ${ }^{(3)}$

Vários materiais apresentam a mesma rede cristalina, sendo os átomos presentes nessas estruturas variados de acordo com cada composto. A presença de uma mesma estrutura cristalina pode gerar picos de difração em planos semelhantes para estes materiais, contudo, a presença de átomos (íons) diferentes, com tamanhos distintos, irá diferir no espaçamento entre esses picos (ângulos de difração), quando os espectros forem comparados. ${ }^{(1-3,5)}$

O estudo dos materiais, baseado na técnica de difração pode ocorrer pela comparação entre o espectro de difração obtido pelo seu material de estudo com padrões de espectros já registrados. A verificação das características entre os espectros da amostra e o padrão, tais como ângulo de difração, largura do pico a meia altura, espaçamento e quantidade de picos é fundamental para identificação do composto presente na amostra, seja ela pura ou uma mistura. Cada composição de uma mistura apresenta estruturas cristalinas diferentes, o que promoverá picos de difração diferentes, assim, a identificação de cada composto, chamado de fase, pode também ser feita mediante a comparação com os padrões de referência já conhecidos. ${ }^{(1-3,5)}$

Esses padrões são publicados em diversos trabalhos científicos e sua base de dados é encontrada num sistema chamado ICDD, do inglês International Center for Diffraction Data, agrupado em bancos de dados conhecidos como PDF, antigamente conhecido como fichas JCPDS. 
Referências bibliográficas (Anexo B)

1. PADILHA, A. F.; FILHO, F. A. Técnicas de análise microestrutural. São Paulo: Hemus, 2004.

2. CULLITY, B. D. Elements of X-ray diffraction. Massachusetts/US: ADDISONWESLEY PUBLISHING COMPANY, Inc., 1956.

3. RODRIGUES, J. de A. Raios X: difração e espectroscopia. São Carlos/SP: EdUFSCar, 2005.

4. CALLISTER JR, W. D. Materials Science and Engineering: An introduction. 7 ed. New York, N. Y.: Wiley, 2007.

5. DINGER, D. R. Characterization Techniques for Ceramists. United States: Morris Publishing, 2005. 